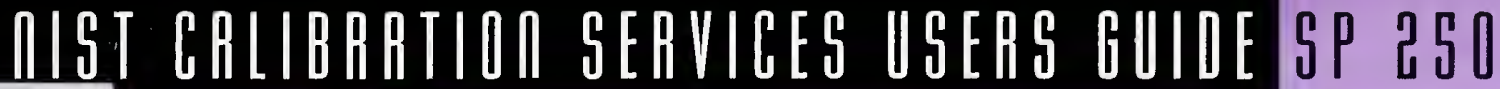

NAT'L INST. OF STAND \& TECH R.I.C.

NIST

PUBLICATIONS

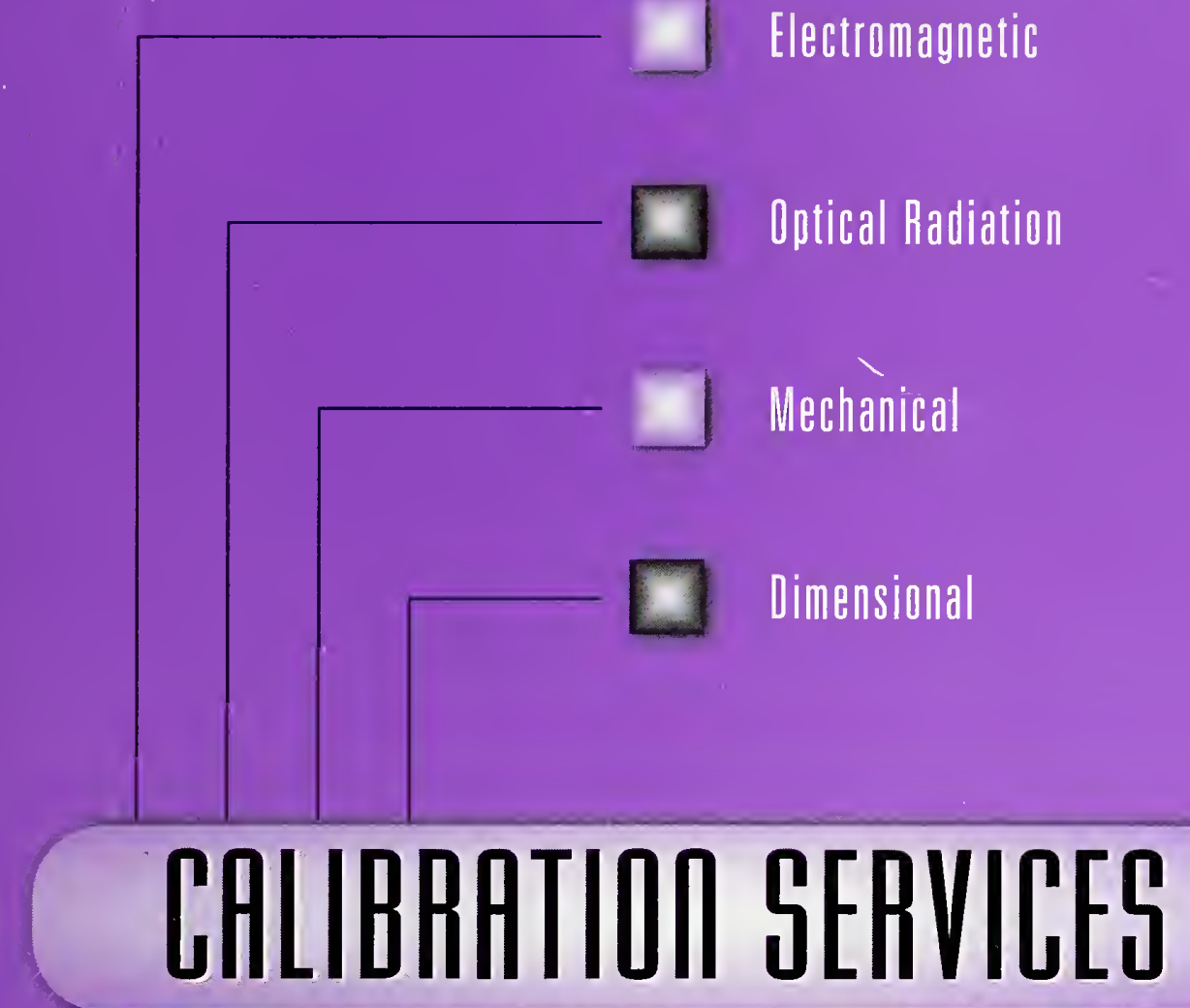

Thermodynamic

Time and Frequeney

Ionizing Radiation

QC

100

.057

N0. 250

Phone: 301-975-2002

US Department of Commerce

Fax: 301-869-3548

Technology Administration

National Institute of Standards and Technology

1998 J: calibrations@nist.gov

Calibration Program, Bldg. 820 Room 236, Gaithersburg, MD 20899

NG 
Calibrations

Standard Reference Materials

Standard Reference Data

Legal Metrology Services

Standards and Code Information

Laboratory Accreditation

Industrial Partnerships 


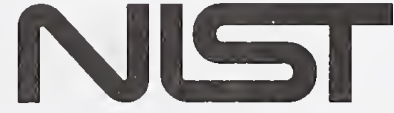

J. L. Marshall, Editor

Calibration Program

Office of Measurement Services

Technology Services

National Institute of Standards and Technology

Gaithersburg, MD 20899-0001

NIST Special Publication

Revised January 1998

(Supersedes 1991 Edition)

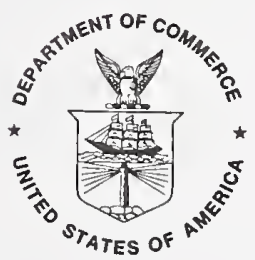

U.S. Department of Commerce

William M. Daley, Secretary

Technology Administration

Gary R. Bachula, Acting Undersecretary for Technology

National Institute of Standards and Technology

Raymond G. Kammer, Director 
National Institute of Standards and Technology

Special Publication 250, 1998 Edition

Natl. Inst. Stand. Technol., Spec. Publ. 250, 1998 Ed.,

228 pages (Revised Jan. 1998)

\section{U.S. GOVERNMENT PRINTING OFFICE}

WASHINGTON: 1998

For sale by the Superintendent of Documents,

U.S. Government Printing Office, Washington, DC 20402

U.S. Government Printing Office

Washington: 1998 
The NIST Calibration Services Users Guide provides detailed descriptions of the NIST calibration services, special-test services, and measurement assurance programs currently available as of the fourth quarter of 1997. This revised edition of NIST Special Publication (SP) 250 reflects important changes in services since the last edition was published. A detailed description is given of each measurement service, and a large number of NIST technical experts are cited (who may be contacted for further information concerning services or measurement problems). The current edition will be published in hard copy and maintained on the Internet. See the Calibration Program's Web Site at: http://ts.nist.gov/calibrations

A Fee Schedule listing current prices for the services described in the Users Guide is published annually as NIST SP 250 Appendix. NIST will notify users of changes in services or proposed changes in services by means of announcements in the Fee Schedule and on the Internet. In addition, information about upcoming NIST Measurement Seminars will be announced in both locations. It is important that you refer to the current issue of the Fee Schedule or the Web site in order to have up-to-date information with respect to NIST contacts.

A companion document to this guide is NIST Special Publication 260, NIST Standard Reference Materials Catalog. This document describes 1,200 Standard Reference Materials (SRM's) certified by NIST for use in industrial quality control, materials testing, environmental testing, and clinical testing applications. A copy of SP 260 may be obtained by calling (301) 975-6776, or by faxing (301) 948-3730.

The Calibration Program welcomes suggestions on how this publication can be made more useful to those who rely on NIST calibration services. Suggestions are also welcome concerning needs for new calibration services, measurement assurance programs, or other measurement services.

Sharrill Dittmann

Calibration Program 


\section{Abstract}

The National Institute of Standards and Technology (NIST) Calibration Services Users Guide provides detailed descriptions of NIST calibration services, measurement assurance programs, and special-test services currently available. The following measurement areas are covered: (1) dimensional; (2) mechanical, including flow, acoustic, and ultrasonic; (3) thermodynamic; (4) optical radiation; (5) ionizing radiation; (6) electromagnetic, including dc, ac, rf, and microwave; and (7) time and frequency. A separate Fee Schedule (NIST Special Publication 250 Appendix) is issued annually, providing current prices for the services offered, updates on points-of-contact, and information on NIST measurement seminars. See also the most current information at the Internet Web Site: http://ts.nist.gov/calibrations

Key words: calibration; measurement assurance; measurement services; standards; traceability. 


\section{Acknowledgments}

Many NIST staff members contributed to the development and preparation of this guide. Over 50 members of the NIST technical staff contributed data and information that have been incorporated into the guide. Special thanks go to John Mayo-Wells, Barry Taylor, and Simone Yaniv for their efforts. Joanne Marshall served as production manager and coordinated preparation of the Users Guide. Editorial and production assistance was provided by Carroll Brickenkamp and Dawn Geraci. General support was provided by Tracy Arnold, Paula Hewitt, Denise Lockard, and Ernest Garner of the Calibration Program Staff. The NIST Publication Production staff made many valuable suggestions and typeset the final draft.

\section{Sharrill Dittman}

Chief, Calibration Program 
Table

5.1 Uncertainty of the NIST Low Velocity Airflow Measurement Facility .........

5.2 Uncertainty of the NIST Airflow Measurement Capabilities in the Dual Test-Section Wind Tunnels .........................................

5.3 Typical Expanded Uncertainties for Pressure Calibrations of Type-L Microphones ....

6.1 Relative Expanded Uncertainties of Piston Gage Standards in Gage Mode......

6.2 Calibration Uncertainties for Total Immersion Thermometers

6.3 Maximum Expanded Uncertainties of SPRTs at NIST

6.4 NIST Expanded Uncertainties for Comparison Measurements of RIRTs

6.5 NIST Two-Pressure Humidity Generator, Mark 2, Range and Uncertainty .....

7.1 Calibration Uncertainties for Spectroradiometric Source Measurements

7.2 Detector Measurement Services Uncertainties

7.3 NIST Spectroradiometric Detector Measurement Services

7.4 Laser Power and Energy Measurement Capabilities

7.5 Measurement Capabilities of Automated Calibration System for Optical Fiber Power Meters

7.6 Low-Level MAP Transfer Standards ....

8.1 Specifications for Calibration of Solutions of Gamma-Ray Emitting Radionuclides Having Half Lives Greater Than 15 Days ....

8.2 Specifications for Calibration of Gamma-Ray Emitting Radionuclides Having Half Lives Less Than 15 Days

8.3 Specifications for Calibrations Using the $2 \pi \alpha$ Proportional Counter and the $0.8 \pi \alpha$ Defined Solid Angle Counter.

8.4 Specifications for Special Tests of Beta-Particle-Emitting Solution Sources

8.5 Irradiation Parameters for Fission Spectra and Maxwellian Thermal Neutron Fields

8.6 Tungsten-Anode X-ray and Gamma-Ray Beam-Quality Parameters

8.7 Tungsten-Anode ISO X-Ray Beam-Quality Parameters

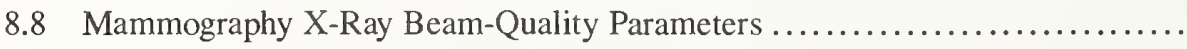


8.10 Uncertainties for Beta-Particle Source and Instrument Calibrations........... 108

9.1 Temperature and Current Levels for Customer's Resistors................. 114

9.2 Calibration Uncertainties for DC Resistance Standards ................... 115

9.3 Calibration Uncertainties for Capacitance Standards with Coaxial Connectors..................................................

9.4 Calibration Uncertainties for Capacitance Standards with Terminal

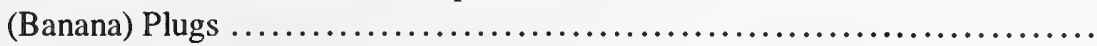

9.5 Expanded Uncertainties of NIST DC Voltage Measurement .............. 130

$9.6 \quad 25$-Point Standard DMM Test .................................. 135

9.7 AC-DC Difference Calibration Service ............................. 137

9.8 Measurement Ranges and Uncertainties for Low-Frequency TVC Services....................................................

9.9 Measurement Ranges and Uncertainties for High-Frequency TVC Services.....................................................

9.10 Measurement Ranges and Uncertainties for Peak-to-Peak Detector Services......................................................

9.11 Measurement Ranges and Uncertainties for RF Micropotentiometer Calibrations....

9.12 Available Values of the Parameters for Routine Wattmeter, Watthour, Varmeter and Varhour Testing......................................

9.13 Measurement Ranges and Uncertainties for Coaxial Thermistor Mounts.......

9.14 Measurement Ranges and Uncertainties for Waveguide Thermistor Mounts....

9.15 Measurement Ranges and Uncertainties for Coaxial Two-Port Devices........

9.16 Measurement Ranges and Uncertainties for Waveguide Two-Port Devices.....

9.17 Measurement Ranges and Uncertainties for Coaxial One-Port Devices ........

9.18 Measurement Ranges and Uncertainties for Waveguide One-Port Devices .....

9.19 Summary of NIST Standard Field Strength Facilities

9.20 NIST Impulse Generator Spectrum Amplitude Measurement Service Capabilities

9.21 Uncertainty for Calibration of Fast Repetitive Pulse Transition Parameters .... 


\section{List of Figures}

Figure Page

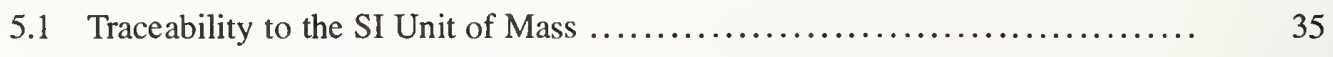

5.2 NIST's Relative Expanded Uncertainties for Normal Calibrations of Mass Standards ........................................... 35

5.3 Relationship of Force to SI Units ................................ 39

6.1 Uncertainties of the NIST Low-Pressure and Vacuum Standards ............ 55

6.2 Uncertainties of the NIST Leak and Low-Gas-Flow Standards ............. 55

7.1 Measurement Uncertainty for NIST Spectral Radiance Calibrations .......... 79

7.2 Measurement Uncertainty for NIST Spectral Irradiance Calibrations........... 79

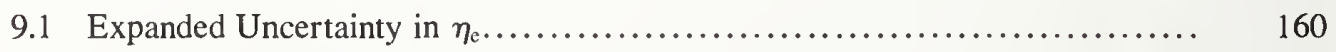

9.2 Reflected and Transmitted Voltage Waves for a Typical Two-port Device ..... 163 


\section{Contents}

\section{Chapter 1- \\ Policies}
A. Introduction
B. Types of Services
C. Other NIST Measurement Transfer Standards
D. Criteria for Quality Assurance
E. Fees
F. Reports of Calibration/Test Results
G. Traceability
H. NIST Policy on Reporting Measurement Uncertainty
I. NIST Policy Regarding Use of Metric (SI) Units
J. References to NIST in Advertisements
K. Disclaimer
L. Questions and Inquiries

Chapter 2-

Ordering Instructions for Domestic Customers
A. Customer Inquiries
B. Prearrangements and Scheduling
C. Purchase Orders
D. Shipping, Insurance, and Risk of Loss
E. Turnaround Time
F. Customer Checklist

\section{Chapter 3-}
Special Instructions for Foreign Customers
A. Foreign Inquiries
B. Criteria for Providing Service
C. Special Instructions
D. Shipping Charges
Chapter 4-
Dimensional Measurements

A. Length Measurements

A.I Gage Blocks

10010C...... Gage Blocks

A.2 Line Standards

10020C...... Line Standards

A.3 Surveying Tapes

$10030 \mathrm{C} \ldots . .$. . Surveying and Oil Gaging Tapes

10040S ...... Special Tests of Surveying Leveling Rods 
A.4 Other Length Standards

10050S ..................Special Tests of Length Standards

$10060 \mathrm{~S}$

Special Tests of Sieves

A.6 Algorithms Testing and Evaluation Program for Coordinate Measuring Systems

10070S-10071S ............Special Test of CMS Software:

NIST-Generated Data Sets

10080S-10081S .Special Test of CMS Software:

Customer-Generated Data Sets

B. Diameter Measurements

$11010 \mathrm{~S}$ Special Tests of Cylindrical Diameter

Standards (i.e., Plug and Pin Gages)

$11020 \mathrm{C} . . . . . . . . . . . . . . . .$. Measuring Wires for Threads and Gears

11030S ..................Special Tests of Spherical Diameter

Standards: Balls

$11040 \mathrm{~S}$ .Special Tests of Internal Diameter

Standards: Ring Gages

11050S ....................Special Tests of Length and Diameter

11060 S ....................Special Tests of Step Gages

C. Complex Dimensional Standards

$12010 \mathrm{C}$

API Threaded Plug and Ring Gages

12020S ..................Special Tests of Threaded Plug and Ring Gages

12030S ..................Special Tests of Two Dimensional Gages

12040S ...................Special Complex Dimensional Tests

D. Optical Reference Planes and Roundness Standards

$13010 \mathrm{~S}$ .Special Tests of Optical Reference Planes (Flats)

$13020 \mathrm{~S}$ .Special Tests of Roundness

$13030 \mathrm{~S}$ Special Tests of Roundness Calibration

Specimens

E. Angular Measurements

$14010 \mathrm{C}$ Angle Gage Blocks

$14020 \mathrm{~S}$ Special Tests of Optical Polygons

$14030 \mathrm{~S}$ Special Tests of Rotary and Indexing Tables

$14040 \mathrm{~S}$ .Special Tests of Optical Wedges

$14050 \mathrm{~S}$ Special Angular Measurements 
G. Surface Texture

$15010 \mathrm{C}$

Roughness Calibration Specimens

15020C............ Surface Roughness Comparison Specimens

15030C............ Step Height Calibration Specimens

$15040 \mathrm{~S}$ Special Roughness Tests

H. Hydrometers

$16010 \mathrm{C}$

Reference Standard Hydrometers

I. Volume and Density

17010C............. Volume Standards

$17020 \mathrm{~S}$.

Special Tests of Volume Standards

$17040 \mathrm{~S}$ Special Tests of Density: Liquids

\section{Chapter 5-}

\section{Mechanical Measurements}

A. Flow Measurements

$18010 \mathrm{C}$.

Gas Flow Meters

$18020 \mathrm{C}$

Water Flow Meters

$18030 \mathrm{C}$.

Hydrocarbon Flow Meters

$18040 \mathrm{C}$

Transfer Standards

$18050 \mathrm{~S}$

Special Tests Using Gas or Liquid Flows

B. Flow Measurements at Cryogenic Temperatures

$18800 \mathrm{~S}$ Special Tests of Cryogenic Liquid Flow

C. Airspeed Instruments

19010C............. Pitot-Static Tubes

19020C............. Low Airspeed Instruments

19030S ............ Meteorological Airspeed Instrumentation

19040S ............ Special Tests of Airspeed Instruments

D. Mass Standards

22010C-22030C .... Weight Sets (1 mg to $30 \mathrm{~kg}$ )

$22040 \mathrm{C} \ldots \ldots \ldots$....... Single Weights $(1 \mathrm{mg}$ to $1 \mathrm{~kg}$ )

$22060 \mathrm{C}-22100 \mathrm{C}$.... Single Weights $(2 \mathrm{~kg}$ to $30,000 \mathrm{~kg}$ )

$22110 \mathrm{C}$............ Single Weights (>30 kg to $1200 \mathrm{~kg}$, Calibrated in

a Weighing Design)

22130C-22150C .... Single Weights for Deadweight Pressure Testers

22170 S ........... Special Mass Measurement Services

22180M ........... Measurement Assurance Program for Mass 
E. Force Measurements

23010C-23250C....... Force Transducers

23260 S ............. Special Tests of Force Transducers

F. Vibration Measurements

24010C-24030C....... Pickup Sensitivity

24040S ............. Special Shock Measurements

24050S ............. Special Tests of Pickup Sensitivity

24060S .............. Special Vibration Tests

G. Acoustic Measurements

25010C-25050C...... Pressure and Free-Field Responses of Microphones

25060S ............. Special Tests of Acoustic Devices

25070S ............ Special Tests of Audiometers/Earphones

H. Ultrasonic Reference Block Measurements

$26030 \mathrm{~S}$

. Special Tests of Area Amplitude Aluminum

Reference Blocks

$26040 \mathrm{~S}$

. Special Tests of Area Amplitude Titanium or

Steel Ultrasonic Reference Blocks

$26050 \mathrm{~S}$

. Special Tests of Distance Amplitude Aluminum

Reference Blocks

$26060 \mathrm{~S}$

. Special Tests of Distance Amplitude Titanium or

Steel Ultrasonic Reference Blocks

$26070 \mathrm{~S}$

Special Tests of Distance and Area Amplitude

Aluminum Titanium or Steel Ultrasonic

Reference Blocks

I. Ultrasonic Transducer Measurements

$26100 \mathrm{C}$

Ultrasonic Power Output

J. Acoustic Emission Transducer Measurements

\section{Chapter 6-}

\section{Thermodynamic Quantities}

A. Pressure Measurements

29010C ............. Deadweight Piston Gages

29020C ............ Controlled Clearance Piston Gages

29030 C.............. Pressure Gages and Transducers

29035C .............. Non-Mercurial Barometers

29040S ............. Special Tests of Pressure Gages 
B. Low Pressure, Vacuum, and Leak Measurements

30010C-30011C...... Low-Pressure Transducer

30020C-30021 C....... Differential Low-Pressure Transducer

30025C ............. Ball-Type Deadweight Tester

30029C-30031C...... Spinning Rotor Gages

30032S ............ Special Tests of Spinning Rotor Gages

30034C-30038C....... Ionization Gages

30040S ............ Special Tests of Low-Pressure Gages

30050S ............. Special Tests of Vacuum Gages

$30060 \mathrm{~S}$............. Special Tests of Leak Artifacts

30061C-30062C....... Helium Leaks

30063S ............. Special Tests of Low-Gas-Flow Instruments

C. Laboratory and Industrial-Grade Thermometers

31010C-31050C....... Laboratory Thermometers

$31100 \mathrm{C} \ldots \ldots \ldots \ldots . .$. Quantity Tests of Liquid-in-Glass Thermometers

31110S-31150S ....... Special Tests of Thermometers

$31170 \mathrm{~S}$............. Special Tests of Calorimetric Thermometers

31180S ............. Special Tests of Beckmann Thermometers

31260 S ............. Special Thermometry Services

D. Thermocouples, Thermocouple Materials, Thermometer Indicators

66

32010C-32061C...... Type S, R, B, E, J, K, N, and T, Thermocouple

Comparison Calibrations

$32070 \mathrm{C}$

. Thermocouple Materials Tested Against Pt

Thermoelectric Standard

$32090 \mathrm{C}$

Type S or R Thermocouple Calibration at Metal

Freezing Points

$32091 \mathrm{C}$

Type S or T, Thermocouple Freezing-point

Determination

32100C-32101C...... Digital Thermometer Indicator or Potentiometer

32110C-32147C...... Thermocouples or Thermocouple Materials

Tested Against Pt Thermoelectric Standard,

Temperature Measured with SPRT

$32150 \mathrm{~S}$

Special Tests of Thermocouples and Thermocouple

Materials

E. Resistance Thermometry

33010C-33130C...... Capsule SPRT

33140C-33141C....... Rhodium-Iron or Germanium Resistance Thermometers

33150C-33310C...... Long Stem SPRT

33350 S ............. Special Tests of Resistance Thermometers

33360S ............. Special Tests of Thermometric Fixed-Point Devices

33370M-33380M ..... Measurement Assurance Program for Temperature 
F. Radiance Temperature Measurements

35010C-35040C....... Radiance Temperature Standard, Disappearing

Filament Optical Pyrometer

35050C-35060C...... Radiance Temperature Standard, Ribbon Filament

Lamp

35070S ............. Special Tests of Radiation Thermometers

G. Humidity Measurements

36010C-36020C...... Dew-Point Hygrometers

36030C .............. Electric Hygrometers

$36040 \mathrm{C}$.............. Electrolytic Hygrometers

36050C .............. Aspirated Hygrometers

36060C .............. Pneumatic Bridge Hygrometers

36070S .............. Special Tests of Humidity

\section{Chapter 7-}

\section{Optical Radiation Measurements}

A. Photometric Measurements

$37010 \mathrm{C}$

Luminous Intensity and Color Temperature Standard Lamps

$37020 \mathrm{~S}$ Special Tests for Luminous Intensity and Color Temperature of Submitted Lamps

37030C-37040C...... Color Temperature Standard Lamps

37050S ............. Special Tests for Color Temperature of Submitted Lamps

37060S ............. Special Tests for Total Luminous Flux of Submitted Incandescent Lamps and Fluorescent Lamps

37070C .............. Opal Glass Luminance Coefficient Standards

37080S ............. Special Tests for Submitted Luminance Sources and Transmitting Diffusers

37090S ............ Special Tests for Photometers, Illuminance Meters, and Luminance Meters

37100S ............. Special Photometric Tests

37110 S ............ Special Tests for Submitted Flashing-Light Photometers

B. Optical Properties of Materials Measurements

38010C-38040C....... Spectral Transmittance Filters

38050C .............. Wavelength Standards

38060S ............. Special Tests of Spectral Transmittance or

Spectral Reflectance

38070M-38074M ..... Measurement Assurance Programs for Retroreflectance

38080M ............ Measurement Assurance Program for Transmittance 
C. Spectroradiometric Measurements

C.I Spectroradiometric Source Measurements

39010C-39030C...... Spectral Radiance Lamps

39040C-39050C....... Spectral Irradiance Lamps

$39060 \mathrm{~S}$

Special Tests of Radiometric Sources

C.2 Spectroradiometric Detector Measurements

39071S-39072S ...... UV Silicon Photodiodes

39073S-39074S ...... V Visible to Near IR Silicon Photodiodes

39075S ............. Special Tests of Near IR Photodiodes

39080S ............. Special Tests of Radiometric Detectors

39081S ............. Special Tests of Photodetector Responsivity

Spatial Uniformity

$39090 \mathrm{~S}$ Special Tests of IR Detectors

D. Radiometric Standards in the Far Ultraviolet

D.l Standard Sources

$40010 \mathrm{C}$.............. Spectral Irradiance Standard, Argon Mini-Arc

40020 C .............. Spectral Radiance Standard, Argon Mini-Arc

40030C .............. Spectral Irradiance Standard, Deuterium Arc Lamp

40040S ............. Special Tests of Radiometric Devices in the Near and Vacuum Ultraviolet

D.2 Standard Detectors in the Far Ultraviolet

40510C-40531C....... Detector Standard, Windowless Photodiode

40540C ............. Uncalibrated Windowless Photodiode

40560C-40561C...... Detector Standard, Windowed Photodiode

$40599 \mathrm{~S}$

Special Tests on Detectors from the Ultraviolet to the Soft X-Ray Region

E. Lasers and Optoelectronic Components Used with Lasers

42110C-42111C...... Laser Power and Energy Meter (or Detector) Calibrations

42120M ............ Laser Power and Energy Measurement Assurance Program

42130C-42131C...... Optical Fiber Power Meter (or Detector) Calibrations

42140M ............ Optical Fiber Power Meter Measurement Assurance Program

42150M ............ Low-Level Laser Measurement Assurance Program

42151C.............. Low-Level Laser Radiometer Calibration

42160 S ............ Special Test for Frequency Response Measurements of Detectors

42161S ............ Special Test for Impulse Response Measurements of Detectors

$42162 S$............. Special Test for High Accuracy Laser and Optical Fiber Power Measurements

42163S ............. Special Test for Linearity Measurements of Laser and Optical Fiber Power Meters (or Detectors)

$42164 \mathrm{~S}$ Special Test for Spectral Responsivity Measurements of Laser and Optical Fiber Power Meters (or Detectors) 


\section{Chapter 8- Ionizing Radiation Measurements}

A. Radioactivity Sources

43010C-43020C...... Gamma-Ray-Emitting Radionuclides in Solution

43030C-43050C...... Alpha-Particle-Emitting Solid Sources

43060S-43070S ...... Special Tests of Beta-Particle-Emitting Solution Sources

$43090 \mathrm{~S}$............. Special Tests of Alpha-Particle-Emitting Solid Sources

B. Neutron Sources and Neutron Dosimetry

44010C-44020C....... Radioactive Neutron Sources

$44060 \mathrm{C}$............. Personnel Protection Instrumentations

44070C-44090C....... Activation Detector Dosimetry

44100 S .............. Special Tests of Neutron Sources and Dosimeters

C. Dosimetry of X-Rays, Gamma-Rays, and Electrons

C.l X-Ray and Gamma-Ray Measuring Instruments

46010C-46011C...... Radiation Detectors Calibration/Correction Factor

46020C-46021C....... Passive Dosimeters

46030 S ............. Special Tests of High-Gain Electrometers

Charge Sensitivity

46040 S ............. Special Tests of X-Ray Penetrameters, Ardran-Crookes

Type

46050 S .............. Special Tests of X-Ray and Gamma-Ray Measuring Instruments

C.2 Gamma-Ray Sources, Beta-Particle Sources, and Measuring Instruments 47010C-47011C...... Gamma-Ray Sources

47030C-47035C...... Beta-Particle Sources

47036C .............. Ionization Chambers Calibrated with Beta-Particle

Sources for Radiation Protection

47040 S ............. Special Tests of Gamma-Ray and Beta-Particle Sources

C.3 Dosimetry of High-Energy Electron Beams

48010M-4801 1M ..... Dose Interpretation of NIST-Packaged Dosimeters

Irradiated by Customer

$48020 \mathrm{~S}$

Special Tests of Electron-Beam Dosimeters

D. Dosimetry for High-Dose Applications

$49010 \mathrm{C}$

Calibration Irradiations of Customer-Supplied

Dosimeters with ${ }^{60} \mathrm{Co}$ Gamma Rays 
49020C-49030C...... Dose Interpretation of NIST Transfer Dosimeters Irradiated by Customer

49040S .............. Special Tests of Dosimeters by Reading with Spectrophotometer

$49041 \mathrm{~S}$ Spectrophotometric Readings of Dosimeters, Ultra-Violet and Visible Spectrum Scan

49050S Special Measurement Services for Dosimeter Response and Dose Distributions

\section{Chapter 9-}

\section{Electromagnetic Measurements}

A. Resistance Measurements

A.l DC Resistance Standards and Measurements

51100 S ............. Special Resistance Measurement Services

$51110 \mathrm{M}$............. Measurement Assurance Program for Resistance

$51130 \mathrm{C}-51131 \mathrm{C} . . . . .$. Standard Resistors $1 \Omega$ and $10 \mathrm{k} \Omega$

$51132 \mathrm{C}-51142 \mathrm{C} \ldots . . .$. Standard Resistors $10^{-4} \Omega$ to $10^{6} \Omega$

51143C-51154C....... High-Value Standard Resistors: $10^{7} \Omega$ to $10^{12} \Omega$

51160C-51163C....... High-Current Standard Resistors-Shunts

A.2 High-Voltage Standard Resistors

$51210 \mathrm{C} \ldots \ldots \ldots \ldots . . . .$. High-Voltage Standard Resistors

A.3 High-Frequency Standard Resistors

High-Frequency Standard Resistors; Two-Terminal

B. Impedance Measurements (Except Resistors)

B.I Low-Frequency Capacitance and Inductance Measurements and Standards

52110 S ............. Special LF Impedance Measurements

52120 S ............. Special Measurement Assurance Program for

Standard Capacitors

52130C-52131C....... Fused-Silica Dielectric Standard Capacitors

52140C-52176C....... Standard Capacitors

52180C-52181C....... Standard Inductors

B.2 High-Frequency Standard Capacitors and Inductors

52210S-52211S ...... Two-Terminal, Low-Loss Standard Capacitors

$52221 \mathrm{C} \ldots \ldots \ldots \ldots . . . .$. Three-Terminal, Low-Loss Standard Capacitors

52310 S ............ Two-Terminal, High- $Q$ Standard Inductors

B.3 Power-Frequency Capacitors

$52400 \mathrm{C} . . . . . . . . . .$. Power-Frequency Capacitors

52710C-52711C...... Inductive $Q$-Standards 
C. Voltage Measurements

C.I DC Voltage Measurements and Standards

53110S ............... Special DC Voltage Measurements

$53120 \mathrm{M}$............. Measurement Assurance Program for DC Voltage

53130C-53131C....... Saturated Standard Cell

53140C .............. Platinum Resistance Thermometer Temperature

Determination for Standard Cell Calibration

53150C .............. Unsaturated Standard Cells

53160C-53161C...... Solid-State Voltage Reference Standards

53180S-53190S ...... Special Handling

C.2 AC Voltage Measurements

$53200 \mathrm{~S}$

Digital Multimeters (DMMs) and Multifunction

Calibrators

53201S ............. Low-Voltage AC-DC Transfer Standards

53202S-53203S ...... Special 25-Point Test of Digital Multimeters (DMMs)

C.3 AC-DC Thermal Voltage and Current Converters (to I MHz)

146

53310 S ............. Special Ac-dc Measurement Services

53350C-53352C....... Ac-dc Difference Calibration

(Voltage or Current)

C.4 RF-DC Thermal Voltage and Current Converters (100 Hz to $1 \mathrm{GHz}$ )

$53405 \mathrm{~S}$.............. Special Tests of AC Thermal Voltage Converters

53410C-53415C....... Low-Frequency TVC Calibration

53420C-53421C....... High-Frequency TVC Calibration

53430S-53431S ....... Peak-to-Peak Detectors

53440S-53445S ....... RF Micropotentiometers

C.5 Data Converters

D. Precision Ratio Measurements

D.I Inductive Dividers

54110 S ............ Special Ratio Measurements and Tests of Inductive

Voltage Dividers

54120C-54131C....... Inductive Voltage Dividers

D.2 Resistive Dividers

54210C-54211S ....... Resistor and Resistive Dividers

54212C-54213S ....... Resistor and Resistive Dividers, $60 \mathrm{~Hz}$ Measurements

54214S ............ Resistor and Resistive Dividers, Pulsed High-Voltage

Conditions 
$54310 \mathrm{~S}$............. Capacitive Dividers, $60-\mathrm{Hz}$ Measurements

54311S ............ Capacitive Dividers, Pulsed High-Voltage

Conditions

D.4 Mixed Dividers

$54410 \mathrm{~S}$

Pulse Voltage Measuring Systems, Including

Kerr Cells

D.5 Voltage and Current Transformers

54510C-54513C....... Voltage Transformers

54520C-54522C....... Current Transformers

$54600 \mathrm{~S}$............. Special Tests of Dividers and Transformers

E. Phase Meters and Standards and VOR Measurements

$55110 \mathrm{~S}$ Special Tests of Phase Standards and Related Instruments

$55120 \mathrm{C}-55141 \mathrm{C}$. Phase Meters

F. Power and Energy Measurements, Low-Frequency

56110 S ............. Special Tests of AC-DC Wattmeters

56200C-56202C...... Watt, Watthour, Var or Varhour Meter

$56210 \mathrm{M}$............. Measurement Assurance Program for Watthour

Meters

$56220 \mathrm{~S}$ Fast Turn-Around Energy Measurements, Low-Frequency

G. RF, Microwave and Millimeter-Wave Measurements

G.1 Thermistor Mounts

61110 S-61136S ....... Commercial Coaxial Thermistor Mounts

61137C-61138C....... NIST Model CN Coaxial Mounts

61144S-61155S ....... Waveguide Thermistor Mounts

61160 S ............. High Power Wattmeters

61190 S ............. Special Microwave and RF Power Measurement

Services

G.2 Scattering Parameters of Passive Multi-Port Devices

61210S-61221S ....... Coaxial Fixed and Variable Attenuators

61230S-61243S ...... Rectangular Waveguide Fixed and Variable

Attenuators

61249S ............. Special Attenuation Measurements

61250 S .............. Time Delay, Coaxial and Waveguide

61260S-61271S ....... Coaxial One-Port Devices

61280S-61293S ....... Waveguide One-Port Devices

61294 S ............. Special Reflection Coefficient Measurements

$61295 S-61296 S$..... Coaxial Fixed and Variable Phase Shifters

$61297 \mathrm{~S}$............. Special Tests of Phase Shifters 
G.3 High Accuracy Attenuation Measurements

61310C............. Coaxial Fixed and Variable Attenuators

61320C .............. Waveguide Below-Cutoff (Piston) Attenuators

61330 S ............. Attenuation Measurements of Three-Port and

Two-Port Devices

61350C ............. Coaxial Fixed and Variable Phase Shifters

G.4 Thermal Noise Measurements

61410S-61465S ....... Noise Temperature Measurements

61495 S ............. Special Noise Temperature Measurements

G.5 Dimensional Verification of Coaxial Air Line Standards

. Dimensional Measurement of Air Lines

and Verification of Characteristic Impedance

from Dimensional Measurements

G.6 Dielectric and Magnetic Material Measurements

61620 S ............. Special Tests for Dielectric and Magnetic Materials

61640 S .............. Special Consulting and Advisory Services

for Dielectric and Magnetic Materials

H. Electromagnetic Field Strength and Antenna Measurements

H.l Microwave Antenna Parameter Measurements

$63100 \mathrm{~S}$

Gain and Polarization Calibrations of Standard

Antennas Using Extrapolation Range

$63200 \mathrm{~S}$

Measurement of Pattern, Gain, and Polarization

of Arbitrary Antennas Using Near-Field

Scanning Techniques

63300S ............. Special Test Service for Calibration of Probes

Used with Near-Field Scanning Facilities

63400 S ............. Special Consulting, Advisory, and Other Services

H.2 Field Strength Parameter Measurements

64100S ............. Special-Test Service for Antennas/Field Strength

Measurements, Utilizing the Transverse

Electromagnetic (TEM) Cell Method

$64200 \mathrm{~S}$ Special-Test Service for Antennas/Field Strength

Measurements, Utilizing the Open Area Test Site

and Standard Antenna Method

$64300 \mathrm{~S}$

Special-Test Service for Antennas/Field Strength/

Reflectivity Measurements, Utilizing the

Anechoic Chamber and Standard Field Method 
I. Pulse Waveform Measurements

65100S ............. Impulse Spectrum Amplitude

65200S ............. Fast Repetitive Pulse Transition Parameters

$65250 \mathrm{~S}$.............. Fast Repetitive Pulse Settling Parameters

$65300 \mathrm{~S}$............. Network Impulse Response (Transfer Function)

of Coaxial Networks

65400 S ............. Pulse Time Delay Interval

\section{Chapter 10-}

\section{Time and Frequency Measurements}

A. Broadcast and Measurement Services

$76100 \mathrm{~S}$

Frequency Measurement Service

$76110 \mathrm{~S}$

Global Time Service

B. Characterization of Oscillators

$77100 \mathrm{C}$

Oscillator Frequency Calibration

$77110 \mathrm{C}$

Characterization of Atomic Frequency Standards

$77120 \mathrm{C}$

Characterization of Oscillators: Time Domain

$77130 \mathrm{C}$

Characterization of Oscillators and Amplifiers:

Phase Noise in the Frequency Domain

$77131 \mathrm{C}$ Characterization of Oscillators and Amplifiers:

Amplitude Noise in the Frequency Domain

$77135 \mathrm{C}$ . Tests of RF PM/AM Noise Measurement Systems:

On-Site Tests

$77136 \mathrm{C}$

. Tests of Microwave PM/AM Noise Measurement

Systems: On-Site Tests

$77140 \mathrm{~S}$ Special Time/Frequency Measurements:

Oscillators and Other Components 


\title{
Chapter
}

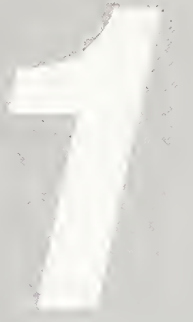

\author{
A Introduction \\ $B$ Types of Services \\ C Other NIST Measurement Transfer Standards \\ D Criteria for Quality Assurance \\ E Fees \\ F Reports of Calibration/Test Results \\ G Traceability \\ H NIST Policy on Reporting Measurement Uncertainty \\ I NIST Policy Regarding Use of Metric (SI) Units \\ $J$ References to NIST in Advertisements \\ K Disclaimer \\ L Questions and Inquiries
}




\section{Introduction}

The calibration services of the National Institute of Standards and Technology (NIST) are designed to help the makers and users of precision instruments achieve the highest possible levels of measurement quality and productivity. The services listed in this Guide constitute the highest order of calibration services available in the United States. They directly link a customer's precision equipment or transfer standards to national and international measurement standards. These services are offered to public and private organizations and individuals alike.

\section{(2) Types of Calibration Services}

- Calibration Services

- Special Tests

- Measurement Assurance Programs (MAPs)

NIST provides Calibration Services using well-characterized, stable and predictable measurement processes. NIST calibrates instruments and devices that are metrologically suitable as reference or transfer standards.

Special Tests are either unique or seldom-performed calibrations or measurements requested by the customer.

Measurement Assurance Programs are quality control programs for calibrating a customer's entire measurement system. In a typical MAP, a stable artifact or set of artifacts, called transfer standards, are first measured by NIST and then sent to a customer's laboratory for a series of measurements. The transfer standards are then returned to NIST for remeasurement, along with the participating laboratory's data. NIST reports its comparative findings to the customer and, when necessary, offers guidance on achieving and maintaining measurement quality.
Successful use of a NIST MAP requires that the customer make periodic measurements of in-house check standards to estimate their measurement process uncertainty and to ensure that the measurement process remains in a state of statistical control. Unless a laboratory has a measurement quality assurance program to monitor its own measurement process parameters continuously, there is no value in participating in a MAP. In fact, NIST recommends that its customers establish and use a measurement quality assurance program to monitor their measurement parameters, whether or not they participate in a MAP.

\section{Other NIST Measure- - ment Transfer Services}

\section{National Voluntary Laboratory Accreditation Program (NVLAP)}

NIST does not audit, or regulate metrology laboratories as part of MAP or other calibration services. Calibration laboratories and testing facilities may be accredited by NIST under the National Voluntary Laboratory Accreditation Program (NVLAP). The basic procedures and general accreditation requirements of NVLAP are described in NIST Handbook 150 . A participating laboratory may voluntarily take steps to improve or assess its measurement process. For further information about NVLAP, contact:

National Voluntary Laboratory Accreditation Program (NVLAP)

National Institute of Standards and Technology

Building 820, Room 282

Gaithersburg, MD 20899-0001

Telephone: (301) 975-4016

E-Mail: NVLAP@nist.gov

Fax: (301) 926-2884

Internet: http://ts.nist.gov/nvlap 
Standard Reference Materials Program (SRMP)

Calibration assistance and alternative paths for traceability are provided by NIST's Standard Reference Materials Program. For examples:

Chemical measurement instruments are not calibrated at NIST, but NIST provides various Standard Reference Materials (SRMs), some of which are used to calibrate chemical measuring systems.

Dimensional Measurements-NIST also provides several SRMs for calibrating instruments for dimensional measurements. These include socketed ball bars and probe performance spheres for coordinate measuring machines; surface roughness blocks to calibrate stylus instruments; powders and solids to calibrate particle size measuring instruments; and magnification, linewidth measurement, and optical fiber diameter standards for instruments such as scanning electron, optical, and video microscopes.

Sieves-NIST provides a series of SRMs for evaluating and calibrating various types of particle size measuring instruments, including light and electrical zone flow-through counters, optical and electron microscopes, sedigraphs, and wire cloth sieving devices.

Thermodynamic Property Measurements-NIST offers SRMs for calibrating instruments used to determine thermodynamic properties, such as enthalpy and heat capacity, heat of combustion, heat of solution, vapor pressure of metals, and thermal expansion and resistance. Also available are defining fixed points of the International Temperature Scale, ITS(90), melting points, triple points, secondary temperature reference points, thermocouples and thermometers.

Liquid Densitities-NIST offers SRMs of certified density for the determination of liquid densities.

Photometric Measurements-In addition to calibrations and special tests, NIST also offers SRMs for spectrophotometry, including diffuse transmittance (photographic step tablets).

For further information about SRMs, contact:
Standard Reference Materials Prograrn (SRMP)

National Institute of Standards and Technology

Building 202, Room 204

Gaithersburg, MD 20899-0001

Telephone: (301) 975-6776

E-Mail: SRMINFO@nist.gov

Fax: (301) 948-3730

Internet: http://s.nist.gov/srm

\section{Standard Reference Data Program (SRDP)}

Very few calibrations can be conducted without quantitative information related to measurements of physical or chemical properties. NIST develops and publishes evaluated data for technical and scientific applications called Standard Reference Data (SRD). For further information about SRD, contact:

\section{Standard Reference Data Program (SRDP) \\ National Institute of Standards and Technology \\ Building 820, Room 113 \\ Gaithersburg, MD 20899-0001 \\ Telephone: (301) 975-2208 \\ E-Mail: SRDATA@nist.gov \\ Fax:(301) 926-0416 \\ Internet: http://www.nist.gov/srd}

\section{Weights and Measures Program (OWM)}

The NIST Office of Weights and Measures (OWM) provides measurement services to State and local governments responsible for marketplace transactions involving measurements. State weights and measures laboratories provide alternative sources for calibration services in mass, length, volume, and certain other measurement areas. For further information about OWM, contact:

Office of Weights and Measures

(OWM)

National Institute of Standards and Technology

Building 820, Room 232

Gaithersburg, MD 20899-0001

Telephone: (301) 975-4004

E-Mail: jkoenig@nist.gov

Fax: (301) 926-0647

Internet: http://www.nist.gov/owm 


\section{Criteria for Quality Assurance}

All the measurement services listed in this document meet rigorous criteria for quality assurance. Calibration Services and MAPs satisfy the most demanding and explicit requirements in that they are carried out regularly under pre-established and well-defined conditions; the measurement processes are wellcharacterized, stable, and statistically controlled; and quality-control procedures are well-defined and strictly followed. Fur thermore, each Calibration Service or MAP is planned and documented to provide continuity of service over time.

A Special Test is so designated for one or more of the following reasons: (1) the specific type of calibration is seldom requested, thus precluding the maintenance of a large statistical base for characterizing the measurement process;

(2) the requested test is unique; or (3) the service is still under development-meaning the measurement or calibration methods are still being perfected, or the quality-control documentation has not all been completed.

\section{E. Fees}

NIST recovers the costs of calibration services by charging a fee for each calibration performed. These fees range from a low of several hundred dollars to calibrate a laboratory thermometer to $\$ 75,000$ or more for special tests of large microwave antenna systems.

The costs of services are published in the Fee Schedule (NIST SP250 Appendix), which is updated and published annually to reflect changes in prices and services. Even so, the cost of many services may vary according to your exact calibration specifications; you must therefore provide the technical contact with an exact description of work before receiving a price quote. Please refer to Section $\mathrm{L}$ of this Chapter for information on obtaining a copy of the current Fee Schedule or Users Guide.
NOTE: Fees for NIST services do not include shipping costs or insurance.

\section{Reports of Calibration/ Test Results}

Reports on calibrations or other services are the property of the customer. Copies are supplied to other parties only as required by Federal law or requested in writing by the customer. The results of calibrations and tests performed by NIST apply only to the specific instrument or standard at the time of test unless otherwise clearly stated.

\section{Traceability}

The International Vocabulary of Basic and General Terms in Metrology (VIM; 1993) defines traceability as:

The property of the result of a measurement or the value of a standard whereby it can be related to stated references, usually national or international standards, through an unbroken chain of comparisons all having stated uncertainties.

Many government regulations and commercial contracts require regulated organizations or contractors to verify that the measurements they make are "traceable" and to support the claim of traceability by keeping records that their own measuring equipment has been calibrated by laboratories or testing facilities whose measurements are part of this "unbroken chain." The purpose of requiring traceability is to ensure that measurements are accurate representations of the specific quantity subject to measurement, within the uncertainty of the measurement.

NIST reports calibration results, with the measurement values accompanied by the uncertainties associated with the methods, operators, and environment at NIST. Users of these calibration services make their own measurements with the calibrated instruments or artifacts. In addition to the uncertainty indicated by 
NIST, other uncertainties are inherent in the instrument, associated with the method or protocol in using the instrument, with the operator of the instrument, and with the physical environment (pressure, temperature, humidity, etc.) in which the measurements are made. Thus, the measurements made with the calibrated instruments or artifacts by organizations outside NIST have associated total uncertainty budgets, only one component of which is the uncertainty reported by NIST.

NIST often receives calls to verify the authenticity of a NIST Report of Test number appearing on another organization's report. Although NIST can verify the authenticity of its report numbers, the number itself does not provide complete assurance or evidence that the measurement value provided by another organization is traceable. Not only should there be an unbroken chain of comparisons, each provided measurement should be accompanied by a statement of uncertainty associated with the farthest link in the chain from NIST, that is, from the facility providing the most recent measurement value. NIST does not have that information; only the facilities that provided the measurement values to the customer can provide the associated uncertainties and describe the traceability chain.

In summary, to adequately establish an audit trail for traceability, a proper calibration result must include: the assigned value, a stated uncertainty, identification of the standards used in the calibration, and the specification of any environmental conditions of the calibration where correction factors should be applied, if the standard or equipment were to be used under different environmental conditions.

NIST does not define nor enforce traceability except in its NVLAP laboratory accreditation program. Moreover, NIST is not legally required to comply with traceability requirements of other Federal agencies, nor do we determine what must be done to comply with another party's contract or regulation calling for such traceability. However, NIST can and does provide technical advice on making measurements consistent with national standards.

Although NIST supports making the user aware of traceability and provides the user with details as to how traceability is established, NIST does not allow the prominent display of its name on proprietary products or in the advertising of them. (See Section J).

\section{NIST Policy on Report- ing Measurement Uncertainty}

To ensure that NIST uncertainty statements are consistent across the organization and with international practice, NIST policy requires that all NIST measurements be accompanied by statements of uncertainty as discussed in NIST Technical Note 1297.' This publication is based on the approach to expressing uncertainty in measurements recommended by the International Committee on Weights and Measures (CIPM). ${ }^{2}$ That committee established general rules for evaluating and expressing uncertainty in measurements that are intended to be applicable to a broad spectrum of measurements. Copies of NIST TN 1297 are available upon request (see Section L) or on the web site at:

\section{http://physics.nist.gov/Pubs/guidelines/ contents.html}

Throughout this publication, uncerntainties are expressed as standard uncertainties or expanded uncertainties. Standard uncertainties have a coverage factor, $k$, of 1 , and denote a level of confidence of approximately $68 \%$. Unless noted otherwise, a coverage factor, $k$, of 2 (95\% confidence level) applies to any expanded uncertainty provided in this guide. The expanded uncertainties are exactly twice as large as the standard uncertainties.

\footnotetext{
'Guidelines for Evaluating and Expressing the Uncertainty of NIST Measurement Results, NIST Technical Note 1297, 1994 Edition.

${ }^{2}$ Guide to the Expression of Uncertainty in Measurement, International Standards Organization (ISO), 1993 Edition.
} 
The uncertainty of a measurement consists of two categories of components: "Type A" are those uncertainties evaluated by statistical methods, and "Type B" uncertainties are evaluated by other means, usually scientific judgment using all relevant information such as previous data, or experience with materials or instrument behaviors. Some sections of this Guide discuss and list the components of uncertainty associated with the measurements.

\section{NIST Policy Regarding - Use of Metric (SI) Units}

In accordance with the Metric Conversion Act of 1975 as amended by Section 5164 of the Omnibus Trade and Competitiveness Act of 1988 and as required by related provisions of the Code of Federal Regulations, the National Institute of Standards and Technology (NIST) uses the modern metric system of measurement units (International System of Units-SI) in all publications. When the field of application or the special needs of users of NIST publications require the use of non-SI units, the values of quantities are first stated in the SI units and the corresponding values expressed in non-SI units follow in parentheses. Copies of NIST SP $811^{3}$ are available upon request (see Section L) or on the web site at:

http://physics.nist.gov/Pubs/SP811/ sp811.html

\section{References to NIST in
Advertisements}

The NIST measurement or test results or reports shall not be used to indicate or imply that NIST approves, recommends, or endorses the manufacturer, supplier, or user of any instruments or standards or that NIST in any way guarantees or predicts the future performance of items after calibration or test. No reference shall be made to NIST or to reports or results furnished by NIST in any advertising or sales promotions which might indicate or imply that NIST approves, recommends,

\footnotetext{
${ }^{3}$ Guide for the Use of the International System of Units (SI), NIST Special Publication 811, 1995 Edition.
}

or endorses any proprietary product or proprietary material.

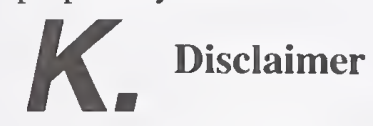

Commercial products, materials, and instruments, are identified in NIST communications and documents for the sole purpose of adequately describing experimental or test procedures. In no event does such identification imply recommendation or endorsement by NIST of a particular product; nor does it imply that a named material or instrument is necessarily the best available for the purpose it serves.

\section{Questions and Inquiries}

This Users Guide and the Fee Schedule (SP250 Appendix) are intended to make the task of selecting and ordering an appropriate calibration service as quick and easy as possible. Nevertheless, when questions arise you should contact NIST for immediate clarification.

General inquiries about the NIST calibration services, assistance in determining the availability of services, and requests for complimentary copies of the Calibration Services Users Guide, the Fee Schedule, Guide for the International System of Units (SP 811), and Guidelines for Evaluating and Expressing the Uncertainty of NIST Measurement Results (TN 1297) may be addressed to:

\section{Calibration Program \\ National Institute of Standards and Technology \\ Building 820, Room 236 \\ Gaithersburg, MD 20899-0001 \\ Telephone: (301) 975-2002 \\ Fax: (301) 869-3548 \\ E-Mail: calibrations@nist.gov}

Visit the NIST Calibration Program Web Site on the Internet:

$$
\text { http://ts.nist.gov/calibrations }
$$

For technical questions concerning a specific service, contact the NIST staff member responsible for that calibration area. Consult the section of the Users Guide or Fee Schedule that lists the service in question for names, addresses, e-mail and telephone numbers. 


\section{Chapter}

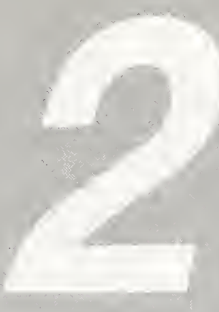
A Customer Inquiries
B Prearrangements and Scheduling
C Purchase Orders
D Shipping, Insurance, and Risk of Loss
E Turnaround Time
F Customer Checklist 
4 . Customer Inquiries

General customer inquiries for information or clarifications about the NIST calibration services may be directed as indicated in Section L of Chapter 1.

\section{P. Prearrangements and Scheduling}

Services should be arranged in advance, beginning with direct contact with a NIST technical staff member responsible for the desired service. Use the appropriate technical section of the Users Guide or Fee Schedule to determine whom to contact. This advance communication may answer your questions, clarify the policies and procedures briefly described here, and will permit you to schedule a tentative calibration date. Following the in:tial communication, you must complete and submit a purchase order and prepare to ship the item according to the procedures described below or agreed upon with the technical contact. If a calibration is scheduled far in advance, the item should not be shipped until shortly before the scheduled date; you must submit the purchase order (complete with the name and number of the desired service) before a firm calibration date can be assigned. When NIST receives your purchase order and assigns a firm service date, your order will be confirmed by the technical contact.

\section{Purchase Orders}

Before you ship an item for calibration, send a purchase order to the address listed in the appropriate technical section of the Users Guide or Fee Schedule. The purchase order must:

1) State both the name and number of the NIST service (listed in this Guide as the "Service ID Number") being requested. FAILURE TO INCLUDE THE ORDER NUMBER WILL

\section{SERIOUSLY IMPEDE}

SCHEDULING AND SERVICE.

2) Clearly identify the item(s) being sent for calibration, including any serial number(s) or model number(s).

3) Give the name, address, and telephone number of your company's procurement officer, purchasing agent or other administrative/ financial authority.

4) Give the name, address, and telephone number of your company's technical contact, if different from above.

5) List separately the instructions and address for return shipment, insurance, mailing address for the calibration/test report, and billing address. (Federal or State agency requests for calibration services should be accompanied by a document authorizing that the cost of the service be billed to the agency.)

6) Clearly state any special or necessary conditions of test-such as operating frequency or temperature.

7) Clearly state your customer identification number; i.e., social security number (EIN) for individuals; tax identification number (TIN) for organizations; or agency location code (ALC) for government customers.

8) If the calibration or test report is to be handled in a special manner, give instructions on the purchase order.

NOTE: Receipt of orders by NIST does not imply acceptance of any provisions set forth in the order that are contrary to the policy, practice, or regulations of NIST or of the U.S. Government. In general, NIST will not sign any affidavits, acknowledgment forms, or other documents required by company policy governing the procurement of goods and services. 


\section{Dhipping, Insurance, and Risk of Loss}

Ship the instrument or standard to the mailing address of the technical group providing the service. Please note that the mailing address is not the same for all technical groups.

Please adhere rigorously to the following procedures:

1) Ship only items in good repair. Apparatus in disrepair will not be calibrated. If defects are found after calibration has begun, the procedure will be terminated, a report issued, and a charge levied for work completed.

2) Use strong, reusabie packing materials and containers marked clearly and indelibly on the outside with the requestor's name, address, and the following notation: REUSABLE CONTAINER, DO NOT DESTROY.

3) Follow any special shipping procedures given in the technical sections of this Guide, particularly those sections covering radiation and dosimetry measurements.

4) Insure the shipments to and from NIST and clearly state the method of return shipment. NIST will not assume liability for loss or damage, unless such loss and damage result solely from the negligence of NIST personnel. If return shipment by parcel post is requested or is suitable, NIST will prepay the return shipment but will not insure it. When no shipping or insurance instructions are furnished, NIST will return the shipment by common carrier, collect and uninsured.

5) Shipments to NIST must be at FOB destinations. (Customer pays for shipping.)

6) Return shipments are sent FOB origin. (Customer pays for shipping.)

NOTE: Fees for NIST services do not include shipping costs.

\section{E Turnaround Time}

The normal turnaround time for NIST calibration services varies greatlyusually from several weeks to several months depending on the type of service requested and the service schedule. Some services are scheduled only once or twice a year, with appointments made months in advance of the service date. To avoid unnecessary scheduling or administrative delays in the calibration process, always make arrangements with the techrical contact for the service you wish to utilize prior to shipping your instrument or artifact to us.

\section{F Customer Checklist}

Please refer to the next page in this chapter for a Customer Checklist which is intended to assist you in developing the basic information required to process an order for calibration services at NIST. 


\section{Customer Checklist for Ordering NIST Calibration Services}

\begin{tabular}{|c|c|}
\hline 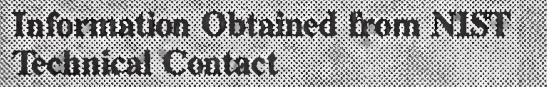 & Comments: \\
\hline NIST Contact (name/telephone) & Provide this information on your purchase order (po) \\
\hline Is the service available? & $\begin{array}{l}\text { Please make sure customer's technical contact discusses service } \\
\text { with NIST technical contact before proceeding. }\end{array}$ \\
\hline NIST Service Identification Number & Provide this information on your po \\
\hline Estimated cost of services & Provide this information on your po \\
\hline Estimated turnaround time & $\begin{array}{l}\text { Many calibration services are batched. Find out when to send } \\
\text { the instrument. }\end{array}$ \\
\hline \multicolumn{2}{|l|}{ Special instructions } \\
\hline \multicolumn{2}{|l|}{ Packaging instructions } \\
\hline \multicolumn{2}{|l|}{ Shipping instructions } \\
\hline \multicolumn{2}{|l|}{ Other precautions } \\
\hline \multicolumn{2}{|l|}{ 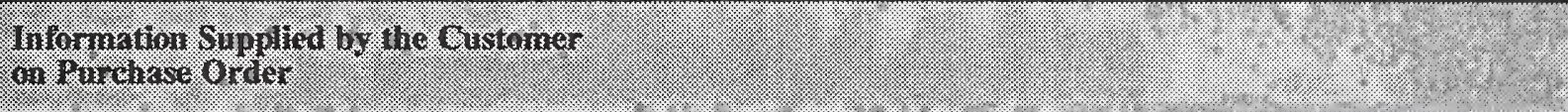 } \\
\hline \multicolumn{2}{|l|}{ Purchase order number } \\
\hline \multicolumn{2}{|l|}{ Purchase order date } \\
\hline \multicolumn{2}{|l|}{ Customer's tax identification number } \\
\hline \multicolumn{2}{|l|}{ Customer's mailing address } \\
\hline \multicolumn{2}{|l|}{ Customer's billing address } \\
\hline \multicolumn{2}{|l|}{$\begin{array}{l}\text { Name, telephone number, fax number, } \\
\text { e-mail address of administrative or } \\
\text { procurement contact point at customer's } \\
\text { location }\end{array}$} \\
\hline \multicolumn{2}{|l|}{$\begin{array}{l}\text { Name, telephone number, fax number, } \\
\text { e-mail address of technical contact point } \\
\text { at customer's location }\end{array}$} \\
\hline \multicolumn{2}{|l|}{$\begin{array}{l}\text { Ship-to address (including NIST technical } \\
\text { contact name) }\end{array}$} \\
\hline \multicolumn{2}{|l|}{$\begin{array}{l}\text { Return address (for shipment back } \\
\text { to customer) }\end{array}$} \\
\hline \multicolumn{2}{|l|}{ NIST Service Identification Number } \\
\hline \multicolumn{2}{|l|}{ Estimated cost } \\
\hline \multicolumn{2}{|l|}{$\begin{array}{l}\text { Shipping terms (no FOB destination on } \\
\text { return shipment) }\end{array}$} \\
\hline $\begin{array}{l}\text { Special instructions from customer's } \\
\text { technical contact }\end{array}$ & \\
\hline
\end{tabular}




\section{Chapter}

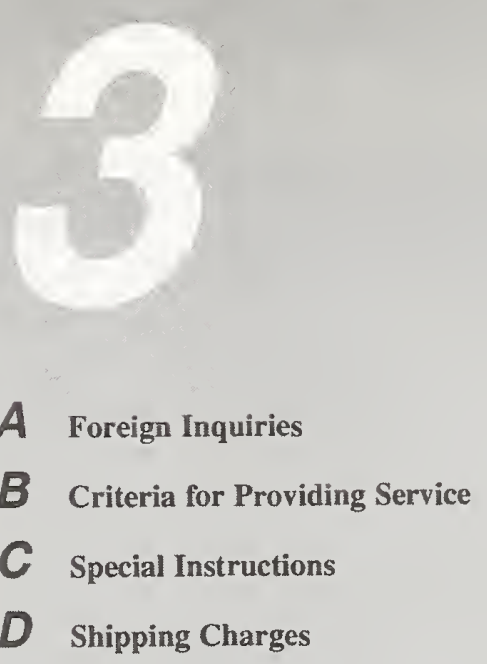




\section{Special Instructions_Foreign Customers}

4 Foreign Inquiries

Foreign customers should address all inquiries to:

Calibration Program

National Institute of Standards and Technology

Building 820, Room 236

Gaithersburg, MD 20899-0001

United States of America

Telephone: (301) 975-2002

Fax: (301) 869-3548

E-mail: calibrations@nist.gov

Visit the NIST Calibration Program Web Site on the Internet:

http://ts.nist.gov/calibrations

NOTE: Please clearly indicate your city and country on all correspondence so that we may promptly respond to your request.

\section{Criteria for Providing Service}

NIST is authorized to provide measurement services, including calibration services, for organizations or individuals located outside the United States. The Calibration Program must review each request for calibration services to determine if services are available in the requestor's country. Foreign customers may be asked to provide a written justification stating why NIST should perform this service if an official standards laboratory in the requestor's country can provide the requested service(s). Foreign customers must provide the following information, in writing, to the Calibration Program (see address above):

1. Identification of the item(s) to be calibrated, including serial and model numbers.
2. A detailed description of the measurements that are needed, or indicate the service identification number as given in this Guide (NIST SP250) or the Fee Schedule (NIST SP250 Appendix).

3. A description of any special requirement/circumstance that might affect the decision to provide the service. For example, will adjustments have to be made to the instrument, or will the time period be restricted in which the device is available for calibration?

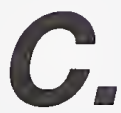

\section{Special Instructions}

If the request for calibration service is accepted by NIST, the requesting organization will be notified of the cost of service and will be given the NIST technical staff contact that will perform the measurements. The requesting organization must then complete the following steps:

1. Contact the NIST technical staff that will perform the service to determine the time schedule.

2. Send a purchase order to the Calibration Program. Provide complete addresses, including country, for returning the instrument and for mailing the calibration or test report.

3. NIST policy requires prepayment for all NIST calibration services requested by non-U.S. organizations. Before proceeding with any service(s) we will need a check, money order or a bank wire transfer. The prepayment must be for the full amount and be drawn on a U.S. bank. The prepayment methods are as follows: 
Money Orders \& Prepayment Checks

Checks made payable to the National Institute of Standards and Technology (NIST) should be mailed to:

National Institute of Standards and Technology

Calibration Program

Building 820, Room 236

Gaithersburg, MD 20899-0001

\section{Bank Wire Transfers}

Federal Reserve Bank of New York

33 Liberty Street

New York, NY 10045

Phone: (212)720-5330

ABA\#021030004

Account \# 13060001

Account Name: Treas NYC/CTR/

$\mathrm{BNF}=/ \mathrm{NIST} / \mathrm{AC}-13060001$

Reference "Calibrations" so it will enable us to identify your payment. In addition, please be sure to pay any fees assessed for your bank wire transfers; otherwise, they will deduct it from your prepayment wire.

PLEASE NOTE: Our account number and name are of critical importance and must be referenced in order for NIST to be properly credited with your payment. It must appear in the precise manner shown to allow for the automated processing and classification of the funds transfer message. Questions on bank wiring can be directed to Randy Angleberger at (301) 975-2694, or E-Mail: randy.angleberger@nist.gov

4. Before shipping the instrument or standard to the appropriate NIST technical unit, you must arrange with a customs broker for entry of the instrument into the U.S. with transportation from the port of entry to NIST prepaid. Air freight is most satisfactory. Entry bond is required for instruments not manufactured in the U.S. If arrangements are made with a broker in the country of origin, that broker should, in turn, have a U.S. customs broker in or near the port of entry to arrange for the entry of the instrument and its transportation to NIST. Direct arrangements can be made with customs brokers located in the Washington, $\mathrm{DC} /$ Baltimore, Maryland, metropoli$\tan$ area or in the Denver, Colorado, area, as appropriate. These brokers must arrange for transportation to the port of exit after testing/calibration has been completed.

\section{Shipping Charges}

The calibration fees quoted do not include shipping, insurance, or the services of a customs broker. You must arrange and pay for these services separately. For your information, NIST currently uses the following customs brokers:

\section{Gaithersburg, Maryland \\ Laing International \\ P.O. Box 16144 \\ Washington, DC 20041 \\ Phone: (703) 471-9279 \\ Fax: (703) 471-8436 \\ Boulder, Colorado \\ G. L. Gumbert \\ 4725 Paris Street, Suite 200 \\ Denver, CO 80239 \\ Phone: (303) 371-9550 \\ Fax: (303) 373-0850}

You are not required to use these customs brokers, but may select a broker of your choice. 



\section{Chapter}

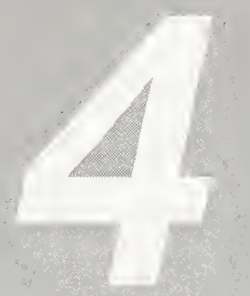
A Length Measurements
B Diameter Measurements
C Complex Dimensional Standards
D Optical Reference Planes and Roundness Standards
E Angular Measurements
F Laser Measurements
G Surface Texture
H Hydrometers
I Volume and Density 


\section{Length Measurements* \\ A.1 Gage Blocks}

Technical Contacts:

\begin{abstract}
Eric S. Stanfield
Tel: 301/975-3471

email: eric.stanfield@nist.gov

Howard H. Harary

Tel: 301/975-3485

email: hharay@nist.gov

Mailing Address: Building 220, Room B113, National Institute of Standards and Technology,

Gaithersburg, MD 20899-0001
\end{abstract}

\section{Service}

ID No. Items

\section{C Gage Blocks}

Square or rectangular blocks up to $500 \mathrm{~mm}(20 \mathrm{in})$ long are routinely calibrated and the lengths reported in English or metric units. For blocks longer than $500 \mathrm{~mm}$ (20 in), the NIST technical contact should be consulted in advance to discuss alternative measurement techniques, approximate costs, and scheduling.

The reported measurement uncertainty** depends on the length of the blocks. For blocks near $2 \mathrm{~mm}(0.1 \mathrm{in})$, the expanded uncertainty** is approximately $25 \mathrm{~nm}$. The uncertainty is larger for blocks significantly longer or shorter than $2 \mathrm{~mm}$. A report describing the NIST gage block laboratory measurement assurance process is sent to all new customers or on request to past customers.

\section{References-Gage Blocks}

The Gage Block Handbook, T. Doiron and J. S. Beers, NIST Monogr. 180 (1995).

Drift Eliminating Designs for NonSimultaneous Comparison Calibrations, T. Doiron, J. Res. Natl. Inst. Stand. Technol. 98 (2), 217-224 (1993).

A Gage Block Measurement Process Using Single Wavelength Interferometry, J. S. Beers, Natl. Bur. Stand. (U.S.), Monogr. 152 (1975).
* See Chapter 1, Section C for information on dimensional measurement artifacts available through the Standard Reference Materials Program.
** See Chapter 1, Section $\mathrm{H}$ for more information about uncertainty. 


\section{A.}

\author{
Technical Contact:
}

\author{
William Penzes \\ Tel: 301/975-3477 \\ email:wpenzes@nist.gov
}

Mailing Address: Building 220, Room A117,

National Institute of Standards and Technology,

Gaithersburg, MD 20899-0001

\section{Service}

ID No. Items

10020C Line Standards
$2 \mu \mathrm{m}$ to $10 \mu \mathrm{m}$ wide and are between $20 \mu \mathrm{m}$ to $100 \mu \mathrm{m}$ long, if there is good contrast between the line and the background, and if the graduated surface of the artifact is flat within $10 \mu \mathrm{m}$. Expanded uncertainties* of $1 \mathrm{~nm}$ can be achieved for intervals of $1 \mathrm{~mm}$ or less. For intervals of about $1 \mathrm{~m}$, standard uncertainties* of $50 \mathrm{~nm}$ can be achieved.

\section{References—Line Standards}

\section{NIST Length Scale Interferometer} Measurement Assurance, J. S. Beers and W. B. Penzes, Natl. Inst. Stand. Technol., NISTIR 4998 (Dec. 1992). Length Scale Measurement Procedures at the National Bureau of Standards, J. S. Beers, NBSIR 87-3625 (1987).

\section{Line Standards (10020C)}

Line scales are calibrated on an instrument called a Line Scale Interferometer (LSI). The NIST LSI consists of a scanning electro-optical line detector, a high precision one-axis motion system, and a high accuracy heterodyne interferometer for determining the displacement of the test artifact beneath the line detector. The wavelength of a stabilized helium-neon laser corrected for temperature, humidity, and atmospheric pressure is used as the length standard. The instrument is housed in a temperature controlled chamber in which all environmental properties are carefully monitored.

The minimum line spacing on a line standard is $1 \mu \mathrm{m}$ and the maximum line spacing of $1 \mathrm{~m}$ can be measured on this instrument. The line width can be varied from $1 \mu \mathrm{m}$ to $100 \mu \mathrm{m}, 2 \mu \mathrm{m}$ to $10 \mu \mathrm{m}$ being optimum. The maximum overall length of a line standard should not exceed $1020 \mathrm{~mm}$, and the maximum width of any part of the standard should not exceed $150 \mathrm{~mm}$.

The accuracy of the calibration of a line standard depends significantly on the shape and optical properties of the graduation lines, the background, and the flatness of the graduated surface. The accuracy of the calibration will be optimum if the lines are uniform, have straight parallel edges, uniform reflectivity, are
* See Chapter 1, Section $\mathrm{H}$ for more information about uncertainty. 


\section{Length Measurements A.3 Surveying Tapes}

\author{
Technical Contact:
}

Ronald G. Hartsock

Tel: 301/975-3465

email: rhartsock@nist.gov

Mailing Address: Building 220, Room B113, National Institute of Standards and Technology,

Gaithersburg, MD 20899-0001

\section{Service}

ID No.

10030C Surveying and Oil Gaging Tapes

10040S Special Tests of Surveying Leveling Rods

\section{Surveying and Oil Gaging Tapes (10030C)}

The calibration of surveying tapes and oil gáging tapes is carried out in a laboratory that houses two permanent working standards, a laser interferometer, and a $50 \mathrm{~m}$ (200 ft) stainless steel bench. For the most part, measurements are performed using a laser system that is referenced against a cube-corner retroreflector attached to a microscope, which is used manually for line location. The laboratory is maintained at $20^{\circ} \mathrm{C}$, but a control system can vary the chamber temperature from $15^{\circ} \mathrm{C}$ to $40^{\circ} \mathrm{C}$ for special tests. Calibration of tapes will normally be made with the tape under tension and supported on a horizontal flat surface. Unless otherwise requested, the total length and each $15 \mathrm{~m}$ or $50 \mathrm{ft}$ subinterval will be measured and reported. Each interval calibrated on a surveying tape will have computed lengths for two (single catenary), three, four, and five equidistant points of support.

The laser standard is capable of calibrating tapes with scribed graduations with a relative expanded uncertainty* of $2 \times 10^{-6}$. Calibrations made with respect to the stainless steel tape bench

* See Chapter 1, Section $\mathrm{H}$ for more information about uncertainty. are normally reported with a relative expanded uncertainty of $10 \times 10^{-6}$. A NIST serial number will be engraved on each calibrated tape for identification.

\section{Special Tests of Surveying Leveling Rods (10040S)}

Leveling rods are currently calibrated using either of two methods. One method involves the comparison of the rod to a $3 \mathrm{~m}$ standard at the intervals of $1 \mathrm{~m}, 2 \mathrm{~m}$, and $3 \mathrm{~m}$ (Other intervals can be accommodated.). A second system provides automated measurement at multiple intervals and automatic report generation. Both systems incorporate a $7 \mathrm{~m}$ onedimensional measuring machine with a helium-neon laser interferometer interfaced to a minicomputer. The automated system uses a motorized carriage and a photoelectric microscope for automatic edge detection of the graduations. Measurements can be made on virtually any type of linear scale or leveling rods with scribed, engraved, or painted graduations. The expanded uncertainty* for high-quality new Invar leveling rods is $50 \mu \mathrm{m}$ and $100 \mu \mathrm{m}$ for used rods. Current studies suggest that these may be lowered in the future to near $20 \mu \mathrm{m}$ and $50 \mu \mathrm{m}$, respectively. The length of intervals will be reported as measured at $25^{\circ} \mathrm{C}$ unless otherwise requested. The report can be supplied in either written or digital form. 


\title{
1 Length Measurements A.4 Other Length Standards
}

\author{
Technical Contacts:
}

Eric S. Stanfield

Tel: 301/975-3471

Howard H. Harary

Tel: 301/975-3485

email: eric.stanfield@nist.gov email: hharary@nist.gov

Mailing Address: Building 220, Room B113, National Institute of Standards and Technology, Gaithersburg, MD 20899-0001

Special Tests of Length Standards (10050S)

Measurements on end standards with spherical ends, gage blocks of unusual shape or exotic materials, or measurement of standards between* 24 in and 240 in can sometimes be done, but agreement with the technical contact should be made before sending material.

* This is a special test when customer requests characterization in inches rather than SI units. 


\section{Technical Contacts:}

Eric S. Stanfield

Tel: 301/975-3471

email: eric.stanfield@nist.gov

\author{
Howard H. Harary \\ Tel: 301/975-3485 \\ email: hharary@nist.gov
}

Mailing Address: Building 220, Room B113, National Institute of Standards and Technology, Gaithersburg, MD 20899-0001

Service

ID No. Items

10060S Special Tests of Sieves

\section{Special Tests of Sieves (10060S)}

Sieves are tested using a high accuracy optical projector. The average wire diameter of both the warp and shoot wires are determined by measuring 20 or more wires at five different positions along the diameter of the sieve. The average opening is found by measuring the average pitch of the wires and subtracting the average wire diameter. These results are compared with the tolerances in the ASTM E-11 specifications. The frame dimensions are also checked.

* See Chapter 1, Section C for information on calibration materials available from the Standard Reference Materials Program. 


\section{Length Measurements A.6 Algorithms Testing and Evaluation Program for Coordinate Measuring Systems}

\author{
Technical Contacts:
}

\begin{abstract}
Cathleen Diaz Pluguez Tel: 301/975-2889

email: cdpluguez@nist.gov

\author{
Craig M. Shakarji \\ Tel: 301/975-3545 \\ email: shakarji@nist.gov
}

Mailing Address: Building 220, Room A127, National Institute of Standards and Technology, Gaithersburg, MD 20899-0001
\end{abstract}

\begin{tabular}{ll}
$\begin{array}{l}\text { Service } \\
\text { ID No. }\end{array}$ & Items \\
\hline $10070 S$ & $\begin{array}{l}\text { Special Test of CMS Software: NIST-Generated Data Sets } \\
\text { (Basic Service) }\end{array}$ \\
$10071 S$ & $\begin{array}{l}\text { Special Test of CMS Software: NIST-Generated Data Sets } \\
\text { (Per Geometry Evaluated) }\end{array}$ \\
100805 & $\begin{array}{l}\text { Special Test of CMS Software: Customer-Generated Data } \\
\text { Sets (Basic Service) } \\
\text { Special Test of CMS Software: Customer-Generated Data } \\
\text { Sets (Per Geometry Evaluated) }\end{array}$
\end{tabular}

General Information (10070S-10081S)

The Algorithm Testing and Evaluation Program for Coordinate Measuring Systems (ATEP-CMS) evaluates the performance of data analysis software used in coordinate measuring systems (CMSs). Tested software is treated as a filter that transforms point coordinate data into feature parameters according to a defined transfer function. NIST evaluates the accuracy of the filter under conditions typical of those found in industrial practice. NIST independently compares the output of the software under test to predetermined corresponding reference values. NIST uses orthogonal-distance least squares algorithms and supports the following geometry types: circle, line, plane, sphere, cylinder, cone and torus. In the Special Tests, the reported measurement uncertainty is determined by the effects of computational roundoff and convergence settings used to generate the reference fits, the propagation of these effects through the comparison algorithms, and sampling uncertainty due to the number of data sets used to perform the test.

\section{Special Test of CMS Software: NIST- Generated Data Sets (10070S-10071S)}

The customer and NIST will agree on general guidelines for determining the ranges of parameters (geometry types, form errors, measurement errors, sampling plans) to be used in defining the customer's test experiments.

NIST then provides the customer with NIST-generated data sets based on these guidelines. The customer produces fit results from their data analysis software using the NIST-generated data sets.

NIST generates fit results from the same data sets using the ATEP-CMS reference algorithms. The two sets of fit results are then compared by NIST. NIST then provides the customer with a Report of Special Test containing results of the test and the combined standard uncertainty.

\section{Special Test of CMS Software: Customer-Generated Data Sets (10080S-10081S)}

NIST receives customer-generated data sets and corresponding fit results from the data analysis software to be tested. NIST then generates fit results from the same data sets using the ATEP-CMS reference algorithms. The two sets of fits are then compared by NIST. NIST then provides the customer with a Report of Special Test containing results of the test and the combined standard uncertainty. 
References-Algorithm Testing and Evaluation Program for Coordinate Measuring Systems

Methods for Performance Evaluation of Coordinate Measuring System Software, ASME B89.4.10-199x, ASME, New York, NY (1997).

Algorithm Testing and Evaluation Program for Coordinate Measuring Systems: Testing Methods, C. Diaz, Natl. Inst. Stand. Technol., NISTIR 5686 (1995).

Evaluation of Software for Coordinate Measuring Systems, C. Diaz and T. Hopp, Proc. Of the 1995 SME Clinic, CMMs Week, June 5-8, Soc. of Manuf. Eng., Dearborn, MI; also in Proc. Of the 1995 Interface Symp., June 21-24, Interface Foundation of North America, Carnegie Mellon Univ., Pittsburgh, PA (June 1995).

Testing Coordinate Measuring Systems Software, C. Diaz and T. H. Hopp, Proc. 1994 Natl. Conf. Stand. Lab. Ann. Workshop and Symp. (Aug. 1994).

Concept for an Algorithm Testing and Evaluation Program at NIST, C. Diaz, Natl. Inst. Stand. Technol., NISTIR 5366 (Jan. 1994).

Computational Metrology, T. H. Hopp, Manufacturing Review 6 (4), 295-304, ASME, NY (1993). 


\section{B.}

\section{Diameter Measurements}

\section{Technical Contacts:}

\author{
Eric S. Stanfield \\ Tel: 301/975-3471 \\ email: eric.stanfield@nist.gov
}

\author{
Howard H. Harary \\ Tel: 301/975-3485 \\ email: hharary@nist.gov
}

Mailing Address: Building 220, Room B113, National Institute of Standards and Technology,

Gaithersburg, MD 20899-0001

Service

ID No.

Items

11010S Special Tests of Cylindrical Diameter Standards (i.e., Plug and Pin Gages)

$11020 \mathrm{C}$ Measuring Wires for Threads and Gears

11030 S Special Tests of Spherical Diameter Standards: Balls

$11040 \mathrm{~S}$ Special Tests of Internal Diameter Standards: Ring Gages

11050 S Special Tests of Length and Diameter

$11060 \mathrm{~S}$ Special Tests of Step Gages

Special Tests of Cylindrical Diameter Standards (i.e., Plug and Pin Gages) (11010S)

Plain plug gages (not threaded) are calibrated using a laser-interferometer-based micrometer. The uncertainty of the diameter is dependent on the geometry of the artifact, particularly the roundness. Please consult the technical contacts listed above about auxiliary measurements needed to assure a satisfactory level of accuracy.

\section{Measuring Wires for Threads and Gears (11020C)}

This service provides for measurement of the diameter of thread and gear measuring wires by either comparison to NIST master wires or absolute calibration with a laser-interferometer-based micrometer. Both types of calibrations are carried out under a measurement assurance program based on the measurement of control wires.

All measuring wires submitted for test should be in substantially new condition, each wire should be appropriately bottled, and the bottle should be labeled with an identification number. In shipping wires, extreme care should be taken to prevent corrosion; all wires should be properly greased and their bottles rigidly contained inside an appropriate packing case.

Thread measuring wires for $60^{\circ}$ and $29^{\circ}$ threads are tested for compliance with the latest specifications in commercial use. These wires are calibrated, and the deformed diameter under standard conditions (as called out in the $\mathrm{H} 28$ Screw Thread Standard) are reported.

The primary elements of uncertainty are based on the reproducibility of the check standards and estimates of the uncertainty in the deformation corrections. For wires in good condition the expanded uncertainty* is $0.10 \mu \mathrm{m}$ (4 $\mu \mathrm{in})$.

\section{Special Tests of Spherical Diameter Standards: Balls (11030S)}

Ball diameters are determined from multiple comparisons in random orientations with either NIST master balls or calibrated gage block stacks. The ball diameter reported is the undeformed size as calculated with the Hertz relations. For calibrations at a specific orientation or with roundness traces to reduce the geometric components of uncertainty, the technical contact listed should be contacted before the calibration is submitted.

\section{Special Tests of Internal Diameter Standards: Ring Gages (11040S)}

Ring gages are calibrated by mechanical comparison to a calibrated gage block stack. The gage block stack is calibrated by multicolor interferometry to minimize the uncertainty due to wringing and geometry variations in the stack. The diameter is measured at one marked orientation. The technical contact listed should be consulted about calibrations needed in different orientations or roundness traces needed for a fuller determination of the ring geometry, if needed.

* See Chapter 1, Section H for more information about uncertainty. 


\section{Special Tests of Length and Diameter (11050S)}

NIST has a wide variety of state-of-theart metrology equipment and can provide services associated with dimensional quality control as special tests. A threedimensional measuring machine is available for calibration of two- and three-dimensional ball plates, two-dimensional grid plates, and other artifacts of complex shape. Please consult with the technical contacts listed.

\section{Special Tests of Step Gages (11060S)}

Step gages having flat parallel faces can be measured in lengths up to $1.2 \mathrm{~m}$ (60 in). These tests are performed at the NIST Gaithersburg site or at the DOE Y-12 plant in Oak Ridge, TN. All of these calibrations are made under the metrological control of the Dimensional Metrology Group and use NIST calibrated check standards in a Measurement Assurance Program.
References-Diameter Measurements

Federal Standard H-28, Screw Thread Standards for Federal Services, English and metric versions. These handbooks are available from the General Services Administration (GSA).

American National Standard B 1.2, ANSI, New York.

On the Measurement of Thread Measuring Wires, B. N. Norden, Natl. Bur. Stand. (U.S.) Report 10987 (Jan. 1973).

Measurements of Cylindrical Standards, R. C. Veale, Natl. Bur. Stand. (U.S.), NBSIR 73-136 (1973).

On the Compression of Cylinders in Contact with a Plane Surface, B. Norden, Natl. Bur. Stand. (U.S.), NBSIR 73-243 (1973). 


\section{Complex Dimensional Standards}

\author{
Technical Contacts:
}

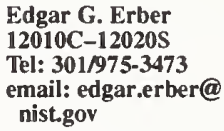

Tel: 301/975-3472

email: dennis.everett@

nist.gov
Howard Harary

Tel.: 301/975-3485

email: hharary@nist.gov
National Measurement Laboratory, Lindfield, N.S.W., Australia

Laboratory National d'Essais, Paris, France

Instituto Nacional de Technologia Industrial, Buenos Aires, Argentina

National Institute of Metrology, Beijing, People's Republic of China

As required, the API laboratory is temperature controlled at $20^{\circ} \mathrm{C}$. Parameters measured for plug gages are length of plug, taper, pitch diameter, major diameter, thread lead, lead and following thread half-angles, depth of thread, pitch line width, and radius of curvature.

Parameters measured for ring gages are length of ring, taper, thread lead, minor diameter, lead and following thread half-angles, counter bore, depth of thread, pitch line width, radius of curvature, and standoff.

Elements of rotary gages, buttress gages, extreme line casings, and large casing and tubular gages are measured on a coordinate measuring machine with an expanded uncertainty* of $2.5 \mu \mathrm{m}$ (0.0001 in) for diameters under $254 \mathrm{~mm}$, increasing to $5.0 \mu \mathrm{m}(0.0002 \mathrm{in})$ as the gage diameter increases to $500 \mathrm{~mm}$. Profile measurements are made on a contour tracing machine with an expanded uncertainty of $12.5 \mu \mathrm{m}$ (0.0005 in).

All gages received must be marked with the API monogram and the API registration number. If not so marked, the gages will be returned to the customer uncalibrated. Gages which meet the specifications will be marked as specified in the API Standards. All thread gages must be submitted in sets of plug and ring. The name of the gage owner should be given for inclusion in the Report of Calibration.

* See Chapter 1, Section $\mathrm{H}$ for more information about uncertainty. 
Special Tests of Threaded Plug and Ring Gages (12020S)

NIST will provide special tests of threaded plug and ring gages in the areas listed for API gages (12010C). The accuracy of these calibrations is determined substantially by the quality of the artifact, but high quality artifacts yield uncertainties approximately the same as API gages.

\section{Special Tests of Two-Dimensional Gages (12030S)}

NIST can provide special tests of twodimensional gages, ball plates or grid plates, with dimensions up to $600 \mathrm{~mm} \times 600 \mathrm{~mm}$ (24 in $\times 24$ in). The accuracy of the calibration depends substantially on the quality of the gage, but expanded uncertainties* of $1 \mu \mathrm{m}$ or less are obtainable for high quality artifacts.
Special Complex Dimensional Tests, by Prearrangement (12040S)

For requirements not covered by the services described above, special arrangements may be made by contacting Howard Harary (301) 975-3485.

\section{References-Complex Dimensional Standards}

On Characterizing Measuring Machine Geometry, R. J. Hocken and B. Borchardt, Natl. Bur. Stand. (U.S.), NBSIR 79-1752 (1979).

Three Dimensional Metrology,

R. J. Hocken, et al., Annals of the CIRP, 26/1 (1977).

* See Chapter 1, Section $\mathrm{H}$ for more information about uncertainty. 


\section{Optical Reference Planes \& Roundness Standards}

\section{Technical Contacts:}

$\begin{array}{ll}\text { Eric S. Stanfield } & \text { Howard Harary } \\ \text { Tel: 301/975-3471 } & \text { Tel: 301/975-3485 } \\ \text { email: eric.stanfield@ } & \text { email: hharary@nist.gov } \\ \text { nist.gov } & \end{array}$

Mailing Address: Building 220, Room B113, National Institute of Standards and Technology, Gaithersburg, MD 20899-0001

\begin{tabular}{ll}
\hline Service & \\
ID No. & Items \\
\hline 13010 S & Special Tests of Optical Reference Planes (Flats) \\
13020S & Special Tests of Roundness \\
13030S & Special Tests of Roundness Calibration Specimens \\
\hline
\end{tabular}

\section{Special Tests of Optical Reference} Planes (Flats) (13010S)

Optical reference planes are tested interferometrically, with the test surface horizontally supported on three equally spaced pads located at 0.7 of the radius from the center. The measurement is performed along two marked orthogonal diameters. The technical contact listed should be consulted for these calibrations.

Roundness Calibration Specimens and Measurements, Special Tests of Roundness (13020S and 13030S)

The deviation from roundness at eight or more positions around nominally round standards is determined. The size of the calibration step or deviation from roundness is determined. The departure from roundness of components and gages is measured, and the results are reported in graphical form.

NIST will provide special tests of roundness calibration specimens by request. Please consult with the technical contacts listed.

\section{References-Optical Reference Planes}

The Calibration of an Optical Flat by Interferometric Comparison to a Master Optical Flat, C. P. Reeve, Natl. Bur. Stand. (U.S.), NBSIR 75-975 (Dec. 1975). 


\section{Angular Measurements}

\author{
Technical Contacts:
}

\author{
Eric S. Stanfield \\ Tel: 301/975-3471 \\ email: eric.stanfield@ \\ nist.gov
}

\author{
Howard Harary \\ Tel: 301/975-3485 \\ email: hharary@nist.gov
}

Mailing Address: Building 220, Room B113

National Institute of Standards and Technology,

Gaithersburg, MD 20899-0001

\section{Service}

ID No.

Items

14010C Angle Gage Blocks

14020S Special Tests of Optical Polygons

14030S Special Tests of Rotary and Indexing Tables

14040S Special Tests of Wedges

14050S Special Angular Measurements, by Prearrangement

\section{Angle Gage Blocks (14010C)}

Angle blocks are measured in an angle comparator system consisting of a special chamber and two autocollimators. The blocks are placed in the chamber to minimize air currents and stray light effects. The test blocks are compared to NIST master angle blocks following an intercomparison method to eliminate thermal drift. Measurements are made in both top up and bottom up positions. Check standard blocks are measured during the procedure and used for process control. Standard size block sets include $(1,3,5,20$, and $30)^{\prime}$ sizes; (1, 3, 5, 20, and 30)" sizes; as well as $1^{\circ}, 3^{\circ}, 5^{\circ}, 15^{\circ}, 30^{\circ}$, and $45^{\circ}$ sizes.

The expanded uncertainty* for this calibration is approximately $0.18^{\prime \prime}$ for ideal blocks, however, this value varies with the condition and geometry of the test block gaging surfaces. Customer angle blocks with poor gaging surfaces blocks can have uncertainties as high as $0.3^{\prime \prime}$ to $0.4^{\prime \prime}$. Angle blocks with dimensions other than standard (1 in by $2(2.54 \mathrm{~cm}$ by $5.08 \mathrm{~cm})$ in measuring faces) require different measurement methods and generally result in higher uncertainties.

All angle blocks submitted for calibration should be in substantially new block condition and each marked with an identification number. In shipping angle blocks, the same care exercised in gage block shipment should be used.

\section{Special Tests of Optical Polygons (14020S)}

Optical polygons are calibrated using an indexing table stack, an autocollimator and circle closure measurement techniques. Currently only polygons with nominally equal integer angles between faces can be measured. For example, a 12 sided polygon with nominally $30^{\circ}$ angles between faces can be measured, but a 13 sided polygon with nominally $27.69^{\circ}$ between faces cannot be measured. Check standard optical polygons are used for process control.

The expanded uncertainty for this calibration is approximately 0.14 "; however, this value varies with the condition and geometry of the polygon faces.

\section{Special Tests of Rotary and Indexing Tables (14030S)}

Indexing tables (limited, fixed-increment, high repeatability) and rotary tables (continuous increment, low repeatability) are calibrated using an autocollimator and reflecting target, an indexing table stack, and circle closure techniques. The standard set of angular increments is every $30^{\circ}$.

Additionally, every $5^{\circ}$ of the first $30^{\circ}$ interval, and every $1^{\circ}$ of the first $5^{\circ}$ interval can be measured. Check standard indexing tables are used for process control during the measurement procedure.

The expanded uncertainty* for this calibration is approximately $0.14^{\prime \prime}$; however, this value varies with the locking mechanism repeatability and the scheme of angles chosen to be measured.

* See Chapter 1, Section $\mathrm{H}$ for more information about uncertainty. 


\section{Special Tests of Optical Wedges (14040S)}

Optical wedges are calibrated using an autocollimator, a reflecting target, the test wedge and a repeated reversal measurement series. Fixed angle and adjustable wedges can be calibrated. The wedge is inserted between the autocollimator and reflecting target and measured. The wedge is removed, rotated $180^{\circ}$ about the same base, re-inserted and measured. In this reversal technique the difference in the two measurements is equal to twice the actual angle. Check standard wedges are measured for process control.

The expanded uncertainty* for this calibration is approximately $0.12^{\prime \prime}$; however, this value varies with condition and geometry of tine wedge surfaces.

\section{Special Angular Measurements, by} Prearrangement (14050S)

For angular measurement requirements not covered by the services described above, special arrangements may be
* See Chapter 1, Section $\mathrm{H}$ for more information about uncertainty. made by contacting Engineering Metrology Staff (301) 975-3471. Requests for service will be discussed and honored if current equipment and means are available.

Artifacts such as optical squares (pentaprisms), apex angle measurements of prisms, true squares, and polygons not already described, typically fall into this category.

\section{References-Angular Measurements}

Uncertainty and Dimensional Calibrations, Ted Doiron, John R. Stoup, NIST Journal of Research (In Press).

The Calibration of Angle Blocks by Intercomparison, C. P. Reeve, Natl. Bur. Stand. (U.S.), NBSIR 801967 (1980). The Calibration of Indexing Tables by Subdivision, C. P. Reeve, Natl. Bur. Stand. (U.S.), NBSIR 75-750 (1975). 


\title{
Laser Measurements
}

\section{Technical Contacts:}

\author{
Jack Stone \\ Howard H. Harary \\ Tel: 301/975-3485 \\ email: jack.stone@nist.gov email: hhrary@nist.gov
}

Mailing Address: Building 220, Room B113

National Institute of Standards and Technology,

Gaithersburg, MD 20899-0001

\section{Service}

ID No.

Items

$14510 S$ Laser Frequency/Wavelength

\section{Laser Frequency/Wavelength} (14510S)

The frequency (or, equivalently, the vacuum wavelength) of a red $\mathrm{He}-\mathrm{Ne}$ laser is determined by comparison to an iodine-stabilized He-Ne laser. The attainable accuracy of this technique is ultimately limited by the uncertainty in the wavelength of the iodine stabilized laser. The relative standard uncertainty* of the laser vacuum wavelength at NIST is $5 \times 10^{-11}$. The relative expanded uncertainty is $1 \times 10^{-10}$. The relative expanded uncertainty can be reduced to $5 \times 10^{-11}$ on special requests. As a practical matter, however, the uncertainty of a comparison is usually determined by the limited reproducibility of the laser under test.

* See Chapter 1, Section $\mathrm{H}$ for more information about uncertainty. 


\section{$G$. Surbere Thumer}

\section{Technical Contact:}

Charles D. Foreman

Tel: 301/975-5836

Email: charles.foreman@nist.gov

Mailing Address: Building 220, Room A117,

National Institute of Standards and Technology,

Gaithersburg, MD 20899-0001

Service

ID No. Items

15010C Roughness Calibration Specimens

15020C Surface Roughness Comparison Specimens

15030C Step Height Measurements

15040S Special Roughness Tests

\section{Roughness (15010C-15040S)*}

NIST provides measurement services for roughness calibration specimens, other types of roughness specimens, and step height calibration specimens (see standards ASME B46.1-1995 and ISO 5436).

Surface roughnesses up to $10 \mu \mathrm{m} \mathrm{Ra}$ and step heights up to $50 \mu \mathrm{m}$ are measured by means of a computerized stylus instrument system. Using an interferometrically measured step, the system is calibrated at each value of magnification employed during a measurement. Certain horizontal parameters are calibrated using a laser interferometer. A number of other statistical parameters and functions may also be calculated, including the rms roughness, average slope, average wavelength, skewness, amplitude density function, autocorrelation function, and power spectral density.

In measurements of roughness, surface profiles are taken according to American National Standard, ASME B46.1-1995, using a $0.8 \mathrm{~mm}$ cutoff length and a traversing length of $4 \mathrm{~mm}$. In step height measurements, straight lines are fitted by

\footnotetext{
* Also see Chapter 1, Section C for Standard Reference Materials to calibrate stylus instruments that measure surface roughness.
}

the method of least squares to the top and bottom of the profile of the step, and the step height is calculated from the vertical difference of the lines at the middle of the step transition. The uncertainty in the NIST calibration for step height or Ra depends on a number of factors, the most important being the step or $\mathrm{Ra}$ value itself. The expanded uncertainties** range approximately from $0.4 \mu \mathrm{m}$ at a step height of $50 \mu \mathrm{m}$ to $0.5 \mathrm{~nm}$ at a step height of about $8 \mathrm{~nm}$. Comparable uncertainties are achieved for measurements of Ra.

\section{References-Surface Texture}

Stylus-laser surface calibration system, T. V. Vorburger, J. F. Song, C.H.W. Giauque, T. B. Renegar, E. P. Whitenton, and M. C. Croarkin, Precision Engineering 19, 157 (1996). Methods of Characterizing Surface Topography, T. V. Vorburger, Tutorials in Optics, D. T. Moore, ed. (Optical Society of America, Washington, DC, 1992).

Standard Reference Specimens in Quality Control of Engineering Surfaces, J. F. Song and T. V. Vorburger, J. Res. Natl. Inst. Stand. Technol. 96, 271 (1991).

Surface Finish Metrology Tutorial, T. V. Vorburger and J. Raja, NISTIR 89-4088 (National Institute of Standards and Technology, Gaithersburg, MD, June 1990).

Surface Texture, J.F. Song and T. V. Vorburger, ASM Handbook 18, 334.

** See Chapter 1, Section H for more information about uncertainty. 


\section{Hydrometers}

\section{Technical Contacts:}

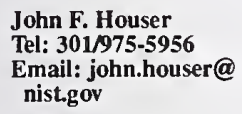

George E. Mattingly

Tel: 301/975-5939

Email: gmattingly@ nist.gov

Mailing Address: Building 230, Room 105, National Institute of Standards and Technology, Gaithersburg, MD 20899-0001

Service ID No. Items

16010C Reference Standard Hydrometers

\section{Reference Standard Hydrometers (16010C)}

NIST provides measurement services for reference hydrometers. These reference standard hydrometers are generally used as laboratory standards to calibrate other hydrometers. Reference hydrometers should be made of smooth, transparent glass, free of bubbles or other imperfections. The hydrometer should bear an inscription which indicates the purpose of the instrument. This inscription should denote the reference temperature at which it is to be used. The maker's name or trade mark and an identification number should be inscribed on the hydrometer scale. Hydrometers accepted for calibration must conform to specified requirements. The technical contacts listed above can give guidance on these requirements.

Reference hydrometers accepted for calibration include specific gravity, proof spirit for alcohol solutions, API degrees for petroleum measurements, degrees Baume heavy and degrees Baume light, and other arbitrary scales, all subject to discussion with the technical contacts. Specific gravity hydrometers cover the specific gravity range of 0.65 to 2 . The hydrometer scale should be divided into $0.001,0.0005,0.0002$, or 0.0001 units of

specific gravity. Proof spirit hydrometers cover the range of 0 to 200 proof. The alcohol hydrometer scale should be divided in whole, half, fifth or tenth percents.

Visual inspection should be made by the customer before shipping to NIST for calibration. The hydrometer should be packed in a safe reusable shipping container.

NIST will provide a three-point calibration on these reference hydrometers. Additional points can be provided at an additional charge if requested. The calibration at NIST consists of comparing NIST master hydrometers directly with the customer's hydrometers in a liquid of low surface tension.

Hydrometer Facilities Uncertainty: The expanded uncertainty* for NIST master hydrometers depends on stem scale. Components of the expanded uncertainty* include the Type A Standard Uncertainty, composed of the imprecisions of such process components as scale readings, thermal gradient of the calibration fluid, etc., and Type B Standard Uncertainty, based on direct comparisons to solid density standards (plummets), density of water, and precision mass standards.

\section{References-Hydrometer \\ Measurements}

Testing of Hydrometers, J. C. Hughes, Natl. Bur. Stand. (U.S.), NBS Circular 555.

ASTM Standard E100-81 Standards Specifications for ASTM Hydrometers, Annual Book of ASTM Standards 14.01 .

An Improved High-Precision Calibration Procedure for Reference Standard Hydrometers, H. A. Bowman and W. H. Gallagher, J. Res. Natl. Bur. Stand. (U.S.) 73C (June 1969).

* See Chapter 1, Section $\mathrm{H}$ for more information about uncertainty. 


\section{Volume and Density}

\section{Technical Contacts:}

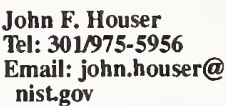

George E. Mattingly Tel: 301/975-5939

Email: george.mattingly@ nist.gov

Mailing Address: Building 230, Room 105

National Institute of Standards and Technology,

Gaithersburg, MD 20899-0001

\begin{tabular}{ll}
\hline $\begin{array}{l}\text { Service } \\
\text { ID No. }\end{array}$ & Items \\
\hline 17010C & Volume Standards \\
$17020 \mathrm{~S}$ & Special Tests of Volume Standards \\
$17040 \mathrm{~S}$ & Special Tests of Density: Liquids
\end{tabular}

\section{Volume Standards (17010C)}

The procedure used for testing glass volumetric apparatus is to weigh the amount of distilled water contained or delivered with reference to the graduations marked on the instrument, the volume being computed from the density of the water. The quality of the markings and the care exercised in reading or setting the liquid level are major factors in test calibration and usage. NIST does not provide routine calibration services for glassware; however, NIST will accept factory standards and replacement glassware for the State Weights and Measures Offices or Departments, in the range of $10^{-2} \mathrm{~L}$ to $5 \mathrm{~L}$, which conform to specified requirements. The technical contacts given above can give guidance on these requirements.

NIST provides a calibration service for metal volumetric test measures. The volumetric test measures which are accepted for calibration should be free

from dents, rust, etc. Special care should be taken by the customer to insure the cleanliness of the inside of the test measures. Should the test measure be equipped with a bottom drain valve, it is the customer's responsibility to insure that the valve be in proper working condition. These test measures should bear an inscription which indicates the nominal value of its volume, the thermal coefficient of expansion, an identification number, and its reference temperature. The scale plate should be legible in that the scale division can be estimated to one-tenth of a single division. A scale calibration is provided; however NIST does not adjust scales. The zero index or the scale should, therefore, be adjusted prior to the calibration. The slickerplate-type volume standards should be adjusted by the manufacturer.

Normally NIST will accept for calibration, test measures with sizes in the range of $5 \mathrm{~L}$ to $7600 \mathrm{~L}$ or $1 \mathrm{gal}$ to $2000 \mathrm{gal}$. The calibration procedure for these test measures consists of determining the contained volume or delivered volume by either gravimetric determinations, which is the result of direct comparisons with mass standards, or by the use of transfer standards, for which volumes have been predetermined. The reported result for the calibrated volume is the arithmetic mean of two independent observations. The reported volume is corrected to a requested reference temperature.

Volume Facilities Uncertainty: The uncertainty for NIST volume standards will vary with the instrument size and design. Relative expanded uncertainties* range from $0.003 \%$ to $0.065 \%$.

\section{Special Tests of Volume Standards (17020S)}

Special tests may be made on volume standards other than those mentioned above. The technical contacts cited above should be contacted regarding testing.

* See Chapter 1, Section $\mathrm{H}$ for more information about uncertainty. 


\section{Special Tests of Density Liquids*} (17040S)

Currently NIST is involved in a research project to improve its capabilities to measure liquid density. Contact the technical contacts cited above.

\section{References-Volume and Density Measurements}

ASTM Standard 694-83 Standard Specifications for Volumetric Ware, Annual Book of ASTM Standards 14.02.

The Equivalence of Gravimetric and Volumetric Test Measure Calibration, R. Schoonover, Natl. Bur. Stand. (U.S.), NBSIR 74-454 (Feb. 1987).

* See Chapter 1, Section C for information about the Standard Reference Materials Program. NIST offers Standard Reference Materials of certified density.

Calibration of Small Volumetric Laboratory Glassware, J. Lembeck, Natl. Bur. Stand. (U.S.), NBSIR 74-461 (Oct. 1974).

Procedures for the Calibration of Volumetric Test Measures, J. F. Houser, Natl. Bur. Stand. (U.S.), NBSIR 73-287 (Aug. 1973).

Testing of Volumetric Standards, J. C. Hughes and B.C. Keysar, Natl. Bur. Stand. (U.S.), NBS Monograph 62 (Apr. 1963).

Testing of Glass Volumetric Apparatus, J. C. Hughes, Natl. Bur. Stand. (U.S.), NBS Circular 602 (Apr. 1959). 


\section{Chapter}

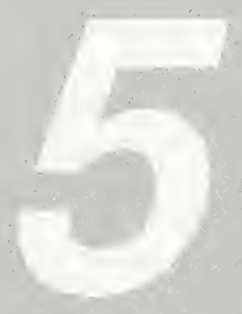

A Flow Measurements

B Flow Measurements at Cryogenic Temperatures

C Airspeed Instruments

D Mass Standards

E Force Measurements

F Vibration Measurements

G Acoustic Measurements

H Ultrasonic Reference Block Measurements

| Ultrasonic Transducer Measurements

$J$ Acoustic Emission Transducer Measurements 


\section{A.}

\section{Flow Measurements}

\section{Technical Contacts:}

John D. Wright

Tel: 301/975-5937

Email: john.wright@nist.gov
George E. Mattingly

Tel: 301/975-5939

Email: george.mattingly@nist.gov
Mailing Address: Building 230, Room 105

National Institute of Standards and Technology,

Gaithersburg, MD 20899-0001

\begin{tabular}{ll} 
Service & \\
ID No. & Items \\
\hline $18010 \mathrm{C}$ & Gas Flow Meters \\
$18020 \mathrm{C}$ & Water Flow Meters \\
$18030 \mathrm{C}$ & Hydrocarbon Flow Meters \\
$18040 \mathrm{C}$ & Transfer Standards \\
$18050 \mathrm{~S}$ & Special Tests Using Gas or Liquid Flows \\
\hline
\end{tabular}

\section{Gas Flow Meters (18010C)}

NIST provides calibration services for gas flow meters using piston provers, bell provers, and a Pressure-VolumeTemperature-time (PVTt) system. Throughout this section, flow rates are quoted at standard conditions of $\mathrm{P}=101325 \mathrm{~Pa}$ and $\mathrm{T}=20^{\circ} \mathrm{C}$. The piston and bell provers cover flow ranges from $3.7 \times 10^{-5} \mathrm{~m}^{3} / \mathrm{min}$ to $1.4 \mathrm{~m}^{3} / \mathrm{min}\left(1.3 \times 10^{-3} \mathrm{ft}^{3} / \mathrm{min}\right.$ to $51 \mathrm{ft}^{3} / \mathrm{min}$ ). Gases available for calibration work in the piston and bell provers are: dry air, nitrogen, carbon dioxide, and argon. The piston and bell provers have connections for meters with Swagelok ${ }^{\text {TM }}, \mathrm{A} / \mathrm{N}$, or National Pipe Thread fittings from $0.64 \mathrm{~cm}$ to $5 \mathrm{~cm}$ (1/4 in to 2 in) in diameter.

The PVTt system permits calibrations with dry air for flows from $0.86 \mathrm{~m}^{3} / \mathrm{min}$ to $78 \mathrm{~m}^{3} / \mathrm{min}\left(30 \mathrm{ft}^{3} / \mathrm{min}\right.$ to $2740 \mathrm{ft}^{3} / \mathrm{min}$ ). Calibrations are normally performed using a set of critical flow nozzles as working standards.
Pipe diameters from $5 \mathrm{~cm}$ to $20 \mathrm{~cm}$ (2 in to 8 in) with ASA $150 \mathrm{lb}$ flanges* are available and arrangements for other connections can be made upon request. Straight runs of piping of up to $18 \mathrm{~m}$ are available.

Meters can be tested if the flow range, gas, and piping connections are suitable, and if the system to be tested has precision appropriate for calibration with the NIST flow measurement uncertainty. The relative expanded uncertainty* for the NIST gas flow systems is $0.22 \%$ or better. A normal flow calibration includes five different flows, with five averages of the meter readings and the standard flow made at each flow, with this entire test sequence repeated on a second day. It is helpful if the customer specifies the flow set points and the instrumentation requirements of the meter (pressure, temperature, full scales required, etc.).

\section{Water Flow Meters (18020C)}

The water flow facility consists of a reservoir, pumps, meter runs, and weigh tanks. The system operates as a constant flow facility and uses timed collections of water to compute the average flow through the meter being calibrated. The relative expanded uncertainty** for these facilities is $0.12 \%$. Flows up to $38 \mathrm{~m}^{3} / \mathrm{min}(10,000 \mathrm{gal} / \mathrm{min})$ can be provided in pipes up to $40.6 \mathrm{~cm}$ (16 in) in diameter. Pipe connections should be ASA $150 \mathrm{lb}$ steel flanges, Victaulic ${ }^{\mathrm{TM}}$ couplings, or adapters thereto. The normal testing sequence is the same as that described for gas flow meters.

\section{Hydrocarbon Flow Meters (18030C)}

Calibrations of hydrocarbon flow meters can be performed using a surrogate liquid for JP-4 and JP-5 jet fuels. Both volumetric and gravimetric systems can be used over the flow range from

\footnotetext{
* ASA $150 \mathrm{lb}$ flanges is a commercial designation for these connectors.

** See Chapter 1, Section $\mathrm{H}$ for more information about uncertainty.
} 
$3.5 \times 10^{-5} \mathrm{~m}^{3} / \mathrm{min}$ to $1.5 \mathrm{~m}^{3} / \mathrm{min}$ (0.01 gal $/ \mathrm{min}$ to $400 \mathrm{gal} / \mathrm{min})$. The relative expanded uncertainty* for the hydrocarbon flow system is $0.12 \%$. Preferred piping connections are $\mathrm{A} / \mathrm{N}$ fittings, ASA $150 \mathrm{lb}$ flanges, and National Pipe Threads up to $7.6 \mathrm{~cm}$ ( 3 in) in diameter.

\section{Transfer Standards (18040C)}

Transfer standards are available for in situ calibrations of flow meters or flow standards at the customer site. Details about this calibration service can be obtained from the technical contacts listed at the beginning of this section.

\section{Special Tests Using Gas or Liquid Flows (18050S)}

Special tests for liquid and gas flows are available. Examples include interlaboratory comparisons, round robin tests, and proving other fluid measurement systems. Tests to establish or maintain realistic flow measurement traceability for flow facilities can be designed and performed for specific situations. Details about this calibration service can be obtained from the technical contacts listed at the beginning of this section.

Special tests can be done using gas mixtures that simulate auto exhaust. These tests can range from $0.06 \mathrm{~m}^{3} / \mathrm{min}$ to $6.2 \mathrm{~m}^{3} / \mathrm{min}\left(2 \mathrm{ft}^{3} / \mathrm{min}\right.$ to $220 \mathrm{ft}^{3} / \mathrm{min}$ ) where temperatures can range from $20^{\circ} \mathrm{C}$ to $400^{\circ} \mathrm{C}$; relative expanded uncertainties are $1 \%$ or better.

Special tests are also available through Service ID No. $30063 \mathrm{~S}$. These tests which use nitrogen can be done in the range from $10^{-8} \mathrm{~mol} / \mathrm{s}$ to $10^{-3} \mathrm{~mol} / \mathrm{s}$ $\left(2 \times 10^{-4} \mathrm{~cm}^{3} / \mathrm{s}\right.$ to $\left.20 \mathrm{~cm}^{3} / \mathrm{s}\right)$ with relative expanded uncertainties*

* See Chapter 1, Section $\mathrm{H}$ for more information about uncertainty. that range from $0.1 \%$ to $0.05 \%$ (low to high range, respectively.) The range of flow rates are quoted at standard conditions of $\mathrm{P}=101325 \mathrm{~Pa}$ and $\mathrm{T}=20^{\circ} \mathrm{C}$. Specific details should be discussed with the technical contacts listed above or with Stuart Tison at (301) 975-2857.

\section{References-Flow Measurements}

Flowmeter Calibration Facility for Heated Gas Mixtures, J. D. Wright and P. I. Espina, NCSL Proc., Atlanta (1997).

Flow Metrology: Standards, Calibrations, and Traceabilities, G. E. Mattingly, Flow Measurement: Practical Guides for Measurement and Control, D. W. Spitzer, ed., ISA, Research Triangle Park, 1991.

Gas Flow Metrology, G. E. Mattingly, NCSL Newsletter 29 (1), 9-16 (Jan. 1989).

NBS Primary Calibration Facilities for Air Flow Rate, Air Speed, and Slurry Flow, K. R. Benson, N. E. Mease, G. Kulin, and G. E. Mattingly, Proc. Intl. Flow Meas. Symp., Washington, DC, 1986, Amer. Gas Assoc., Arlington, VA.

The National Measurement System for Fluid Flow, W. C. Haight, P. S. Klebanoff, F. W. Ruegg, and G. Kulin, Natl. Bur. Stand. (U. S.), NBSIR 75-930 (Aug. 1976). 
Flow Measurements at Cryogenic Temperatures

\section{Technical Contacts:}

Jennifer L. Scott
Tel: 303/497-3684
Email: jennifer.scott@
nist.gov
Fax: 303/497-5224

\author{
Paula M. Hewitt \\ Administration and Logistics \\ Tel: 303/497-3753 \\ Email: paula.hewitt@nist.gov \\ Fax: 303/497-3970
}

Mailing Address: M.C. 838.07,

National Institute of Standards and Technology,

325 Broadway,

Boulder, CO 80303-3328

Service

ID No.

Items

18800S Special Tests of Cryogenic Liquid Flow

\section{Special Tests of Cryogenic Liquid Flow (18800S)}

Measurement services are provided for cryogenic liquid flow. A dynamic weighing system is used to measure totalized mass flow and, with liquid density provided by the NIST Standard Reference Database 12: Thermophysical Properties of Pure Fluids, volumetric flow. Mass flow measurements are performed using liquid nitrogen at flow rates of $1 \mathrm{~kg} / \mathrm{s}$ to $10 \mathrm{~kg} / \mathrm{s}$, over a pressure range of $0.4 \mathrm{MPa}$ to $0.76 \mathrm{MPa}$, and a temperature range of $80 \mathrm{~K}$ to $90 \mathrm{~K}$. The relative expanded uncertainty* within this flow range, is $0.17 \%$. For volumetric flow rate measurement, the uncertainty in fluid density must also be included. The relative expanded uncertainty for volumetric flow rate is $0.53 \%$. Lower flow rates may be possible, but the uncertainty at these flows is undetermined.

* See Chapter 1 , Section $\mathrm{H}$ for more information about uncertainty.
References_Flow Measurements at Cryogenic Temperatures

Uncertainty Analysis of the NIST Nitrogen Flow Facility, J. L. Scott and M. A. Lewis, Natl. Inst. Stand. Technol. Tech. Note 1364 (Apr. 1994).

Progress Report on Cryogenic Flowmetering at the National Bureau of Standards, J. A. Brennan, J. F. LaBreque, and C. H. Kneebone, Proc. 1 st Biennial Symp. Instrumentation in the Cryogenic Industry, Houston, TX, Oct. 11-14, 1976, 1, 621, Instr. Soc. of America, Pittsburgh, PA (1976).

NBS-CGA Cryogenic Flow Measurement Program, J. A. Brennan, R. W. Stokes, C. H. Kneebone, and D. B. Mann (Proc. ISA Intl. Instrument. Automation Conf. and Exhibit, New York, NY, Oct. 28-31, 1974), Paper in Adv. in Instrument. 29, 612.1 (Instr. Soc. of America, Pittsburgh, PA, 1974).

Cryogenic Flow Research Facility Provisional Accuracy Statement, J. W. Dean, J. A. Brennan, D. B. Mann, and C. H. Kneebone, Natl. Bur. Stand. (U.S.), Tech. Note 606 (July 1971). 


\section{Airspeed Instruments}

\section{Technical Contacts:}

$\begin{array}{cll}\text { James Michael Hall } & \text { Vern E. Bean } & \text { George E. Mattingly } \\ \text { Tel: 301/975-5947 } & \text { Tel: 301/975-4830 } & \text { Tel: 301/975-5939 } \\ \begin{array}{c}\text { Email: j.hall@ } \\ \text { nist.gov }\end{array} & \begin{array}{c}\text { Email: vern.bean@ } \\ \text { nist.gov }\end{array} & \begin{array}{c}\text { Email: george.mattingly@ } \\ \text { nist.gov }\end{array}\end{array}$

Mailing Address: Building 230, Room 105, National Institute of Standards and Technology, Gaithersburg, MD 20899-0001

\begin{tabular}{ll}
$\begin{array}{l}\text { Service } \\
\text { ID No. }\end{array}$ & Items \\
\hline 19010C & Pitot-Static Tubes $1.3 \mathrm{~m} / \mathrm{s}$ to $67 \mathrm{~m} / \mathrm{s}(3 \mathrm{mph}$ to $150 \mathrm{mph})$ \\
$19020 \mathrm{C}$ & $\begin{array}{l}\text { Low Airspeed Instruments } \\
0.76 \mathrm{~m} / \mathrm{s} \text { to } 10.2 \mathrm{~m} / \mathrm{s}(15 \mathrm{fpm} \text { to } 2,000 \mathrm{fpm})\end{array}$ \\
$19030 \mathrm{~S}$ & $\begin{array}{l}\text { Meteorological Airspeed Instrumentation } \\
1.3 \mathrm{~m} / \mathrm{s} \text { to } 67 \mathrm{~m} / \mathrm{s}(3 \mathrm{mph} \text { to } 150 \mathrm{mph})\end{array}$ \\
$19040 \mathrm{~S}$ & \begin{tabular}{l} 
Special Tests of Airspeed Instruments \\
\hline
\end{tabular}
\end{tabular}

\section{Airspeed Instruments} (19010C-19040S)

Calibration of airspeed measuring devices is performed in one of two special wind tunnels, as described in the Proceedings of the 1992 Measurement Science Conference. The differential pressure measured from ellipsoidal-nosed Pitot-static tubes provides the basis of airspeed measurement in these facilities. Pitot-static tubes and meteorological instruments are calibrated in the NIST Dual Test Section Wind Tunnel. Low velocity airspeed measurements are made using Laser Doppler Velocimetry (LDV) in the NIST Low Velocity Airflow Facility, described in NBS Technical Note 989. Calibration of the LDV is done using the Pitot-static tube at velocities which produce a sufficiently large differential pressure in the tube that the uncertainty in the pressure does not propagate unacceptable levels of error into the velocity determination. Use of the LDV capability in the low velocity range, where the Pitot-static tube has large measurement uncertainties due to the inability to measure accurately the associated small differential pressures, allows considerably improved measurement uncertainty. Air density values in the tunnels are computed from pressure, temperature, and humidity measurements in the settling chambers of the tunnels.

Details on the range and expanded uncertainty of the currently offered NIST airspeed calibrations are shown in Tables 5.1 and 5.2.

Special tests of airspeed instruments can be arranged. Examples include in-situ calibrations of airspeed instrumentation, proving other airspeed measurement systems, and tests where appropriate scaling will allow the results to be applicable to fluids other than air. Details can be obtained and arrangements made through the technical contacts cited above.

Table 5.1. Uncertainty* of the NIST Low Velocity Airflow Measurement Facility

\begin{tabular}{|c|c|c|}
\hline$(\mathrm{m} / \mathrm{s})$ & Velocity $\underset{(\mathrm{mi} / \mathrm{h})}{\mathbb{R}}$ & $\begin{array}{l}\text { Relative Expanded Uncertainty } \\
\qquad(\%)\end{array}$ \\
\hline 0.15 & 0.33 & 4.0 \\
\hline 0.25 & 0.56 & 2.4 \\
\hline 0.5 & 1.1 & 1.2 \\
\hline 1 to 10 & 2.2 to 22 & 0.6 \\
\hline
\end{tabular}

* See Chapter 1, Section H for more information about uncertainty.

Table 5.2. Uncertainty* of the NIST Airflow Measurement Capabilities in the Dual Test-Section Wind Tunnels

\begin{tabular}{ccc}
\hline (m/s) & Velocity & $\begin{array}{c}\text { Relative Expanded Uncertainty } \\
(\%)\end{array}$ \\
\hline 0.4 & 1 & 8.0 \\
1 & 2 & 3.8 \\
2 & 5 & 1.3 \\
3 & 6 & 0.6 \\
5 & 11 & 0.45 \\
10 & 22 & 0.31 \\
15 to 67 & 34 to 150 & 0.28 \\
\hline
\end{tabular}

* See Chapter 1, Section H for more information about uncertainty.

\section{References-Airspeed Measurements}

Air Speed Calibrations at the National Institute of Standards and Technology, N. E. Mease, W. G. Cleveland, Jr., G. E. Mattingly, and J. M. Hall, Proc. 1992 Meas. Sci. Conf., Anaheim, CA (1992).

A Low Velocity Airflow Calibration and Research Facility, L. P. Purtell and P. S. Klebanoff, Natl. Bur. Stand. (U.S.), Tech. Note 989 (May 1979). 
Mass Standards

\section{Technical Contact:}

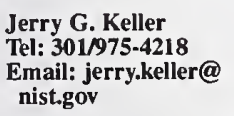

$$
\begin{aligned}
& \text { William E. Crupe } \\
& \text { Tel: 301/975-4215 } \\
& \text { Email: wcrupe@ } \\
& \text { nist.gov }
\end{aligned}
$$

\section{Zeina J. Jabbour Email: zeina.jabbour@ nist.gov}

Mailing Address: Building 233, Room A147, National Institute of Standards and Technology, Gaithersburg, MD 20899-0001

Shipping Address: National Institute of Standards and Technology, I-270 at Quince Orchard Road, Building 233, Room A147, Gaithersburg, MD 20899-0001

Note: For weights larger than $30 \mathrm{~kg}(50 \mathrm{lb})$, contact J. G. Keller prior to shipment.

Service

ID No. Items

$22010 \mathrm{C}$ Weight Set (1 mg to $100 \mathrm{~g})$

$22020 \mathrm{C}$

Weight Set (1 mg to $1 \mathrm{~kg}$ )

$22030 \mathrm{C}$

Weight Set $(2 \mathrm{~kg}$ to $30 \mathrm{~kg}$ )

$22040 \mathrm{C}$

Single Weights ( $1 \mathrm{mg}$ to $1 \mathrm{~kg}$ )

$22060 \mathrm{C}$

Single Weights ( $2 \mathrm{~kg}$ to $30 \mathrm{~kg}$ )

$22080 \mathrm{C}$ Single Weights (>30 kg to $1200 \mathrm{~kg}, 2$ double substitution weighings)

$22100 \mathrm{C}$ Single Weights (> $1200 \mathrm{~kg}$ to $30,000 \mathrm{~kg}$ )

$22110 \mathrm{C}$ Single Weights (>30 kg to $1200 \mathrm{~kg}$, calibrated in a weighing design)

22130C Single Weights for Deadweight Pressure Testers $5.9 \mathrm{~kg}$ to $22.7 \mathrm{~kg}$ (13 lb to $50 \mathrm{lb}$ )

22140C Single Weights for Deadweight Pressure Testers $>22.7 \mathrm{~kg}(>50 \mathrm{lb})$

22150C Single Weights for Deadweight Pressure Testers $<5.9 \mathrm{~kg}(<13 \mathrm{lb})$

22170S Special Mass Measurement Services

22180M Measurement Assurance Program for Mass

\section{Mass (22010C-22110C)}

NIST maintains the national standard for mass in the form of the prototype kilogram (K20) and provides services to support the parts of the national measurement system that rely directly or indirectly on mass measurements.

These services include the calibration of suitable weight sets. Figure 5.1 shows the traceability to the SI unit of mass for the unit of mass as disseminated by NIST. A calibration consists of establishing a mass value and the appropriate uncertainty for that value for each weight that has been designated to be a reference standard. It is desirable, but not necessary, that a weight meet the adjustment tolerances established for NBS Classes A, B, M, S, S-1, or equivalent prior to submission. Weights are available from manufacturers, many of whom can directly furnish documentation suitable for meeting quality assurance contracts and requirements.

NIST calibrates individual weights or sets in the range of $1 \mathrm{mg}$ to $30 \mathrm{~kg}$ or $0.45 \mathrm{~kg}$ to $22.7 \mathrm{~kg}$ ( $1 \mathrm{lb}$ to $50 \mathrm{lb}$ ) in decimal subdivisions. If the weights are designated as reference standards, they must be of design, material, and surface finish comparable to NBS Classes A, B, $\mathrm{M}, \mathrm{S}$, or S-1. These include ASTM Type I and II, classes 1, 2, 3, 4, and OIML E1, E2, F1 and F2. NIST also calibrates large mass standards $27.3 \mathrm{~kg}$ to $27300 \mathrm{~kg}$ $(60 \mathrm{lb}$ to $60000 \mathrm{lb})$ if the design, material, and surface finish are compatible with the intended usage. For these large mass standards, an adjustment with reference to a nominal or desired value can be included as a part of the calibration procedure.

In the absence of instructions from the customer, weights will be cleaned prior to calibration. If weights are to be calibrated "as found" (without cleaning), and returned without cleaning, customers should note this in their instructions to NIST. If weights are to calibrated "as found" and calibrated again after cleaning, double the fee will apply. The values of true mass (and an apparent mass correction) included in the report will be determined by using computed volumes based on the manufacturer's statement of density of the material, or on the density computed from measured volumes, or, in the absence of this information, on estimated density values. 


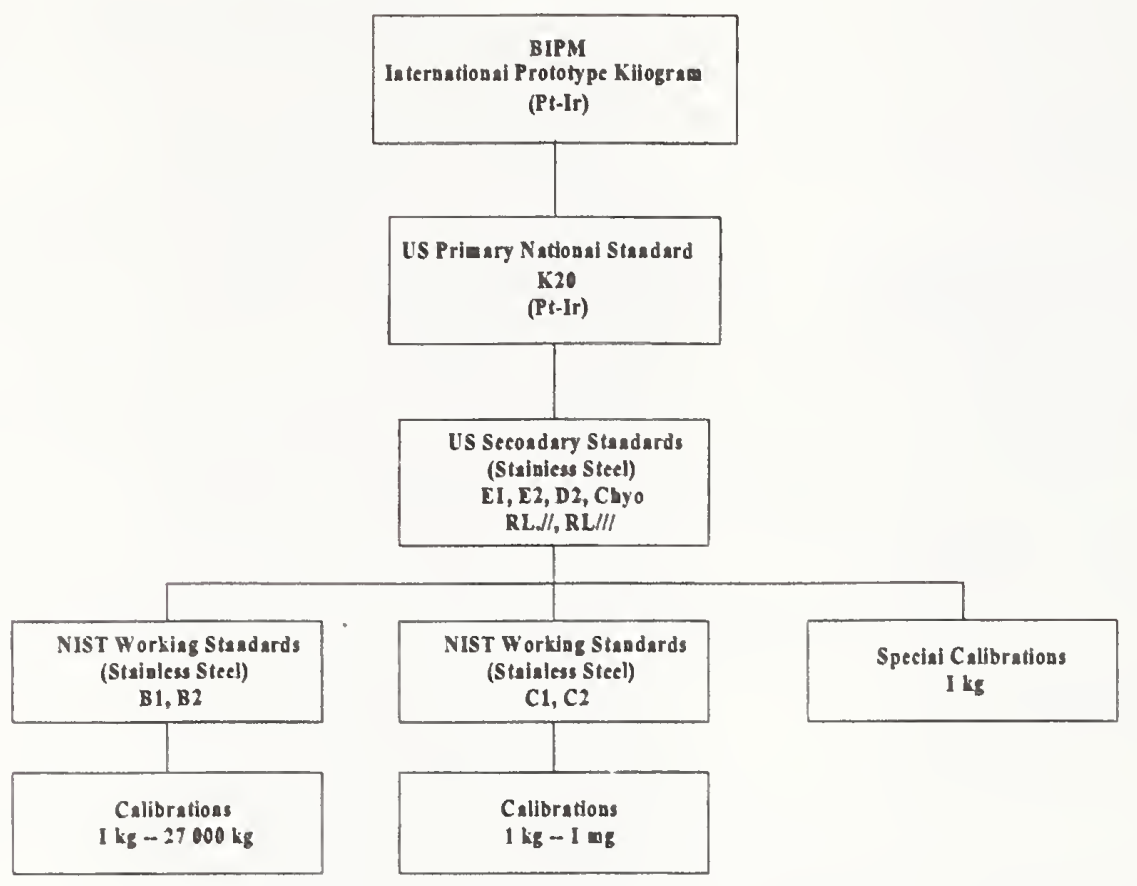

Figure 5.1 Traceability to the SI Unit of Mass.

However, $1 \mathrm{~kg}$ mass standards fabricated from stainless steel and of one-piece construction will have their density determined as part of a "first-time" calibration at NIST. The apparent mass corrections are computed for $20^{\circ} \mathrm{C}$ with reference to Normal Brass (density' $8400 \mathrm{~kg} / \mathrm{m}^{3}$ at $0^{\circ} \mathrm{C}$ and volume coefficient of expansion $0.000054 /{ }^{\circ} \mathrm{C}$ ) and to stainless steel (density $8000 \mathrm{~kg} / \mathrm{m}^{3}$ at $20^{\circ} \mathrm{C}$ ) in a comventional air density of $1.2 \mathrm{~kg} / \mathrm{m}^{3}$. Apparent mass corrections to any other basis can be furnished if requested. Typical relative standard uncertainties* range from $50 \times 10^{-0}$ at $1 \mathrm{~kg}$. up to $330 \times 10^{-6}$ at $1 \mathrm{mg}$. and $0.2 \times 10^{-6}$ at $10 \mathrm{~kg}$. Figure 5.2 shows the NIST uncertainties for normal calibrations of mass standards over the range $10^{-8} \mathrm{~kg}$ to $10^{+} \mathrm{kg}$.

* See Chapter 1. Section H for more information about uncertainty.

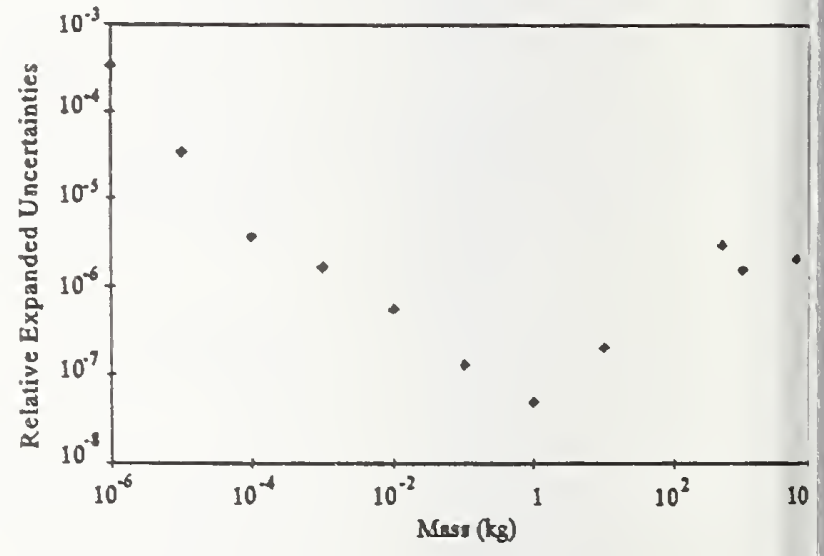

Figure 5.2. NIST's Relative Expanded Uncertainties for Normal Calibrations of Mass Standards.

Single Weights for Deadweight Pressure Testers (22130C-22150C)

Weights are compared to discrete standards by the method of double substitution weighing. 


\section{Special Mass Measurement Services (22170S)}

For tests not covered by the previous descriptions, the NIST technical contact cited at the beginning of this section should be consulted to determine whether a test can be performed and to obtain an estimate of the price of the test.

\section{Measurement Assurance Program for Mass (22180M)}

This service is most appropriate for primary calibration laboratories. Total relative uncertainties ranging from a few parts in $10^{7}$ to a few parts in $10^{5}$ for $1 \mathrm{~kg}$ can be obtained. Unlike most other NIST MAP services, the Mass MAP service does not involve the use of a NIST-owned transport standard that is shipped to participants for measurement. The transfer standards in the Mass MAP are a set of mass standards owned by the participant and sent to NIST for calibration. These standards are referred to as the starting standards. In addition to the starting standards, the mass MAP participant must also furnish a set of much smaller weights called "sensitivity weights." The choice of both the starting standards and the sensitivity weights will depend on the particular mass range of interest to the participant; NIST staff can provide advice regarding suitable starting standards and sensitivity weights for a particular range of mass weighings. In addition to the starting standards and the sensitivity weights, the participating facility should have a working set of weights known as the "test set" and a set of weights to be used as check standards. This set usually consists of weights in the range of $1 \mathrm{~g}$ to $1000 \mathrm{~g}$. This service, like other NIST MAP services, samples the participant's measurement process and establishes its uncertainty. Once the participant has become well-established in the Mass MAP, two options are possible:

(1) NIST personnel do all of the data analysis and record keeping for the participant and provide periodic reports on the uncertainty of the participant's mass measurements.

(2) The participant keeps all records and calculates the uncertainties of his measurements using NIST methods and computer codes.
The implementation of the Mass MAP in its most complete form typically proceeds in four distinct phases, which may be abbreviated somewhat if the participant already has a suitable mass measurement quality control system.

Phase I: Each new participant completes a questionnaire on equipment and facilities and receives a written description of the NIST process, methods and procedure to be used, an introduction to the interpretation of results, and information on the use of these results in measurement decisions. At the participating laboratory, the suitability of the weighing equipment is verified, the starting standards selected or procured, and operators are trained, if the procedures are entirely new. The starting standards and sensitivity weights are sent to NIST for calibration. If the starting standards have a NIST calibration history, those data are reviewed and, if satisfactory, are considered, along with the data from the more recent determinations to arrive at assigned values for the starting standards. NIST will recommend a weighing design to be used for calibrating the test weight. This weighing design prescribes the set of observations for intercomparing the test weights with known weights. NIST will also supply data sheets to be used throughout the first three phases of the program for recording data taken using the design. The objective of the first phase is to ensure that the new participant is familiar with good laboratory practices for high precision weighing. If the participating laboratory has an established mass measurement capability and an existing quality control procedure for mass measurements, Phase I is abbreviated considerably.

Phase II: The starting standards and sensitivity weights are returned to the participant and, following the prescribed procedures, measurements are made by the participant over a period of time to verify that a state of statistical control exists. The data sheets are sent to NIST for review, comments, and processing after each measurement. If there are unanticipated problems, or if the procedure has not been followed exactly, more measurements may be required. After three or more successful calibrations in the user's facility, NIST analyzes the data to determine the values of the check standards. 
Phase III: A comprehensive report is issued by NIST containing a review of the actions and decisions in each of the phases, control charts for the check standards to be used in the participant's facility, and a comparison of the values assigned to the starting standards by NIST and by the participant. It is assumed at this point that the participating facility is now ready to extend the operation of the MAP to its regular workload.

Phase IV: Having thus established measurement comparability, the MAP user can then, in principle, operate independently of NIST. As long as there is no indication of a loss of statistical control of the process, no further checking with NIST should be necessary. Most participants request a recheck of the starting standards every few years to ensure that no undetected !nng-term drift has taken place.

For work that differs from the items normally calibrated by the participant, NIST can provide consulting help and assistance necessary to accommodate a greater range of weights, calibrate pound standards, and extend pound standards to large weights normally associated with force measurement. Although the usual Mass MAP service uses two one kilogram masses as the starting standards, the program is sufficiently flexible that the same methods can be used with other mass values.

\section{References-Mass Standards}

New Assignment of Mass Values and Uncertainties to NIST Working Standards, R. S. Davis, J. Res. Natl. Inst. Stand. Technol. 95 (1), 79 (Jan.-Feb. 1990).

NIST Measurement Services: Mass Calibrations, R. S. Davis, Natl. Inst. Stand. Technol. Spec. Publ. 250-31 (Jan. 1989).

A Primer for Mass Metrology, K. B. Jaeger and R. S. Davis, Natl. Bur. Stand. (U.S.), Spec. Publ. 700-1 (Nov. 1984).

Air Buoyancy Correction in High-Accuracy Weighing on Analytical Balances, R. M. Schoonover and F. E. Jones, Anal. Chem. 53 (6), 900 (May 1981).

National Bureau of Standards Mass Calibration Computer Software, R. N. Varner and R. C. Raybold, Natl. Bur. Stand. (U.S.), Tech. Note 1127 (July 1980).

Quick and Accurate Density Determination of Laboratory Weights, R. M.
Schoonover and R. S. Davis, Proc. 8th Conf. IMEKO, Krakow, Poland (1980).

Precision Laboratory Standards of Mass and Laboratory Weights. A reprint of NBS Circular 547, Section 1, T. W. Lashof and L. B. Macurdy, August 1954, Natl. Bur. Stand. (U.S.), NBSIR 78-1476 (Oct. 1978).

The National Measurement System for Mass, Volume, and Density, P. E. Pontius, J. R. Whetstone, and J. A. Simpson, Natl. Bur. Stand. (U.S.), NBSIR 75-928 (May 1978).

Direct Determination of Air Density in a Balance through Artifacts Characterized in an Evacuated Weighing Chamber, W. F. Koch, R. S. Davis, and V. E.

Bower, J. Res. Natl. Bur. Stand. (U.S.), 83 (5), 407 (Sept.-Oct. 1978).

The Air Density Equation and the Transfer of the Mass Unit, F. E. Jones, J. Res. Natl. Bur. Stand. (U.S.) 83 (5), 419 (Sept.-Oct. 1978).

Designs for the Calibration of Standards of Mass, J. M. Cameron, M. C. Croarkin, and R. C. Raybold, Natl. Bur. Stand. (U.S.), Tech. Note 952 (June 1977).

The Air Density Equation and the Transfer of the Mass Unit, F. E. Jones, Natl. Bur. Stand. (U.S.), NBSIR 77-1278 (July 1977).

Measurement Assurance, J. M. Cameron, Natl. Bur. Stand. (U.S.), NBSIR 77-1240 (1977).

Mass and Mass Values, P. E. Pontius, Natl. Bur. Stand. (U.S.), Monogr. 133 (Jan. 1974).

Weight Cleaning Procedures, H. E. Almer, Natl. Bur. Stand. (U.S.), NBSIR 74-443 (Nov. 1973).

On Uncertainty in Mass Measurement, J. R. Donaldson, Natl. Bur. Stand. (U.S.), NBSIR 73-151 (Mar. 1973).

Method of Calibrating Weights for Piston Gages, H. E. Almer, Natl. Bur. Stand. (U.S.), Tech. Note 577 (May 1971).

Realistic Uncertainties and the Mass Measurement Process, P. E. Pontius and J. M. Cameron, Natl. Bur. Stand. (U.S.), Monogr. 103 (Aug. 1967).

Introduction to Intercomparison Methods in Mass Measurement, H. E. Almer, Natl. Bur. Stand. (U.S.), Report 9487 (Feb. 1967).

Measurement Philosophy of the Pilot Program for Mass Calibration, P. E. Pontius, Natl. Bur. Stand. (U.S.), Tech. Note 288 (May 1966). 


\section{Force Measurements}

\section{Technical Contacts:}

Rick L. Seifarth
Tel: 301/975-6652
Email: ricky.seifarth@
nist.gov

Simone L. Yaniv Tel: 301/975-6655 Email: simone.yaniv@ nist.gov

Mailing Address: Building 202, Room 221, National Institute of Standards and Technology, Gaithersburg, MD 20899-0001

Shipping Address:

National Institute of Standards and Technology, I-270 at Quince Orchard Road,

Building 202, Room 123, Gaithersburg, MD 20899-0001

\begin{tabular}{|c|c|}
\hline $\begin{array}{l}\text { Service } \\
\text { ID No. }\end{array}$ & Items \\
\hline $23010 \mathrm{C}$ & $\begin{array}{l}\text { Force Transducers to } 112540 \mathrm{~N}(25300 \mathrm{lbf}) \\
1 \text { mode }\end{array}$ \\
\hline $23020 \mathrm{C}$ & Extra observation \\
\hline $23030 \mathrm{C}$ & Additional bridges \\
\hline $23040 \mathrm{C}$ & $\begin{array}{l}\text { Force Transducers to } 112540 \mathrm{~N} \text { ( } 25300 \mathrm{lbf} \text { ), } \\
2 \text { modes }\end{array}$ \\
\hline $23050 \mathrm{C}$ & Extra observation \\
\hline $23060 \mathrm{C}$ & Additional bridges \\
\hline $23070 \mathrm{C}$ & $\begin{array}{l}\text { Force Transducers, } 112544 \mathrm{~N} \text { to } 498201 \mathrm{~N} \\
(25301 \mathrm{lbf} \text { to } 112000 \mathrm{lbf}), 1 \text { mode }\end{array}$ \\
\hline $23080 \mathrm{C}$ & Extra observation \\
\hline $23090 \mathrm{C}$ & Additional bridges \\
\hline $23100 \mathrm{C}$ & $\begin{array}{l}\text { Force Transducers, } 112544 \mathrm{~N} \text { to } 498201 \mathrm{~N} \\
(25301 \mathrm{lbf} \text { to } 112000 \mathrm{lbf}), 2 \text { modes }\end{array}$ \\
\hline $23110 \mathrm{C}$ & Extra observation \\
\hline $23120 \mathrm{C}$ & Additional bridges \\
\hline $23130 \mathrm{C}$ & $\begin{array}{l}\text { Force Transducers, } 498205 \mathrm{~N} \text { to } 1334467 \mathrm{~N} \\
(112001 \mathrm{lbf} \text { to } 300000 \mathrm{lbf}), 1 \text { mode }\end{array}$ \\
\hline $23140 \mathrm{C}$ & Extra observation \\
\hline $23150 \mathrm{C}$ & Additional bridges \\
\hline $23160 \mathrm{C}$ & $\begin{array}{l}\text { Force Transducers, } 498205 \mathrm{~N} \text { to } 1334467 \mathrm{~N} \\
(112001 \mathrm{lbf} \text { to } 300000 \mathrm{lbf}), 2 \text { modes }\end{array}$ \\
\hline $23170 \mathrm{C}$ & Extra observation \\
\hline $23180 \mathrm{C}$ & Additional bridges \\
\hline $23190 \mathrm{C}$ & $\begin{array}{l}\text { Force Transducers, } 1334471 \mathrm{~N} \text { to } 4448222 \mathrm{~N} \\
(300001 \mathrm{lbf} \text { to } 1000000 \mathrm{lbf} \text { ), } 1 \text { mode }\end{array}$ \\
\hline $23200 \mathrm{C}$ & Extra observation \\
\hline $23210 \mathrm{C}$ & Additional bridges \\
\hline $23220 \mathrm{C}$ & $\begin{array}{l}\text { Force Transducers, } 1334471 \mathrm{~N} \text { to } 4448222 \mathrm{~N} \\
(300001 \mathrm{lbf} \text { to } 1000000 \mathrm{lbf}), 2 \text { modes }\end{array}$ \\
\hline $23230 \mathrm{C}$ & Extra observation \\
\hline $23240 \mathrm{C}$ & Additional bridges \\
\hline $23250 \mathrm{C}$ & $\begin{array}{l}\text { Force Transducers over } 4448222 \mathrm{~N} \text { (1000 } 000 \mathrm{lbf} \text { ) } \\
\text { compression only }\end{array}$ \\
\hline $23260 \mathrm{~S}$ & Special Tests of Force Transducers \\
\hline
\end{tabular}

Force Transducers (23010C-23250C)

NIST provides calibration services for force-measuring devices by applying known forces, either tension or compression, to the elastic device and recording the sensed deformation. Most calibrated devices are either proving rings or load cells. The deformation of proving rings is usually measured by means of a micrometer screw and vibrating reed, which are an integral part of the device. Load cells, which utilize strain gauge bridges, produce an electrical output that is related to the applied force.

The calibration report describes the relationship between the applied force and the measured deformation, either in electrical or mechanical units. A load cell can be calibrated using (1) a readout device furnished by the customer, in which case the load cell and the readout device are calibrated as a system, and the calibration is valid only when the load cell and the readout device are used together; or (2) instrumentation furnished by NIST, in which case data are reported in terms of the ratio of the output voltage to the DC excitation voltage $(\mathrm{mV} / \mathrm{V})$. In the latter case, the customer must possess the necessary electrical instrumentation and expertise to utilize the calibration results. The relative standard uncertainty* of the calibration of the voltage-ratio measurement instrumentation used at NIST is $0.0005 \%$.

Tension or compression calibrations in the range of $0.445 \mathrm{kN}$ to $4.448222 \mathrm{MN}$ (100 lbf to $1000000 \mathrm{lbf}$ ) are performed using deadweight machines. NIST has six deadweight machines with maximum capacities of $2226 \mathrm{~N}$ (505 lbf), $27134 \mathrm{~N}$ (6 $100 \mathrm{lbf}), 112540 \mathrm{~N}$ (25 $300 \mathrm{lbf})$, $498201 \mathrm{~N}(112000 \mathrm{lbf}), 1334467 \mathrm{~N}$ (300 $000 \mathrm{lbf}$ ), and $4448222 \mathrm{~N}$ (1 $000000 \mathrm{lbf}$ ). The standard uncertainty of the applied forces incorporates the uncertainties associated with the determination of the mass of the deadweight, the acceleration due to gravity and the air density. The relative standard uncertainty* of applied force is $0.0005 \%$.

* See Chapter 1, Section $\mathrm{H}$ for more information about uncertainty. 
Comparison calibrations in the range of $4448226 \mathrm{~N}$ to $53378659 \mathrm{~N}$ (1 $000001 \mathrm{lbf}$ to $12000000 \mathrm{lbf}$ ) in compression only are performed in a universal testing machine. In this case, the system to be calibrated is loaded in series with load cells that have been previously calibrated in a deadweight machine. See Figure 5.3 for the relationship of force to S.I. units.

\section{Special Tests of Force Transducers (23260S)}

Temperature sensitivity, pressure sensitivity, and creep tests of force transducers are measured. The ranges of test parameters and environmental conditions may be limited by the characteristics of the force transducer and the availability of special test fixtures. These speciail tests should be discussed with the designated NIST technical contact before the work is scheduled.

\section{References-Force Measurements}

Force Measurment Services at NIST: Equipment, Procedures and Uncertainties, T. W. Bartel, S. L. Yaniv and R. L. Seifarth, Proc. Natl. Conf. Stand. Lab. and Symp. (1997).
Creep and Creep Recovery Response of Load Cells Tested According to U.S. and International Evaluation Procedures, T. W. Bartel and S. L. Yaniv J. Res. Natl. Inst. Stand. Technol. 102, 349-362 (May 1997).

Standard Practices for Force Verification of Testing Machines, ASTM Designation E4-96, Annual Book of ASTM Standards 3.01 (1997).

Automation of Strain-Gauge Load-Cell Force Calibrations, K. W. Yee, Natl. Inst. Stand. Technol. NISTIR 4823 (Apr. 1992).

Standard Practice of Calibration of Force-Measuring Instruments for Verifying the Force Indication of Testing Machines, ASTM Designation E74-95, Annual Book of ASTM Standards 3.01 (1994).

Summary of the Intercomparison of the Force Standard Machines of the National Institute of Standards and Technology, USA, and the Physikalisch-Technische Bundesanstalt, Germany, S. L. Yaniv, A. Sawla, and M. Peters, J. Res. Natl. Inst. Stand. Technol. 96, 529 (1991).

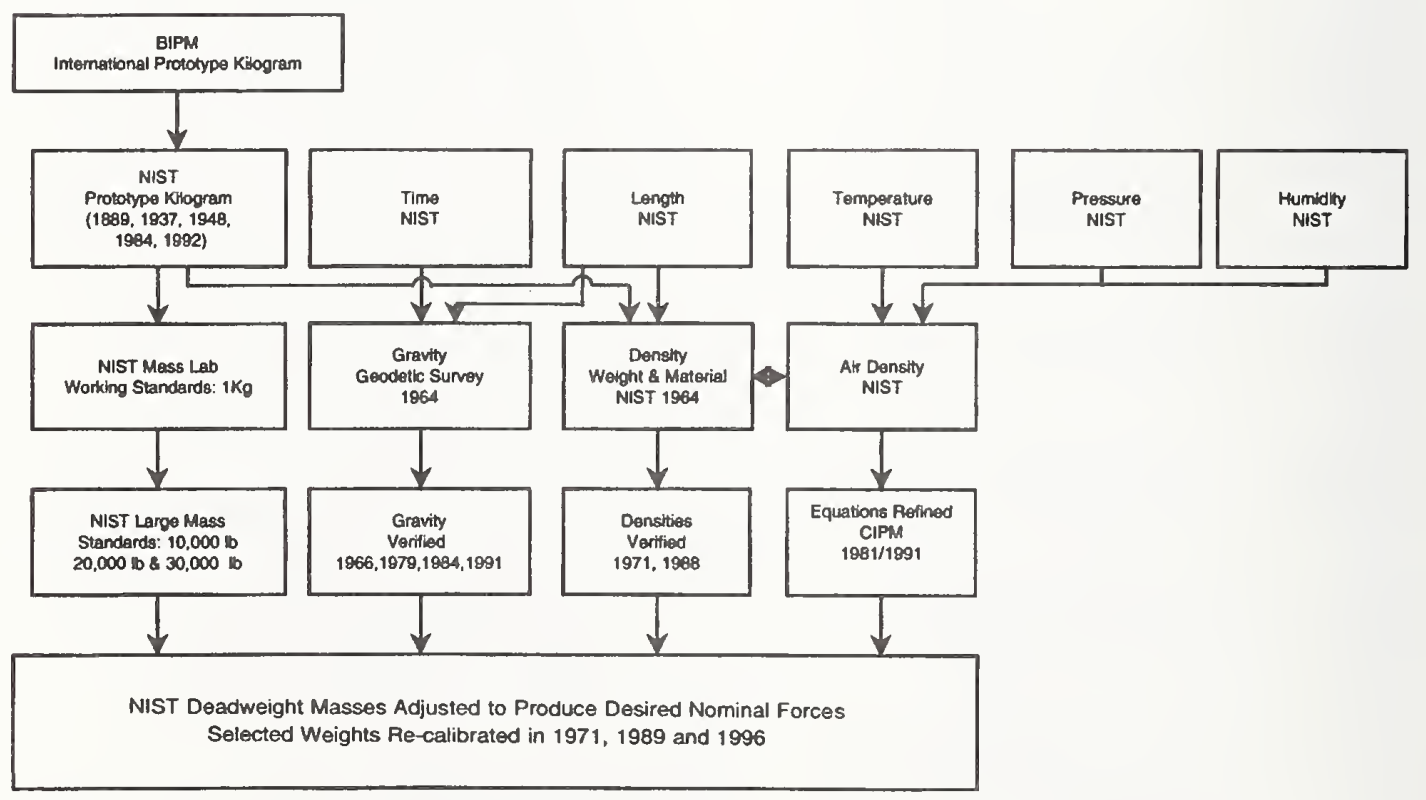

Figure 5.3. Relationship of Force to SI Units. 
Metrological Regulations for Load Cells, OIML Recommendation No. 60, Intl.

Org. for Legal Metrol., Paris 1991 (E).

A New Statistical Model for the Calibration of Force Sensors, C. P. Reeve, Natl. Bur. Stand. (U.S.) Tech. Note 1246 (June 1988).

Force Calibration at the National Bureau of Standards, R. A. Mitchell, Natl. Bur. Stand. (U.S.) Tech. Note 1227 (Aug. 1986).

Interlaboratory Comparison of Force Calibrations Using ASTM Method E74-74, R. W. Peterson, L. Jenkins, and R. A. Mitchell, Natl. Bur. Stand. (U.S.), Tech. Note 1211 (Apr. 1985).

Progress in Force Measurement at NBS, R. A. Mitchell, Proc. 10th Conf. IMEKO TC-3 on Measurement of Force and Mass, Kobe, Japan (Sept. 1984).

Inherent Problems in Force Measurements, P. E. Pontius and R. A. Mitchell, Exper. Mech. 22 (3) (Mar. 1982).

Force Sensor-Machine Interaction, R. A. Mitchell and P. E. Pontius, Proc. 27th Intl. Instrum. Symp. (ISA), Indianapolis, IN, Instrumentation in the Aerospace Industry 27, 225 (1981).
Characterizing the Creep Response of Load Cells, R. A. Mitchell and S. M. Baker, VDI-Berichte 312, 43 (1978). Interlaboratory Comparison of Force Calibrations Using ASTM Method E74-74, Phase I, R. W. Peterson and R. L. Bloss, Natl. Bur. Stand. (U.S.), NBSIR 76-1145 (Aug. 1976).

A Study of the National Force Measurement System, D. E. Marlowe, Natl. Bur. Stand. (U.S.), NBSIR 75-929 (June 1975).

Universal Testing Machine of 12-Millionlbf Capacity at the National Bureau of Standards, A. F. Kirstein, Natl. Bur. Stand. (U.S.), Spec. Publ. 355 (Sept. 1971).

Studies of Calibration Procedures for Load Cells and Proving Rings as Weighing Devices, G. B. Anderson and R. C. Raybold, Natl. Bur. Stand. (U.S.), Tech. Note 436 (Jan. 1969).

Gravity Measurements and the Standards Laboratory, D. R. Tate, Natl. Bur. Stand. (U.S.), Tech. Note 491 (Aug. 1969).

Uncertainties Associated with Proving Ring Calibration, T. E. Hockersmith and $\mathrm{H}$. H. Ku, Preprint No. 12.3-2-64 ISA Conference, Instr. Soc. of America, Res. Triangle Park, NC (Oct. 1964). 


\section{Vibration Measurements}

\author{
Technical Contacts:
}

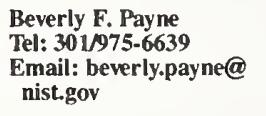

$$
\begin{aligned}
& \text { Charles O. Schoemaker } \\
& \text { Tel: 301/975-6694 } \\
& \text { Email: cshoemaker@ } \\
& \text { nist.gov }
\end{aligned}
$$

David J. Evans (24040S)

Tel: 301/975-6637

Email: david.evans@ nist.gov

\begin{tabular}{|c|c|c|c|c|}
\hline $\begin{array}{l}\text { Service } \\
\text { ID No. }\end{array}$ & Items & Freq. Range & $\begin{array}{l}\text { Peak Accel. } \\
\left(g_{\mathrm{n}}\right)\end{array}$ & $\begin{array}{l}\text { Rel. Exp. } \\
\text { Uncer }^{*} \text {. in \% }\end{array}$ \\
\hline $24010 \mathrm{C}$ & $\begin{array}{l}\text { Pickup } \\
\text { Sensitivity }\end{array}$ & $2 \mathrm{~Hz}$ to $160 \mathrm{~Hz}$ & 0.2 to 2 & 1 to 2 \\
\hline $24020 \mathrm{C}$ & $\begin{array}{l}\text { Pickup } \\
\text { Sensitivity }\end{array}$ & $10 \mathrm{~Hz}$ to $3500 \mathrm{~Hz}$ & 2 to 10 & 1 to 2 \\
\hline $24030 \mathrm{C}$ & Pickup & $10 \mathrm{~Hz}$ to $10 \mathrm{kHz}$ & 2 to 10 & 1 to 2 \\
\hline $24040 \mathrm{~S}$ & $\begin{array}{l}\text { Shock } \\
\text { Measurement }\end{array}$ & $250 \mathrm{~Hz}$ to $10 \mathrm{kHz}$ & 20 to 10000 & 3 to 5 \\
\hline $24050 \mathrm{~S}$ & $\begin{array}{l}\text { Pickup } \\
\text { Sensitivity }\end{array}$ & $3 \mathrm{kHz}$ to $20 \mathrm{kHz}$ & 4 to 200 & 1 to 3 \\
\hline
\end{tabular}

Mailing Address: Building 233, Room A147, National Institute of Standards and Technology, Gaithersburg, MD 20899-0001

*See Chapter 1, Section $\mathrm{H}$ for more information about uncertainty.

\section{Pickup Sensitivity (24010C-24030C)}

NIST calibrations of vibration exciters and pickups are performed by comparison with the response characteristics of NIST standards or by absolute measurements. A calibration consists of measuring the transfer function of the instrument, usually referred to as the sensitivity. For a pickup, it is the ratio of the electrical output to a mechanical input. The magnitude of the latter is set in accordance with the calibration method, the type of vibration exciter, and the frequency of vibration. The magnitude of the output depends, of course, on the nature of the test device. In the case of an accelerometer with signal conditioner, the practice has been to express the output in millivolts, and the input in units of $g_{\mathrm{n}}$, the standard acceleration of free fall:

$$
g_{\mathrm{n}}=9.80665 \mathrm{~ms}^{-2} .
$$

The acceleration sensitivity is then given in $\mathrm{mV} / g_{\mathrm{n}}$. For charge-output devices without signal conditioners, the acceleration sensitivity is stated in picocoulombs per $g_{\mathrm{n}}\left(\mathrm{pC} / g_{\mathrm{n}}\right)$. All measurements are performed at $23 \pm 3^{\circ} \mathrm{C}$. The calibration of an accelerometer is reported in tabular form as the sensitivity magnitude at a set of discrete frequencies; the phase component can be furnished at additional cost on request.

The NIST vibration standards are periodically calibrated by reciprocity and/or interferometric techniques, two independent and absolute methods. The use of these standards in the calibration of stable transducers furnishes calibration data with a typical relative expanded uncer tainty* of $1 \%$ to $2 \%$ depending on the frequency range.

\section{Special Shock Measurement Services (24040S)}

The shock facility provides a comparison calibration of accelerometers by subjecting them to half-sinewave pulses with peak amplitudes of $20 g_{n}$ to $10000 g_{n}$ and pulse widths from $0.1 \mathrm{~ms}$ to $40 \mathrm{~ms}$. Both time and frequency domain measurements can be performed.

\section{Special Tests of Pickup Sensitivity (24050S)}

This test measures the pickup sensitivity by the fringe-disappearance method, using an automated Michelson interferometer. As presently configured, the system operates between $3 \mathrm{kHz}$ and $20 \mathrm{kHz}$. The method requires precise setting of vibration amplitude to $121.10 \mathrm{~nm}$; consequently, the acceleration amplitude in the stated frequency range increases from about $4 g_{\mathrm{n}}$ to $200 g_{\mathrm{n}}$.

\section{Special Vibration Tests (24060S)}

Calibration of vibration and shockmeasuring instruments to specifications other than those above, as well as other specified measurements, can be performed by prearrangement.

* See Chapter 1, Section $\mathrm{H}$ for more information about uncertainty. 
For example, an interferometer calibration for frequencies less than $2 \mathrm{~Hz}$ or greater than $10 \mathrm{kHz}$ can be performed on request. Consult with the technical contacts cited at the beginning of this section.

\section{References-Vibration Measurements}

An Application of Parameter Estimation Theory in Low Frequency Accelerometers, B. F. Payne and M. R. Serbyn, 14th Transducer Workshop, Telemetry Group, Range Commanders Council, Colorado Springs, CO (June 1987).

A Description of NBS Calibration Services in Mechanical Vibration and Shock, D. C. Robinson, M. R. Serbyn, and B. F. Payne, Natl. Bur. Stand. (U.S.), Tech. Note 1232 (Feb. 1987).

An Automated Fringe Counting Laser Interferometer for Low Frequency Vibration Measurements, B. F. Payne, Proc. ISA Symp., Seattle, WA (May 1986).

Automation of Vibration Testing at the National Bureau of Standards, B. F. Payne, Proc. 30th Tech. Meeting, Inst. of Environ. Sciences (May 1984).

An Automated System for the Measurement of Pickup Sensitivity, B. F. Payne and M. R. Serbyn, Proc. Natl. Conf. Stand. Lab. Ann. Workshop and Symp. II-11.1-II-11.22 (July 1983).

The Application of Back-to-Back Accelerometers to Precision Vibration Measurements, B. F. Payne, J. Res. Natl. Bur. Stand. (U.S.) 88 (3), 171 (May-June 1983).
A Real-Time Active Vibration Controller, M. R. Serbyn and W. B. Penzes, ISA Transactions 21 (3), 55 (1982).

Development of a Low-Frequency-Vibration Calibration System, R. S. Koyanagi, Exp. Mech. 15, 443 (Nov. 1975).

Shock Calibration of Accelerometers, C. Federman, W. Walston, and J. Ramboz, Minutes of the 8th Transducer Workshop: Telemetry Group, Inter-Range Instrumentation Group, Range Commanders Council, WrightPatterson AFB, OH (Apr. 1975).

Piezoelectric Shakers for Wide Frequency Calibration of Vibration Pickups, E. Jones, B. Yelon, and S. Edelman, J. Acoust. Soc. Am. 46 (6), 1556 (June 1969).

Improved Transfer Standard for Vibration Pickups, E. Jones, D. Lee, and S. Edelman, J. Acoust. Soc. Am. 41 (2), 354 (Feb. 1967).

Electrodynamic Vibration Standard with a Ceramic Moving Element, T. Dimoff, J. Acoust. Soc. Am. 40 (3), 671 (Sept. 1966).

Calibration of Vibration Pickups at Large Amplitudes, E. Jones, S. Edelman, and K. S. Sizemore, J. Acoust. Soc. Am. 33 (11), 1462 (Nov. 1961).

Calibration of Vibration Pickups by the Reciprocity Method, S. Levy and R. R. Bouche, J. Res. Natl. Bur. Stand. (U.S.) 57 (4), 227 (Oct. 1956). 


\section{(7) Acoustic Measurements}

\section{Technical Contacts:}

\author{
Victor Nedzelnitsky \\ Tel: 301/975-6638 \\ Email: vnedzelnitsky@ \\ nist.gov
}

\author{
David J. Evans \\ Tel: 301/975-6637 \\ Email: david.evans@nist.gov
}

Mailing Address: Building 233, Room A147,

National Institute of Standards and Technology,

Gaithersburg, MD 20899-0001

\begin{tabular}{|c|c|}
\hline $\begin{array}{l}\text { Service } \\
\text { ID No. }\end{array}$ & Items \\
\hline $25010 \mathrm{C}$ & $\begin{array}{l}\text { Pressure Response: WE Type } 640 \text { AA microphones or } \\
\text { equivalent (e.g., Tokyo Riko Type ECL MR103, Bruel \& } \\
\text { Kjaer Type } 4160 \text {, Bruel \& Kjaer Types } 4144 \text { or } 4132 \text { with } \\
\text { DB0111 adapter). } 50 \mathrm{~Hz} \text { to } 10000 \mathrm{~Hz}\end{array}$ \\
\hline $25020 \mathrm{C}$ & $\begin{array}{l}\text { Pressure Response: WE Type } 640 \text { AA microphones or } \\
\text { equivalent (e.g., Tokyo Riko Type ECL MR 103; Bruel \& } \\
\text { Kjaer Type } 4160 \text {; Bruel \& Kjaer Types } 4144 \text { or } 4132 \text { with } \\
\text { DB0111 adapter). } 50 \mathrm{~Hz} \text { to } 20000 \mathrm{~Hz}\end{array}$ \\
\hline $25030 \mathrm{C}$ & $\begin{array}{l}\text { Pressure Response: Tokyo Riko Type ECL MR112, Bruel } \\
\text { \& Kjaer Type } 4134 \text {, or equivalent half-inch microphones, } \\
50 \mathrm{~Hz} \text { to } 10000 \mathrm{~Hz}\end{array}$ \\
\hline $25040 \mathrm{C}$ & $\begin{array}{l}\text { Pressure Response: Tokyo Riko Type ECL MR112, Bruel } \\
\text { \& Kjaer Type } 4134 \text {, or equivalent half-inch microphones, } \\
50 \mathrm{~Hz} \text { to } 20000 \mathrm{~Hz}\end{array}$ \\
\hline $25050 \mathrm{C}$ & $\begin{array}{l}\text { Free-Field Response: Tokyo Riko Type ECL MR1 12, } \\
\text { Bruel \& Kjaer Types } 4133,4134,4165,4166,4180 \text {, or } \\
\text { equivalent half-inch microphones, } 2500 \mathrm{~Hz} \text { to } 20000 \mathrm{~Hz}\end{array}$ \\
\hline $25060 \mathrm{~S}$ & Special Tests of Acoustic Devices \\
\hline $25070 \mathrm{~S}$ & Special Tests of Audiometers/Earphones \\
\hline
\end{tabular}

Pressure and Free-Field Responses of Microphones (25010C-25050C)

Pressure calibrations (Service ID Nos. 25010C and 25020C) are performed on Type-L one-inch microphones* satisfying the requirements of American National Standard S1.12-1967 (R1977), Specifications for Laboratory Standard Microphones and its impending revision. The microphones submitted for pressure calibration must be suitable for use with the calibrating couplers shown in Figures 6 and 10 of the applicable American National Standard S1.10-1966 (R1986).

*Type-L one-inch is a commercial designation for these microphones.
Table 5.3. Typical Expanded Uncertainties** for Pressure Calibrations of Type-L Microphones

\begin{tabular}{cr}
$\begin{array}{c}\text { Expanded } \\
\text { Uncertainty** } \\
\text { (dB) }\end{array}$ & Frequency Range \\
\hline 0.09 & $50 \mathrm{~Hz}$ to $7 \mathrm{kHz}$ \\
0.26 & $7 \mathrm{kHz}$ to $10 \mathrm{kHz}$ \\
0.17 & $10 \mathrm{kHz}$ to $17 \mathrm{kHz}$ \\
0.32 & $17 \mathrm{kHz}$ to $20 \mathrm{kHz}$ \\
\end{tabular}

** See Chapter 1, Section $\mathrm{H}$ for more information about uncertainty.

Further information is contained in the references for acoustic measurements.

Since American National Standards Institute publications S1.10-1966 (R1986) and S1.12-1967 (R1977) were issued, certain types of half-inch diameter precision microphones have attained widespread use. Therefore, NIST has developed procedures (Service ID Numbers 25030C and 25040C) for determining the pressure response levels of half-inch microphones by comparison with NIST-owned Type-L standard microphones, which in turn are calibrated periodically by the reciprocity technique. The technique used, precautions to be observed, and uncertainties of measurement are essentially the same as those given above for one-inch microphones. Significantly different aspects of the procedures for half-inch microphones, such as ground shield configuration, are described in the test report. Since several half-inch laboratory standard microphones have been available for only a relatively short time, their long-term stability has yet to be determined.

The free-field response levels of certain Type-L microphones (e.g., Western Electric Type 640AA condenser microphones) can be computed from pressure response levels reported by NIST. However, certain precautions must be taken, and there is some degradation in accuracy. 
Therefore, for the most demanding freefield measurement requirements, NIST offers a calibration service (Service ID No. 25050C) for determining the freefield response levels for half-inch microphones. The calibrations are made over the frequency range of $2.5 \mathrm{kHz}$ to $20 \mathrm{kHz}$ at normal incidence. Response levels (sensitivity levels) are reported in terms of open-circuit voltage per unit sound pressure (in the absence of the microphone) of a plane progressive wave whose direction of propagation is normal to the plane of the diaphragm. The calibrations are performed in a well-characterized anechoic chamber. A typical expanded uncertainty* in this calibration is approximately $0.21 \mathrm{~dB}$ or less at each frequency within the range of $2.5 \mathrm{kHz}$ to $6.3 \mathrm{kHz}$ and $0.15 \mathrm{~dB}$ or less at each frequency within the range of $6.3 \mathrm{kHz}$ to $20 \mathrm{kHz}$. Calibrations can be performed with or without protective grids on the microphone. For the most precise free-field measurements, the customer should contact the NIST staff person cited at the beginning of this section for recommendations prior to submitting the microphone to NIST for calibration.

\section{Special Tests of Acoustic Devices (25060S)}

Acoustical measurement services are available by special arrangement. These services include extended frequency ranges of calibration, additional data points, measurements at very low sound pressure levels, and calibration of certain pistonphones and acoustic calibrators. NIST has a large general-purpose anechoic chamber available for special calibrations requiring such a facility. The frequency-dependent and positiondependent acoustical performance of this chamber, including extremely low background noise, was carefully controlled during design and construction and is documented in archival journal publications.

* See Chapter 1, Section $H$ for more information about uncertainty.

\section{Special Tests of Audiometers/ Earphones (25070S)}

Earphones are tested on the NIST 9-A Coupler from $125 \mathrm{~Hz}$ to $8000 \mathrm{~Hz}$. Measurements of audiometer/earphone response and linearity can be made at very low sound pressure levels.

\section{References-Acoustic Measurements}

Calibration of Pressure and Gradient

Microphones, V. Nedzelnitsky, Encyclopedia of Acoustics, Ed. in Chief M. J. Crocker, John Wiley \& Sons, Inc., New York, 1869-1879 (1997).

Primary Method for Free-Field Calibration, V. Nedzelnitsky, AIP Handbook of Condenser Microphones, Eds., G. S. K. Wong and T. F. W.

Embleton, Am. Inst. of Physics Press, Woodbury, NY, 103-109 (1995).

Laboratory Microphone Calibration Methods at the National Institute of Standards and Technology, U.S.A., V. Nedzelnitsky, AIP Handbook of Condenser Microphones, Eds., G. S. K. Wong and T. F. W. Embleton, Am. Inst. of Physics Press, Woodbury, NY, 145-161 (1995).

Method for Calibration of Microphones, Amer. Natl. Stand. Inst. S1.10-1966 (R1986), New York, NY.

Specifications for Laboratory Standard Microphones, Amer. Natl. Stand. Inst. S1.12-1967 (R1977), New York, NY.

Free-Field Reciprocity Calibration of Microphones, E. D. Burnett and V. Nedzelnitsky, J. Res. Natl. Bur. Stand. (U.S.) 92 (2), 129 (Mar.-April 1987).

Traceability of Acoustical Instrument Calibration to the National Bureau of Standards, V. Nedzelnitsky, Proc. INTER-NOISE 80, II, Dec. 8-10, 1980, Miami, FL, G. C. Maling, Jr., Ed., Poughkeepsie, NY: Noise Control Foundation, 1043 (1980).

Calibration of Laboratory Condenser Microphones, V. Nedzelnitsky, E. D. Burnett, and W. B. Penzes, Proc. 10th Transducer Workshop, Transducer Committee, Telemetry Group, Range Commanders Council, Colorado Springs, CO (June 1979). 
Acoustical Properties of the National Bureau of Standards Anechoic Chamber, W. Koidan and G. R. Hruska, J. Acoust. Soc. Am. 64 (2), 501 (Aug. 1978).

edge Design for the National Bureau of Standards Anechoic Chamber, W. Koidan, G.R. Hruska, and M. A. Pickett, J. Acoust. Soc. Am. 52 (4) (Part 1), 1071 (1972).

Calibration of Standard Condenser Microphones: Coupler Versus Electrostatic Actuator, W. Koidan, J. Acoust. Soc. Am. 44 (5), 1451 (Nov. 1968).
Calibrations of Microphones, Vibration Pickups, and Earphones, R.K. Cook, S. Edelman, and W. Koidan, J. Audio Eng. Soc. 13 ( 4) (Oct. 1965).

Free-Field Correction for Condenser Microphones, W. Koidan and D. S. Siegel, J. Acoust. Soc. Am. 36 (11), 2233 (Nov. 1964).

Hydrogen Retention System for Pressure Calibration of Microphones in Small Couplers, W. Koidan, J. Acoust. Soc. Am. 35 (4), 614 (Apr. 1963).

Method of Measurement of $E^{\prime} / I^{\prime}$ in the Reciprocity Calibration of Condenser Microphones, W. Koidan, J. Acoust. Soc. Am. 32 (5), 611 (May 1960). 


\section{Ultrasonic Reference Block Measurements}

\author{
Technical Contacts:
}

\author{
John A. Slotwinski \\ Tel: 301/975-2171 \\ Email: jslotwinski@nist.gov
}

\author{
Gerald V. Blessing \\ Tel: 301/975-6627 \\ Email: gblessing@nist.gov
}

Mailing Address: Building 233, Room A147, National Institute of Standards and Technology, Gaithersburg, MD 20899-0001

Service

ID No.

Items

26030S Special Tests of Area Amplitude Aluminum Reference Blocks-Set of Eight Blocks

26040S Special Tests of Area Amplitude Titanium or Steel Ultrasonic Reference Blocks--Set of Eight Blocks

26050S Special Tests of Distance Amplitude Aluminum Reference Blocks-Set of Fifteen Blocks

26060S Special Tests of Distance Amplitude Titanium or Steel Ultrasonic Reference Blocks-Set of Fifteen Blocks

26070S Special Tests of Distance and Area Amplitude Aluminum, Titanium or Steel Ultrasonic Reference BlocksMiscellaneous Sets

Special Tests of Aluminum Reference Blocks (26030S, 26050S, and 26070S)

The ultrasonic response of 7075 aluminum alloy ASTM E127-type flatbottom-hole $(\mathrm{FBH})$ reference blocks of $12.7 \mathrm{~mm}$ (and greater) metal path distances is determined relative to a NIST reference block. The immersion, pulseecho, longitudinal wave, $5 \mathrm{MHz}$ quartz transducer testing system specified in ASTM E127-95 is used according to NIST-modified procedures (see publication NISTIR 5430) for improved measurement precision. Instrument gain settings are established using a selected 5-0050 block rather than the steel spheres stipulated in ASTM E127-95, and relative gain settings for different FBH sizes are determined from ratios of the respective $\mathrm{FBH}$ areas, rather than from the results of tests of various steel spheres. A specific set of NIST FBH check-standard blocks is tested along with the customer's block. The long-term precision and stability of the NIST testing system are monitored using a database reflecting the results of repeated tests of a set of check standard blocks. Standard deviation data representing the uncertainties associated with a particular test are reported for each block and hole size.

Relative expanded uncertainties* range from $3 \%$ to $12 \%$. Upon request, block response can be determined using the procedures specified in the ASTM Recommended Practice E127-95. Turnaround is expedited by prearrangement with the technical contacts.

\section{Special Tests of Titanium or Steel} Reference Blocks (26040S, 26060S, and 26070S)

Steel and titanium ultrasonic reference blocks can be calibrated using procedures similar to those described in ASTM E428.

\section{References-Ultrasonic Reference Block Measurements}

Standard Practice for Fabricating and Checking Aluminum Alloy Ultrasonic Standard Reference Blocks, E-127-95, in Annual Book of ASTM Standards 03.03, Philadelphia, PA, Amer. Soc. for Testing and Materials (1995).

NIST Calibration of ASTM E127-Type Ultrasonic Reference Blocks, J. A. Slotwinski, and G. V. Blessing, Natl. Inst. Stand. Technol., NISTIR 5430 (May 1994).

An Assessment of Ultrasonic Reference Block Calibration Methodology, G. V. Blessing, Natl. Bur. Stand. (U.S.), NBSIR 83-2710 (June 1983).

Recent Improvements to the ASTMType Ultrasonic Reference Block System, D. J. Chwirut, Natl. Bur. Stand. (U.S.), NBSIR 79-1742 (Feb. 1979).

* See Chapter 1, Section H for more information about uncertainty. 
The Evaluation of Search Units Used for Ultrasonic Reference Block Calibrations, D. J. Chwirut and G. D. Boswell, Natl. Bur. Stand. (U.S.), NBSIR 78-1454 (Feb. 1978).
Improved Ultrasonic Standard Reference Blocks, G. F. Sushinsky, D. G. Eitzen, D. J. Chwirut, C. J. Bechtoldt, and A. W. Ruff, Natl. Bur. Stand. (U.S.), NBSIR 76-984 (Nov. 1976). 


\section{Ultrasonic Transducer Measurements}

\author{
Technical Contacts:
}

$\begin{array}{ll}\text { Steven E. Fick } & \text { Gerald V. Blessing } \\ \text { Tel: 301/975-6629 } & \text { Tel: 301/975-6627 } \\ \text { Email: sfick@nist.gov } & \text { Email: gblessing@nist.gov }\end{array}$

Mailing Address: Building 233, Room A147, National Institute of Standards and Technology, Gaithersburg, MD 20899-0001

Service ID No. Items

26100C Ultrasonic Power Output

\section{Ultrasonic Power Output (26100C)}

Measurements of total ultrasonic forward power radiated into a reflectionless water load are offered for the purpose of characterizing ultrasonic systems and transducers. Ultrasonic systems are characterized by measurement of output power under operating conditions specified by the customer. Transducers for which continuous-wave electrical input voltage can accurately and reproducibly be measured are characterized by a radiation conductance determined from measurements of input voltage and output power. A typical calibration report for an ultrasonic system provides the results of at least three measurements of output power for each operating condition specified. Calibration reports for transducers typically present a single value of radiation conductance derived from at least 15 measurements spanning an appropriate range of output power. Resonance frequencies of transducers are determined from the results of iterative spot-frequency relative measurements of radiation conductance.

Continuous-wave ultrasonic power is measured using a radiation force balance which allows power to be determined from the force required to arrest the motion of a conical target that diverts the output beam of the transducer under test into a bank of absorbers. Absolute power can be measured at spot frequencies between $0.5 \mathrm{MHz}$ and $30 \mathrm{MHz}$. The relative expanded uncertainty* is dominated by frequency dependent effects and ambient vibration levels at the time of measurement, and ranges from $0.4 \%$ to $7 \%$ for power levels above a few $\mathrm{mW}$. The best-case minimum detectable power is about $100 \mu \mathrm{W}$; high-power measurements are limited by the onset of cavitation in the water load itself. Transducers of diameter no greater than $45 \mathrm{~mm}$ can be tested in this apparatus.

Pulsed ultrasonic power is measured for the purpose of characterizing ultrasonic systems comprising a transducer and an electrical driver. Transducers by themselves cannot be independently characterized with nonsinusoidal drive waveforms since the electrical input signals cannot at present be adequately measured. Systems to be tested must be capable of generation of a sequence of at least 15 pulses in a $500 \mathrm{~ms}$ interval under external triggering.

\section{References-Ultrasonic Transducer Measurements}

Ultrasonic Power Output Measurement by Pulsed Radiation Pressure, S. E. Fick and F.R. Breckenridge, J. Res. Inst. Stand. Technol. 101, 659 (1996).

An Ultrasonic Absolute Power Transfer

Standard, S. E. Fick, F. R. Breckenridge, C. E. Tschiegg, and D. G. Eitzen, J. Res. Natl. Bur. Stand. (U.S.) 89 (2), 209 (Mar. 1984).

Ultrasonic Transducer Power Output by Modulated Radiation Pressure, M.

Greenspan, F. R. Breckenridge, and C. E. Tschiegg, J. Acoust. Soc. Am. 63 (4), 1031 (Apr. 1978). * See Chapter 1, Section $\mathrm{H}$ for more information
about uncertainty. 


\section{Acoustic Emission Transducer Measurements}

\author{
Technical Contacts:
}

Steven E. Fick
Tel: 301/975-6629
Email: sfick@nist.gov

Gerald V. Blessing

Tel: 301/975-6627

Email: gblessing@nist.gov

Mailing Address: Building 233, Room A147, National Institute of Standards and Technology, Gaithersburg, MD 20899-0001

Service

ID No. Items

26200C Acoustic Emission Transducer Sensitivity

\section{Acoustic Emission Transducer Sensi- tivity (26200C)}

Acoustic emission transducer sensitivity is expressed as the voltage output of the transducer per unit of perpendicular surface motion (displacement or velocity) induced by an impulsive elastic wave traveling on the surface, or through the bulk, of a steel test block. Sensitivity is computed by comparing the output of the transducer under test (TUT) to an independently derived estimate of the surface motion that would occur if the transducer were not present. The magnitude and phase of the computed sensitivity are reported as a function of frequency for discrete frequencies separated by approximately $10 \mathrm{kHz}$ in the interval $0.1 \mathrm{MHz}$ to $1 \mathrm{MHz}$.

For surface-pulse tests, the TUT and a capacitive displacement transducer (CDT) are placed at symmetric locations $10 \mathrm{~cm}$ from the center of the circular upper end face of the test block, which is a cylinder $90 \mathrm{~cm}$ diameter and $43 \mathrm{~cm}$ long, positioned with its axis of rotation vertical. Elastic waves are induced in the block by rapid unloading due to breakage of a quasi-statically loaded glass capillary source located at the center of the upper surface of the block. The CDT output, corrected for aperture effects, provides a direct measurement of surface

motion which, from independent measurements of the homogeneity of test block properties, bears a known similarity to the surface motion at the TUT location.

For through-pulse testing, the source is located on the lower end face of the block, directly opposite the TUT. Because phenomena intrinsic to bulk wave propagation would excessively complicate the task of correcting its output, the CDT output is not used. Instead, an estimate of upper surface motion at the TUT location is obtained from calculations based on the measured unloading force due to breakage of the glass capillary.

\section{References-Acoustic Emission}

Transducer Measurements Acoustic Emission Transducer Calibration by means of the Seismic Surface Pulse, F. R. Breckenridge, J. Acoust. Emission 1 (2), (Apr. 1985).

Calibration and Sensor Activities, D. G. Eitzen, F. R. Breckenridge, R. B. Clough, E. R. Fuller, N. N. Hsu, and J. A. Simmons, Chapter 2.0 in Fundamental Developments for Quantitative Acoustic Emission Measurements, EPRI NP-2089, Research Project 608-1, Palo Alto, CA, Electric Power Research Institute, 2-1-2-52 (Oct. 1981).

Surface-Wave Displacement: Absolute Measurements Using a Capacitive Transducer, F. R. Breckenridge and M. Greenspan, J. Acoust. Soc. Am. 69 (4), 1177 (Apr. 1981).

Characterization and Calibration of Acoustic Emission Sensors, N. N. Hsu and F. R. Breckenridge, Matls. Eval. 39 (1), 60 ( Jan. 1981).

Acoustic Emission: Some Applications of Lamb's Problem, F. R. Breckenridge, C. E. Tschiegg, and M. Greenspan, J. Acoust. Soc. Am. 57 (3), 626 (Mar. 1975). 



\section{Chapter}

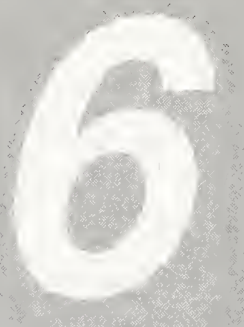

A Pressure Measurements

$B$ Low Pressure, Vacuum, and Leak Measurements

C Laboratory and Industrial-Grade Thermometers

D Thermocouples, Thermocouple Materials, and Thermometer Indicators

E Resistance Thermometry

F Radiance Temperature Measurements

G Humidity Measurements 
A.

\section{Pressure Measurements}

Technical Contacts:

$\begin{array}{lll}\begin{array}{l}\text { James W. Schmidt } \\ \text { (all services) }\end{array} & \begin{array}{l}\text { R. Gregory Driver } \\ \text { (pneumatic gages) }\end{array} & \begin{array}{l}\text { Donald B. Ward } \\ \text { (hydraulic gages) }\end{array} \\ \text { Tel.: 301/975-2458 } & 29010 \mathrm{C}, 29030 \mathrm{C}, 29035 \mathrm{C}, & 29010 \mathrm{C}, 29020 \mathrm{C}, \\ \text { Email: jschmidt@nist.gov } & \text { 29040S } & \text { 29030C } \\ & \text { Tel: 301/975-4832 } & \text { Tel: 301/975-6561 } \\ & \text { Email: rdriver@nist.gov } & \begin{array}{l}\text { Email: dbward@ } \\ \text { nist.gov }\end{array}\end{array}$

Mailing Address: Building 220, Room A55, National Institute of Standards and Technology, Gaithersburg, MD 20899-0001

\begin{tabular}{ll}
\hline Service & \\
ID No. & Items \\
\hline 29010 C & Deadweight Piston Gages \\
29020 C & Controlled Clearance Piston Gages \\
29030 C & Pressure Gages and Transducers \\
$29035 C$ & Non-Mercurial Barometers and Manometers \\
29040 S & Special Tests of Pressure Gages \\
\hline
\end{tabular}

Piston Gages and Pressure Transducers (29010C-29035C)

NIST provides measurement services for the calibration of piston gages (PG) and transducers operating with gas in the range of $7 \mathrm{kPa}$ to $110 \mathrm{MPa}$ and with oil in the range of $1 \mathrm{MPa}$ to $280 \mathrm{MPa}$. Work is in process to extend the upper range for oil piston gage calibration services to $500 \mathrm{MPa}$. Calibrations of customer piston gages are done in the gage mode by the cross-floating technique using NIST working standard piston gages. NIST pneumatic working standards have been calibrated at the low end of the pressure range using the NIST mercury manometers and are modeled to extend their range to higher pressures. The NIST working standards for oil service have been calibrated using three controlledclearance piston gages. Relative expanded uncertainties** associated with such calibrations are shown in Table 6.1.

* See Chapter 1, Section C for information available from the Standard Reference Materials Program on calibrating certain thermodynamic property measurement instruments.

** See Chapter 1, Section $\mathrm{H}$ for more information about uncertainty.
Table 6.1. Relative Expanded Uncertainties** of Piston Gage Standards in Gage Mode

\begin{tabular}{llc}
\hline Type of Instrument & \multicolumn{1}{c}{ Range } & $\begin{array}{c}\text { Relative Expanded } \\
\text { Uncertainty** } \\
\left(\times 10^{-6}\right)\end{array}$ \\
\hline Gas-operated PG & $7 \mathrm{kPa}$ to $105 \mathrm{kPa}$ & 13 \\
& $105 \mathrm{kPa}$ to $1.4 \mathrm{MPa}$ & 19 \\
& $1.4 \mathrm{kPa}$ to $17.3 \mathrm{MPa}$ & 33 \\
& $17.3 \mathrm{kPa}$ to $103 \mathrm{MPa}$ & 38 \\
Oil-operated PG & $1 \mathrm{MPa}$ to $29 \mathrm{MPa}$ & 22 \\
& $29 \mathrm{MPa}$ to $140 \mathrm{MPa}$ & 37 \\
& $140 \mathrm{MPa}$ to $280 \mathrm{MPa}$ & 49 \\
\hline
\end{tabular}

** These expanded uncertainties are based on recent evaluations of NIST "transfer" piston gage standards. Uncertainty estimates are continually being revised to reflect development of new primary pressure standards and improvements in measurement techniques.

\section{Special Tests of Pressure Gages} (29040S)

Special tests of pressure gages and other pressure measuring devices may be performed on request. This includes, special test $30040 \mathrm{~S}$ for deadweight piston gages, an absolute mode test in the pressure range $7 \mathrm{kPa}$ to $350 \mathrm{kPa}$ that can provide relative expanded uncertainties that are smaller than those given in Table 6.1. A minimum piston gage test will require data at five or more pressures for each gas desired. Call Mr. Driver for further information about this service.

\section{References-Pressure Measurements}

Research at High Pressures (Primary

Pressure Standards), J. S. Schmidt, D. B. Ward, and S. A. Tison, Proc. 1997 Natl. Conf. Stand. Lab., Workshop and Symp. (accepted for publication).

Development of High Pressure

(110 MPa) Gas Calibration Service at NIST, S. W. Doty, C. D. Ehrlich, R. F. Kayser and S. A. Tison, Proc. Of the 1995 Measurement Science Conference.

A Look at Uncertainties over Twenty Decades of Pressure Measurement, C. D. Ehrlich, Proc. of the XIII IMEKO World Congress (Sept. 1994) 
An Intercomparison of Pressure Standards in the Hydraulic Pressure Region up to $28 \mathrm{MPa}$ between NPL (India) and NIST (USA), J. K. N. Sharma, K. K. Jain, C. D. Ehrlich, J. Res. Natl. Inst. Stand. Technol. (1994).

Elastic Distortion Calculations on a Special Piston Gage (PG27) up to $28 \mathrm{MPa}$ in Different Operational Modes, G. F. Molinar, P. C. Cresto, C. Ehrlich and J. Houck, Metrologia 30 (6) (1994).

A Review of the State of the Art in GasOperated Piston Gages, C. D. Ehrlich, Metrologia 30 (6), 585 (1994).

Operational Mode and Gas Species Effects on Rotational Drag in Pneumatic Dead Weight Pressure Gages, J. W. Schmidt, B. E. Welch and C. D. Ehrlich, Meas. Sci. Technol. 4, 26-34 (1993).

Intercomparison of the Effective Areas of a Pneumatic Piston Gage Determined by Different Techniques, K. Jain, C. Ehrlich, J. Houck and J. K. N. Sharma, Meas. Sci. Technol. 4, 249257 (1993).

Intercomparison of Hydraulic Pressure Measurements to $28 \mathrm{MPa}$ using a Single Piston Gage in the ControlledClearance, Reentrant and Simple Configurations, K. Jain, C. Ehrlich and J. Houck, Review of Scientific Instruments 63, 3127, (1992).
The Reduction of Uncertainties for Absolute Piston Gage Pressure Measurements in the Atmospheric Pressure Range, B. E. Welch, R. E. Edsinger, V. E. Bean and C. D. Ehrlich, J. Res. Natl. Inst. Stand. Technol. 94, 343 (Nov.-Dec. 1989).

Practical Uncertainty Limits to the Mass Determination of a Piston-Gage Weight, R. S. Davis and B. E. Welch, J. Res. Natl. Bur. Stand. (U.S.), 93 (4) (July-Aug. 1988).

International Comparison in the Pressure Range 20-100 MPa, J.C. Legras, S.L. Lewis, G. F. Molinar, Metrologia 25, 21-28 (1988).

The Pressure Balance, Theory and Practice, R. S. Dadson, S. L. Lewis, and G. N. Peggs, Her Majesty's Stationary Office, London, England (1982).

Piston Gages, P. L. M. Heydemann and B. E. Welch, Chapter 4, Experimental Thermodynamics, Vol. II, in Experimental Thermodynamics of NonReacting Fluids, B. Le Neindre and B. Vodar, Eds., Part 3, 147, Butterworth and Co., London, England (1975). 


\section{Low-Pressure, Vacuum, and Leak Calibrations}

\section{Technical Contacts:}

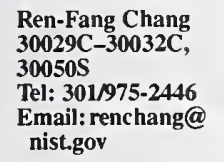

Archie Miiller
30010C-30025C,
30040S,
Tel: 301/975-5932
Email: archie.miller@
nist.gov

$\begin{array}{ll}\text { Patrick J. } & \text { Stuart A. } \\ \text { Abbott } & \text { Tison } \\ \text { 30034C-30038C, } & \text { 30063S } \\ \text { 30060S-30062C } & \text { Tel: 301/975-2857 } \\ \text { Tel: 301/975-4838 } & \begin{array}{c}\text { Email:stison@ } \\ \text { Email: patrick. } \\ \text { nist.gov } \\ \text { abbott@nist.gov }\end{array}\end{array}$

Mailing Address: Building 220, Room A55, National Institute of Standards and Technology, Gaithersburg, MD 20899-0001

\section{Shipping Address:}

National Institute of Standards and Technology,

I-270 at Quince Orchard Rd.,

Building 220, Room A55,

Gaithersburg, MD 20899-0001

\section{Service}

ID No.

Items

30010C One Low-Pressure Transducer (Absolute or Differential) Relative to Vacuum

30011C Additional Transducers (cost per unit)

30020C One Differential Low-Pressure Transducer Relative to Near Atmospheric Pressure

30021C Additional Transducers (cost per unit)

30025C Ball-Type Deadweight Tester

30029C Spinning Rotor Gages, below 0.1 Pa, Nitrogen Gas With NIST Controller

30030C Spinning Rotor Gages, below 0.1 Pa, Nitrogen Gas, Customer Controller with IEEE-488

30031C Spinning Rotor Gages, below 0.1 Pa, Additional Gas

30032S Special Tests of Spinning Rotor Gages, Transition Range (above $0.1 \mathrm{~Pa}$ )

30034C Ionization Gages, $10^{-4}$ to $10^{-1} \mathrm{~Pa}$, Nitrogen Gas

30035C Ionization Gages, $10^{-5}$ to $10^{-1} \mathrm{~Pa}$, Nitrogen Gas

30036C Ionization Gages, $10^{-7}$ to $10^{-1} \mathrm{~Pa}$, Nitrogen Gas

30037C Ionization Gages, Additional Filament or Gas for Above Tests

30038C Ionization Gages, NIST-Supplied Gage Tube for Above Tests

30040S Special Tests of Low-Pressure Gages

30050S Special Tests of Vacuum Gages

$30060 \mathrm{~S}$ Special Tests of Leak Artifacts $\left(10^{-13} \mathrm{~mol} / \mathrm{s}\right.$ to $\left.10^{-6} \mathrm{~mol} / \mathrm{s}\right)$

$30061 \mathrm{C}$ Helium Leaks, Primary Calibration $\left(10^{-13} \mathrm{~mol} / \mathrm{s}\right.$ to $10^{-6} \mathrm{~mol} / \mathrm{s}$ )

$30062 \mathrm{C}$ Helium Leaks, Comparison Calibration $\left(10^{-13} \mathrm{~mol} / \mathrm{s}\right.$ to $10^{-9} \mathrm{~mol} / \mathrm{s}$ )

$30063 \mathrm{~S}$ Special Tests of Low-Gas Flow Instruments

\section{General Notes:}

$$
1 \text { Torr }=133.322 \mathrm{~Pa}
$$

Due to the time and effort required to prepare vacuum instrumentation for operation it is particularly important that these instruments be known to be in proper operating condition when they are submitted for calibration. Equipment will be inspected upon receipt and the customer notified of any obvious damage. If the schedule permits, we will cooperate with the customer's efforts to repair or replace damaged equipment so that calibration can proceed. However, concealed damage or operational deficiencies most likely will not be detected before the instrument is operating on the vacuum system or the calibration has started; in such cases, if the equipment cannot be calibrated, we will charge $20 \%$ of the regular calibration fee for capacitance diaphragm gages and $30 \%$ of the regular fee for spinning rotor and ionization gages.

\section{Low-Pressure Calibrations (30010C-30025C and 30040S)}

Low-pressure gages are calibrated by direct comparison to NIST UIM (Ultrasonic Interferometer Manometer) primary standards. Calibrations relative to vacuum are performed with either an oil UIM that has a range of $135 \mathrm{~Pa}$ (1 Torr), or one of two mercury UIMs that have ranges of $140 \mathrm{kPa}$ (1100 Torr) and $360 \mathrm{kPa}$ (2700 Torr). Calibrations relative to higher reference pressures (up to $200 \mathrm{kPa}$ ) are performed with either the $360 \mathrm{kPa}$ UIM or a new low-differentialpressure standard based on a $13 \mathrm{kPa}$ (100 Torr) mercury UIM. The expanded uncertainty* due to systematic effects of the mercury UIM standards is $5.2 \times 10^{-6}$ of reading plus $18 \mathrm{mPa}$; the expanded uncertainty of the oil UIM standard is $100 \times 10^{-6}$ of reading plus $2 \mathrm{mPa}$.

* See Chapter 1, Section H for more information about uncertainty. 
Pressure measuring devices accepted for calibration generally fall into three categories. The first are absolute pressure transducers or differential pressure transducers that are operated relative to vacuum, such as capacitance diaphragm gages or quartz bourdon gages (Service ID Numbers $30010 \mathrm{C}$ and 30011C). The second category includes differential pressure transducers of a similar type intended for use with reference pressures near atmospheric pressure (Service ID Numbers $30020 \mathrm{C}$ and $30021 \mathrm{C})$. The third category includes certain types of dead weight testers, such as ball gages (Service ID Number $30025 \mathrm{C}$ ) and low range piston gages (Service ID Number 30040S). Calibrations of transducers relative to vacuum are performed in batches twice a year. Please call for deadline dates for the next calibration batch. Other calibrations are performed on request as NIST schedules and equipment availability permit.

\section{Spinning Rotor Gages (30029C-30032S)}

Spinning Rotor Gages (SRGs, also called Molecular Drag Gages) are calibrated on a new Transition Range Standard of the orifice-flow type with an extended range from $10^{-4} \mathrm{~Pa}$ to $30 \mathrm{~Pa}$ and a relative expanded uncertainty* between $0.3 \%$ and $1.0 \%$. The routine calibrations, 30029C-30031C, cover molecular-flow pressures below $0.1 \mathrm{~Pa}$, where the SRG can, for all practical purposes, be characterized by a constant effective accommodation coefficient without a viscosity correction. Calibrations in this range can be performed using either the customer's controller or a NIST controller. The vacuum flange for the thimble assembly must be bakeable (2.75 in "Conflat" type preferred) unless special arrangements have been made.

\footnotetext{
* See Chapter 1, Section $\mathbf{H}$ for more information about uncertainty.
}

These calibrations are performed with nitrogen, in batches, typically two or three times a year. Please call for the next scheduled calibration date, or to arrange for a gas other than nitrogen.

Viscosity effects become increasingly important above $0.1 \mathrm{~Pa}$. As a special service (30032S), SRGs can be calibrated up to $30 \mathrm{~Pa}$ on the Transition Range standard, and up to $100 \mathrm{~Pa}$ using an ultrasonic interferometer manometer. This requires that the ball, thimble, suspension head, and controller be calibrated as unit. Please call for scheduling and costs.

\section{Ionization Gages (30034C-30038C)}

A standard of the orifice-flow type covers the pressure range from $10^{-1} \mathrm{~Pa}$ to $10^{-7} \mathrm{~Pa}\left(10^{-3}\right.$ Torr to $10^{-9}$ Torr $)$ for inert gases with a relative expanded uncertainty* of $0.7 \%$ or less in the range $10^{-5} \mathrm{~Pa}$ to $10^{-3} \mathrm{~Pa}$, increasing to $2 \%$ at $10^{-7} \mathrm{~Pa}$. To be acceptable for calibration all gages must be bakeable to $250^{\circ} \mathrm{C}$ and should be welded to "Conflat" type flanges. Standard procedure is to calibrate the gage and its control electronics as a package, although gages may be calibrated using NIST electronics by special arrangement. Unless specifically requested by the customer, all hot-cathode gages will be calibrated with $1 \mathrm{~mA}$ electron emission current and the preset bias voltages supplied by the customer's controller. Note that ionization gage controllers that do not regulate the emission current or deliberately change it are not considered suitable as transfer standards. After a gage has been calibrated via any of the Service ID Numbers 30034-30036C, calibration of the gage for additional gases or additional filaments (30037C) may be done for a reduced fee. Cold-cathode gages can be calibrated by special arrangement at the same fees. Ionization gage calibrations are generally performed twice a year; please call for scheduled dates.

For an additional fee, NIST will provide glass-envelope Bayard-Alpert 
ionization gages with tungsten filaments and mounted on non-rotatable 2.75 in "Conflat" type flanges* (30038C). These will be calibrated with the user's electronics.

\section{Special Tests of Low-Pressure Gages (30040S)}

Instruments requiring special calibration procedures or prolonged testing can often be accommodated as a special test. This includes, as a complement to the 29000 Service ID Numbers, the determination of deadweight piston gage effective area using the NIST ultrasonic interferometer manometer as the reference standard. This test can be done in either the gage or absolute mode for a variety of gases. Please call for additional information.

\section{Special Tests of Vacuum Gages (30050S)}

Instruments requiring special calibration procedures or prolonged testing can often be accommodated as a special test. Please call for additional information.

\section{Leaks (30060S-30062C)}

Leak artifacts are calibrated in the range $1 \times 10^{-6} \mathrm{~mol} / \mathrm{s}$ to $1 \times 10^{-13} \mathrm{~mol} / \mathrm{s}$ $\left(2 \times 10^{-2}\right.$ std. $\mathrm{cm}^{3} / \mathrm{s}$ to $2 \times 10^{-9}$ std. $\mathrm{cm}^{3} / \mathrm{s}$ at $0{ }^{\circ} \mathrm{C}$ ). Flow rates are quoted at standard conditions for leak measurements of $\mathrm{P}=101325 \mathrm{~Pa}$ and $\mathrm{T}=0{ }^{\circ} \mathrm{C}$. When referenced to the specific temperature, std. $\mathrm{cm}^{3} / \mathrm{s}$ can be converted to $\mathrm{mol} / \mathrm{s}$ by multiplying by $4.45 \times 10^{-5}$. The calibration can be performed directly by the NIST primary leak standard (30061C) which has a range-dependent relative expanded uncertainty** between $0.2 \%$ and $4.5 \%$. For a lower fee, helium leak artifacts in the range $1 \times 10^{-9} \mathrm{~mol} / \mathrm{s}$ to

* 2.75 in Conflat flange is an industrial designation for connectors.

** See Chapter 1, Section H for more information about uncertainty.
$1 \times 10^{-13} \mathrm{~mol} / \mathrm{s}$ may be calibrated $\left(2 \times 10^{-5} \mathrm{std} . \mathrm{cm}^{3} / \mathrm{s}\right.$ to $2 \times 10^{-4} \mathrm{std} . \mathrm{cm}^{3} / \mathrm{s}$ at $0^{\circ} \mathrm{C}$ ) on a comparison system with respect to NIST-calibrated reference leaks $(30062 \mathrm{C})$. In both cases, the temperature dependence of the leak is measured and the Report of Calibration will include tabulated leak rates at $1{ }^{\circ} \mathrm{C}$ intervals from $0{ }^{\circ} \mathrm{C}$ to $50^{\circ} \mathrm{C}$. All leak artifacts submitted for measurement must be ultrahigh vacuum compatible and clean. The vacuum connection must have a standard 2.75 in "Conflat" type flange or $1 / 4$ in VCR type fitting (30061C). An easily observable customer identification number or code must be engraved on the circumference of the vacuum flange or reservoir. By special arrangement (30060S), leaks can be calibrated with gases other than helium, such as argon and common refrigerants. Leaks can also be calibrated as a function of reservoir pressure. Calibrations using the NIST primary leak standard are performed once a year, usually in January. Comparison calibrations are performed throughout the year. Please call for further information.

\section{Special Tests of Low-Gas-Flow Instruments (30063S)}

High precision low-gas-flow instruments are calibrated in the range of $\left(10^{-8}\right.$ to $\left.10^{-3}\right) \mathrm{mol} / \mathrm{s}$ with inert gases and other gases by special arrangement. The calibration is performed by direct comparison to a NIST primary flow standard and can be accomplished with down stream pressures ranging from $10 \mathrm{~Pa}$ (vacuum) to $300 \mathrm{kPa}$. The relative expanded uncertainties* in the measured flow are range dependent and vary from $0.05 \%$ at a flow of $10^{-3} \mathrm{~mol} / \mathrm{s}$ to $0.1 \%$ at a flow of $10^{-8} \mathrm{~mol} / \mathrm{s}$. Gas flows higher than $10^{-3} \mathrm{~mol} / \mathrm{s}$ are described under Service ID Numbers $18010 \mathrm{C}$ and $18050 \mathrm{~S}$. On-site proficiency tests may also be accomplished by special arrangement. 


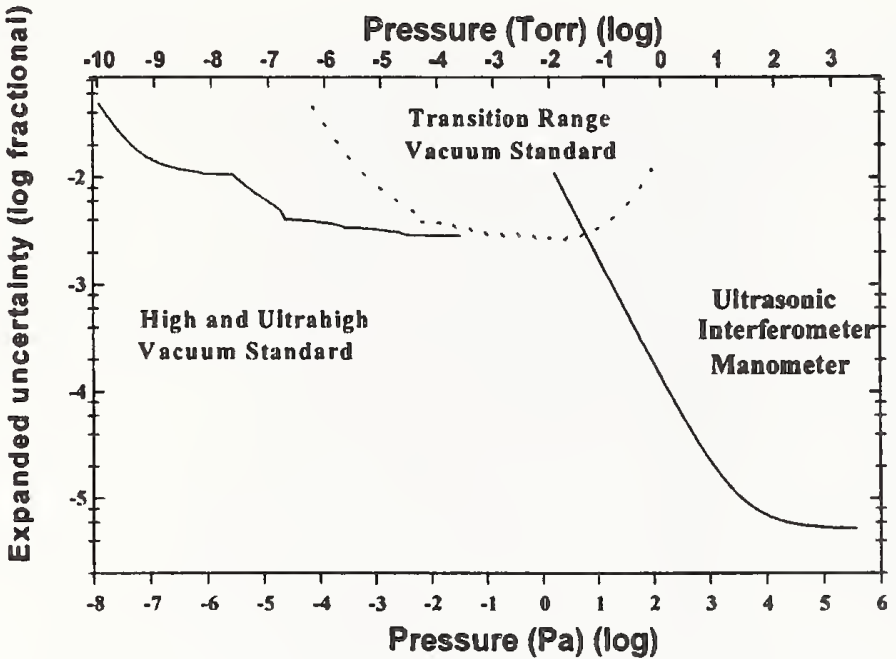

Figure 6.1. Uncertainties of the NIST Low-Pressure and Vacuum Standards.

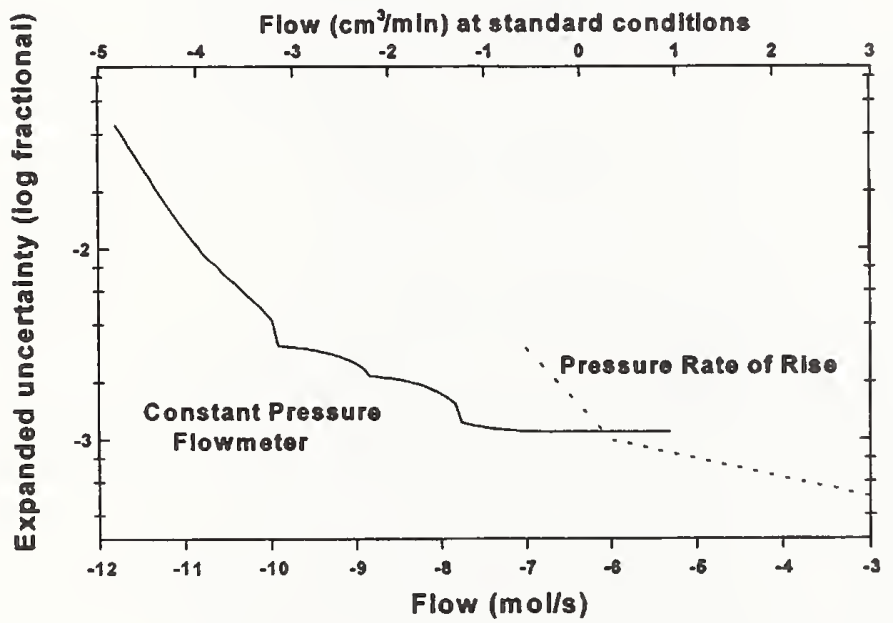

Figure 6.2. Uncertainties of the NIST Leak and LowGas- Flow Standards.

\section{References-Low Pressure}

Development of a Low DifferentialPressure Standard, C. R. Tilford and A. P. Miiller, Proc. Natl. Conf. Stand. Lab. Ann. Workshop and Symp. (1997)
Measurement Performance of Capacitance Diaphragm Gages and Alternative Low-Pressure Transducers, A. P. Miiller, Proc. Natl. Conf. Stand. Lab. Ann. Workshop and Symp. (1997).

Pressure and Vacuum Measurements, C. R. Tilford, Chapter 2 in Volume VI of Physical Methods of Chemistry, W. Rossiter, J. F. Hamilton, and R. C. Baetzold, ed., John Wiley \& Sons, New York (1992).

The NBS Ultrasonic Interferometer Manometer and Studies of Gas Operated Piston Gages, C. R. Tilford and R. W. Hyland, Metrology, Proc. 11th Triennial World Congress of the International Measurementation Confederation (IMEKO), Houston, TX, 16-21 Oct. 1988, W. C. Rutledge, ed. (Instrum. Soc. of America), Res. Triangle Park, NC (1988) p. 277.

New Developments In Barometric Range Pressure Standards, C. R. Tilford, Proc. 1988 Natl. Conf. Stand. Lab. Workshop and Symp. pp. 35-1 to 3515 (1988).

The Speed of Sound in a Mercury Ultrasonic Interferometer Manometer, C. R. Tilford, Metrologia 24, 121 (1987).

Zero Stability and Calibration Results for a Group of Capacitance Diaphragm Gages, R. W. Hyland and C. R. Tilford, J. Vac. Sci. Technol. A 3, 1731 (1985).

Ultrasonic Manometers for Low and Medium Vacua Under Development at NBS, P. L. M. Heydemann, C. R. Tilford, and R. W. Hyland, J. Vac. Sci. Technol. 14, 597 (Jan.-Feb. 1977).

\section{References-Vacuum}

Comparison of the standards for high and ultrahigh vacuum at NIST, NPL, and PTB, K. Jousten, A. R. Filippelli, C. R. Tilford, and F. J. Redgrave, J. Vac. Sci. Technol. A 15, 1 (1997)

Comments on the stability of BayardAlpert ionization gages, C. R. Tilford, A. R. Filippelli, and P. J. Abbott, J. Vac. Sci. Technol. A 13, 485 (1995). 
Long-term stability of Bayard-Alpert gage performance: Results obtained from repeated calibrations against the NIST primary vacuum standard, A. R. Filippelli, and P. J. Abbott, J. Vac. Sci. Technol. A 13, 2582 (1995)

Influence of the filament potential wave form on the sensitivity of glass-envelope Bayard-Alpert gages, P. J. Abbott and J. P. Looney, J. Vac. Sci. Technol. A 12, 542 (1994)

PC-based spinning rotor gage controller, J. P. Looney, F. G. Long, D. F. Browning and C.R. Tilford, Rev. Sci. Instr. 65 (9), 3012 (1994)

Behavior of commercial spinning rotor gages in the transition regime, $\mathrm{J}$. Setina, and J. P. Looney, Vacuum 44, 577 (1993).

NIST Measurement Services: High Vacuum Standard and Its Use, S. Dittmann, Natl. Inst. Stand. Technol. Spec. Publ. 250-34 (1989).

The National Bureau of Standards Primary High-Vacuum Standard, C. R. Tilford, S. Dittmann, and K. E. McCulloh, J. Vac. Sci. Technol. A 6, 2853 (1988).

Low-Range Flowmeters for Use with Vacuum and Leak Standards, K. E. McCulloh, C. R. Tilford, C. D. Ehrlich, and F. G. Long, J. Vac. Sci. Technol. A 5, 376 (1987).
Long-Term Stability of Two Types of Hot Cathode Ionization Gages, S. D. Wood and C. R. Tilford, J. Vac. Sci. Technol. A 3, 542 (1985).

Sensitivity of Hot Cathode Ionization Gages, C. R. Tilford, J. Vac. Sci. Technol. A 3, 546 (1985).

\section{References-Leaks and Low-Flow}

A critical evaluation of thermal mass flow meters, S. A. Tison, J. Vac. Sci. Technol. A 14, 2582 (1996)

Commercial helium permeation leak standards: Their properties and reliability, P. J. Abbott, and S. A. Tison, J. Vac. Sci. Technol. 14 (May-June 1996)

Using Characterized Variable Reservoir Helium Permeation Leaks to Generate Low Flows, S. A. Tison and P. Mohan, J. Vac. Sci. Technol. A 12, 564 (1994).

Experimental Data and Theoretical Modeling of Gas Flow Through Metal Capillary Leaks, S. A. Tison, Vacuum 44, 1171 (1993).

Transfer Leak Studies and Comparisons of Primary Leak Standards at the National Bureau of Standards and Sandia National Laboratories, R. W. Hyland, C. D. Ehrlich, and C. R. Tilford, J. Vac. Sci. Technol. A 4, 334 (1986).

A Note on Flow Rate and Leak Rate Units, C. D. Ehrlich, J. Vac. Sci. Technol. A 4, 2384 (1986). 


\section{Laboratory and Industrial-Grade Thermometers*}

\section{Technical Contact:}

C. Dawn Vaughn

Tel: 301/975-4822

Email: c.vaughn@nist.gov

Mailing Address: Building 221, Room B128,

National Institute of Standards and Technology,

Gaithersburg, MD 20899-0001

\section{Shipping Address:}

National Institute of Standards and Technology,

I-270 at Quince Orchard Rd.,

Building 221, Room B241,

[Attn: C. Dawn Vaughn, ext. 4822]

Gaithersburg, MD 20899-0001

Note: The minimum number of test points per thermometer is two. Fahrenheit ranges are not direct conversions of the Celsius ranges.

\begin{tabular}{|c|c|}
\hline $\begin{array}{l}\text { Service } \\
\text { ID No. }\end{array}$ & Items \\
\hline $31010 \mathrm{C}$ & $\begin{array}{l}\text { Laboratory Thermometers }\left(0^{\circ} \mathrm{C} \text { to } 150^{\circ} \mathrm{C}\right) \\
\left(32^{\circ} \mathrm{F} \text { to } 300^{\circ} \mathrm{F}\right)\end{array}$ \\
\hline $31020 \mathrm{C}$ & $\begin{array}{l}\text { Laboratory Thermometers }\left(151^{\circ} \mathrm{C} \text { to } 315^{\circ} \mathrm{C}\right) \\
\left(300^{\circ} \mathrm{F} \text { to } 600^{\circ} \mathrm{F}\right)\end{array}$ \\
\hline $31030 \mathrm{C}$ & $\begin{array}{l}\text { Laboratory Thermometers }\left(316^{\circ} \mathrm{C} \text { to } 550^{\circ} \mathrm{C}\right) \\
\left(600^{\circ} \mathrm{F} \text { to } 1022^{\circ} \mathrm{F}\right)\end{array}$ \\
\hline $31040 \mathrm{C}$ & $\begin{array}{l}\text { Laboratory Thermometers }\left(-1{ }^{\circ} \mathrm{C} \text { to }-110^{\circ} \mathrm{C}\right) \\
\left(31^{\circ} \mathrm{F} \text { to }-166^{\circ} \mathrm{F}\right)\end{array}$ \\
\hline $31050 \mathrm{C}$ & $\begin{array}{l}\text { Laboratory Thermometers (Liquid } \mathrm{N}_{2} \text { ) } \\
\left(-196^{\circ} \mathrm{C} \text { or }-321^{\circ} \mathrm{F}\right)\end{array}$ \\
\hline $31100 \mathrm{C}$ & Quantity Tests of Liquid-in-Glass Thermometers \\
\hline $31110 \mathrm{~S}$ & $\begin{array}{l}\text { Special Tests of Industrial Platinum Resistance } \\
\text { Thermometers, Thermistor Thermometers, Digital } \\
\text { Thermometers, and Other Types of Thermometers } \\
\left(0^{\circ} \mathrm{C} \text { to } 150^{\circ} \mathrm{C}\right)\left(32^{\circ} \mathrm{F} \text { to } 300^{\circ} \mathrm{F}\right)\end{array}$ \\
\hline $31120 \mathrm{~S}$ & $\begin{array}{l}\text { Special Tests of Industrial Platinum Resistance } \\
\text { Thermometers, Thermistor Thermometers, Digital } \\
\text { Thermometers, and Other Types of Thermometers } \\
\left(151^{\circ} \mathrm{C} \text { to } 315^{\circ} \mathrm{C}\right)\left(301{ }^{\circ} \mathrm{F} \text { to } 600{ }^{\circ} \mathrm{F}\right)\end{array}$ \\
\hline $31130 \mathrm{~S}$ & $\begin{array}{l}\text { Special Tests of Industrial Platinum Resistance } \\
\text { Thermometers, Thermistor Thermometers, Digital } \\
\text { Thermometers, and Other Types of Thermometers } \\
\left(316^{\circ} \mathrm{C} \text { to } 550^{\circ} \mathrm{C}\right)\left(601{ }^{\circ} \mathrm{F} \text { to } 1022^{\circ} \mathrm{F}\right)\end{array}$ \\
\hline $31140 \mathrm{~S}$ & $\begin{array}{l}\text { Special Tests of Industrial Platinum Resistance } \\
\text { Thermometers, Thermistor Thermometers, Digital } \\
\text { Thermometers, and Other Types of Thermometers } \\
\left(-1{ }^{\circ} \mathrm{C} \text { to }-110^{\circ} \mathrm{C}\right)\left(31^{\circ} \mathrm{F} \text { to }-166^{\circ} \mathrm{F}\right)\end{array}$ \\
\hline
\end{tabular}

* See Chapter 1, Section C for information on other thermodynamic property measurement standards available from the Standard Reference Materials Program.
Service

ID No.

Items

$31150 \mathrm{~S}$ Special Tests of Industrial Platinum Resistance Thermometers, Thermistor Thermometers, Digital Thermometers, and Other Types of Thermometers (Liquid $\left.\mathrm{N}_{2}\right)\left(-196^{\circ} \mathrm{C}\right.$ or $\left.-321^{\circ} \mathrm{F}\right)$

$31170 \mathrm{~S}$ Special Tests of Calorimetric Thermometers

31180 S Special Tests of Beckmann Thermometers

31200 S Preliminary Examination of Ineligible Thermometer

31250S Additional Copy of Report

31260 S Special Thermometry Services, by Prearrangement

\section{Laboratory Thermometers (31010C-31100C)}

This service provides for the calibration of a variety of thermometers covering the range from $-196^{\circ} \mathrm{C}$ to $+550{ }^{\circ} \mathrm{C}$ $\left(-321^{\circ} \mathrm{F}\right.$ to $\left.+1022^{\circ} \mathrm{F}\right)$.

Thermometers belonging to the large and varied group which may be classified as laboratory, or "chemical," thermometers are regularly accepted. These are of the liquid-in-glass type with either solid-stem or enclosed scale. Ordinary household or meteorological thermometers will not, in general, be accepted unless the scale is graduated on the glass stem itself and the thermometer can be readily detached from its mounting for insertion in a liquid bath. Every thermometer submitted must be uniquely identified by a serial number and must pass a preliminary examination for fineness and uniformity of graduation; for cleanliness of the mercury and the capillary bore; for freedom from moisture, gas bubbles, and cracks in the glass; for adequacy or omission of gas filling where needed; for insufficient annealing; and, for misnumbered graduations. When these or other serious defects are found, the thermometer is returned untested.

The thermometers to be calibrated are placed in a constant temperature bath along with a NIST-calibrated standard platinum resistance thermometer (SPRT). The SPRT maintains calibrations traceable to the International Temperature Scale of 1990 (ITS-90), with a maximum expanded uncertainty** of $0.7 \mathrm{mK}$. (See Table 6.2 )

\footnotetext{
** See Chapter 1, Section H for more information about uncertainty.
} 
Table 6.2. Calibration Uncertainties for Total Immersion Thermometers

\begin{tabular}{lcc} 
Type of Thermometer & $\begin{array}{c}\text { Range } \\
\left({ }^{\circ} \mathrm{C}\right)\end{array}$ & $\begin{array}{c}\text { Expanded } \\
\text { Uncertainty* } \\
\left({ }^{\circ} \mathrm{C}\right)\end{array}$ \\
\hline $\begin{array}{l}\text { Mercury-in-glass } \\
\left.\text { (graduations: } 0.1{ }^{\circ} \mathrm{C} \text { or } 0.2{ }^{\circ} \mathrm{C}\right)\end{array}$ & 0 to 100 & 0.024 \\
$\begin{array}{l}\text { Mercury-in-glass } \\
\left.\text { (graduations: } 1{ }^{\circ} \mathrm{C} \text { or } 2{ }^{\circ} \mathrm{C}\right)\end{array}$ & $\begin{array}{r}0 \text { to } 300 \\
300 \text { to } 550\end{array}$ & $\begin{array}{r}0.5 \text { to } 0.1 \\
0.16 \text { to } 0.3\end{array}$ \\
Organic liquid-in-glass & -200 to 0 & 0.2 to 0.5 \\
\hline
\end{tabular}

* See Chapter 1, Section H for more information about uncertainty.

\section{Special Tests of Thermometers (31110S-31150S)}

Special tests may be conducted on temperature-measuring devices such as industrial grade platinum resistance thermometers, digital thermometers, and thermistors. Laboratory personnel should be consulted before submitting items.

\section{References-Laboratory and Industrial-Grade Thermometers}

ASTM Standard E 1, Standard Specification for ASTM Thermometers, Annual Book of ASTM Standards 14.03, p. 1, Amer. Soc. for Test. and Matls., Philadelphia, PA (1996).
ASTM Standard E 77, Standard Test Method for Inspection and Verification of Thermometers, Annual Book of ASTM Standards 14.03, p. 61, Amer. Soc. for Test. and Matls., Philadelphia, PA (1996).

A Procedure for the Effective Recalibration of Liquid-in-Glass Thermometers, J. A. Wise, Natl. Inst. Stand. Technol. Spec. Publ. 819 (Aug. 1991).

Assessment of Uncertainties of Liquidin-Glass Thermometer Calibrations at the National Institute of Standards and Technology, J. A. Wise, NISTIR 5341 (Jan. 1994).

The International Temperature Scale of 1990 (ITS-90), H. Preston-Thomas, Metrologia 27, 3-10 (1990); Metrologia 27, 107 (1990).

NIST Measurement Services: Liquidin-Glass Thermometer Calibration Service, J. A. Wise, Natl. Inst. Stand. Technol. Spec. Publ. 250-23 (Sept. 1988).

Thermometer Calibration: A Model for State Calibration Laboratories, J. A. Wise, and R. J. Soulen, Natl. Bur. Stand. (U.S.), Monogr. 174 (Jan. 1986). 


\section{Thermocouples, Thermocouple Materials, and Thermometer Indicators**}

\section{Technical Contacts:}

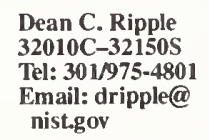

\author{
Karen Garrity \\ 32010C-32101C, 32150S \\ Tel: $301 / 975-4818$ \\ Email: kgarrity@
}

C. Dawn Vaughn 32110C-32147C Email: craughn@

nist.gov Tel: $301 / 975-4822$

Mailing Address: Building 221, Room B128, National Institute of Standards and Technology,

Gaithersburg, MD 20899-0001

\section{Shipping Address:}

National Institute of Standards and Technology,

I-270 at Quince Orchard Road,

[For: 32010C-32101C, 32150S; Attn: D. C. Ripple or K. Garrity, Bldg. 221, Room B229]

[For: 32110C-32147C; Attn: C. D. Vaughn or

D. C. Ripple, Bldg. 221, Room B241]

Gaithersburg, MD 20899-0001

Comparison Calibrations, Temperature Measured with Thermocouple (TC):

\begin{tabular}{|c|c|c|c|c|c|c|}
\hline $\begin{array}{l}\text { Ser- } \\
\text { vice } \\
\text { ID } \\
\text { No. }\end{array}$ & $\begin{array}{l}\text { TC } \\
\text { Type }\end{array}$ & $\begin{array}{l}\text { Temp. } \\
\text { Range } \\
\left({ }^{\circ} \mathrm{C}\right)\end{array}$ & Points & $\begin{array}{c}\text { Min. } \\
\text { Length } \\
(\mathrm{mm})\end{array}$ & $\begin{array}{c}\mathrm{E} \\
\text { Temp. }\end{array}$ & $\begin{array}{l}\text { Expanded } \\
\text { Uncert.* } \\
\left({ }^{\circ} \mathrm{C}\right)\end{array}$ \\
\hline $32010 \mathrm{C}$ & $\mathrm{S}$ & 0 to 1450 & $\begin{array}{l}1^{\circ} \text { or } 1^{\circ} \mathrm{F} \\
\text { Interv. Table }\end{array}$ & 700 & $\begin{array}{r}0 \text { to } \begin{array}{r}1100 \\
1450\end{array}\end{array}$ & $\begin{array}{l}0.3 \\
1.6\end{array}$ \\
\hline $32020 \mathrm{C}$ & $R$ & 0 to 1450 & , , , , & 700 & $\begin{array}{r}0 \text { to } 600 \\
1450\end{array}$ & $\begin{array}{l}0.5 \\
1.6\end{array}$ \\
\hline $32030 \mathrm{C}$ & $B$ & 0 to 1750 & $, \quad, \quad$, & 1000 & $\begin{array}{r}0 \text { to } 800 \\
800 \text { to } 1100 \\
1450 \\
1750\end{array}$ & $\begin{array}{c}(3 \mu \mathrm{V}) \\
0.3 \\
1.6 \\
2.4\end{array}$ \\
\hline $32031 \mathrm{C}$ & $B$ & 800 to 1750 & , , , , & 1000 & $\begin{array}{r}800 \text { to } 1100 \\
1450 \\
1750\end{array}$ & $\begin{array}{l}0.6 \\
1.6 \\
2.4\end{array}$ \\
\hline $32040 \mathrm{C}$ & E & 0 to 1000 & 4 to 15 & 700 & 0 to 1000 & 0.9 \\
\hline $32041 \mathrm{C}$ & $J$ & 0 to 760 & 4 to 15 & 700 & 0 to 760 & 0.7 \\
\hline
\end{tabular}

* See Chapter 1, Section H for more information about uncertainty.

** See Chapter 1, Section C for contact information on the Standard Reference Materials Program, which has thermocouple materials and other temperature standards available for sale.
Comparison Calibrations, Temperature Measured with Thermocouple-Continued:

\begin{tabular}{|c|c|c|c|c|c|c|}
\hline $\begin{array}{l}\text { Ser- } \\
\text { vice } \\
\text { ID } \\
\text { No. }\end{array}$ & $\begin{array}{l}\text { TC } \\
\text { Type }\end{array}$ & $\begin{array}{l}\text { Temp. } \\
\text { Range } \\
\left({ }^{\circ} \mathrm{C}\right)\end{array}$ & Points & $\begin{array}{l}\text { Min. } \\
\text { Length } \\
(\mathrm{mm})\end{array}$ & $\begin{array}{l}\text { Temp. } \\
\left({ }^{\circ} \mathrm{C}\right)\end{array}$ & $\begin{array}{l}\text { Expanded } \\
\text { Uncert.* } \\
\left({ }^{\circ} \mathrm{C}\right)\end{array}$ \\
\hline $32042 C$ & $\mathrm{~K}$ & 0 to 1100 & 4 to 15 & 700 & 0 to 1100 & 1 \\
\hline $32043 \mathrm{C}$ & $\mathrm{N}$ & 0 to 1100 & 4 to 15 & 700 & 0 to 1100 & 1 \\
\hline $32044 C$ & $\mathrm{~T}$ & 0 to 400 & 4 to 15 & 700 & 0 to 400 & 0.4 \\
\hline $32050 \mathrm{C}$ & \multicolumn{6}{|c|}{$\begin{array}{l}\text { Comparison calibration, } 2 \text { point minimum, per point, for all } \\
\text { items above }\end{array}$} \\
\hline $32060 \mathrm{C}$ & \multicolumn{6}{|c|}{$\begin{array}{l}\text { Each additional table of results at } 1^{\circ} \mathrm{C} \text { or } l^{\circ} \mathrm{F} \text { intervals, for } \\
\text { Type S, R, or B at later date }\end{array}$} \\
\hline $32061 \mathrm{C}$ & \multicolumn{6}{|c|}{$\begin{array}{l}\text { Each additional table of results at } 1{ }^{\circ} \mathrm{C} \text { or } 1{ }^{\circ} \mathrm{F} \text { intervals, for } \\
\text { Type } \mathrm{S}, \mathrm{R} \text {, or } \mathrm{B} \text { at time of test }\end{array}$} \\
\hline $32070 \mathrm{C}$ & \multicolumn{6}{|c|}{$\begin{array}{l}\text { Thermocouple materials tested against Pt thermoelectric } \\
\text { standard, } 4 \text { to } 15 \text { points, } 700 \mathrm{~mm} \text { minimum lengths }\end{array}$} \\
\hline
\end{tabular}

* See Chapter 1, Section H for more information about uncertainty.

Calibration at Metal Freezing Points, Minimum TC Wire Diameter $0.4 \mathrm{~mm}$, Freezing Point Determination at $\mathrm{Au}, \mathrm{Ag}$, Al and $\mathrm{Zn}$

\begin{tabular}{|c|c|c|c|c|c|c|}
\hline $\begin{array}{l}\text { Ser- } \\
\text { vice } \\
\text { ID } \\
\text { No. }\end{array}$ & $\begin{array}{l}\text { TC } \\
\text { Type }\end{array}$ & $\begin{array}{l}\text { Temp. } \\
\text { Range } \\
\left({ }^{\circ} \mathrm{C}\right)\end{array}$ & Points & $\begin{array}{c}\text { Length } \\
(\mathrm{mm})\end{array}$ & $\begin{array}{l}\text { Temp. } \\
\left({ }^{\circ} \mathrm{C}\right)\end{array}$ & $\begin{array}{c}\text { Ex- } \\
\text { panded } \\
\text { Uncert.* } \\
\left({ }^{\circ} \mathrm{C}\right)\end{array}$ \\
\hline $32090 \mathrm{C}$ & $\begin{array}{r}\mathrm{S} \\
\text { or } \mathrm{R}\end{array}$ & 0 to 1450 & $\begin{array}{l}\text { Table, } 1{ }^{\circ} \mathrm{C} \text { or } \\
1^{\circ} \mathrm{F} \text { interv. and } \\
\text { equations to } \\
\text { generate table }\end{array}$ & 1000 & $\begin{array}{l}\text { at freezin } \\
\text { points } \\
0 \text { to } 1100 \\
1450\end{array}$ & $\begin{array}{l}0.1 \\
0.1 \\
1.6\end{array}$ \\
\hline
\end{tabular}

32091C Type S or T, freezing point determination, per point, 2 point minimum

* See Chapter 1, Section $\mathrm{H}$ for more information about uncertainty.

Calibration of Digital Thermometer Indicator or Portable Potentiometer

\begin{tabular}{ll}
$\begin{array}{l}\text { Service } \\
\text { ID No. }\end{array}$ & Items \\
\hline $32100 \mathrm{C}$ & Indicator or Potentiometer, first dial or range \\
$32101 \mathrm{C}$ & Indicator or Potentiometer, each additional dial or range
\end{tabular}


Comparison Calibration of Thermocouples or

Thermocouple Materials Tested against Pt

Thermoelectric Standard, Temperature Measured with Platinum Resistance Thermometer, Minimum TC Wire Length $1.0 \mathrm{~m}, 2$ Point Minimum

Service

ID No. Items

$32110 \mathrm{C}$ Range $-110^{\circ} \mathrm{C}$ to $+315^{\circ} \mathrm{C}$ and Liquid $\mathrm{N}_{2}\left(-196^{\circ} \mathrm{C}\right)$ or $-166^{\circ} \mathrm{F}$ to $600{ }^{\circ} \mathrm{F}$ and Liquid $\mathrm{N}_{2}\left(-321^{\circ} \mathrm{F}\right)$, Expanded Uncertainty* $0.4{ }^{\circ} \mathrm{C}$

$32120 \mathrm{C} \quad 316^{\circ} \mathrm{C}$ to $550{ }^{\circ} \mathrm{C}$ or $601{ }^{\circ} \mathrm{F}$ to $1022^{\circ} \mathrm{F}$, Expanded Uncertainty* $0.5^{\circ} \mathrm{C}$

Table at one degree intervals for Type T thermocouple for any of the following options:

(The cost of the table will be in addition to the calibration per point covered under fee schedule service ID numbers $32110 \mathrm{C}-32120 \mathrm{C}$.)

$32141 \mathrm{C}$ Option 1: Table from $-190^{\circ} \mathrm{C}$ to $+300^{\circ} \mathrm{C}$ $\left(-321^{\circ} \mathrm{F}\right.$ to $\left.+572{ }^{\circ} \mathrm{F}\right)$, calibration points at $(-196$, $-110,-50,+100,+200,+300)^{\circ} \mathrm{C}$

$32142 \mathrm{C}$ Option 2: Table from $-190^{\circ} \mathrm{C}$ to $+100^{\circ} \mathrm{C}$

$\left(-321^{\circ} \mathrm{F}\right.$ to $\left.+212^{\circ} \mathrm{F}\right)$, calibration points at $(-196$, $-110,-50,+50,+100)^{\circ} \mathrm{C}$

32143C Option 3: Table from $-110^{\circ} \mathrm{C}$ to $+300^{\circ} \mathrm{C}$ $\left(-166^{\circ} \mathrm{F}\right.$ to $\left.+572^{\circ} \mathrm{F}\right)$, calibration points at $(-110$, $-50,+100,+200,+300){ }^{\circ} \mathrm{C}$

$32144 \mathrm{C}$ Option 4: Table from $-110^{\circ} \mathrm{C}$ to $+100^{\circ} \mathrm{C}$ $\left(-166^{\circ} \mathrm{F}\right.$ to $\left.+212^{\circ} \mathrm{F}\right)$, calibration points at $(-110,-50$, $+50,+100)^{\circ} \mathrm{C}$

$32145 \mathrm{C}$ Option 5: Table from $0{ }^{\circ} \mathrm{C}$ to $300^{\circ} \mathrm{C}\left(32^{\circ} \mathrm{F}\right.$ to $\left.572{ }^{\circ} \mathrm{F}\right)$, calibration points at $(+100,+200,+300){ }^{\circ} \mathrm{C}$

32146C Option 6: Table from $-110^{\circ} \mathrm{C}$ to $0{ }^{\circ} \mathrm{C}\left(-166^{\circ} \mathrm{F}\right.$ to $\left.+32{ }^{\circ} \mathrm{F}\right)$, calibration points at $(-110,-50){ }^{\circ} \mathrm{C}$.

$32147 \mathrm{C}$ Option 7: Table from $-196^{\circ} \mathrm{C}$ to $0^{\circ} \mathrm{C}\left(-321^{\circ} \mathrm{F}\right.$ to $\left.+32{ }^{\circ} \mathrm{F}\right)$, calibration points at $(-196,-110,-50){ }^{\circ} \mathrm{C}$

$32150 \mathrm{~S}$ Special Tests of Thermocouples and Thermocouple Materials

Note: Due to the extra time involved in calibrating sheathed thermocouples, a surcharge of $20 \%$ of the cost of calibrating bare-wire thermocouples will be added to the relevant fees listed for the above.

* See Chapter 1, Section H for more information about uncertainty.
Thermocouples, Thermocouple

Materials and Thermometer Indicators (32010C-32147C)

Calibration services for all commonly used types of thermocouples are provided by NIST from $-196^{\circ} \mathrm{C}$ to $1750{ }^{\circ} \mathrm{C}$ depending upon the wire or thermocouple type. The thermocouples are calibrated by one or a combination of three general methods, depending on the thermocouple type, the temperature range, and the uncertainty required. All three methods provide traceability to the ITS-90. In the first method, thermocouples are calibrated by comparison with a reference thermocouple maintained at NIST. In the second method, thermocouples are calibrated by comparison with a standard platinum resistance thermometer. In the third method, thermocouples are calibrated at four defining fixed-point temperatures on the ITS-90: the freezing points of $\mathrm{Zn}, \mathrm{Al}, \mathrm{Ag}$, and $\mathrm{Au}$. Below $0{ }^{\circ} \mathrm{C}$, the thermocouple calibration is performed in a cryostat; above $0{ }^{\circ} \mathrm{C}$, stirred liquid baths, metal freezingpoint cells, and electric tube-type furnaces are employed for the calibrations. Vacuum or inert gas furnaces are also available for testing thermocouples.

Only the bare wires are required to perform the thermocouple calibrations. It is preferable not to send insulating and protecting tubes as the rate of breakage of these in shipment is high. If the thermocouple is furnished mounted (as in a protection tube assembly), a nominal charge will be made for dismantling the mounting and the various parts will be returned to the sender without reassembling them. Minimum thermocouple length requirements listed in the Service ID Number tables are exclusive of lead wire. Lead wires (for connections) should not be sent with thermocouples. All thermocouple calibration data furnished in reports will be on the basis of a reference junction temperature of $0^{\circ} \mathrm{C}\left(32^{\circ} \mathrm{F}\right)$. The calibration results will be given in ${ }^{\circ} \mathrm{C}$ or ${ }^{\circ} \mathrm{F}$, as requested by the customer.

The calibration of a thermocouple will not be undertaken if it will likely not 
yield the specified expanded uncertainty* or if it possesses unusual characteristics that would prevent the performance of the calibration or test at a reasonable cost. Only unused base-metal thermocouples and thermocouple materials will be accepted for test.

All uncertainties are expressed as expanded uncertainties* and vary with test temperature. In cases where a range of temperatures is given, the stated expanded uncertainty is the maximum of the expanded uncertainties over this range of temperatures.

\section{Special Tests of Thermocouples and Thermocouple Materials (32150S)}

For requirements not covered by calibrations described above, special arrangements may be made by consulting one of the specified staff members.

\section{References-Thermocouples}

ASTM Standard E 220-86(96), Standard Method for Calibration of Thermocouples by Comparison Techniques, Annual Book of ASTM Standards 14.03, 94, Amer. Soc. for Test. and Matls., Philadelphia, PA (1997).

ASTM Standard E 230-96, Standard Specification and Temperature-Electromotive Force (EMF) Tables for Standardized Thermocouples, Annual Book of ASTM Standards 14.03, 106, Amer. Soc. for Test. and Matls., Philadelphia, PA (1997).
* See Chapter 1, Section H for more information about uncertainty.
ASTM Standard E 1751-95, Standard Guide for Temperature Electromotive Force (EMF) Tables for Non-Letter Designated Thermocouple Combinations, Annual Book of ASTM Standards 14.03, 456, Amer. Soc. For Test. And Matls., Philadelphia, PA (1996).

International Electrotechnical Commission Standard, Thermocouples, Part I: Reference Tables, IEC Publication 5841, Intl. Electrotech. Com., Geneva (1994).

Assessment of Uncertainties of Thermocouple Calibrations at NIST, D. Ripple, G. W. Burns, and M. G. Scroger, NISTIR 5340 (1994).

Manual on the Use of Thermocouples in Temperature Measurement, ASTM MNL 12, Amer. Soc. for Test. and Matls., Philadelphia, PA (1993).

Temperature-Electromotive Force Reference Functions and Tables for the Letter-Designated Thermocouple Types Based on the ITS-90, G. W. Burns, M. G. Scroger, G. F. Strouse, M. C. Croarkin, and W. F. Guthrie, Natl. Inst. Stand. Technol. Mongr. 175 (1993).

The International Temperature Scale of 1990 (ITS-90), H. Preston-Thomas, Metrologia 27, 3-10 (1990), Metrologia 27, 107 (1990).

NIST Measurement Services: The Calibration of Thermocouple and Thermocouple Materials, G. W. Burns and M. G. Scroger, Natl. Inst. Stand. Technol. Spec. Publ. 250-35 (April 1989). 


\section{Resistance Thermometry}

\section{Technical Contacts:}

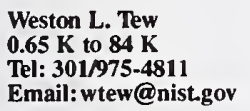

\author{
Gregory F. Strouse \\ $83 \mathrm{~K}$ to $962^{\circ} \mathrm{C}$ \\ Tel: 301/975-4803 \\ Email:gstrouse@nist.gov
}

Mailing Address: Building 221, Room B128, National Institute of Standards and Technology,

Gaithersburg, MD 20899-0001

\section{Shipping Address:}

National Institute of Standards and Technology, I-270 at Quince Orchard Road,

Building 221, Room B04,

[Attn: W. L. Tew or G. F. Strouse]

Gaithersburg, MD 20899-0001

\begin{tabular}{|c|c|}
\hline $\begin{array}{l}\text { Service } \\
\text { ID No. }\end{array}$ & Items \\
\hline $33010 \mathrm{C}$ & Capsule SPRT $\left(13.8 \mathrm{~K}\right.$ to $30^{\circ} \mathrm{C}$ ) $\mathrm{H}_{2}$ to $\mathrm{Ga}$ \\
\hline $33020 \mathrm{C}$ & Capsule SPRT $\left(13.8 \mathrm{~K}\right.$ to $\left.157^{\circ} \mathrm{C}\right) \mathrm{H}_{2}$ to In \\
\hline $33030 \mathrm{C}$ & Capsule SPRT (13.8 K to $232{ }^{\circ} \mathrm{C}$ ) $\mathrm{H}_{2}$ to $\mathrm{S}_{\mathrm{n}}$ \\
\hline $33031 \mathrm{C}$ & Capsule SPRT $\left(24.5 \mathrm{~K}\right.$ to $\left.30^{\circ} \mathrm{C}\right) \mathrm{Ne}$ to $\mathrm{Ga}$ \\
\hline $33032 \mathrm{C}$ & Capsule SPRT ( $24.5 \mathrm{~K}$ to $\left.157^{\circ} \mathrm{C}\right) \mathrm{Ne}$ to In \\
\hline $33033 \mathrm{C}$ & Capsule SPRT ( $24.5 \mathrm{~K}$ to $232^{\circ} \mathrm{C}$ ) Ne to $\mathrm{Sn}$ \\
\hline $33040 \mathrm{C}$ & Capsule SPRT $\left(54 \mathrm{~K}\right.$ to $30^{\circ} \mathrm{C}$ ) $\mathrm{O}_{2}$ to $\mathrm{Ga}$ \\
\hline $33050 \mathrm{C}$ & Capsule SPRT $\left(54 \mathrm{~K}\right.$ to $\left.157^{\circ} \mathrm{C}\right) \mathrm{O}_{2}$ to In \\
\hline $33060 \mathrm{C}$ & Capsule SPRT ( $54 \mathrm{~K}$ to $232^{\circ} \mathrm{C}$ ) $\mathrm{O}_{2}$ to $\mathrm{Sn}$ \\
\hline $33065 S$ & Capsule SPRT ( $83 \mathrm{~K}$ to $\left.0.01^{\circ} \mathrm{C}\right) \mathrm{Ar}$ to TPW \\
\hline $33070 \mathrm{C}$ & Capsule SPRT ( $83 \mathrm{~K}$ to $30^{\circ} \mathrm{C}$ ) Ar to $\mathrm{Ga}$ \\
\hline $33080 \mathrm{C}$ & Capsule SPRT $\left(83 \mathrm{~K}\right.$ to $\left.157^{\circ} \mathrm{C}\right) \mathrm{Ar}$ to In \\
\hline $33090 \mathrm{C}$ & Capsule SPRT ( $83 \mathrm{~K}$ to $232^{\circ} \mathrm{C}$ ) Ar to $\mathrm{Sn}$ \\
\hline $33100 \mathrm{C}$ & Capsule SPRT $\left(0^{\circ} \mathrm{C}\right.$ to $\left.30^{\circ} \mathrm{C}\right)$ TPW to $\mathrm{Ga}$ \\
\hline $33110 \mathrm{C}$ & Capsule SPRT $\left(0^{\circ} \mathrm{C}\right.$ to $\left.157^{\circ} \mathrm{C}\right) \mathrm{TPW}$ to In \\
\hline $33120 \mathrm{C}$ & Capsule SPRT $\left(0^{\circ} \mathrm{C}\right.$ to $\left.232^{\circ} \mathrm{C}\right) \mathrm{TPW}$ to $\mathrm{Sn}$ \\
\hline $33130 \mathrm{C}$ & Capsule SPRT ( $234 \mathrm{~K}$ to $30^{\circ} \mathrm{C}$ ) $\mathrm{Hg}$ to $\mathrm{Ga}$ \\
\hline $33140 \mathrm{C}$ & $\begin{array}{l}\text { Rhodium-Iron or Germanium Resistance } \\
\text { Thermometers }(0.65 \mathrm{~K} \text { to } 24.6 \mathrm{~K})\end{array}$ \\
\hline $33141 \mathrm{C}$ & $\begin{array}{l}\text { Rhodium-Iron or Germanium Resistance } \\
\text { Thermometers ( } 0.65 \mathrm{~K} \text { to } 84 \mathrm{~K} \text { ) }\end{array}$ \\
\hline $33150 \mathrm{C}$ & Long Stem SPRT ( $83 \mathrm{~K}$ to $0.01^{\circ} \mathrm{C}$ ) Ar to TPW \\
\hline $33160 \mathrm{C}$ & Long Stem SPRT ( $83 \mathrm{~K}$ to $30^{\circ} \mathrm{C}$ ) Ar to $\mathrm{Ga}$ \\
\hline $33170 \mathrm{C}$ & Long Stem SPRT ( $83 \mathrm{~K}$ to $157^{\circ} \mathrm{C}$ ) Ar to In \\
\hline $33180 \mathrm{C}$ & Long Stem SPRT ( $83 \mathrm{~K}$ to $232^{\circ} \mathrm{C}$ ) Ar to Sn \\
\hline $33190 \mathrm{C}$ & Long Stem SPRT ( $83 \mathrm{~K}$ to $420^{\circ} \mathrm{C}$ ) Ar to $\mathrm{Zn}$ \\
\hline
\end{tabular}

TPW $=$ triple point of water
Test No. Items

$33200 \mathrm{C}$ Long Stem SPRT $\left(83 \mathrm{~K}\right.$ to $\left.661^{\circ} \mathrm{C}\right) \mathrm{Ar}$ to $\mathrm{Al}$

$33210 \mathrm{C}$ Long Stem SPRT $\left(234 \mathrm{~K}\right.$ to $30^{\circ} \mathrm{C}$ ) $\mathrm{Hg}$ to $\mathrm{Ga}$

$33220 \mathrm{C} \quad$ Long Stem SPRT ( $234 \mathrm{~K}$ to $157^{\circ} \mathrm{C}$ ) $\mathrm{Hg}$ to $\mathrm{ln}$

$33230 \mathrm{C}$ Long Stem SPRT ( $234 \mathrm{~K}$ to $232^{\circ} \mathrm{C}$ ) $\mathrm{Hg}$ to $\mathrm{Sn}$

$33240 \mathrm{C}$ Long Stem SPRT (234 $\mathrm{K}$ to $420^{\circ} \mathrm{C}$ ) $\mathrm{Hg}$ to $\mathrm{Zn}$

$33250 \mathrm{C}$ Long Stem SPRT (234 $\mathrm{K}$ to $661^{\circ} \mathrm{C}$ ) $\mathrm{Hg}$ to $\mathrm{Al}$

$33260 \mathrm{C}$ Long Stem SPRT $\left(0^{\circ} \mathrm{C}\right.$ to $\left.30^{\circ} \mathrm{C}\right) \mathrm{TPW}$ to $\mathrm{Ga}$

$33270 \mathrm{C}$ Long Stem SPRT $\left(0^{\circ} \mathrm{C}\right.$ to $\left.157^{\circ} \mathrm{C}\right) \mathrm{TPW}$ to In

$33280 \mathrm{C}$ Long Stem SPRT $\left(0^{\circ} \mathrm{C}\right.$ to $\left.232^{\circ} \mathrm{C}\right)$ TPW to $\mathrm{Sn}$

$33290 \mathrm{C}$ Long Stem SPRT $\left(0^{\circ} \mathrm{C}\right.$ to $\left.420^{\circ} \mathrm{C}\right) \mathrm{TPW}$ to $\mathrm{Zn}$

$33300 \mathrm{C}$ Long Stem SPRT $\left(0^{\circ} \mathrm{C}\right.$ to $\left.661^{\circ} \mathrm{C}\right) \mathrm{TPW}$ to Al

$33310 \mathrm{C}$ Long Stem SPRT $\left(0^{\circ} \mathrm{C}\right.$ to $\left.962^{\circ} \mathrm{C}\right) \mathrm{TPW}$ to Ag

33320C Additional Copy of Table from Results of

33010C-33310C at Time of Test

33330C Additional Copy of Table from Results of 33010C-33310C at a Later Date

33340C Minimum Charge for Unsuitable Thermometer

33350S Special Tests of Resistance Thermometers

33360S Special Tests of Thermometric Fixed-Point Devices

33370M Measurement Assurance Program for Temperature $83 \mathrm{~K}$ to $420^{\circ} \mathrm{C}$ (Ar to $\mathrm{Zn}$ )

33380M Measurement Assurance Program for Temperature $83 \mathrm{~K}$ to $661{ }^{\circ} \mathrm{C}$ (Ar to $\mathrm{Al}$ )

\section{Resistance Thermometers (33010C-33310C)}

NIST provides calibration services for standard platinum resistance thermometers (SPRTs) from $13.8 \mathrm{~K}$ to $1235 \mathrm{~K}$. Both long-stem and capsule-type SPRTs are calibrated, providing direct access to the International Temperature Scale of 1990 (ITS-90). There are eleven temperature subranges over which an SPRT may be calibrated according to the ITS-90 definitions. From $13.8 \mathrm{~K}$ to $83.8 \mathrm{~K}$, SPRT calibrations are performed by comparison with a set of NIST reference thermometers. From $83.8 \mathrm{~K}$ to $962{ }^{\circ} \mathrm{C}$, calibrations are performed using the ITS-90 defining fixed points as described in NIST Technical Note 1265. Expanded uncertainties*, as described in NISTIR 5319, for SPRT calibrations are given in Table 6.3. The comparison calibration of rhodium-iron resistance thermometers (RIRTs) in the temperature range from

*See Chapter 1, Section $\mathrm{H}$ for more information about uncertainty. 
$0.65 \mathrm{~K}$ to $26 \mathrm{~K}$, using the NIST-maintained ITS-90, is based on a set of reference capsule-type RIRTs. The expanded uncertainty of those calibrations is given in Table 6.4. Extended range RIRT calibrations, for temperatures greater than $26 \mathrm{~K}$ and up to $83.8 \mathrm{~K}$, are accomplished by comparison with reference capsule SPRTs in the range $26 \mathrm{~K}$ to $83.8 \mathrm{~K}$.

Table 6.3. Maximum Expanded Uncertainties of SPRTs at NIST

\begin{tabular}{lc}
\hline $\begin{array}{c}\text { Temperature Subrange } \\
\text { (K) }\end{array}$ & $\begin{array}{c}\text { Maximum } \\
\text { Expanded Uncertainty* } \\
\text { (mK) }\end{array}$ \\
\hline 13.8033 to 273.16 & $0.54^{\mathrm{a}}$ \\
24.5561 to 273.16 & $0.40^{\mathrm{a}}$ \\
54.3584 to 273.16 & $0.29^{\mathrm{a}}$ \\
83.8058 to 273.16 & 0.39 \\
234.3156 to 302.9146 & 0.20 \\
273.15 to 302.9146 & 0.04 \\
273.15 to 429.7485 & 0.32 \\
273.15 to 505.078 & 0.37 \\
273.15 to 692.677 & 0.54 \\
273.15 to 933.473 & 0.68 \\
273.15 to 1234.93 & 1.1 \\
\hline
\end{tabular}

The uncertainty used at the $\mathrm{Ar}, \mathrm{Hg}$, and $\mathrm{H}_{2} \mathrm{O}$ triple points are based on the fixed-point realization.

* See Chapter 1, Section H for more information about uncertainty.

Table 6.4. NIST Expanded Uncertainties for Comparison Measurements of RIRTs

\begin{tabular}{lc}
$\begin{array}{l}\text { Range } \\
\text { (K) }\end{array}$ & $\begin{array}{c}\text { Expanded Uncertainty* } \\
(\mathbf{m K})\end{array}$ \\
\hline 0.65 to 2.0 & 0.5 \\
2.0 to 5.0 & 0.08 \\
5.0 to 8.8 & 0.17 \\
8.8 to 13.8 & 0.21 \\
13.8 to 17.0 & 0.34 \\
17.0 to 20.3 & 0.18 \\
20.3 to 24.5561 & 0.24 \\
24.5561 to 54.3584 & 0.27 \\
54.3584 to 83.8058 & 0.22 \\
\hline
\end{tabular}

*See Chapter 1, Section H for more information about uncertainty.
To qualify for testing, either long-stem or capsule SPRTs must meet two conditions. They must meet the ITS-90 criteria** of $\mathrm{W}(\mathrm{Hg}) \leq 0.844235$ or $\mathrm{W}(\mathrm{Ga}) \geq 1.11807$, and for use above $660^{\circ} \mathrm{C}$ the criterion of $\mathrm{W}(\mathrm{Ag}) \geq 4.2844$. Second, they must be compatible with the NIST calibration equipment. It is important that, insofar as possible, resistance thermometers be protected from any mechanical shock that could alter their calibration. For shipment, the thermometer should be softly supported within a case but not be free to rattle. This necessitates the use of packing material that does not become compacted. The thermometer case should be softly packed inside a shipping container. The shipping container must be sufficiently rigid and strong that it will not appreciably deform under the treatment usually given by common carriers. Styrofoam is not sufficiently rigid to be used as an outside container. Similarly, mailing tubes are unacceptable. Thermometers will not be returned in containers that are obviously unsuitable, such as those closed by nailing. Suitable containers will be provided when a thermometer shipping container is not satisfactory for re-use.

\section{Special Tests of Resistance Thermome- ters and Special Tests of Thermomet- ric Fixed-Point Devices (33350S and 33360S)}

Special tests (e.g., certification, prototype testing) of various resistance thermometers and thermometric fixed-point devices may be made by prior arrangement with the specified technical contacts. Fixed-point cells may be sent to NIST for certification by the method of direct comparison with the applicable NIST laboratory standard fixed-point cell.

**See 1990 publication "The Intemational Temperature Scale of 1990 (ITS-90)" reference at end of the section. 
Measurement Assurance Program for Temperature (33370M and $33380 \mathrm{M}$ )

The purpose of this Measurement Assurance Program (MAP) is to assure the accuracy of the calibration of temperature standards $\left(83 \mathrm{~K}\right.$ to either $420^{\circ} \mathrm{C}$ or $661{ }^{\circ} \mathrm{C}$ ) conducted by participating laboratories when using platinum resistance thermometry. Other temperature ranges are available upon request.

The MAP transport standard consists of sets of three commercial SPRTs packaged in a special shock-proof shipping container (mechanical shock may shift calibration values). These SPRTs are used to assess both the reproducibility and the uncertainty of calibrations performed by the participating laboratory.

MAP participants should use the techniques described in NIST Technical Note 1265 and ITS-90 fixed-point cells, or use an SPRT previously calibrated by NIST. In order to achieve high accuracy, SPRTs used as standards should be either metal sheathed or of the matte-finish glass-sheathed type to avoid systematic errors arising from light-pipe effects in the glass sheath. The participant must have a triple point of water cell and an appropriate resistance bridge.

NIST provides worksheets on which the participant records data. The participant calculates the thermometer constants from experimental data, records them, and prepares tables of either resistance ratio or resistance versus temperature. These completed worksheets and the participant's calibration reports are sent to NIST with the return of the MAP SPRTs.

The SPRTs are recalibrated upon return to NIST and the participant's data are compared with NIST's calibration results. NIST provides a plot of the participating laboratory's temperature deviation from NIST values and a written analysis of the data, including any pertinent observations. In a typical MAP transfer, the participant makes measurements over a period of 1 to 2 months. A typical turnaround time from the date NIST receives the participant's data until a test report is sent to the participant is 4 to 6 weeks. Former participants in the MAP have had expanded uncertainties* that ranged from about $1 \mathrm{mK}$ to several tens of millikelvins.

No rigid recommendations can be given concerning how often a participant should utilize the temperature MAP service. Experience has indicated that when temperature measurements are in a state of statistical control, as evidenced by in-house check standards and control charts used to monitor the measurement process, the participant should be able to go at least 3 years between transfers from NIST without significantly degrading the confidence in the correctness of the measurements.

Among other NIST Services for Temperature Calibration Laboratories, NIST provides Standard Reference Materials for use as defining fixed points of the ITS-90 and as secondary reference points.**

\section{References-Resistance Thermometry}

Assessment of Uncertainties of Calibration of Resistance Thermometers at the National Institute of Standards and Technology, G. F. Strouse and W. L. Tew, Natl. Inst. Stand. Technol. NISTIR 5319, 16 (1994).

NIST Measurement Assurance of SPRT Calibrations on the ITS-90: A Quantitative Approach, Session 1-D, G. F. Strouse and B. W. Mangum, Proc. Meas. Sci. Conf., Anaheim, CA (Jan. 1993).

NIST Implementation and Realization of the ITS-90 Over the Range $83 \mathrm{~K}$ to 1235 K. Reproducibility, Stability, and Uncertainties, G. F. Strouse, Temperature. Its Measurement and Control in Science and Industry, J. F. Schooley, Ed., 6, 169-174, Amer. Inst. Phys., New York, NY (1992).

* See Chapter 1, Section H for more information about uncertainty.

** See Chapter 1, Section C for information on the Standard Reference Materials Program. 
Realization of the ITS-90 Below $83.8 \mathrm{~K}$ at the National Institute of Standards and Technology, E. R. Pfeiffer, Temperature. Its Measurement and Control in Science and Industry, J. F. Schooley, Ed., 6, 155-160, Amer. Inst. Phys., New York, NY (1992).

The International Temperature Scale of 1990 (ITS-90), H. Preston-Thomas, Metrologia 27, 310 (1990); Metrologia 27, 107 (1990).

NBS Measurement Services: Platinum Resistance Thermometer Calibrations, B. W. Mangum, Natl. Bur. Stand. (U.S.), Spec. Publ. 250-22 (1988). Reproducibility of Some Triple Point of Water Cells, G. T. Furukawa and W. R. Bigge, Temperature, Its Measurement and Control in Science and Industry 5, 291, Amer. Inst. Phys., New York, NY (1982).
Standard Reference Materials: Application of Some Metal SRM's as Thermometric Fixed Points, G. T. Furukawa, J. L. Riddle, W. R. Bigge, and E. R. Pfeiffer, Natl. Bur. Stand. (U.S.), Spec. Publ. 260-77 (Aug. 1982).

A Measurement Assurance ProgramThermometer Calibration, G. T. Furukawa and W. R. Bigge, in Natl. Conference on Testing Laboratory Performance, Evaluation, and Accreditation, Natl. Bur. Stand. (U.S.), Spec. Publ. 591, 137 (Aug. 1980).

Determination of the Triple-Point Temperatures of Gallium, B. W. Mangum and D. D. Thornton, Metrologia 15, 201-215 (1979).

Platinum Resistance Thermometry, J. L. Riddle, G. T. Furukawa, and H. H. Plumb, Natl. Bur. Stand. (U.S.), Monogr. 126 (Apr. 1973). 


\section{Radiance Temperature Measurements}

\section{Technical Contact:}

\author{
Charles E. Gibson \\ Tel: 301/975-2329 \\ Fax: 301/869-5700 \\ Email: cgibson@nist.gov
}

Mailing Address: Building 221, Room B208,

National Institute of Standards and Technology,

Gaithersburg, MD 20899-0001

Service

ID No.

Items

Calibration reports are issued giving the radiance temperature of the blackbody at $655.3 \mathrm{~nm}$ versus the scale reading, output current, or output voltage.

35010C Radiance Temperature Standard, Disappearing Filament Optical Pyrometer $\left(800^{\circ} \mathrm{C}\right.$ to $2400^{\circ} \mathrm{C}$, 4 to 12 points, 1 range)

35020C Radiance Temperature Standard, Disappearing Filament Optical Pyrometer (each additional range up to $4200^{\circ} \mathrm{C}$, only available with $35010 \mathrm{C}$ )

35030C Additional Interpolated Values

35040C Radiance Temperature Standard, Disappearing Filament Optical Pyrometer $\left(800^{\circ} \mathrm{C}\right.$ to $4200^{\circ} \mathrm{C}$, 3 or fewer points, 1 range)

Calibration reports are issued giving the radiance temperature of the lamp at $655.3 \mathrm{~nm}$ versus the lamp current.

35050C Radiance Temperature Standard, Ribbon Filament Lamp ( $800{ }^{\circ} \mathrm{C}$ to $2300^{\circ} \mathrm{C}, 6$ to 16 points)

35060C Radiance Temperature Standard, Ribbon Filament Lamp $\left(800{ }^{\circ} \mathrm{C}\right.$ to $2300^{\circ} \mathrm{C}, 5$ or fewer points)

Test reports are issued giving the radiance temperature of the blackbody at $655.3 \mathrm{~nm}, 900 \mathrm{~nm}$, or $1000 \mathrm{~nm}$ versus the indicator reading, output current, or output voltage.

35070S Special Tests of Radiation Thermometers

\begin{tabular}{lcc} 
Standard & $\begin{array}{c}\text { Temperature Range } \\
\left({ }^{\circ} \mathrm{C}\right)\end{array}$ & $\begin{array}{c}\text { Expanded } \\
\text { Uncertainty* } \\
\text { ( }\end{array}$ \\
\hline Ribbon filament lamp & 800 to 1600 & 0.7 \\
& 1600 to 1900 & 1.0 \\
& 1900 to 2300 & 1.5 \\
Leeds \& Northrup & 800 to 1600 & 4 \\
Model 8000 series & 1600 to 2100 & 5 \\
& 1900 to 2300 & 7 \\
Disappearing filament & 2400 to 2700 & 8 \\
optical pyrometer & 2700 to 3200 & 17 \\
& 3200 to 4200 & 25 \\
Pyrometer Instrument & 800 to 1400 & 3 \\
$\quad$ Model 95 & 1400 to 1800 & 4 \\
Disappearing filament & 1800 to 2400 & 5 \\
optical pyrometer & 2400 to 2700 & 8 \\
& 2700 to 3200 & 12 \\
Infrared radiation & 800 to 2000 & 2 \\
thermometer & 2000 to 2700 & 3 \\
\hline
\end{tabular}

* See Chapter 1, Section $\mathrm{H}$ for more information about uncertainty.

This laboratory's quality system is based on the ANSI/NCSL Z540-1 1994 standard and the ISO/IEC Guide 25.

Disappearing Filament Optical Pyrometers and Ribbon Filament Lamps (35010C-35060C)

These calibration services provide access to the International Temperature Scale of 1990 (ITS-90) as realized by NIST for the temperature range $800^{\circ} \mathrm{C}$ to $4200{ }^{\circ} \mathrm{C}$. NIST disseminates the radiance temperature scale by issuing ribbon filament lamp standards of radiance temperature and by calibrating customer supplied pyrometers and radiation thermometers.

High-accuracy monochromatic disappearing filament optical pyrometers are calibrated in the full temperature range. Calibration reports are issued giving the radiance temperature of the NIST blackbody versus the test pyrometer scale reading, output current, or output voltage. 
Ribbon filament lamps are calibrated using the NIST photoelectric pyrometer. Calibration reports are issued giving the radiance temperature of the test lamp at $655.3 \mathrm{~nm}$ versus direct current for the temperature range $800^{\circ} \mathrm{C}$ to $2300^{\circ} \mathrm{C}$. The radiation thermometry portion of ITS-90 is defined in terms of the fixed temperature of the freezing point of gold $\left(1064.18^{\circ} \mathrm{C}\right)$ and the Planck equation for the radiation of a blackbody source. In practice, the temperature scale is realized by constructing a gold-point blackbody and a variable temperature blackbody, and then measuring the spectral radiance ratio at a red wavelength (approximately $650 \mathrm{~nm}$ ) in terms of the Planck equation. Gold-point blackbodies are reproducible to $0.02{ }^{\circ} \mathrm{C}$, but the temperature assignment of the freezing point of gold is uncertain by about $0.23^{\circ} \mathrm{C}$. The spectral radiance ratio measurements can be performed with a relative expanded uncertainty* of $0.2 \%$ to $0.3 \%$. Smaller uncertainties than available in the routine services described above can be provided as special tests subject to the ITS-90 uncertainties noted. Calibrations at wavelengths other than $655.3 \mathrm{~nm}$ can be provided in the wavelength range $250 \mathrm{~nm}$ to $2500 \mathrm{~nm}$ subject to an additional uncertainty due to the quality of the variable temperature blackbody.

\section{Special Tests of Radiation Thermometers (35070S)}

Infrared thermometers are calibrated at $655.3 \mathrm{~nm}, 900 \mathrm{~nm}$, and $1000 \mathrm{~nm}$ as special tests. Absorbing glass filters used for range changing in disappearing filament optical pyrometers can also be calibrated as special tests.

\section{Calibration Schedule}

Radiance temperature calibrations are performed in February, May, August, and November. Requests for calibration services are scheduled after the receipt of a purchase order.

* See Chapter 1, Section $\mathrm{H}$ for more information about uncertainty.

\section{References-Radiation Thermometry}

International Comparison of Radiation Temperature Scales Among Five National Metrological Laboratories Using a Transfer Standard Radiation Thermometer, B. C. Johnson, F. Sakuma, H. Sakate, C. Gibson, G. Machin, T. Ricolfi, M. Battuello, J. Fischer, and H. J. Jung, Metrologia 33, 241 (1996).

Intercomparison of the ITS-90 Radiance Temperature Scales of the National Physical Laboratory (U.K.) and the National Institute of Standards and Technology, B.C. Johnson, C. Gibson, G. Machin, and R. L. Rusby, J. Res. Natl. Inst. Stand. Technol. 99, 731 (1994).

The New International Temperature Scale of 1990 and its Effect on Radiometric, Photometric, and Colorimetric Measurements and Standards, K. D. Mielenz, R. D. Saunders, A. C. Parr, and J. J. Hsia, CIE Proc. 22nd Session Melbourne 1991 no. 91 (1991).

Temperature, Its Measurement and Control in Science and Industry, J. F. Schooley, Ed., 6, Part 1, Amer. Inst. Phys., New York, NY (1992).

Temperature, Its Measurement and Control in Science and Industry, J. F. Schooley, Ed., 6, Part 2, Amer. Inst. Phys. New York, NY (1992).

The International Temperature Scale of 1990, H. Preston-Thomas, Metrologia 27(3), (1990).

The 1990 NIST Scales of Thermal Radiometry, K. D. Mielenz, R. D. Saunders, A. C. Parr, and J. J. Hsia, J. Res. Natl. Inst. Stand. Technol. 95, 621 (1990).

Spectroradiometric Determination of the Freezing Temperature of Gold, K. D. Mielenz, R. D., Saunders, and J. B. Shumaker, J. Res. Natl. Inst. Stand. Technol. 95, 49 (1990).

Temperature, T. J. Quinn, Academic Press, San Diego, CA (1990).

Theory and Practice of Radiation Thermometry, D. P. Dewitt and G. D. Nutter, eds., John Wiley and Sons, New York, NY (1988). 
NBS Measurement Services: Radiance Temperature Calibrations, W. R. Waters, J. H. Walker, and A. T. Hattenburg, Natl. Bur. Stand. (U.S.), Spec. Publ. 250-7 (Oct. 1987).

Applications of Radiation Thermometry, J. C. Richmond and D. P. Dewitt, eds., (American Society for Testing and Materials, Philadelphia, 1985).

The International Practical Temperature Scale of 1968, Amended Edition of 1975, Metrologia 12 (7) (1976).

Temperature, Its Measurement and Control in Science and Industry, 4, Part 1, Instrument Society of America, Pittsburgh, PA (1972).

Corrections in Optical Pyrometry and Photometry for the Refractive Index of Air, W. R. Blevin, Metrologia 8 (146) (1972).

Vacuum Tungsten Strip Lamps with Improved Stability as Radiance Temperature Standards, in Temperature: Its Measurement and Control in Science and Industry, T. J. Quinn and R. D. Lee, 4, Part 1, 395, Instrument Society of America, Pittsburgh, PA (1972).
Intercomparison of the IPTS 68 Above $1064^{\circ} \mathrm{C}$ by Four National Laboratories, in Temperature: Its Measurement and Control in Science and Industry, R. D. Lee, H. J. Kostlowski, T. J. Quinn, P. R. Chandler, T. N. Jones, J. Tapping, and H. Kunz, 4, Part 1, 377, Instrument Society of America, Pittsburgh, PA (1972).

High-Accuracy Spectral Radiance Calibration of Tungsten-Strip Lamps, $\mathrm{H}$. J. Kostkowski, D. E. Erminy, and A. E. Hattenburg, Adv. Geophys. 14 (111) (1970).

The NBS Photoelectric Pyrometer and Its Use in Realizing the International Practical Temperature Scale Above $1064{ }^{\circ} \mathrm{C}, \mathrm{R}$. D. Lee, Metrologia 2 (4), 150 (Oct. 1966).

Theory and Methods of Optical Pyrometry, H. J. Kostkowski and R. D. Lee, Natl. Bur. of Stand. (U.S.), Monograph 41 (Mar. 1962).

Temperature, Its Measurement and Control in Science and Industry, 3, Part 1, Instrument Society of America, Pittsburgh, PA (1962). 


\section{Humidity Measurements}

\section{Technical Contacts:}

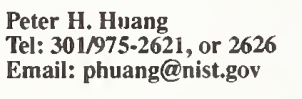

Joseph T. Hodges
Tel: 301/975-2605
Email: joseph.hodges @
nist.gov

Gregory E. Scace Tel: $301 / 975-2626$ Email: gregory.scace@ nist.gov
Mailing Address: Building 221, Room B128, National Institute of Standards and Technology, Gaithersburg, MD 20899-0001

\section{Shipping Address:}

National Institute of Standards and Technology, I-270 at Quince Orchard Road, B349 Physics, Gaithersburg, MD 20899-0001

\begin{tabular}{ll}
$\begin{array}{l}\text { Service } \\
\text { ID No. }\end{array}$ & Items \\
\hline $36010 \mathrm{C}$ & Dew-Point Hygrometers $\left(+25^{\circ} \mathrm{C}\right.$ to $\left.-15^{\circ} \mathrm{C}\right)$ \\
$36020 \mathrm{C}$ & Dew-Point Hygrometers $\left(-70^{\circ} \mathrm{C}\right.$ to $\left.-15^{\circ} \mathrm{C}\right)$ \\
$36030 \mathrm{C}$ & Electric Hygrometers \\
$36040 \mathrm{C}$ & Electrolytic Hygrometers \\
$36050 \mathrm{C}$ & Aspirated Hygrometers \\
$36060 \mathrm{C}$ & Pneumatic Bridge Hygrometers \\
$36070 \mathrm{~S}$ & Special Tests of Humidity
\end{tabular}

\section{Hygrometers (36010C-36060C)}

NIST provides calibration services for a wide variety of humidity-measuring instruments. Calibrations are performed by subjecting the instrument under test to atmospheres of known moisture content produced by the NIST two-pressure humidity generator. The instruments and ranges of calibration are listed below:

A. Dew-Point Hygrometers calibrated over the dew/frost range of $-70{ }^{\circ} \mathrm{C}$ to $+60{ }^{\circ} \mathrm{C}$.

B. Electric Hygrometers classified under this category are sensors which sorb water vapor as a function of relative humidity; associated with this sorption is a corresponding change in an electric parameter (that is, resistance, capacitance). The range of calibration is $3 \%$ to $98 \%$ relative humidity over the temperature range $-55^{\circ} \mathrm{C}$ to $+40^{\circ} \mathrm{C}$.
C. Psychrometers are wet-dry bulb hygrometers (aspirated psychrometers). The contact person should be consulted for the special features of the psychrometer which are necessary in order that the instrument can be calibrated at NIST.

D. Electrolytic Hygrometers are devices which electrolyze water into gaseous oxygen and hydrogen by the application of a voltage in excess of the thermodynamic decomposition voltage for water, and then measure the electrolysis current. The range of calibration in volume ratio is $10^{-6}$ to $3 \times 10^{-2}$.

E. Pneumatic Bridge Hygrometers are instruments that measure the variation of the pressure drop across two combinations of nozzles, operating at critical flow, with a desiccant between one pair of nozzles. The range of calibration in mixing ratio (grams of water vapor/grams of dry air) is 0.0005 to 0.015 .

Table 6.5 illustrates typical NIST uncertainties for measurement of humidity standards with atmospheric air at atmospheric pressures.

\section{Special Tests of Humidity (36070S)}

Tests for response time, hysteresis, and stability can be provided upon request.

Table 6.5. NIST Two-Pressure Humidity Generator, Mark 2, Range and Uncertainty

\begin{tabular}{lcc}
$\begin{array}{l}\text { Humidity } \\
\text { Parameter }\end{array}$ & Range & $\begin{array}{c}\text { Expanded } \\
\text { Uncertainty }\end{array}$ \\
\hline $\begin{array}{lc}\text { Mixing ratio, } \mathrm{r}_{\mathrm{W}} \\
\text { (g water vapor/ }\end{array}$ & $0.0015 \leq \mathrm{r}_{\mathrm{w}}<0.005$ & $1.5 \%$ of value \\
$\mathrm{kg}$ dry air) & $0.005 \leq \mathrm{r}_{\mathrm{w}}<0.1$ & $1.0 \%$ of value \\
& $0.1 \leq \mathrm{r}_{\mathrm{w}}<0.3$ & $0.5 \%$ of value \\
Volume ratio, & $0.3 \leq \mathrm{r}_{\mathrm{w}}<515$ & $0.3 \%$ of value \\
$\mathrm{V}\left(\times 10^{-6}\right.$ ) & $3 \leq \mathrm{V}<10$ & $1.5 \%$ of value \\
& $10 \leq \mathrm{V}<170$ & $1.0 \%$ of value \\
& $170 \leq \mathrm{V}<500$ & $0.5 \%$ of value \\
Dew point tem- & $500 \leq \mathrm{V}<820000$ & $0.3 \%$ of value \\
perature, $\mathrm{T}_{\mathrm{d}}\left({ }^{\circ} \mathrm{C}\right)$ & $-70 \leq \mathrm{T}_{\mathrm{d}}<-35$ & $0.1{ }^{\circ} \mathrm{C}$ \\
Relative humidity, & $-35 \leq \mathrm{T}_{\mathrm{d}}<+40$ & $0.04{ }^{\circ} \mathrm{C}$ \\
RH $(\%)$ at test & $-55 \leq \mathrm{T}_{\mathrm{c}}<-40$ & $3-98 \quad 1.5 \%$ \\
chamber temperature, & $-40 \leq \mathrm{T}_{\mathrm{c}}<-20$ & $3-98 \quad 0.8 \%$ \\
$\mathrm{~T}_{\mathrm{c}}\left({ }^{\circ} \mathrm{C}\right)$ of: & $0 \leq \mathrm{T}_{\mathrm{c}}<0$ & $3-98 \quad 0.2 \%$ \\
\end{tabular}

* See Chapter 1 , Section $\mathrm{H}$ for more information about uncertainty. 


\section{References-Humidity Measurements}

Thermodynamic Properties of Moist Air Containing 1000 to $5000 \mathrm{PPMv}$ of Water Vapor, P. H. Huang, NISTIR 5241, 43-51 (Apr. 1993).

NIST Calibration Services for Humidity Measurement, P. H. Huang, NISTIR 4677-A (Superseding NISTIR 4677, Oct. 1991).

National Basis of Accuracy in Humidity Measurements, S. Hasegawa, ISA Trans. 25 (3), 15-24, 1986.

The NBS Two-Pressure Humidity Generator, Mark 2, S. Hasegawa and J. W. Little, J. Res. Nat. Bur. Stand. (U.S.), 81A (1), 81-88 (Jan.-Feb. 1977).
Vapor Pressure Formulation for Ice, A. Wexler, J. Res. Nat. Bur. Stand. (U.S.), 81A (1), 5-20 (Jan.-Feb. 1977).

Vapor Pressure Formulation for Water in Range $0{ }^{\circ} \mathrm{C}$ to $100^{\circ} \mathrm{C}$. A Revision, A. Wexler, J. Res. Nat. Bur. Stand. (U.S.), 80A (5 and 6), 775-785 (Sept.-Dec. 1976).

Functional Equations for the Enhancement Factors for $\mathrm{CO}_{2}$-Free Moist Air, L. Greenspan, J. Res. Nat. Bur. Stand. (U.S.), 80A (1), 4l-44 (Jan.-Feb. 1976).

The NBS Standard Hygrometer, A. Wexler and D. W. Hyland, NBS Monograph 73, (May 1964). 


\section{Chapter}

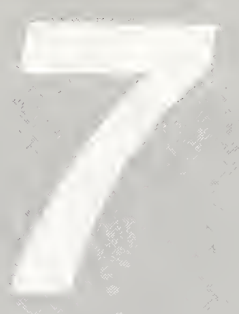

A Photometric Measurements

B Optical Properties of Materials Measurements

C Spectroradiometric Measurements

D Radiometric Standards in the Far Ultraviolet

E Lasers and Optoelectronic Components Used with Lasers 


\section{Optical Radiation Measurements}

\section{Technical Contacts:}

\author{
Yoshi Ohno \\ Tel: 301/975-2321 \\ Email: ohno@nist.gov \\ Magdalena Navarro \\ Tel: $301 / 975-2130$ \\ Email: mnavarro@nist.gov \\ Fax: 301/840-8551
}

Mailing Address: Building 220, Room A320,

National Institute of Standards and Technology,

Gaithersburg, MD 20899-0001

Service

ID No.

Items

37010C Luminous Intensity and Color Temperature Standard Lamps

37020 S Special Tests for Luminous Intensity and Color

Temperature of Submitted Lamps

37030C Color Temperature Standard Lamps

37040C Each Additional Color Temperature for 37030C

37050S Special Tests for Color Temperature of Submitted Lamps

37060S Special Tests for Total Luminous Flux of Submitted

Incandescent Lamps and Fluorescent Lamps

37070C Opal Glass Luminance Coefficient Standards

37080S Special Tests for Submitted Luminance Sources and Transmitting Diffusers

37090S Special Tests for Photometers, Illuminance Meters, and Luminance Meters

37100S Special Photometric Tests

$37110 S$ Special Tests for Submitted Flashing-Light Photometers

\section{General Information}

Calibration services in this area provide access to the photometric scales that are realized and maintained at NIST. Lamp standards of luminous intensity, luminous flux, and color temperature, as well as reference photometers and materials as described below, are issued or calibrated on a routine basis.

This laboratory's quality system is based on the ANSI/NCSL Z540-11994 standard and the ISO/IEC Guide 25.

*See Chapter 1, Section C for information on spectrophotometry standards available from the Standard Reference Materials Program.

Luminous Intensity and Color Temperature Standard Lamps (37010C)

NIST will issue to the customer $1000 \mathrm{~W}$ modified FEL (free electron laser) quartz halogen lamps calibrated for luminous intensity (candela) and color temperature (kelvin). These lamps have a double coil filament and a clear bulb, and are potted on a medium bipost base. The lamps are operated at approximately $7 \mathrm{~A} / 85 \mathrm{~V} \mathrm{dc}$, at a color temperature of $2856 \mathrm{~K}$. The relative expanded uncertainty** of the luminous intensity of these lamps is $0.6 \%$ and the expanded uncertainty of the color temperature is $8 \mathrm{~K}$ at $2856 \mathrm{~K}$.

Special Tests for Luminous Intensity and Color Temperature of Submitted Lamps (37020S)

NIST will calibrate the luminous intensity and color temperature of incandescent lamps with a medium bipost base submitted by customers. The inside frosted lamps, the airway beacon lamps, and the $1000 \mathrm{~W}$ FEL lamps previously issued by NIST can be submitted for recalibration. Customers can specify either the lamp current or the color temperature of the lamp (normally $2856 \mathrm{~K}$ ) for calibration. The uncertainty of calibration is described above.

\section{Color Temperature Standard Lamps (37030C)}

NIST will issue to the customer $1000 \mathrm{~W}$ modified FEL quartz halogen lamps as described in $37010 \mathrm{C}$ calibrated for color temperature. The lamps are usually calibrated for a color temperature of $2856 \mathrm{~K}$. The expanded uncertainty** of the color temperature of these lamps is $8 \mathrm{~K}$ at $2856 \mathrm{~K}$.

\section{Each Additional Color Temperature for $37030 \mathrm{C}(37040 \mathrm{C})$}

The color temperature standard lamps issued for $37030 \mathrm{C}$ can be calibrated for additional color temperature points in a

**See Chapter 1, Section H for more information about uncertainty. 
range from $2000 \mathrm{~K}$ to $3200 \mathrm{~K}$. The expanded uncertainty* of this calibration is $4 \mathrm{~K}$ to $11 \mathrm{~K}$ in the range from $2000 \mathrm{~K}$ to $3200 \mathrm{~K}$.

\section{Special Tests for Color Temperature of Submitted Lamps (37050S)}

NIST will calibrate the color temperature of incandescent lamps with a medium bipost base submitted by customers. The inside frosted lamps, the airway beacon lamps, and the $1000 \mathrm{~W}$ FEL lamps previously issued by NIST can be submitted for recalibration.

\section{Special Tests for Total Luminous Flux of Submitted Incandescent Lamps and Fluorescent Lamps (37060S)}

NIST will calibrate the total luminous flux (lumen) of incandescent lamps and fluorescent lamps submitted by customers. The standard lamps previously issued by NIST can be submitted for recalibration. Miniature lamps may also be accepted. Customers should contact NIST before submitting lamps. The relative expanded uncertainty* of this calibration is typically $1.0 \%$ for incandescent lamps and $2.0 \%$ for fluorescent lamps, depending upon the reproducibility of test lamps.

\section{Opal Glass Luminance Coefficient Standards (37070C)}

NIST will issue flashed opal glass plates, $51 \mathrm{~mm} \times 51 \mathrm{~mm}$, calibrated for luminance coefficient (ratio of luminance/ illuminance, unit: $\left.\mathrm{sr}^{-1}\right)$ for International Commission on Illumination (CIE) Illuminant A (2856 K source). The glass plates, masked with a circular aperture $25 \mathrm{~mm}$ in diameter, are calibrated for the luminance within a circular area of $1 \mathrm{~cm}$ in diameter in the center of the aperture. The relative expanded uncertainty* of this calibration is $0.8 \%$.
* See Chapter 1, Section $\mathrm{H}$ for more information about uncertainty.

\section{Special Tests for Submitted Lumi- nance Sources and Transmitting Diffusers (37080S)}

NIST will calibrate luminance $\left(\mathrm{cd} / \mathrm{m}^{2}\right)$ of submitted sources or the luminance coefficient $\left(\mathrm{sr}^{-1}\right)$ of submitted transmitting diffusers, including opal glass previously issued by NIST. Customers should contact NIST before sending sources or diffusers. The relative expanded uncertainty* of luminance calibration is $0.8 \%$.

\section{Special Tests for Submitted Photome- ters, Illuminance Meters, and Luminance Meters (37090S)}

NIST will calibrate photometers, illuminance meters, and luminance meters submitted by customers. Calibration is usually made with the CIE Illuminant A ( $2856 \mathrm{~K}$ incandescent source) in a range of $0.1 \mathrm{~lx}$ to $3000 \mathrm{~lx}$ for illuminance and $0.1 \mathrm{~cd} / \mathrm{m}^{2}$ to $4000 \mathrm{~cd} / \mathrm{m}^{2}$ for luminance. The relative expanded uncertainty* of calibration is $0.5 \%$ for illuminance and $0.7 \%$ for luminance at normal levels, which will increase at low levels. As an option, NIST can measure the relative spectral responsivity of submitted instruments and calculate spectral mismatch correction factors for a source of known spectral power distribution. Illuminance calibrations at a level up to $100 \mathrm{klx}$ can also be made under a special arrangement.

\section{Special Photometric Tests (37100S)}

NIST can provide special tests for sources, detectors, and photometric instruments other than those stated above under limited conditions by special arrangements with NIST. Customers should contact NIST for consultation.

\section{Special Tests for Submitted Flash- ing-Light Photometers (37110S)}

NIST will calibrate submitted flashinglight photometers to measure integrated illuminance $[1 \mathrm{x} \cdot \mathrm{s}]$ or effective intensity [cd]. Calibration is normally

* See Chapter 1, Section H for more information about uncertainty. 
performed with white light $(\approx 6500 \mathrm{~K}$ ) from a xenon strobe light in the range of $1 \mathrm{~lx} \cdot \mathrm{s}$ to $100 \mathrm{~lx} \cdot \mathrm{s}$ and with red light using an Aviation Red filter. The relative expanded uncertainty* of calibration is $\approx 1 \%$ or larger depending on the performance of the instrument under test.

\section{References - Photometric Measure- ments}

NIST Measurement Services: Photometric Calibrations, Y. Ohno, Natl. Inst. Stand. Technol. Spec. Publ. 250-37 (1997).
* See Chapter 1, Section $\mathrm{H}$ for more information about uncertainty.
Improved Photometric Standards and Calibration Procedures at NIST, Y. Ohno, J. Res. Natl. Inst. Stand. Technol. 102 (3), 323-331 (1997). The Detector-based Candela Scale and Related Photometric Calibration Procedures at NIST, Y. Ohno, C. L. Cromer, J. E. Hardis, and G. Eppeldauer, J. IES 23 (1), 89-98 (1994).

National Institute of Standards and Technology Detector-based Photometric Scale, C. L. Cromer, G. Eppeldauer, J. E. Hardis, T. C. Larason, and A. C. Parr, Applied Optics 32 (16), 2936-2948 (1993). 


\section{Optical Properties of Materials Measurements*}

\author{
Technical Contacts:
}

\author{
P. Yvonne Barnes \\ $38010 \mathrm{C}-38060 \mathrm{~S}$ \\ Tel: 301/975-2345 \\ Email: yvonne.barnes@nist.gov \\ Fax: 301/840-8551 \\ Edward A. Early \\ $38070 \mathrm{M}-38080 \mathrm{M}$ \\ Tel.: 301/975-2343 \\ Email: edward.early@nist.gov \\ Mailing Address: Building 220, Room A320, \\ National Institute of Standards and Technology, \\ Gaithersburg, MD 20899-0001
}

Service

ID No. Items

38010C Spectral Transmittance Filters (Cobalt Blue Glass)

38020C Spectral Transmittance Filters (Copper Green Glass)

38030C Spectral Transmittance Filters (Carbon Yellow Glass)

38040C Spectral Transmittance Filters (Selenium Orange Glass)

38050C Wavelength Standards (Holmium Oxide Glass)

38060S Special Tests of Spectral Transmittance or Spectral Reflectance (Directional-Hemispherical or Bidirectional Geometry) and Appearance

38070M Measurement Assurance Program for Retroreflectance-Complete Package

38071M Retroreflectance MAP-Sheeting Standards or Prismatic Standard with Colored Filters

38072M Retroreflectance MAP — Sheeting Standards and Prismatic Standard without Colored Filters

38073M Retroreflectance MAP — Sheeting Standards or Prismatic Standard without Colored Filters

38074M Retroreflectance MAP-Colored Filters Only

38080M Measurement Assurance Program for Transmittance

This laboratory's quality system is based on the ANSI/NCSL Z540-11994 standard and the ISO/IEC Guide 25.

\section{Spectral Transmittance Filters (38010C-38040C)}

NIST supplies to the customer standards of spectral transmittance for checking the photometric scale of spectrophotometers. These are either $30 \mathrm{~mm}$ polished glass disks or $51 \mathrm{~mm}$

* See Chapter 1, Section C for information on spectral reflectance standard artifacts available through the Standard Reference Materials Program. polished glass squares, 2 to $3 \mathrm{~mm}$ thick, designated as cobalt blue, copper green, carbon yellow, and selenium orange. The relative expanded uncertainty** ranges from approximately $0.2 \%$ to $0.3 \%$ of the value. Information provided to the user includes values of transmittance at $25^{\circ} \mathrm{C}$ at $10 \mathrm{~nm}$ intervals from $380 \mathrm{~nm}$ to $770 \mathrm{~nm}$, the estimated uncertainty of each value, and data as to the effect of temperature change on transmittance at each wavelength.

\section{Wavelength Standards (38050C)}

NIST supplies to the customer holmium oxide glass standards for checking the ultraviolet and visible wavelength calibrations of recording spectrophotometers having a bandpass less than $2 \mathrm{~nm}$. These are made of polished Corning 3130 glass, $51 \mathrm{~mm} \times 51 \mathrm{~mm}$, or cuvette size [11 $\mathrm{mm} \times 15 \mathrm{~mm}$ ], approximately $2.5 \mathrm{~mm}$ thick. A table of wavelengths of minimum transmittance is provided in the report to the user. The expanded uncertainty** is $0.2 \mathrm{~nm}$.

\section{Special Tests of Spectral Transmit- tance or Spectral Reflectance (38060S)}

Measurements of spectral transmittance can be made for the wavelength region $190 \mathrm{~nm}$ to $2500 \mathrm{~nm}$. Measurements of absolute spectral reflectance factors (using either bidirectional or directionalhemispherical geometry) and of spectral specular reflectance (using bidirectional geometry) can be made for the wavelength region $250 \mathrm{~nm}$ to $2500 \mathrm{~nm}$. Color and appearance attributes of materials are provided using bidirectional or directional-hemispherical geometry over the visible spectral region and can be extended depending on available instrumentation. However, arrangements for these measurements on submitted specimens must be made before shipment. The decision as to whether or not to perform the measurements and selection of the instruments to be used will rest with NIST. Specimens not accepted for measurement will be returned. Uncertainty estimates

** See Chapter 1, Section $\mathrm{H}$ for more information about uncertainty. 
will be given and will depend on the optical characteristics of the submitted specimens and whether a primary or transfer instrument is used to perform the measurement.

\section{Measurement Assurance Programs for Retroreflectance (38070M-38074M)}

These Measurement Assurance Programs (MAPs) verify, within certain limits, how well a laboratory can measure the coefficient of luminous intensity. The verification is accomplished by means of a MAP package. The MAP package contains two white bead sheeting retroreflectors, one colorless prismatic retroreflector, and seven colored glass filters. The elements in this package are measured by NIST, then by the participating laboratory, and finally by NIST. Quality control procedures are maintained by using NIST master standards.

The use of three retroreflectors enables the determination of how well the participant can measure coefficient of luminous intensity for white or colorless samples of three kinds of geometries. The luminous transmittance of the seven colored glass filters can be used as a diagnostic tool to check measurements of coefficient of luminous intensity of colored retroreflectors. This is accomplished by checking the conformance of the source-receiver combination to CIE Illuminant $\mathrm{A}$ and $\mathrm{CIE} 2^{\circ}$ standard observer respectively.

The coefficient of luminous intensity of each of the bead sheeting standards is measured at six combinations of observation and entrance angles. The coefficient of luminous intensity of the prismatic retroreflector is measured at 18 combinations of entrance and observation angles. The luminous transmittance of the filters is provided only for the spectral conditions of source and receiver specified above.

A general testing laboratory will probably need the service that utilizes the complete MAP package. However, some laboratories may be specialized. For this reason, we list five options that offer not only the complete package, but also some selected components. These options are:
A. Complete MAP package;

B. Sheeting standards or prismatic standard with colored filters;

C. Sheeting standards or prismatic standard without colored filters;

D. Sheeting standards and prismatic standard without colored filters; and

E. Colored filters only.

Even measurement of the complete MAP package achieves only part of the goal of a MAP service. To fully benefit from the MAP procedure, we suggest that the participant have on hand several check standards to be measured while also measuring the MAP package. These check standards can then be measured periodically to determine any gross error in measurement procedure, and a control chart can be constructed. A control chart is a plot of measurement result versus time, and the measurement process is normally considered to be under control if measurements fall within \pm 2 standard deviations of the mean. For retroreflectance measurements where geometric errors are large, the standard deviation obtained after changing geometrical parameters may be large compared with that obtained from repeated measurements without changing the apparatus. Thus, the total variation for a given instrument can be obtained only by repetition over a period of time and realignment of the experimental apparatus.

The uncertainties of retroreflectometer measurements have three sources: uncertainties associated with values assigned by NIST to the MAP package, participant uncertainties, and uncertainties due to environment and sample interaction.

Repeated measurements without changing the apparatus show that the NIST random error is small relative to the systematic errors. A large fraction of the latter arise when the retroreflector is rearranged and realigned for making measurements with different measurement parameters. The NIST relative expanded uncertainty* for retroreflectance measurement ranges from $2.7 \%$ to $10 \%$ of the value depending on the

* See Chapter 1, Section $\mathrm{H}$ for more information about uncertainty. 
geometry and the type of retroreflectors. The NIST expanded uncertainty for luminous transmittance of the colored glass filters varies up to 0.002 .

\section{Measurement Assurance Program for Transmittance (38080M)}

The Transmittance Measurement Assurance Program (MAP) provides a means for a laboratory to assess the uncertainty of its spectral transmittance measurement capabilities. A laboratory that participates in this program will be sent a package of transmittance filters that have been measured at NIST. These are to be measured by the laboratory on its spectrophotometer(s) and returned, together with the measurement results, to NIST. NIST will then remeasure the filters and send a final analysis of the results to the participating laboratory. The range of filter measurements provided in the MAP package permits an evaluation of the uncertainty of a laboratory's spectral transmission measurements and will often reveal the cause of any systematic errors that exist. The NIST expanded uncer tainty* ranges from approximately $0.03 \%$ to $0.3 \%$ of the value for filters with nominal transmittance from 0.92 to 0.001 .

The MAP package includes seven neutral density filters with nominal transmittances ranging from 0.92 to 0.001 . The filters are available in three sizes. The filter holders are $51 \mathrm{~mm} \times 51 \mathrm{~mm}, 51 \mathrm{~mm} \times 38 \mathrm{~mm}$, or standard cuvette. In addition, the package contains one didymium glass filter or cuvette-sized holmium oxide solution that is to be used for wavelength scale calibration. Several wavelengths of transmittance minima and points of inflection have been measured by NIST for the didymium filter. These wavelengths have been shown to be stable over long periods of time; therefore, these didymium filters are not normally measured by NIST with every use of the MAP package. The didymium filter is useful for triangular

* See Chapter 1, Section $\mathrm{H}$ for more information about uncertainty. bandpasses between $1.5 \mathrm{~nm}$ and $10.5 \mathrm{~nm}$ with an expanded uncertainty* up to $0.2 \mathrm{~nm}$. The holmium oxide solution has been certified at several wavelengths for bandpasses up to $3.0 \mathrm{~nm}$ with an expanded uncertainty* of $0.1 \mathrm{~nm}$. It is strongly suggested that the participating laboratory acquire a set of check standards similar to the NIST filters for maintaining a control chart and measurement assurance.

\section{References-Spectrophotometric Measurements}

NBS Measurement Services: Spectral Reflectance, P. Y. Barnes, E. A. Early, and A. C. Parr, Natl. Inst. Stand. Technol. Spec. Publ. 250-8 (revised 1997).

NIST High Accuracy Reference Reflectometer-Spectrophotometer, J. E. Proctor, P. Y. Barnes, J. Res. Natl. Inst. Stand. Technol. 101 (5) 619 (1996).

45 Degrees/0 Degrees Reflectance Factors of Pressed Polytetrafluoroethylene (PTFE) Powder, Natl. Inst. Technol. Stand. Tech. Note 1413 (1995).

Compliance in Spectrometry:-Quality Assurance of Spectrophotometric Measurements at NIST, J. J. Hsia, T. C. Larason, P. Y. Barnes, Spectrophotometry, Luminescence and Coulour; Science \& Compl. (1995).

Comparison of Regular Transmittance Scales of Four National Standardizing Laboratories, K. L. Eckerle, J. Bastie, J. Zwinkels, V. Saprintsky, and A. Ulyanov, Color Res. Appl. 18 (1), 35-40 (Feb. 1993).

International Intercomparison of Regular Transmittance Scales, K. L. Eckerle, E. Sutter, G. H. C. Freeman, G. Andor, and L. Fillinger, Metrologia 27, 33-38 (1990).

National Scales of Spectrometry in the U.S., J. J. Hsia, Advances in Standards and Methodology in Spectrophotometry 1987, Elsevier Science Publishers, B. V., Amsterdam, 99-109 (1987).

NBS Measurement Services: Spectral Reflectance, V. R. Weidner and J. J. Hsia, Natl. Bur. Stand. (U.S.), Spec. Publ. 250-8 (July 1987). 
NBS Measurement Services: Regular Spectral Transmittance, K. L. Eckerle, J. J. Hsia, K. D. Mielenz, and V. R. Weidner, Natl. Bur. Stand. (U.S.), Spec. Publ. 250-6 (July 1987).

White Opal Glass Diffuse Spectral Reflectance Standards for the Visible Spectrum (SRM's 2015 and 2016), V. R. Weidner, Natl. Bur. Stand. (U.S.), Spec. Publ. 260-82 (1983).

Extension of a Reference Spectrophotometer into the Near Infrared, K. L. Eckerle, V. R. Weidner, J. J. Hsia, and Z. W. Chao, Natl. Bur. Stand. (U.S.), Tech. Note 1175 (Apr. 1983).

Measurement Assurance ProgramTransmittance Standards for Spectrophotometric Linearity Testing: Preparation and Calibration, K. L. Eckerle, V. R. Weidner, J. J. Hsia, and K. Kafadar, J. Res. Natl. Bur. Stand. (U.S.) 88 (1), 25 (1983).

Second-Surface Mirror Standards of Spectral Specular Reflectance (SRM's 2023, 2024, 2025), J. C. Richmond, J. J. Hsia, V. R. Weidner, and D. B. Wilmering, Natl. Bur. Stand. (U.S.), Spec. Publ. 260-79 (Oct. 1982).

Proposed Standards for the NBS Retroreflectance MAP, K. L. Eckerle and J. J. Hsia, Color Res. and Appl. 7(3), 235 (1982).

NBS $45 \%$ Normal Reflectometer for Absolute Reflectance Factors, J. J. Hsia and V. R. Weidner, Metrologia 17, 97 (1981).

NBS Specular ReflectometerSpectro-photometer, V. R. Weidner and J. J. Hsia, Appl. Opt. 19, 1268 (Apr. 1980).
New Reference Retroreflectometer, K. L. Eckerle, J. J. Hsia, V. R. Weidner, and W. H. Venable, Jr., Appl. Opt. 19 (8), 1253 (1980).

Photometry and Colorimetry of Retroreflection: State-of-Measurement Accuracy Report, K. L. Eckerle, Natl. Bur. Stand. (U.S.), Tech. Note 1125 (July 1980).

Inverse-Fourth Apparatus for Photometric Calibrations, D. A. Swyt and J. G. LaRock, Rev. Sci. Instrum. 49 (8), 1083 (Aug. 1978).

Basic Considerations of Densitometer Adjustment and Calibration, R. E. Swing, Natl. Bur. Stand. (U.S.), NBSIR 75-682 (Feb. 1975).

Establishing a Scale of DirectionalHemispherical Reflectance Factor 1: The Van den Akker Method, W. H. Venable, Jr., J. J. Hsia, and V. R. Weidner, J. Res. Natl. Bur. Stand. (U.S.), 82 (1), 29 (July-Aug. 1977).

New Reference Spectrophotometer, K. D. Mielenz, K. L. Eckerle, R. P. Madden, and J. Reader, Appl. Opt. 12 (7), 1630 (July 1973).

The Optics of Densitometry, R. E. Swing, Opt. Eng. 12 (6), 185 (Nov.-Dec. 1973).

Basic Considerations of Densitometer Adjustment and Calibration, R. E. Swing, Natl. Bur. Stand. (U.S.), Report 10970 (Dec. 1972).

Permanence of Glass Standards of Spectral Transmittance, K. S. Gibson and M. A. Belknap, J. Res. Natl. Bur. Stand. (U.S.) 44, 463 (May 1950). 


\section{Spectroradiometric Measurements C.1 Spectroradiometric Source Measurements}

\section{Technical Contact:}

\author{
Charles E. Gibson \\ Tel: 301/975-2329 \\ Email: cgibson@nist.gov \\ Fax: 301/869-5700
}

Mailing Address: Building 221, Room B208, National Institute of Standards and Technology,

Gaithersburg, MD 20899-0001

\section{Service}

ID No.

Items

NIST calibrates and issues a type 30A/T24/13

ribbon filament lamp with a mogul bi-post base.

39010C Spectral Radiance Standard, Ribbon Filament Lamp ( $225 \mathrm{~nm}$ to $2400 \mathrm{~nm}$ )

39020C Spectral Radiance Standard, Ribbon Filament Lamp (225 $\mathrm{nm}$ to $800 \mathrm{~nm}$ )

39030C Spectral Radiance Standard, Ribbon Filament Lamp ( $650 \mathrm{~nm}$ to $2400 \mathrm{~nm}$ )

NIST calibrates and issues a $1000 \mathrm{~W}$, quartz halogen lamp mounted in a medium bi-post base. The calibrations are performed at $50 \mathrm{~cm}$

39040C Spectral Irradiance Standard, 1000 W Quartz-Halogen Lamp ( $250 \mathrm{~nm}$ to $1600 \mathrm{~nm}$ )

39045C Spectral Irradiance Standard, 1000 W Quartz-Halogen Lamp ( $250 \mathrm{~nm}$ to $2400 \mathrm{~nm}$ )

NIST calibrates and issues a $30 \mathrm{~W}$ deuterium arc lamp mounted in a medium bi-post base.

39050C Spectral Irradiance Standard, 30 W Deuterium Lamp $(200 \mathrm{~nm}$ to $400 \mathrm{~nm})$

39060 S Special Tests of Radiometric Sources

Calibration Schedule: Spectroradiometric source calibrations are performed in March, June, September, and December. Requests for calibration services are scheduled after receipt of a purchase order.

\section{C.1. Spectroradiometric Source} Measurements (39010C-39060S)

This laboratory's quality system is based on the ANSI/NCSL Z540-1-1994 standard and the ISO/IEC Guide 25.

\section{Spectral Radiance Lamps (39010C- 39030C) \\ Tungsten ribbon filament lamps (30A/T24/13) are supplied by NIST}

Table 7.1. Calibration Uncertainties for Spectroradiometer Source Measurement

\begin{tabular}{|c|c|c|c|}
\hline Standard & $\begin{array}{l}\text { Wave- } \\
\text { length } \\
(\mathrm{nm})\end{array}$ & $\begin{array}{c}\text { Typical } \\
\text { values } \\
\left(\mathrm{W} \mathrm{cm}^{-3} \mathrm{sr}^{-1}\right)\end{array}$ & $\begin{array}{c}\text { Relative } \\
\text { Expanded } \\
\text { Uncertainty* } \\
(\%)\end{array}$ \\
\hline $\begin{array}{l}\text { Ribbon } \\
\text { filament } \\
\text { lamp }\end{array}$ & $\begin{array}{r}225 \\
250 \\
350 \\
655 \\
900 \\
1700 \\
2400\end{array}$ & $\begin{array}{c}5.5 \\
36 \\
3.0 \times 10^{3} \\
1.3 \times 10^{5} \\
2.2 \times 10^{5} \\
1.1 \times 10^{5} \\
4.0 \times 10^{4}\end{array}$ & $\begin{array}{l}1.5 \\
1.3 \\
1.0 \\
0.6 \\
0.6 \\
0.5 \\
0.4\end{array}$ \\
\hline $\begin{array}{l}\text { Quartz } \\
\text { halogen } \\
\text { lamp }\end{array}$ & $\begin{array}{r}250 \\
350 \\
655 \\
900 \\
1600 \\
2400\end{array}$ & $\begin{array}{c}0.2 \\
85 \\
170 \\
230 \\
120 \\
40\end{array}$ & $\begin{array}{l}1.8 \\
1.1 \\
0.9 \\
1.1 \\
1.4 \\
4.4\end{array}$ \\
\hline $\begin{array}{l}\text { Deuterium } \\
\text { arc lamp }\end{array}$ & $\begin{array}{l}200 \\
250 \\
400\end{array}$ & $\begin{array}{l}0.5 \\
0.3 \\
0.05\end{array}$ & $\begin{array}{l}5.0 \\
3.2 \\
3.2\end{array}$ \\
\hline
\end{tabular}

* See Chapter 1, Section $\mathrm{H}$ for more information about uncertainty.

as lamp standards of spectral radiance. The lamps are calibrated at 34 wavelengths from $225 \mathrm{~nm}$ to $2400 \mathrm{~nm}$, with a target area $0.6 \mathrm{~mm}$ wide by $0.8 \mathrm{~mm}$ high. The irradiance temperature ranges from about $2650 \mathrm{~K}$ at $225 \mathrm{~nm}$, and $2475 \mathrm{~K}$ at $654.6 \mathrm{~nm}$, to $1610 \mathrm{~K}$ at $2400 \mathrm{~nm}$. Also see related services $40010 \mathrm{C}-40040 \mathrm{~S}$ in next section.

\section{Spectral Irradiance Lamps (39040C-39050C)}

These spectral irradiance standards are supplied by NIST. Lamp standards of spectral irradiance are provided in two forms. For general use, tungsten filament, $1000 \mathrm{~W}$ quartz halogen type FEL lamps are calibrated at 31 wavelengths in the range $250 \mathrm{~nm}$ to $2400 \mathrm{~nm}$. The working distance is $50 \mathrm{~cm}$. For use in the ultraviolet region, deuterium arc lamps are calibrated at 21 wavelengths from $200 \mathrm{~nm}$ to $400 \mathrm{~nm}$. The deuterium lamps are intended 


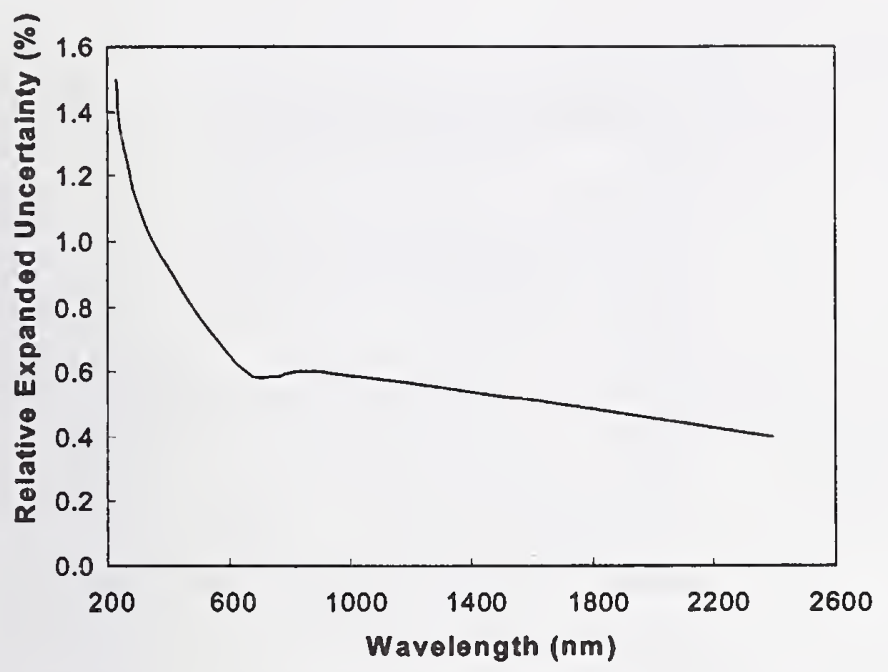

Figure 7.1. Measurement Uncertainty for NIST Spectral Radiance Calibrations.

primarily for the spectral region $200 \mathrm{~nm}$ to $250 \mathrm{~nm}$. The relative expanded uncertainty* in relative spectral distribution is $3 \%$. It is strongly recommended that the deuterium standards be compared to an FEL tungsten standard over the range $250 \mathrm{~nm}$ to $300 \mathrm{~nm}$ each time the deuterium lamp is operated to take advantage of the accuracy of the relative spectral distribution.

\section{Special Tests of Radiometric Sources (39060S)}

Spectroradiometric source calibrations are performed in the Facility for Automatic Spectral Calibrations (FASCAL). This instrument has the capability of performing spectral radiance measurements from $200 \mathrm{~nm}$ to $2500 \mathrm{~nm}$ and measuring radiance temperatures from $1050 \mathrm{~K}$ to $2700 \mathrm{~K}$ with an adjustable spectral bandwidth down to $0.1 \mathrm{~nm}$. Spectral irrdiance measurement capability from $200 \mathrm{~nm}$ to $2400 \mathrm{~nm}$ at flux levels down to $0.1 \mathrm{~W} / \mathrm{cm}^{3}$ is also

* See Chapter 1, Section $\mathrm{H}$ for more information about uncertainty. available. For both spectral radiance and irradiance measurements a wide variety of sources and measurement geometries are possible. Special tests utilizing the capabilities of FASCAL are occasionally performed depending on the availability of the equipment and associated personnel.

\section{References-Radiometric Measurements}

Results of a NIST/VNIIOFI comparison of spectral-radiance measurements, R. D. Saunders, C. E. Gibson, K. D. Meilenz, V. I. Sapritsky, K. A. Sudarev, and B. B. Khlevnoy, Metrologia 3, 449 (1995).

The New International Temperature Scale of 1990 and its Effect on Radiometric, Photometric, and Colorimetric Measurements and Standards, K. D. Mielenz, R. D. Saunders, A. C. Parr, and J. J. Hsai, CIE Proc. 22nd Session Melbourne 1991, no. 91 (1991).

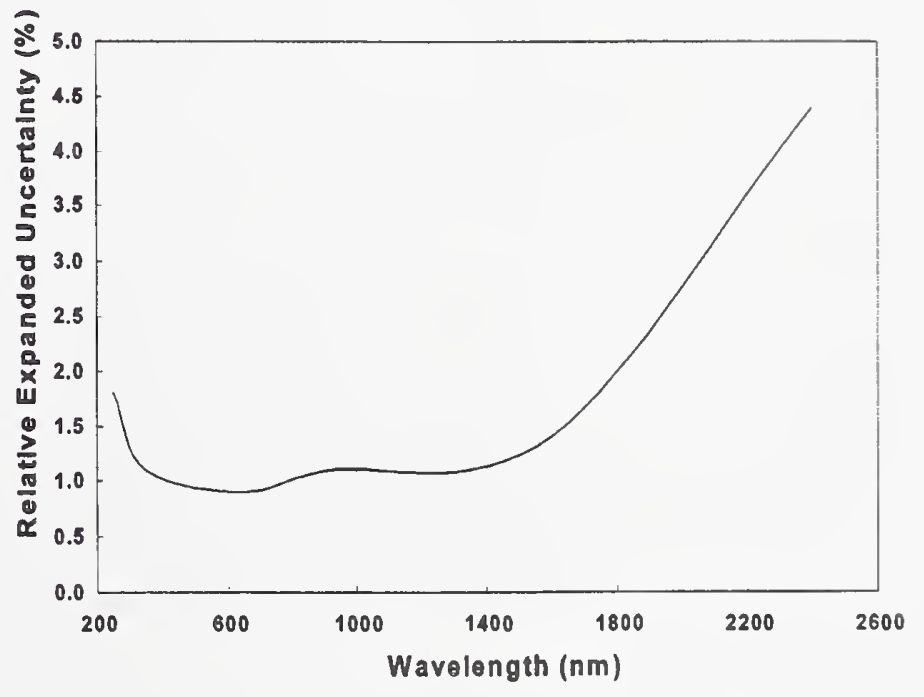

Figure 7.2. Measurement Uncertainty for NIST Spectral Irradiation Calibrations. 
Results of a CCPR Intercomparison of Spectral Irradiance Measurements by National Laboratories, J. H. Walker, R. D. Saunders, J. K. Jackson, and K. D. Mielenz, J. Res. Natl. Inst. Stand. Technol. 96, 647 (1991).

The 1990 NIST Scales of Thermal Radiometry, K. D. Mielenz, R. D. Saunders, A. C. Parr, and J. J. Hsia, J. Res. Natl. Inst. Stand. Technol. 95, 621 (1990).

Spectroradiometric Determination of the Freezing Temperature of Gold, K. D. Mielenz, R. D. Saunders and J.

Shumaker, J. Res. Natl. Inst. Stand. Technol. 95, 49 (Jan.-Feb. 1990).

The International Temperature Scale of 1990 (ITS-90), H. Preston-Thomas, Metrologia 27, 2-310 (1990).

NBS Measurement Services: Spectral Irradiance Calibrations, J. H. Walker,
R. D. Saunders, J. K. Jackson, and D. A. McSparron, Natl. Bur. Stand. (U.S.), Spec. Publ. 250-20 (Sept. 1987).

NBS Measurement Services: Spectral Radiance Calibrations, J. H. Walker, R. D. Saunders, and A. T. Hattenburg, Natl. Bur. Stand. (U.S.), Spec. Publ. 250-1 (Jan. 1987).

Spectral Irradiance Standard for the Ultraviolet: The Deuterium Lamp, R. D. Saunders, W. R. Ott, and J. M.

Bridges, Appl. Opt. 17, 593 (1978).

The 1973 NBS Scale of Spectral Irradiance, R. D. Saunders and J. B. Shumaker, Natl. Bur. Stand. (U.S.), Tech. Note 594-13 (1977).

High-Accuracy Spectral Radiance Calibration of Tungsten-Strip Lamps, H. J. Kostkowski, D. E. Erminy, and A. T. Hattenburg, Adv. Geophys. 14, 111 (1970). 


\section{Spectroradiometric Measurements C.2 Spectroradiometric Detector Measurements}

\author{
Technical Contacts:
}

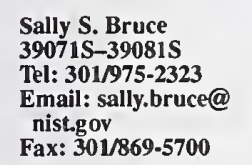

\author{
George Eppeldauer \\ $39090 \mathrm{~S}$ \\ Tel: 301/975-2338 \\ Email: george.eppeldauer@ \\ nist.gov
}

ranges from $0.4 \%$ to $13 \%$, depending on the wavelength.

\section{Retest of UV Silicon Photodiodes (39072S)}

Special tests of previously supplied (39071S) NIST (UV) silicon photodiodes are performed by measuring spectral responsivitiy (in the unit $A / W$ ) from $200 \mathrm{~nm}$ to $500 \mathrm{~nm}$.

\section{Visible to Near Infrared (NIR) Silicon Photodiodes (39073S)}

National Institute of Standards and Technology, Gaithersburg, MD 20899-0001

\begin{tabular}{ll}
\hline $\begin{array}{l}\text { Service } \\
\text { ID No. }\end{array}$ & Items \\
\hline $39071 S$ & UV Silicon Photodiodes \\
$39072 S$ & Retest of UV Silicon Photodiodes \\
$39073 S$ & Visible to NIR Silicon Photodiodes \\
$39074 S$ & Retest of Visible to NIR Silicon Photodiodes \\
$39075 S$ & Special Tests of NIR Photodiodes \\
$39080 S$ & Special Tests of Radiometric Detectors \\
$39081 S$ & $\begin{array}{l}\text { Special Tests of Photodetector Responsivity Spatial } \\
\text { Uniformity }\end{array}$ \\
$39090 S$ & Special Tests of IR Detectors \\
\hline
\end{tabular}

This laboratory's quality system is based on the ANSI/NCSL Z540-1-1994 standard and the ISO/IEC Guide 25.

\section{UV Silicon Photodiodes (39071S)}

NIST will supply the customer with a $1 \mathrm{~cm}^{2}$ UDT Sensors, Inc. model UV100 silicon photodiode characterized in the ultraviolet (UV) spectral region. The UV silicon photodiode includes the measured spectral responsivity (in the unit $\mathrm{A} / \mathrm{W}$ ) from $200 \mathrm{~nm}$ to $500 \mathrm{~nm}$ in $5 \mathrm{~nm}$ steps and the relative changes in responsivity over the photosensitive area at $350 \mathrm{~nm}$. The photosensitive area of the photodiodes is under filled for the measurements with a $1.5 \mathrm{~mm}$ diameter beam. The spectral responsivity is measured at radiant power levels of less than $20 \mu \mathrm{W}$. The bandpass of the measurement is $4 \mathrm{~nm}$. The relative expanded uncertainty*

* See Chapter 1, Section $\mathrm{H}$ for more information about uncertainty.
NIST will supply the customer with a $1 \mathrm{~cm}^{2}$ Hamamatsu model S2281 silicon photodiode characterized in the visible to near infrared (NIR) spectral region. The spectral response (in the unit $\mathrm{A} / \mathrm{W}$ ) photodiode is measured from $350 \mathrm{~nm}$ to $1100 \mathrm{~nm}$ in $5 \mathrm{~nm}$ increments. The relative change in responsivity over the photosensitive area is also measured at $500 \mathrm{~nm}$. The photosensitive area of the photodiodes is underfilled for the measurements with a $1.1 \mathrm{~mm}$ diameter beam. The spectral responsivity is measured at radiant power levels of less than $1 \mu \mathrm{W}$. The bandpass of the measurement is $4 \mathrm{~nm}$. The relative expanded uncertainty* ranges from $0.2 \%$ to $6 \%$, depending on the wavelength. The spectral range can be extended to $200 \mathrm{~nm}$ with a relative expanded uncer tainty* from $0.2 \%$ to $13 \%$ for an additional fee.

\section{Retest of Visible to NIR Silicon Photodiodes (39074S)}

Special tests of previously supplied (39073S) NIST visible to NIR silicon photodiodes are performed by measuring responsivity (in the unit $\mathrm{A} / \mathrm{W}$ ) from $350 \mathrm{~nm}$ to $110 \mathrm{~nm}$. The spectral range can be extended to $200 \mathrm{~nm}$ for an additional fee.

\section{Special Tests of NIR Photodiodes (39075S)}

Special tests of customer-supplied NIR photodiodes are performed by measuring spectral responsivity (in the unit $\mathrm{A} / \mathrm{W}$ ) from $700 \mathrm{~nm}$ to $1800 \mathrm{~nm}$. A $1.1 \mathrm{~mm}$ diameter beam is centered on and underfills the photosensitive area. 
The spectral responsivity is measured at radiant power levels of less than $1 \mu \mathrm{W}$. The bandpass of the measurement is $4 \mathrm{~nm}$. The relative expanded uncertainty* ranges from $0.7 \%$ to $7 \%$ or greater, depending on the wavelength and the individual item measured. Customers should contact Thomas Larason or Sally Bruce to discuss details before submitting a formal request.

\section{Special Tests of Radiometric Detectors (39080S)}

Special tests of radiometric detectors generally used in the ultraviolet, visible, and infrared regions of the spectrum can be performed. Responsivity of detectors can be measured between $200 \mathrm{~nm}$ and $1800 \mathrm{~nm}$ at power levels less than $4.0 \mu \mathrm{W}$. Examples of detcctor characteristics that can be determined in a special test include spectral responsivity (expressed in the unit $\mathrm{A} / \mathrm{W}$ ) and quantum efficiency (electrons per photon). The relative expanded uncertainty* ranges from $0.2 \%$ to $13 \%$ or greater, depending on the wavelength and the individual item measured. Measurements of the relative change in responsivity over the photosensitive area (responsivity spatial uniformity) are conducted under Service ID Number $39081 \mathrm{~S}$. Since special tests of this type are unique, details of the tests should be discussed with Thomas Larason or Sally Bruce before submitting a formal request.

\section{Special Tests of Photodetector Responsivity Spatial Uniformity (39081S)}

Special tests of measuring the relative changes in responsivity across the photosensitive area (responsivity spatial uniformity) can be performed for customer-supplied photodetectors. The uniformity is typically measured at a single wavelength in $0.5 \mathrm{~mm}$ spatial increments with a beam diameter of

*See Chapter 1, Section $\mathrm{H}$ for more information about uncertainty.
$1.5 \mathrm{~mm}$ in the $200 \mathrm{~nm}$ to $400 \mathrm{~nm}$ spectral region at power levels less than $20 \mu \mathrm{W}$, and a beam of diameter $1.1 \mathrm{~mm}$ in the $400 \mathrm{~nm}$ to $1800 \mathrm{~nm}$ spectral region at power levels less than $1 \mu \mathrm{W}$. The relative expanded uncertainty* ranges from $0.0024 \%$ to $0.5 \%$ or greater, depending on the wavelength and the individual item measured. Customers should contact Thomas Larason or Sally Bruce to discuss details before submitting a formal request.

\section{Special Tests of IR Detectors (39090S)}

Special tests of customer-supplied ambient temperature infrared detectors can be performed in the $2 \mu \mathrm{m}$ to $20 \mu \mathrm{m}$ wavelength range. Measurements at longer wavelength are possible, and may be provided to customers having special requirements. The special tests include spectral power responsivity and spatial response measurements. The standard configuration uses a $1.3 \mathrm{~mm}$ diameter monochromatic beam to under fill the active area of the detector with an $\mathrm{f} / \#$ between $\mathrm{f} / 4$ and $\mathrm{f} / 8$. The monochromator output beam is chopped $(\approx 39 \mathrm{~Hz})$ and has a radiant power ranging from $1 \mu \mathrm{W}$ at a wavelength of $4 \mu \mathrm{m}$ to $\approx 10 \mathrm{nW}$ at $18 \mu \mathrm{m}$. The optical bandpass of the measurement is $\approx 1 \%$ of the test wavelength. The relative expanded uncertainty* is typically $\approx 5 \%$. Customers should contact George Eppeldauer to discuss details before submitting a formal request or to get information on extended measurement capability. 
Table 7.2. Detector Measurement Services Uncertainties*

Expanded Uncertainty

Relative Estimated Uncertainty* $\delta S_{\text {TEST }} / S_{\text {TEST }}[\%]$

\begin{tabular}{|c|c|c|c|c|}
\hline $\begin{array}{c}\text { Wavelength } \\
\text { [nm] }\end{array}$ & UV 100 (UV) & $\begin{array}{r}\text { S1337 } \\
\text { (Visible) }\end{array}$ & GE (NIR) & $\begin{array}{l}\text { InGaAs } \\
\text { (NIR) }\end{array}$ \\
\hline 200 & 13.10 & & & \\
\hline 250 & 1.42 & & & \\
\hline 300 & 2.56 & & & \\
\hline 350 & 1.88 & 2.96 & & \\
\hline 400 & 1.50 & 1.56 & & \\
\hline 450 & 0.38 & 0.24 & & \\
\hline 500 & 0.38 & 0.22 & & \\
\hline 550 & & 0.20 & & \\
\hline 600 & & 0.20 & & \\
\hline 650 & & 0.20 & & \\
\hline 700 & & 0.20 & 2.48 & 2.50 \\
\hline 750 & & 0.22 & 1.98 & 2.02 \\
\hline 800 & & 0.22 & 1.86 & 1.88 \\
\hline 850 & & 0.24 & 1.54 & 1.58 \\
\hline 900 & & 0.22 & 1.28 & 1.30 \\
\hline 950 & & 2.62 & 1.88 & 1.90 \\
\hline 1000 & & 1.74 & 1.66 & 1.66 \\
\hline 1050 & & 3.16 & 1.80 & 1.82 \\
\hline 1100 & & 5.58 & 1.58 & 1.58 \\
\hline 1150 & & & 1.94 & 1.94 \\
\hline 1200 & & & 2.30 & 2.30 \\
\hline 1250 & & & 2.60 & 2.60 \\
\hline 1300 & & & 2.60 & 2.60 \\
\hline 1350 & & & 3.46 & 3.46 \\
\hline 1400 & & & 4.80 & 4.80 \\
\hline 1450 & & & 4.64 & 4.64 \\
\hline 1500 & & & 5.66 & 5.66 \\
\hline 1550 & & & 5.06 & 5.08 \\
\hline 1600 & & & 5.20 & 5.24 \\
\hline 1650 & & & 6.10 & 6.14 \\
\hline 1700 & & & 5.98 & 6.08 \\
\hline 1750 & & & 5.98 & 6.10 \\
\hline 1800 & & & 5.52 & 5.82 \\
\hline
\end{tabular}

\section{Spectroradiometric Detector Measurement References:}

NIST Measurement Services: Spectroradiometric Detector Measurements: Parts I and II-Ultraviolet and Visible to Near Infrared Detectors, T. C. Larason, S. S. Bruce, C. L. Cromer, and A. C. Parr, Natl. Inst. Stand. Technol., Spec. Publ. 250-xx (in preparation).

* See Chapter 1, Section $\mathrm{H}$ for more information about uncertainty.
Table 7.3. NIST Spectroradiometric Detector Measurement Services

\begin{tabular}{|c|c|c|c|}
\hline $\begin{array}{c}\text { Service } \\
\text { ID No. }\end{array}$ & Item of Test & $\begin{array}{c}\text { Range } \\
\text { (nm) }\end{array}$ & $\begin{array}{c}\text { Relative } \\
\text { Expanded } \\
\text { Uncertainty* } \\
(\%)\end{array}$ \\
\hline $39071 \mathrm{~S}$ & $\begin{array}{l}\text { UV Silicon Photodiodes } \\
\text { (UDT UV 100) }\end{array}$ & 200 to 500 & 0.4 to 13 \\
\hline $39072 \mathrm{~S}$ & $\begin{array}{l}\text { Retest of UV Silicon } \\
\text { Photodiodes }\end{array}$ & 200 to 500 & 0.4 to 13 \\
\hline $39073 \mathrm{~S}$ & $\begin{array}{l}\text { Visible to NIR Silicon } \\
\text { Photodiodes (Hamamatsu } \\
\text { S2281) }\end{array}$ & 400 to 1100 & 0.2 to 6 \\
\hline $39074 S$ & $\begin{array}{l}\text { Retest of Visible to NIR } \\
\text { Silicon Photodiodes } \\
\text { (Hamamatsu S1337-1010BQ } \\
\text { or S2281) }\end{array}$ & 400 to 1100 & 0.2 to 6 \\
\hline $39075 \mathrm{~S}$ & $\begin{array}{l}\text { Special Tests of NIR } \\
\text { Photodiodes }\end{array}$ & 700 to 1800 & 0.7 to 7 \\
\hline $39080 \mathrm{~S}$ & $\begin{array}{l}\text { Special Tests of Radiometric } \\
\text { Detectors }\end{array}$ & 200 to 1800 & 0.2 to 13 \\
\hline 3908 IS & $\begin{array}{l}\text { Special Tests of Photodetector } \\
\text { Responsivity Spatial } \\
\text { Uniformity }\end{array}$ & 200 to 1800 & 0.0024 to 0.5 \\
\hline
\end{tabular}

NIST Measurement Services: Spectroradiometric Detector Measurements: Part III-Infrared Detectors, A. L. Migdall and G. Eppeldauer, Natl. Inst. Stand. Technol., Spec. Publ. 250-xx (in preparation).

National Institute of Standards and Technology High-accuracy Cryogenic Radiometer, T. R. Gentile, J. M. Houston, J. E. Hardis, C. L. Cromer, and A. C. Parr, Appl. Opt. 35, 10561068 (1996).

Realization of a Scale of Absolute Spectral Response Using the National Institute of Standards and Technology High-accuracy Cryogenic Radiometer, T. R. Gentile, J. M. Houston, and C. L. Cromer, Appl. Opt. 35, 43924403 (1996). 
A National Measurement System for Radiometry, Photometry, and Pyrometry Based upon Absolute Detectors, A. C. Parr, Natl. Inst. Stand. Technol., Tech. Note 1421 (1996).

Developing Quality System Documentation Based on ANSI/NCSL Z540-11994 The Optical Technology Division's Effort, S. S. Bruce and T. C. Larason, Natl. Inst. Stand. Technol., Internal Report 5866 (1996).

High Accuracy Measurement of Aperture Area Relative to a Standard Known Aperture, J. B. Fowler and G. Dezsi, J. Res. Natl. Inst. Stand. Technol. 100, 277-283, (1995).

Building a Quality System Based on ANSI/NCSL Z540-1-1994-An Effort by the Radiometric Physics Division at NIST, S. S. Bruce and T. C. Larason, Proc. Natl. Conf. Stand. Lab. Ann. Workshop and Symp. 1995, Dallas, TX (July 16-20, 1995).

A Cryogenic Silicon Resistance Bolometer for Use as an Infrared Transfer Standard Detector, G. Eppeldauer, A. L. Migdall, and C. L. Cromer, Thermal Phenomena at Molecular and Microscales and in Cryogenic Infrared Detectors, edited by M. Kaviany et al., ASME HTD 277, pp. 63-67, New York, NY (1994).

The Radiometric Physics Division's Efforts at Building a Quality System Based on ISO/IEC Guide 25, T. C. Larason, Asociacion Mexicana De Metrologia, A. C. 1994 Conf., Acapulco, Mexico (May 10-13, 1994).

Characterization of a High Sensitivity Composite Silicon Bolometer, G. Eppeldauer, A. L. Migdall, and C. L. Cromer, Metrologia 30, 317-320 (1993).

Comparison Between Cryogenic Radiometry and the Predicted Quantum Efficiency of PN Silicon Photodiode Light Traps, E. F. Zalewski and C. C. Hoyt, Metrologia 28, 203-206 (1991).

Fourteen-Decade Photocurrent Measurements with Large-Area Silicon Photodiodes at Room Temperature, G. Eppeldauer and J. E. Hardis, Appl. Opt. 30, 3091-3099 (1991).
Photodetector Spectral Response Based on $100 \%$ Quantum Efficient Detectors, J. M. Houston and E. F. Zalewski, Optical Radiation Measurements II, James M. Palmer, ed., Proc. SPIE 1109, pp. 268-277 (1989).

Current Status of, and Future Directions in, Silicon Photodiode Self-Calibration, J. Geist, Optical Radiation Measurements II, James M. Palmer, ed., Proc. SPIE 1109, 246-256 (1989).

The NBS Photodetector Spectral Response Calibration Transfer Program, E. F. Zalewski, Natl. Bur. Stand. (U.S.), Spec. Publ. 250-17, 45 (1988). Apparatus Function of a Prism-Grating Double Monochromator, R. D. Saunders and J. B. Shumaker, Appl. Opt. 25, 3710-3714 (1986).

Automated Radiometric Linearity Tester, R. D. Saunders and J. B. Shumaker, Appl. Opt. 23, 3504-3506 (1984).

Silicon Photodiode Device with $100 \%$ External Quantum Efficiency, E. F. Zalewski and C. R. Duda, Appl. Opt. 22, 2867-2873 (1983).

Silicon Detector Nonlinearity and Related Effects, A. R. Schaefer, E. F. Zalewski, and J. Geist, Applied Optics 22, 1232 (1983).

Introduction to Coherence in Radiometry, Chapter 10 in Self-Study Manual on Optical Radiation Measurements: Part I-Concepts, Chapter 10, J. B. Shumaker, F. E. Nicodemus, ed., Natl. Bur. Stand. (U.S.), Tech. Note 910-6 (1983).

The Relative Spectral Responsivity and Slit-Scattering Function of a Spectroradiometer, Chapter 7 in Self-Study Manual on Optical Radiation Measurements: Part I-Concepts, Chapters 7, 8, and 9, H. J. Kostkowski, F. E. Nicodemus, ed., Natl. Bur. Stand. (U.S.), Tech. Note 910-4 (1979).

An Introduction to the Measurement Equation, Chapter 5 in Self-Study Manual on Optical Radiation Measurements: Part I-Concepts, Chapters 4 and 5, H. J. Kostkowski and F. E. Nicodemus, F. E. Nicodemus, ed., Natl. Bur. Stand. (U.S.), Tech. Note 910-2 (1978). 
Detector Spectral Response from 350 to $1200 \mathrm{~nm}$ Using a Monochromator Based Spectral Comparator, A.

Corrons, and E. F. Zalewski, Natl. Bur. Stand. (U.S.), Tech. Note 988 (1978). Spectral Radiometry: A New Approach Based on Electro-Optics, J. Geist, M. A. Lind, A. R. Schaefer, and
E. F. Zalewski, Natl. Bur. Stand. (U.S.), Tech. Note 954 (1977).

Comparison of the Laser Power and Total Irradiance Scales Maintained by the National Bureau of Standards, J. Geist, L. B. Schmidt, and W. E. Case, Appl. Opt. 12, 2773-2776 (1973). 


\section{Radiometric Standards in the Far Ultraviolet D.1 Standard Sources}

\author{
Technical Contact:
}

Terrell Moore

Tel: 301/975-3229

Email: tmoore@nist.gov

Mailing Address: Building 221, Room A167,

National Institute of Standards and Technology, Gaithersburg, MD 20899-0001

Service

ID No.

Items

40010C Spectral Irradiance Standard, Argon Mini-Arc (140 $\mathrm{nm}$ to $330 \mathrm{~nm}$ )

40020C Spectral Radiance Standard, Argon Mini-Arc (115 $\mathrm{nm}$ to $330 \mathrm{~nm}$ )

40030C Spectral Irradiance Standard, Deuterium Arc Lamp (165 $\mathrm{nm}$ to $200 \mathrm{~nm}$ )

40040S Special Tests of Radiometric Devices in the Near and Vacuum Ultraviolet
This laboratory's quality system is based on the ANSI/NCSL Z540-1-1994 standard and the ISO/IEC Guide 25.

\section{Source Calibrations in the Ultraviolet} (40010C-40040S)

NIST maintains a collection of secondary standard sources such as argon maxiarcs, argon mini-arcs, and deuterium arc lamps in the near and vacuum ultraviolet radiometric standards program to provide calibrations for user-supplied sources. The calibrations of these sources are traceable to a hydrogen arc whose radiance is calculable and which NIST maintains as a primary standard. Irradiance calibrations are now also traceable to the NIST electron storage ring, SURF II, against which working standard irradiance sources are periodically calibrated. The collection also includes tungsten strip lamps and tungsten halogen lamps whose calibrations are based on a blackbody rather than a hydrogen arc. Customer-supplied sources are calibrated in both radiance and irradiance by comparing them with NIST secondary standards.

Argon arcs are used to calibrate other sources in the wavelength range $115 \mathrm{~nm}$ to $330 \mathrm{~nm}$ for radiance and $140 \mathrm{~nm}$ to $330 \mathrm{~nm}$ for irradiance. The lower wavelength limit is determined in radiance by the cutoff of the magnesium fluoride windows used in the arcs and in irradiance by the decrease in signal produced by the addition of a diffuser. Deuterium arc lamps are used in the range $165 \mathrm{~nm}$ to $200 \mathrm{~nm}$, with the low wavelength cutoff due to the onset of blended molecular lines. The high wavelength limit is the starting point of the range of another calibration group at NIST. (See Service ID Numbers $39010 \mathrm{C}-39050 \mathrm{C}$, previous section.) The tungsten lamps are used at $250 \mathrm{~nm}$ and above, since their signals are too weak at shorter wavelengths. It should be noted that the wavelength range of the NIST arcs partially overlaps the range of tungsten lamps, thus providing an independent check on calibrations.

An argon mini-arc lamp supplied by the customer is calibrated for spectral irradiance at $10 \mathrm{~nm}$ intervals in the wavelength region $140 \mathrm{~nm}$ to $300 \mathrm{~nm}$. Absolute values are obtained by comparison of the radiative output with laboratory standards of both spectral irradiance and spectral radiance. The spectral irradiance measurement is made at a distance of $50 \mathrm{~cm}$ from the field stop. Relative expanded uncertainties* are $10 \%$ in the wavelength region $140 \mathrm{~nm}$ to $200 \mathrm{~nm}$ and $5 \%$ in the wavelength region $200 \mathrm{~nm}$ to $330 \mathrm{~nm}$. A measurement of the spectral transmission of the lamp window is included in order that the calibration be independent of possible window deterioration or damage. The spectral radiance of argon mini-arc radiation sources is determined with a relative expanded uncertainty* of $7 \%$

over the wavelength range $140 \mathrm{~nm}$ to $330 \mathrm{~nm}$ and $20 \%$ over the wavelength range $115 \mathrm{~nm}$ to $140 \mathrm{~nm}$. The calibrated area of the $4 \mathrm{~mm}$ diameter radiation source is the central $0.3 \mathrm{~mm}$ diameter

* See Chapter 1, Section $\mathrm{H}$ for more information about uncertainty. 
region. Typical values of the spectral radiance are as follows: at $250 \mathrm{~nm}$, $L_{\lambda}=30 \mathrm{~mW} \mathrm{~cm}^{-2} \mathrm{~nm}^{-1} \mathrm{sr}^{-1}$; and at $150 \mathrm{~nm}, L_{\lambda}=3 \mathrm{~mW} \mathrm{~cm}^{-2} \mathrm{~nm}^{-1} \mathrm{sr}^{-1}$. The transmission of the demountable lamp window and that of an additional $\mathrm{MgF}_{2}$ window are determined individually so that the user may check periodically for possible long-term variations.

The deuterium arc lamp is calibrated at 10 wavelengths from $165 \mathrm{~nm}$ to $200 \mathrm{~nm}$, at a distance of $50 \mathrm{~cm}$. Typical values of spectral irradiance are $0.5 \mathrm{~W} / \mathrm{cm}^{3}$ at $165 \mathrm{~nm}, 0.3 \mathrm{~W} / \mathrm{cm}^{3}$ at $170 \mathrm{~nm}$, and $0.5 \mathrm{~W} / \mathrm{cm}^{3}$ at $200 \mathrm{~nm}$. The relative expanded uncertainty* is $10 \%$. The lamp is normally supplied by NIST and requires $300 \mathrm{~mA}$ at about $100 \mathrm{~V}$.

\section{References-Source Calibrations in the Ultraviolet}

Radiometric Calibrations of Portable Sources in the Vacuum Ultraviolet, J. Z. Klose, J. M. Bridges, and W. R. Ott, J. Res. Natl. Bur. Stand. (U.S.), 93, 21 (1988).

NBS Measurement Services: Radiometric Standards in the Vacuum Ultraviolet,
*See Chapter 1, Section H for more information about uncertainty.
J. Z. Klose, J. M. Bridges, and W. R. Ott, Natl. Bur. Stand. (U.S.), Spec. Publ. 250-3 (June 1987).

Radiance of a Pt/Cr-Ne Hollow Cathode Spectral Line Source,

J. Z. Klose and J. M. Bridges, Appl. Opt. 26, 5202 (1987).

VUV Spectral Irradiance Calibrations: Method and Applications, W. R. Ott, J. M. Bridges, and J. Z. Klose, Opt. Lett. 5, 225 (1980).

Spectral Irradiance Standard for the Ultraviolet: The Deuterium Lamp, R. D. Saunders, W. R. Ott, and J. M. Bridges, Appl. Opt. 17, 593 (1978).

Spectral Radiance Calibrations between 165-300 nm: An Interlaboratory Comparison, J. M. Bridges, W. R. Ott, E. Pitz, A. Schultz, D. Einfield, and D. Stuck, Appl. Opt. 16, 1788 (1977). VUV Radiometry, 3: The Argon MiniArc as a New Secondary Standard of Spectral Radiance, J. M. Bridges and W. R. Ott, Appl. Opt. 16, 367 (1977). NBS UV Radiometric Standards,

W. R. Ott, Natl. Bur. Stand. (U.S.), Spec. Publ. 456, 107 (1976). 


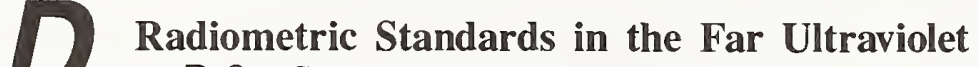 D.2 Standard Detectors in the Far Ultraviolet}

\author{
Technical Contact:
}

\author{
L. Randall Canfield \\ Tel: 301/975-3728 \\ Email: r.canfield@nist.gov
}

Mailing Address: Building 245, Room B119, National Institute of Standards and Technology, Gaithersburg, MD 20899-0001

\begin{tabular}{|c|c|}
\hline $\begin{array}{l}\text { Service } \\
\text { ID No. }\end{array}$ & Items \\
\hline $40510 \mathrm{C}$ & $\begin{array}{l}\text { Detector Standard, Windowless Photodiode } \\
\text { (5 nm to } 122 \mathrm{~nm})\end{array}$ \\
\hline $40511 \mathrm{C}$ & Recalibration of Detector Standard ( $5 \mathrm{~nm}$ to $122 \mathrm{~nm}$ ) \\
\hline $40520 \mathrm{C}$ & $\begin{array}{l}\text { Detector Standard, Windowless Photodiode } \\
\text { (18 nm to } 122 \mathrm{~nm})\end{array}$ \\
\hline $40521 \mathrm{C}$ & Recalibration of Detector Standard ( $18 \mathrm{~nm}$ to $122 \mathrm{~nm}$ ) \\
\hline $40530 \mathrm{C}$ & $\begin{array}{l}\text { Detector Standard, Windowless Photodiode } \\
(52 \mathrm{~nm} \text { to } 122 \mathrm{~nm})\end{array}$ \\
\hline $40531 \mathrm{C}$ & Recalibration of Detector Standard (52 $\mathrm{nm}$ to $122 \mathrm{~nm}$ ) \\
\hline $40540 \mathrm{C}$ & Uncalibrated Windowless Photodiode \\
\hline $40560 \mathrm{C}$ & $\begin{array}{l}\text { Detector Standard, Windowed Photodiode } \\
(116 \mathrm{~nm} \text { to } 254 \mathrm{~nm})\end{array}$ \\
\hline $40561 \mathrm{C}$ & Recalibration of Detector Standard (116 nm to $254 \mathrm{~nm}$ \\
\hline $40599 \mathrm{~S}$ & $\begin{array}{l}\text { Special Tests on Detectors from the Ultraviolet } \\
(254 \mathrm{~nm}) \text { to the Soft X-Ray Region }(5 \mathrm{~nm})\end{array}$ \\
\hline
\end{tabular}

This laboratory's quality system is based on the ANSU/NCSL Z540-1-1994 standard and the ISO/IEC Guide 25 .

\section{Detector Calibrations in the Ultra- violet $(40510 \mathrm{C}-40599 \mathrm{~S})$}

Calibrated transfer standard detectors for the far ultraviolet are available from NIST to cover the spectral region $5 \mathrm{~nm}$ to $254 \mathrm{~nm}$. Users are furnished with the quantum efficiency as a function of wavelength; quantum efficiency is defined as the number of photoelectrons per incident photon. Three detector types are available to cover this range: (1) a windowless silicon semiconductor photodiode for the wavelength region $5 \mathrm{~nm}$ to
$254 \mathrm{~nm}$ (available under Service ID No. 40599S); (2) a windowless photoemissive diode with an $\mathrm{Al}_{2} \mathrm{O}_{3}$ photocathode for the wavelength region $5 \mathrm{~nm}$ ro $122 \mathrm{~nm}$; and (3) a $\mathrm{MgF}_{2}$-windowed photodiode with a semi-transparent CsTe photocathode for the wavelength region $116 \mathrm{~nm}$ to $254 \mathrm{~nm}$. The detectors have been extensively studied regarding radiometrically important parameters such as photocathode spatial uniformity and temporal stability of conversion efficiency. It should be noted that the silicon photodiode is not solar blind, while the windowless photoemissive diode is. Stray light considerations should be evaluated before making a choice for the $5 \mathrm{~nm}$ to $122 \mathrm{~nm}$ region.

The relative expanded uncertainties* in the measured quanturn efficiencies are $7 \%$ to $22 \%$ in the $5 \mathrm{~nm}$ to $122 \mathrm{~nm}$ windowless photodiode region, and $9 \%$ to $10 \%$ in the $116 \mathrm{~nm}$ to $254 \mathrm{~nm}$ windowed photodiode region.

NIST working standard calbrations are based on the rare gas ionization chamber in the $5 \mathrm{~nm}$ to $92 \mathrm{~nm}$ region, and on the calculable synchrotron flux from the NIST electron storage ring, SURF II, at wavelengths longer than $110 \mathrm{~nm}$. Two facilities at SURF II are used in these calibrations, one in the $5 \mathrm{~nm}$ to $50 \mathrm{~nm}$ region and a second in the $116 \mathrm{~nm}$ to $254 \mathrm{~nm}$ region. A separate laboratory facility is used for the $50 \mathrm{~nm}$ to $92 \mathrm{~nm}$ calibration of working standards.

Outgoing detectors are calibrated by direct intercomparison with precalibrated working standards that are periodically recalibrated. Windowless $\mathrm{Al}_{2} \mathrm{O}_{3}$ photodiodes are fabricated in-house; the windowless Si photodiodes and the windowed CsTe photodiodes are procured commercially and tested for stability and spatial homogeneity. Only those photodiodes meeting stringent NIST quality specifications are selected as transfer standards. The calibration costs include the cost of the detector and screening services unless a recalibration of previously used detectors is requested.

* See Chapter 1, Section $\mathrm{H}$ for more information about uncertainty. 
Special detectors that do not lend themselves to convenient on-site cross-calibration may also be calibrated at NIST if the detectors merit radiometric application and if the NIST calibration facilities are suitable and available for the particular device.

\section{References-Detector Calibrations in the Ultraviolet}

Stable Silicon Photodiodes for Absolute Intensity Measurements in the VUV and Soft X-Ray Regions, E. M. Gullikson, R. Korde, L. R. Canfield, and R. E. Vest, J. Electron Spectrosc. Relat. Phenon. 80, 313 (1996).
NBS Measurement Services: Far Ultraviolet Detector Standards, L. R. Canfield and N. Swanson, Natl. Bur. Stand.

(U.S.), Spec. Publ. 250-2 (June 1987). Time Response of NBS Windowless XUV Radiometric Transfer Standards, E. B. Saloman, Appl. Opt. 14, 1764 (1975).

Far Ultraviolet Detector Standards, L. R. Canfield and N. Swanson,

J. Res. Natl. Bur. Stand. (U.S.), 92, 97 (1987). 


\section{Lasers and Optoelectronic Components Used with Lasers}

\author{
Technical Contacts:
}

Thomas R. Scott
Tel: 303/497-3651
Email: thomas.scott
@nist.gov

\author{
Christopher L. Cromer \\ (Laser Radiometry) \\ Tel: 303/497-5620 \\ Email: christopher. \\ cromer@nist.gov
}

Paula M. Hewitt

Administration and Logistics

Tel: $303 / 497-3753$

Email: paula.hewitt@nist.gov

Fax: 303/497-3970

Mailing Address: M. C. 813.10,

National Institute of Standards and Technology,

325 Broadway,

Boulder, CO 80303-3328

\begin{tabular}{|c|c|}
\hline $\begin{array}{l}\text { Service } \\
\text { ID No. }\end{array}$ & Items \\
\hline $42110 \mathrm{C}$ & $\begin{array}{l}\text { Laser Power and Energy Meter (or Detectors Used } \\
\text { with Lasers) Calibrations (single wavelength and power) }\end{array}$ \\
\hline $42111 \mathrm{C}$ & $\begin{array}{l}\text { Same as } 42110 \mathrm{C} \text {, Additional Wavelengths } \\
\text { or Powers }\end{array}$ \\
\hline $42120 \mathrm{M}$ & $\begin{array}{l}\text { Laser Power and Energy Measurement Assurance } \\
\text { Program (MAP) }\end{array}$ \\
\hline $42130 \mathrm{C}$ & $\begin{array}{l}\text { Optical Fiber Power Meter (or Detectors Used } \\
\text { with Lasers) Calibrations (single wavelength and } \\
\text { connector type) }\end{array}$ \\
\hline $42131 \mathrm{C}$ & $\begin{array}{l}\text { Same as } 42130 \mathrm{C} \text {, Additional Wavelengths or } \\
\text { Connector Types }\end{array}$ \\
\hline $42140 \mathrm{M}$ & $\begin{array}{l}\text { Optical Fiber Power Meter Measurement Assurance } \\
\text { Program (MAP) }\end{array}$ \\
\hline $42150 \mathrm{M}$ & $\begin{array}{l}\text { Low-Level Laser Measurement Assurance Program } \\
\text { (MAP) }\end{array}$ \\
\hline $42151 \mathrm{C}$ & Low-Level Laser Radiometer Calibration \\
\hline $42160 \mathrm{~S}$ & $\begin{array}{l}\text { Special Test for Frequency Response Measurements } \\
\text { of Detectors Used with Lasers }\end{array}$ \\
\hline $42161 \mathrm{~S}$ & $\begin{array}{l}\text { Special Test for Impulse Response Measurements } \\
\text { of Detectors Used with Lasers }\end{array}$ \\
\hline $42162 S$ & $\begin{array}{l}\text { Special Tests for High Accuracy Laser and Optical } \\
\text { Fiber Power Measurements }\end{array}$ \\
\hline $42163 S$ & $\begin{array}{l}\text { Special Test for Linearity Measurements of Laser } \\
\text { and Optical Fiber Power Meters (or Detectors } \\
\text { Used with Lasers) }\end{array}$ \\
\hline $42164 S$ & $\begin{array}{l}\text { Special Test for Spectral Responsivity Measurements } \\
\text { of Laser and Optical Fiber Power Meters (or Detectors } \\
\text { Used with Lasers) }\end{array}$ \\
\hline $42165 \mathrm{~S}$ & $\begin{array}{l}\text { Special Test for Spatial Uniformity of Laser and Optical } \\
\text { Fiber Power Meters and Detectors Used with Lasers }\end{array}$ \\
\hline $42170 \mathrm{~S}$ & $\begin{array}{l}\text { Special Test for General Laser Measurements, } \\
\text { by Prearrangement }\end{array}$ \\
\hline $42180 S$ & $\begin{array}{l}\text { Special Test for General Optical Fiber Power } \\
\text { Measurements, by Prearrangement }\end{array}$ \\
\hline
\end{tabular}

\section{General Information}

The NIST Optoelectronics Division develops and maintains the U.S. national standards for the characterization of lasers, along with detectors and other optical and optoelectronic components used with lasers and in laser-based systems. These standards support applications of lasers in manufacturing, electronics, medicine, communications, and the military, among other fields, and are generally used to provide calibrations of instruments used in these areas.

For calibrating instruments used to measure the power or energy emitted by a laser, specially designed standards consisting of several types of isoperibol (constant temperature environment) calorimeters have been developed and used for many years. Low-level laboratory standards are realized using solidstate photodetectors and other thermal detectors. Well-characterized transfer standards (calibrated against the primary standards) are also maintained as laboratory standards for calibrations and for use in Measurement Assurance Program (MAP) intercomparisons. As part of a continuing process, new standards are being developed and implemented to improve accuracy and dynamic range. For example, the Division is developing ultra-high accuracy laser power measurement capability using a new cryogenically cooled electrical substitution laser power meter. The laboratory standards and secondary transfer standards are used in specially designed, beamsplitter-based calibration systems that allow various power and energy detectors to be compared to the standards.

The Optoelectronics Division maintains the capability of measuring other laser parameters, for example, beam profile and relative intensity noise. Because these measurements are generally less well defined than power and energy measurements, they are undertaken as Special Tests, after consultation with the customer. Instruments used in optical communications generally accept or receive optical power through a connectorized optical fiber. 
Wavelength ranges of interest are generally centered on $850 \mathrm{~nm}, 1300 \mathrm{~nm}$, and $1550 \mathrm{~nm}$. In addition to power measurements in these ranges, calibrations of the frequency response (or impulse response) of detectors and analog and digital receivers used in optical communications can be provided. NIST also provides several Standard Reference Materials* for calibrating instruments used in optical communications.

The Optoelectronics Division can also characterize many other optical and optoelectronic components used with lasers. Within existing capabilities, Special Test measurements can be provided. Those needing such measurements are invited to contact the Division.

\section{Laser Power and Energy Meter (or Detectors Used with Lasers) Calibrations $(42110 \mathrm{C}-42111 \mathrm{C})$}

Within the ranges listed in Table 7.4, NIST can perform calibrations at the power (or energy) and wavelength specified by the customer. These ranges are determined by the combined limits of our standards and available laser sources. For these measurements, the instrument to be measured is sent to NIST, where it is then compared to the appropriate laboratory reference standard using a calibrated beamsplitter measurement system. Normally, the response of the detector is characterized but no physical adjustments are made to the test instrument. At the completion of the calibration measurements, the instrument and a calibration report are sent to the customer. The calibration report summarizes the results of the measurements and provides a detailed listing of the associated measurement uncertainties.

The laboratory standard isoperibol calorimeters used as references for these measurements were designed and built at NIST and all their critical parameters (electrical calibration coefficient, absorptivity, window transmittance, etc.) have been evaluated for the laser wavelengths

* See Chapter 1, Section C for information on other thermodynamic property measurement standards available from the Standard Reference Materials Program.
Table 7.4. Laser Power and Energy Measurement Capabilities

\begin{tabular}{lcrr}
\hline $\begin{array}{l}\text { Primary } \\
\text { Standard }\end{array}$ & Wavelength & Power Range & $\begin{array}{c}\text { Typical } \\
\text { Relative } \\
\text { Expanded } \\
\text { Uncertainty** } \\
\text { (\%) }\end{array}$ \\
\hline C-series & $488.0,514.5 \mathrm{~nm}$ & $1 \mathrm{nW}$ to $500 \mathrm{~mW}$ & 0.5 to 1.0 \\
& $632.8 \mathrm{~nm}$ & $1 \mathrm{nW}$ to $20 \mathrm{~mW}$ & 0.5 to 1.0 \\
& $830 \mathrm{~nm}$ & $100 \mu \mathrm{WW}$ to $20 \mathrm{~mW}$ & 0.5 to 1.0 \\
& $1064 \mathrm{~nm}$ & $1 \mathrm{~mW}$ to $1 \mathrm{~W}$ & 0.5 to 1.0 \\
Q-series & $1319 \mathrm{~nm}$ & $100 \mu \mathrm{W}$ to $100 \mathrm{~mW}$ & 0.5 to 1.0 \\
(Q-switched) & $1523 \mathrm{~nm}$ & $100 \mu \mathrm{W}$ to $1 \mathrm{~mW}$ & 0.5 to 1.0 \\
K-series & $1.06 \mu \mathrm{m}$ & $1 \mathrm{~mJ} / \mathrm{pulse}$ to $60 \mathrm{~mJ} / \mathrm{pulse}$ & 1.1 to 1.9 \\
QUV- & $1.06 \mu \mathrm{m}$ & $1 \mathrm{~mW}$ to $1 \mathrm{~W}$ & 1.6 to 2.5 \\
Series & $10.6 \mu \mathrm{m}$ & $1 \mathrm{~W}$ to $300 \mathrm{~W}$ & 1.6 to 2.5 \\
& $248 \mathrm{~nm}$ & $35 \mathrm{~mW}$ to $900 \mathrm{~W}$ & 1.0 to 3.0 \\
& $($ pulsed) & $0.4 \mathrm{~mJ} / \mathrm{pulse}$ & \\
\hline
\end{tabular}

**See Chapter 1, Section $\mathrm{H}$ for more information about uncertainty.

and energies for which they are used. The characteristic voltage response of the standard isoperibol calorimeters is described by first principles of thermodynamics and linear system analysis. Accurate quantitative responsivity characterization (including linearity and stability) of the calorimeters is

accomplished by periodically performed, electrical heater calibrations.

The laser power and energy measurements are accomplished using a calibrated beamsplitter arrangement in which both the standard and the test meter are exposed to the laser beam simultaneously. In addition to the isoperibol calorimeters, solid-state photodiodes and trap detectors are used as laboratory standards, especially at powers below $1 \mathrm{~mW}$. The beamsplitters used in these systems have been characterized for all specific wavelengths for which they are used. Small angles of incidence are used to minimize polarization and angular position uncertainties.

The laser sources used for these calibration measurements with the primary standards consist of the following types (subject to change): (1) helium-neon $(632.8 \mathrm{~nm}$ and $1523 \mathrm{~nm}),(2)$ argon ion $(488.0 \mathrm{~nm}$ and $514.5 \mathrm{~nm})$, (3) Nd:YAG (1064 nm and $1319 \mathrm{~nm} \mathrm{CW}$, and 
$1064 \mathrm{~nm}$ Q-switched), (4) diode laser $(825 \mathrm{~nm}$ to $833 \mathrm{~nm})$, (5) carbon dioxide $(10.6 \mu \mathrm{m})$ and $(6) \mathrm{KrF}$ excimer $(248 \mathrm{~nm})$.

\section{Laser Power and Energy Measurement Assurance Program (MAP) (42120M)}

The Measurement Assurance Program (MAP) is available at the wavelengths and powers listed in Table 7.4. The laser MAP intercomparisons are implemented by means of transfer standards, which have been evaluated and characterized relative to the national primary standards. The measurement system and primary standards discussed above are used to calibrate the transfer standards for the intercomparisons. The characteristics of these transfer standards are well understood, and their associated accuracies do not differ significantly from those associated with direct comparisons to the primary standards. For a specified wavelength and power or energy, the appropriate transfer standard is selected and sent from NIST to the MAP participant. The participant calibrates the NIST transfer standard using their measurement system and then returns both his data and the transfer standard to NIST. Before and after the NIST transfer standard is shipped to the participant, NIST performs calibration measurements on the detector to provide continuity during the intercomparison. At the completion of the intercomparison, NIST evaluates the participant's measurement results relative to the NIST calibration results on this same meter. A MAP intercomparison report summarizing the intercomparison and listing the associated measurement uncertainties is then submitted to the participant. Customers who have the capability and require higher accuracy may request MAP services using appropriate high-accuracy transfer standards such as the photodiode trap detectors.

\section{Optical Fiber Power Meter (or Detectors Used with Lasers) Calibrations $(42130 \mathrm{C}-42131 \mathrm{C})$}

Optical fiber power meters are calibrated using an automated calibration system in which the test meter and the laboratory standard are alternately exposed to a stable diode laser source. During the measurement process, the input power to the test meter is monitored with a fiber coupler and reference detector assembly. Table 7.5 summarizes the current capabilities of this system. The laboratory standard used for these measurements is an electrically calibrated pyroelectric radiometer (ECPR) which has been calibrated against a primary standard calorimeter. Various diode laser sources are used to provide the available wavelengths. The calibrations can be accomplished with either a collimated beam or a connectorized fiber configuration. We can accommodate most commonly used fiber connectors (such as $\mathrm{FC} / \mathrm{PC}$, ST, biconic, SC, SMA, FC/APC, HMS-10 etc.).

Table 7.5. Measurement Capabilities of Automated Calibration System for Optical Fiber Power Meters

\begin{tabular}{lccc}
$\begin{array}{l}\text { Laboratory } \\
\text { Standard }\end{array}$ & $\begin{array}{c}\text { Wavelength Window } \\
(\mathbf{n m})\end{array}$ & $\begin{array}{c}\text { Power Range } \\
(\boldsymbol{\mu W})\end{array}$ & $\begin{array}{r}\text { Typic } \\
\text { Uncertaint } \\
(\%)\end{array}$ \\
\hline ECPR & 670 & 10 to 200 & 0.5 to 1. \\
ECPR & 780 & 10 to 200 & 0.5 to 1. \\
ECPR & 850 & 10 to 200 & 0.5 to 1. \\
EPCR & 980 & 10 to 200 & 0.5 to 1. \\
EPCR & 1300 & 10 to 200 & 0.5 to 1. \\
EPCR & 1500 & 10 to 200 & 0.5 to 1.
\end{tabular}

* See Chapter 1, Section H for more information about uncertainty.

Optical Fiber Power Meter Measurement Assurance Program (MAP) $(42140 \mathrm{M})$

NIST maintains a set of calibrated transfer standards, which are available for MAP intercomparisons of optical fiber power meters. These transfer standards are calibrated at the wavelengths listed in Table 7.6 using the optical fiber power meter calibration system discussed above. If the MAP is to be conducted using a fiber with attached connector, then customers are asked to provide the specific fiber and connector which is used in their laboratories. As in the laser MAP procedures listed above, measurements are made on the NIST transfer standard both before and after the MAP participant's measurements are conducted. At the conclusion 
of the MAP process, a calibration report that summarizes the measurements and associated uncertainties is sent to the participant.

\section{Low-Level Laser Radiometer Calibra- tions and Measurement Assurance Program (MAP) (42150M)}

NIST has designed and constructed special silicon and germanium diode detectors to measure pulse energy and peak power of low-level, $1064 \mathrm{~nm}$ laser pulses of about $10 \mathrm{~ns}$ to $150 \mathrm{~ns}$ duration. These diode detectors have been evaluated for spatial uniformity, bandwidth, and linearity, and are used as transfer standards for intercomparisons. The output response of each detector has been calibrated against a transfer standard which, in turn, has been calibrated against the $\mathrm{C}$-series calorimeter. The system for calibrating these transfer standards uses a CW $\mathrm{Nd}$ :YAG laser whose radiation is acoustooptically modulated to produce short, well defined pulses. The beam intensity is attenuated to low-levels using a multiple reflection precision wedge beamsplitter. The transfer standards are available for intercomparisons at the powers listed in Table 7.6.

Table 7.6. Low-Level MAP Transfer Standards

\begin{tabular}{llc} 
Transfer Standard & Energy [Power Range] & $\begin{array}{c}\text { Relative Expanded } \\
\text { Uncertainty* } \\
(\%)\end{array}$ \\
\hline Silicon PIN & $\begin{array}{l}10^{-14}\left(\mathrm{~J} / \mathrm{cm}^{2}\right) /[\text { pulse] to } \\
10^{-11}\left(\mathrm{~J} / \mathrm{cm}^{2}\right) /[\text { pulse] }\end{array}$ & 6 to 8 \\
Germanium PIN & $10^{-15}\left(\mathrm{~J} / \mathrm{cm}^{2}\right) /[$ pulse] & 15 \\
Silicon APD & $10^{-8} \mathrm{~W} / \mathrm{cm}^{2}$ [peak] to & 6 to 8 \\
& $10^{-4} \mathrm{~W} / \mathrm{cm}^{2}$ [peak] & \\
\hline
\end{tabular}

Special Test for Frequency Response Measurements of Detectors Used with Lasers (42160S)

NIST measures the frequency response of photodetectors using the difference frequency beat note from 2 single frequency Nd:YAG lasers operating at $1319 \mathrm{~nm}$. Measurements can be performed between $300 \mathrm{kHz}$ and $50 \mathrm{GHz}$.

* See Chapter 1, Section $\mathrm{H}$ for more information about uncertainty.
Normalized frequency response is proportional to the ratio of the generated microwave power to the DC power supplied through the bias current. A photodetector suitable for calibration includes a connectorized fiber pigtail and precision coaxial microwave connector. Highest accuracy measurements are attained when the photodiode and power sensor are calibrated as one unit. A transfer standard of this type can be used to determine the optical modulation index of an arbitrary optical source with sinusoidal modulation. Options available include measurement of frequency response of a separate photodetector using NIST power sensors, or normalization to optical power to give absolute response. Each of these options gives a degradation in measurement uncertainty due to power sensor calibration and fiber connector insertion loss, respectively. Measurements may also include correction for electrical impedance mismatch when separate power sensors are used.

\section{Special Test for Impulse Response Measurements of Detectors Used with Lasers (42161S)}

NIST uses a Ti:sapphire laser to generate $150 \mathrm{fs}$ optical pulses in the $750 \mathrm{~nm}$ to $850 \mathrm{~nm}$ wavelength region. The electrical impulse resulting from the optical input to the detector is measured on a calibrated oscilloscope with $50 \mathrm{GHz}$ bandwidth. The resulting waveform is Fourier-transformed, and the frequency response of the oscilloscope is deconvolved to give the magnitude of the photodetector frequency response.

\section{High Accuracy Laser and Optical Fiber Power Measurements (42162S)}

A cryogenically cooled electrical substitution radiometer (ESR) has been installed in our measurement laboratory and is now being thoroughly evaluated. Using this instrument as a reference, uncertainties smaller than those listed in Tables 7.5 and 7.6 are available on request for certain wavelengths and measurement conditions. These high accuracy measurements are appropriate only for certain transfer standards (such as photodiode trap detectors) capable of maintaining high accuracies. 
Special Test for Linearity Measurements of Laser and Optical Fiber Power Meters (or Detectors Used with Lasers) (42163S)

Linearity of optical fiber power meters and detectors used with lasers can be measured at the three nominal wavelength regions of $850 \mathrm{~nm}, 1300 \mathrm{~nm}$ and $1550 \mathrm{~nm}$ using automated NIST-designed measurement systems. These systems are based on dual beam superposition, in which the radiation from two optical paths is incident (both jointly and individually) onto the detector. The system can provide linearity characterizations covering a $60 \mathrm{~dB}$ to $90 \mathrm{~dB}$ power range. Various other wavelengths and powers are also available upon request.

\section{Special Test for Spectral Responsivity Measurements of Laser and Optical Fiber Power Meters (or Detectors Used with Lasers) (42164S)}

Spectral responsivity measurements on laser power meters and detectors used with lasers can be performed over the wavelength region $450 \mathrm{~nm}$ to $1700 \mathrm{~nm}$. High resolution spectral responsivity measurements can be performed over limited wavelength regions centered on $850 \mathrm{~nm}, 1300 \mathrm{~nm}$, and $1550 \mathrm{~nm}$. These limited-range spectral response measurements can be performed with or without connectorized fibers attached. Measurements over the wider wavelength region are also available at lower accuracy.

\section{Special Test for Spatial Uniformity of Laser and Optical Fiber Power Meters (or Detectors Used with Lasers) (42165S)}

Detector uniformity is measured using a specially designed system which provides a small beam of laser radiation (at nominal wavelengths of $850 \mathrm{~nm}, 1300 \mathrm{~nm}$, or $1550 \mathrm{~nm}$ ) which is scanned across the detector surface. The resulting detector output response is displayed graphically and analyzed statistically. This information is useful for characterizing the quality of a detector used with lasers and or identifying interference effects caused by, for example, windows with parallel surfaces. Other wavelengths are available upon request.

\section{Special Test for General Laser Measurements (42170S)}

The Optoelectronics Division conducts research not described specifically above on a variety of problems in the characterization of optoelectronics components. Consequently, we are interested in discussing and supporting all measurements involving laser detectors, sources, components, and instrumentation. Examples of measurement areas include beam profile, relative intensity noise (RIN), optical density or attenuation, and polarization (retardance).

\section{Special Test for General Optical Fiber Power Measurements (42180S)}

In support of instrumentation used with optical fiber power systems, various optical fiber power related measurements are available by request and prearrangement. These include power measurements at customer-selected wavelengths (in the $\pm 20 \mathrm{~nm}$ regions around $850 \mathrm{~nm}$, $1300 \mathrm{~nm}$, and $1550 \mathrm{~nm}$ ), optical attenuator characterization, high power measurements, and power meter measurements involving unusual connector or fiber types.

\section{References-Laser Power and Energy}

NBS Laser Power and Energy Measurements, T. R. Scott, Proc. SPIE O-E LASE '88, Optoelectronics and Laser Applications in Science and Engineering (1988).

A System for Calibrating Laser Power Meters for the Range 5-1000 W., E. D. West and L. B. Schmidt, Natl. Bur. Stand. (U.S.), Tech. Note 685 (May 1987).

A System for Measuring Energy and Peak Power of Low-Level 1.064- $\mu \mathrm{m}$ Laser Pulses, A. A. Sanders and A. L. Rasmussen, Natl. Bur. Stand. (U.S.), Tech. Note 1058 (Oct. 1982).

Documentation of the NBS C, K, and Q Laser Calibration Systems, W. E. Case, Natl. Bur. Stand. (U.S.), Int. Report, NBSIR 82-1676 (Sep.1982). 
A System for Measuring The Characteristics of High Peak Power Detectors of Pulsed $\mathrm{CO}_{2}$ Radiation, P. A. Simpson, Natl. Bur. Stand. (U.S.), Tech Note 1023 (Sept. 1980).

Quality Assurance Program for the NBS $\mathrm{C}, \mathrm{K}$, and Q Laser Calibration Systems, W. Case, Natl. Bur. Stand. (U.S.), Int. Report, NBSIR 79-1619 (Aug. 1979).

Absolute Reference Calorimeter for Measuring High Power Laser Pulses, D. L. Franzen and L. B. Schmidt, Appl. Opt. 15, 3115 (Dec. 1976).

A Calorimeter for High-Power CW Lasers, R. L. Smith, T. W. Russell, W. E. Case, and A. L. Rasmussen, IEEE Trans. Instr. Meas. IM-21, (4) (Nov. 1972).

A Reference Calorimeter for Laser Energy Measurement, E. D. West, W. E. Case, A. L. Rasmussen, and L. B. Schmidt, J. Res. Natl. Bur. Stand. (U.S.), 76A (1), 13 (Jan.-Feb. 1972).

Data Analysis for Isoperibol Laser Calorimetry, E. D. West, Natl. Bur. Stand. (U.S.), Tech. Note 396 (Feb. 1971).

Theory of Isoperibol Calorimetry for Laser Power and Energy Measurement, E. D. West and K. L. Churney, J. Appl. Phys. 41, (6), 2705 (May 1970).

Deep-UV Excimer Laser Measurements at NIST, R. W. Leonhardt and T. R. Scott, Integrated Circuit Metrology, Inspection, and Process Control IX, Proc. SPIE 2439, 448-459.

Low-Level Pulsed 1064 nm Laser Radiometer Transfer Standard, R.W. Leonhardt, Optical Radiation Measurements III, Proc. SPIE 2815, 154-159.

\section{References-Optical Fiber Power Meter Measurements}

Nonlinearity of Optical Power Meters, I. Vayshenker, S. Yang, X. Li, and T.R. Scott, Natl. Inst. Stand. Technol. Spec. Publ. 905, 101-104, (1996).

Errors Due to Connectors in Optical Fiber Power Meters, I. Vayshenker, X. Li, D. Keenan and T.R. Scott, Natl. Inst. Stand. Technol. Spec. Publ. 905, 49-52, (1996).
Automated Measurement of Nonlinearity of Optical Fiber Power Meters, I. Vayshenker, S. Yang, X. Li, and T. R. Scott, Proc. Int. Symp. IMEKO, 2550, San Diego, CA (July 11-12, 1995).

Optical Detector Nonlinearity: Simulation, S.Yang, I. Vayshenker, X. Li, M. Zander and T.R. Scott, Natl. Inst. Stand. Technol., Tech. Note 1376 (May 19, 1995).

Accurate Measurement of Optical Detector Nonlinearity, S. Yang, I.

Vayshenker, X. Li, and T. R. Scott, Proc. Natl. Conf. Stand. Lab. Workshop and Symp., Session 5A, 353-362, (July-Aug., 1994).

Optical Power Meter Calibration Using Tunable Laser Diodes, I. Vayshenker, X. Li, and T. R. Scott, Proc. Natl. Conf. Stand. Lab. Workshop and Symp., Session 5A, 362-372, (JulyAug., 1994).

Optical Detector Nonlinearity: A Comparison of Five Methods, S. Yang, I. Vayshenker, X. Li, and T. R. Scott, Digest, Conf. Precision Electromagnetic Measurements, 455-456 (June-July 1994).

Calibrated Optical Fiber Power Meters: Errors Due to Variations in Connectors, Xiaoyu Li and R. L. Gallawa, Fiber and Integrated Optics 7 (1988).

Calibration of Optical Fiber Power Meters: The Effect of Connectors, R. L. Gallawa and Xiaoyu Li, Appl. Opt. 26, 1170 (Apr. 1987).

Optical Fiber Power Meters: A Round Robin Test of Uncertainty, R. L. Gallawa and Shao Yang, Appl. Opt. 25, 1066 (Apr. 1986).

\section{References-Optoelectronic Frequency Response}

A Transfer Standard for Measuring Photoreceiver Frequency Response, P. D. Hale, C.M. Wang, R. Park, and W. Y. Lau, IEEE J. Lightwave Technol. 14, 2457 (1996).

Comparison of Photodiode Frequency Response Measurements to $40 \mathrm{GHz}$ between NPL and NIST, A. D. Gifford, D. A. Humphreys, and P. D. Hale, Electron. Lett. 31, 397 (1995). 


\section{Chapter}

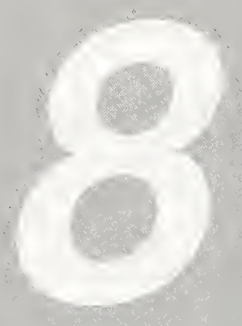
A Radioactivity Sources
$B$ Neutron Sources and Neutron Dosimetry
C Dosimetry of X-Rays, Gamma-Rays, and Electrons
D Dosimetry for High-Dose Applications 
Radioactivity Sources

\author{
Technical Contacts:
}

\begin{tabular}{|c|c|c|c|}
\hline M. P. Unterweger & Jeffrey T. Cessna & Pamela A. Hodge & Diana Chatterton \\
\hline All Services & $43010 \mathrm{C}, 43020 \mathrm{C}$ & $43030 \mathrm{C}-43050 \mathrm{C}$ & Administration and \\
\hline Tel:301/975-5536 & $43060 \mathrm{C}, 43070 \mathrm{~S}$ & Tel:301/975-5544 & Logistics \\
\hline $\begin{array}{l}\text { Email:munterweger@ } \\
\text { nist.gov }\end{array}$ & $\begin{array}{l}\text { Tel:301/975-5539 } \\
\text { Email:jcessna@ } \\
\text { nist.gov }\end{array}$ & $\begin{array}{l}\text { Email:phodge@ } \\
\text { nist.gov }\end{array}$ & $\begin{array}{l}\text { Tel:301/975-5371 } \\
\text { Email:diana. } \\
\text { chatterton@nist.gov }\end{array}$ \\
\hline
\end{tabular}

Mailing Address: Building 245, Room C114, National Institute of Standards and Technology, Gaithersburg, MD 20899-0001

For shipping, see below.

\section{Service}

ID No. Items

43010C Gamma-Ray-Emitting Radionuclides in Solution (Half Lives Greater Than 15 Days)

43020C Gamma-Ray-Emitting Radionuclides in Solution (Half Lives Less Than 15 Days)

43030C Alpha-Particle-Emitting Solid Sources, NIST $2 \pi \alpha$ Proportional Counter

43040C Alpha-Particle-Emitting Solid Sources, NIST $0.8 \pi \alpha$ Defined-Solid-Angle Counter

43050C Alpha-Particle-Emitting Solid Sources, Using Both Counting Systems

43060S Special Tests of Beta-Particle-Emitting Solution Sources-Liquid Scintillation Counting

43070S Special Tests of Beta-Particle-Emitting Solution Sources, Other Techniques

43090S Special Tests of Alpha-Particle-Emitting Solid Sources

\section{Radioactivity Sources-General Information (43010C-43090S)}

The National Institute of Standards and Technology offers calibration services for over 50 radionuclides. Calibrations are provided to meet the requirements of industry, research, environmental monitoring, and the life sciences. Radioactivity calibration services are available for alpha-particle solid sources, beta-particle solutions, and gamma-ray solutions.

In order to offer such a broad range of services, NIST must place stringent limitations on the physical and chemical form and activity range of sources that can be accepted. To ensure that these specifications are understood, it is essential that there be good communication between the technical user and the technical contact at NIST. When planning to have a source calibrated, the user should discuss the following points with the NIST contact:

A. Type of calibration: More than one type of calibration is often available for a given source. A cobalt- 60 source, for example, may be calibrated in terms of total activity or gamma-rayemission rate. (Inquiries regarding the calibration of radioactive sources for exposure rate should be directed to the Dosimetry Group. See Service ID Numbers $47010 \mathrm{C}$ to $47040 \mathrm{~S}$.) The required uncertainty in the calibration should also be discussed.

B. General packaging and shipping requirements: Two general requirements apply to all sources submitted for calibration: (1) all shipments must conform to applicable Nuclear Regulatory Commission (NRC) and Department of Transportation (DOT) packaging and transport; and (2) source descriptions, including approximate activity, must be provided in advance. The NIST Health Physics Group must approve the receipt of radioactive material, and sources may be refused if the necessary information is not available.

C. Reports of Calibration: A Report of Calibration is sent upon completion of a radioactivity calibration service. If the user has particular requirements for documentation of the calibration, these should be discussed with the technical contact at NIST before the services are performed.

D. Sample Preparation, Packaging, and Shipping: All samples submitted for calibration must be chemically and physically stable. The chemical form of solutions suggested for beta-particle emitters and gamma-ray emitters are described later in this document. A special lot of borosilicate-glass ampoules must be used for gamma-ray emitters. Empty ampoules are provided for this purpose. The volume of material in the ampoule should be $(5.0 \pm 0.2) \mathrm{mL}$. 
Packaging for all sources must be in compliance with DOT and NRC regulations. Copies of regulations may be obtained from Operations Division, Office of Hazardous Materials, Department of Transportation, Washington, DC 20950. Postal regulations prohibit the mailing of radioactive materials that require a caution label under DOT regulations.

Alpha-particle solid sources must be supplied in special source holders designed so that the active area is not touched by any material. For sources to be measured in the $2 \pi \alpha$ counter (Service ID No. 43030C), the diameter of the source must be less than $10 \mathrm{~cm}$ and that of the active surface less than $9 \mathrm{~cm}$. For the $0.8 \pi \alpha$ counter (Service ID No. $43040 \mathrm{C}$ ), the maximum diameter is $1.6 \mathrm{~cm}$.

All sources arriving at NIST are checked by the Health Physics Group for radiation level and source integrity. Sources should be shipped to the attention of the technical contact at NIST, addressed, for example, as follows:

National Institute of Standards and Technology

Health Physics (Radioactivity Group)

Attn: (Name of technical contact)

Building 245, Room B131

Quince Orchard and Clopper Roads

Gaithersburg, MD 20899-0001

\section{Gamma-Ray-Emitting Solution Sources (43010C-43020C)}

Tables 8.1 and 8.2 list 41 radionuclide solutions that may be calibrated in the NIST " $4 \pi$ " $\gamma$ ionization chamber. The sources must be submitted flame-sealed in the special ampoules provided by NIST. The operation of this type of chamber is described in NCRP Report 58, A Handbook of Radioactivity Measurements Procedures, Section 4.4 "Ionization Chambers," and in NBS SP 250-10, Radioactivity Calibrations with the " $4 \pi$ " Gamma Ionization Chamber and other Radioactivity Calibration Capabilities (see references).
Table 8.1. Specifications for Calibration of Solutions of Gamma-Ray Emitting Radionuclides Having Half Lives Greater Than 15 Days

\begin{tabular}{|c|c|c|c|c|}
\hline $\begin{array}{l}\text { Radio- } \\
\text { nuclide }\end{array}$ & $\begin{array}{l}\text { Typical } \\
\text { Relative } \\
\text { Expanded } \\
\text { Uncertainty**(a) } \\
\qquad \%)\end{array}$ & $\begin{array}{l}\text { Activity } \\
\text { Range }^{(\mathbf{b})} \\
\text { (Mbq) }\end{array}$ & Suggested C & hemical Form ${ }^{\text {(c }}$ \\
\hline${ }^{22} \mathrm{Na}$ & 1.1 & 0.4 to 40 & $\mathrm{NaCl}$ & $1 \mathrm{~mol} / \mathrm{L}, \mathrm{HCl}$ \\
\hline${ }^{46} \mathrm{Sc}$ & 0.5 & 0.4 to 40 & $\mathrm{ScCl}_{3}$ & $1 \mathrm{~mol} / \mathrm{L}, \mathrm{HCl}$ \\
\hline${ }^{51} \mathrm{Cr}$ & 0.7 & 2 to 60 & $\mathrm{CrCl}_{3}$ & $0.5 \mathrm{~mol} / \mathrm{L}, \mathrm{HCl}$ \\
\hline${ }^{54} \mathrm{Mn}$ & 0.8 & 2 to 60 & $\mathrm{MnCl}_{2}$ & $1 \mathrm{~mol} / \mathrm{L}, \mathrm{HCl}$ \\
\hline${ }^{57} \mathrm{Co}$ & 0.5 & 2 to 60 & $\mathrm{CoCl}_{2}$ & $1 \mathrm{~mol} / \mathrm{L}, \mathrm{HCl}$ \\
\hline${ }^{59} \mathrm{Fe}$ & 0.9 & 0.4 to 40 & $\mathrm{FeCl}_{3}$ & $1 \mathrm{~mol} / \mathrm{L}, \mathrm{HCl}$ \\
\hline${ }^{60} \mathrm{Co}$ & 0.5 & 0.4 to 40 & $\mathrm{CoCl}_{2}$ & $1 \mathrm{~mol} / \mathrm{L}, \mathrm{HCl}$ \\
\hline${ }^{75} \mathrm{Se}$ & 1.6 & 2 to 60 & $\mathrm{H}_{2} \mathrm{SeO}_{3}$ & $1 \mathrm{~mol} / \mathrm{L}, \mathrm{HNO}_{3}$ \\
\hline $\mathrm{Sr}$ & 1.3 & 2 to 60 & $\mathrm{SrCl}_{2}$ & $1 \mathrm{~mol} / \mathrm{L}, \mathrm{HCl}$ \\
\hline${ }^{88} \mathrm{Y}$ & 0.5 & 0.4 to 40 & $\mathrm{YCl}_{3}$ & $1 \mathrm{~mol} / \mathrm{L}, \mathrm{HCl}$ \\
\hline${ }^{109} \mathrm{Cd}-{ }^{109 m} \mathrm{Ag} *$ & 1.1 & 2 to 60 & $\mathrm{CdCl}_{2}$ & $1.3 \mathrm{~mol} / \mathrm{L}, \mathrm{HCl}$ \\
\hline${ }^{110 m} \mathrm{Ag}-{ }^{110} \mathrm{Ag}$ & 0.6 & 0.4 to 40 & $\mathrm{AgNO}_{3}$ & $1 \mathrm{~mol} / \mathrm{L}, \mathrm{HNO}$ \\
\hline${ }^{113} \mathrm{Sn}-{ }^{113 \mathrm{~m}} \operatorname{In}^{(\mathrm{d})}$ & 2.0 & 2 to 60 & $\begin{array}{l}\mathrm{SnCl}_{2} \text { or } \\
\mathrm{SnCl}_{4}\end{array}$ & $4 \mathrm{~mol} / \mathrm{L}, \mathrm{HCl}$ \\
\hline${ }^{114 \mathrm{~m}} \mathrm{In}$ & 0.7 & 2 to 200 & $\mathrm{InCl}_{2}$ & $3 \mathrm{~mol} / \mathrm{L}, \mathrm{HCl}$ \\
\hline${ }^{123 \mathrm{~m}} \mathrm{Te}$ & 0.7 & 2 to 100 & $\mathrm{TeCl}$ & $2 \mathrm{~mol} / \mathrm{L}, \mathrm{HCl}$ \\
\hline${ }^{133} \mathrm{Ba}$ & 1.0 & 2 to 60 & $\mathrm{BaCl}_{2}$ & $1 \mathrm{~mol} / \mathrm{L}, \mathrm{HCl}$ \\
\hline${ }^{134} \mathrm{Cs}$ & 0.7 & 2 to 60 & $\mathrm{CsCl}$ & $1 \mathrm{~mol} / \mathrm{L}, \mathrm{HCl}$ \\
\hline${ }^{137} \mathrm{Cs}-{ }^{137 \mathrm{~m}} \mathrm{Ba}$ & 1.0 & 2 to 60 & $\mathrm{CsCl}$ & $1 \mathrm{~mol} / \mathrm{L}, \mathrm{HCl}$ \\
\hline${ }^{139} \mathrm{Ce}$ & 0.7 & 2 to 60 & $\mathrm{CeCl}_{3}$ & $1 \mathrm{~mol} / \mathrm{L}, \mathrm{HCl}$ \\
\hline${ }^{141} \mathrm{Ce}$ & 1.3 & 2 to 60 & $\mathrm{CeCl}_{3}$ & $1 \mathrm{~mol} / \mathrm{L}, \mathrm{HCl}$ \\
\hline${ }^{144} \mathrm{Ce}^{*}$ & 0.9 & 2 to 740 & $\mathrm{CeCl}_{3}$ & $1 \mathrm{~mol} / \mathrm{L}, \mathrm{HCl}$ \\
\hline${ }^{152} \mathrm{Eu}$ & 1.1 & 0.4 to 40 & $\mathrm{EuCl}_{3}$ & $1 \mathrm{~mol} / \mathrm{L}, \mathrm{HCl}$ \\
\hline${ }^{153} \mathrm{Gd} *$ & 1.3 & 2 to 60 & $\mathrm{GdCl}_{3}$ & $1 \mathrm{~mol} / \mathrm{L}, \mathrm{HCl}$ \\
\hline${ }^{154} \mathrm{Eu}$ & 0.5 & 0.4 to 40 & $\mathrm{EuCl}_{3}$ & $4 \mathrm{~mol} / \mathrm{L}, \mathrm{HCl}$ \\
\hline${ }^{155} \mathrm{Eu}$ & 1.0 & 2 to 60 & $\mathrm{EuCl}_{3}$ & $4 \mathrm{~mol} / \mathrm{L}, \mathrm{HCl}$ \\
\hline${ }^{169} \mathrm{Yb}^{*}$ & 1.7 & 2 to 60 & $\mathrm{YbCl}_{3}$ & $0.1 \mathrm{~mol} / \mathrm{L}, \mathrm{HC}$ \\
\hline${ }^{195} \mathrm{Au}^{*}$ & 1.5 & 2 to 60 & $\mathrm{KAu}(\mathrm{CN})_{4}$ & $\begin{array}{l}10 \mathrm{~g} / \mathrm{L}, \mathrm{KCN} \\
10 \mathrm{~g} / \mathrm{L}, \mathrm{KCl}\end{array}$ \\
\hline${ }^{203} \mathrm{Hg}$ & 0.9 & 2 to 60 & $\mathrm{Hg}\left(\mathrm{NO}_{3}\right)_{2}$ & $0.1 \mathrm{~mol} / \mathrm{L}, \mathrm{HNC}$ \\
\hline
\end{tabular}

(a) The uncertainty will depend upon the activity level and the chemical form. (b) The source activity should be in the indicated range when it arrives at NIST. The calibration scheduling must be coordinated with the NIST technical contact.

(c) This information is based in large part on the NIST Standard Reference Materials for these radionuclides. For those radionuclides marked with an asterisk, the carrier should be discussed with the NIST technical contact.

(d) The calibration for ${ }^{113} \mathrm{Sn}-{ }^{113 \mathrm{~m}}$ In are in terms of gamma-ray-emission rate rather than activity.

**See Chapter 1, Section $\mathrm{H}$ for more information about uncertainty. 
Table 8.2. Specifications for Calibration of Gamma-RayEmitting Radionuclides Having Half Lives Less Than 15 Days

\begin{tabular}{|c|c|c|c|c|}
\hline $\begin{array}{l}\text { Radio- } \\
\text { nuclide }\end{array}$ & $\begin{array}{l}\text { Typical } \\
\text { Relative } \\
\text { Expanded } \\
\text { Uncer- } \\
\text { tainty }{ }^{* *(a)} \\
(\%)\end{array}$ & $\begin{array}{l}\text { Activity } \\
\text { Range }^{(\mathbf{b})} \\
(\mathbf{M B q})\end{array}$ & Suggested & hemical Form ${ }^{(c)}$ \\
\hline${ }^{24} \mathrm{Na}$ & 0.5 & 0.4 to 40 & $\mathrm{NaCl}$ & $1 \mathrm{~mol} / \mathrm{L}, \mathrm{HCl}$ \\
\hline${ }^{67} \mathrm{Ga}$ & 0.9 & 0.4 to 40 & $\mathrm{GaCl}_{3}$ & $2 \mathrm{~mol} / \mathrm{L}, \mathrm{HCl}$ \\
\hline${ }^{99} \mathrm{Mo}-{ }^{99} \mathrm{mc}$ & 1.1 & 2 to 60 & $\mathrm{Na}_{2} \mathrm{MoO}_{4}$ & $4 \mathrm{~mol} / \mathrm{L}, \mathrm{HNO}_{3}$ \\
\hline${ }^{99 \mathrm{~m}} \mathrm{Tc}$ & 1.0 & 2 to 60 & $\begin{array}{l}\text { No carrier } \\
\text { added/ } \\
\mathrm{Na}^{2} \mathrm{TeO}_{4}\end{array}$ & Saline \\
\hline${ }^{111} \mathrm{In}$ & 0.9 & 2 to 60 & $\mathrm{InCl}_{2}$ & $3 \mathrm{~mol} / \mathrm{L}, \mathrm{HCl}$ \\
\hline${ }^{123} I^{*(c)}$ & 1.0 & 2 to 60 & $\begin{array}{l}\mathrm{KI}, \mathrm{Na}_{2} \mathrm{SO}_{3} \\
\mathrm{LiOH}\end{array}$ & $0.01 \mathrm{~mol} / \mathrm{L}$ \\
\hline${ }^{131} I^{*(c)}$ & 0.9 & 2 to 60 & $\mathrm{KI}, \mathrm{Na}_{2} \mathrm{SO}_{3}$ & $\begin{array}{l}0.01 \mathrm{~mol} / \mathrm{L} \text {, } \\
\mathrm{LiOH}\end{array}$ \\
\hline${ }^{140} \mathrm{Ba}-{ }^{140} \mathrm{La}$ & 2.3 & 0.4 to 40 & $\begin{array}{l}\mathrm{Ba}\left(\mathrm{NO}_{3}\right)_{2} \\
\mathrm{La}\left(\mathrm{NO}_{3}\right)_{3}\end{array}$ & $1 \mathrm{~mol} / \mathrm{L}, \mathrm{HCl}$ \\
\hline${ }^{186} \mathrm{Re}$ & 0.6 & 2 to 600 & $\mathrm{ReCl}_{3}$ & Saline \\
\hline${ }^{197} \mathrm{Hg}$ & 1.6 & 2 to 60 & $\begin{array}{l}\mathrm{Hg}\left(\mathrm{NO}_{3}\right)_{2} \\
\mathrm{HNO}_{3}\end{array}$ & $0.1 \mathrm{~mol} / \mathrm{L}$ \\
\hline${ }^{198} \mathrm{Au}$ & 0.9 & 2 to 60 & $\mathrm{KAu}(\mathrm{CN})_{4}$ & $\begin{array}{l}10 \mathrm{~g} / \mathrm{L}, \mathrm{KCl}, \\
10 \mathrm{~g} / \mathrm{L}, \quad \mathrm{KCN}\end{array}$ \\
\hline${ }^{201} \mathrm{Tl}$ & 1.3 & 2 to 60 & $\mathrm{Tl}\left(\mathrm{NO}_{3}\right)_{3}$ & $\begin{array}{l}0.9 \mathrm{~mol} / \mathrm{L} \\
\mathrm{HNO}_{3}\end{array}$ \\
\hline${ }^{203} \mathrm{~Pb}$ & 1.1 & 2 to 60 & $\mathrm{PbCl}_{2}$ & $0.5 \mathrm{~mol} / \mathrm{L}, \mathrm{HCl}$ \\
\hline
\end{tabular}

(a) The uncertainty will depend upon the activity level and chemical form.

(b) The source activity should be in the indicated range when it arrives at NIST. The calibration scheduling must be coordinated with the NIST technical contact.

(c) This information is based in large part on the NIST Standard Reference Materials for these radionuclides. For those radionuclides marked with an asterisk, the carrier should be discussed with the NIST technical contact. **See Chapter 1, Section $\mathrm{H}$ for more information about uncertainty.

\section{Alpha-Particle-Emitting Solid Sources $(43030 \mathrm{C}-43050 \mathrm{C})$}

Alpha-particle sources may be calibrated using the NIST $2 \pi$ proportional counter, or the NIST $0.8 \pi \alpha$ defined-solid-angle counter. The former calibration is in terms of alpha-particle-emission rate into $2 \pi \alpha$ steradians, while the latter is in terms of total activity. Sources to be measured by $2 \pi \alpha$ proportional counting should be on an electrically conductive backing. A more detailed comparison of these counting systems is given in NCRP Report 58 (Section 3.7) and in NBS SP 250-5, Alpha-Particle Calibrations.
Backscattering corrections for a variety of source-mount materials are discussed in the references given. The source thickness must be such that more than $99.5 \%$ of the emitted alpha particles have an energy greater than $400 \mathrm{keV}$. Further specifications for these calibration services are given in Table 8.3. Service ID No. 43050C includes calibration of the same source using both counting systems.

Large area sources of plutonium238 may also be measured providing the source thickness is as above. The activity range is $10^{2} \mathrm{~Bq}$ to $10^{5} \mathrm{~Bq}$ utilizing large-area internal and external counters.

Table 8.3. Specifications for Calibrations Using the $2 \pi \alpha$ Proportional Counter and the $0.8 \pi \alpha$ Defined Solid Angle Counter

\begin{tabular}{|c|c|c|}
\hline & $\begin{array}{l}\text { Service ID No. } \\
43030 \mathrm{C}\end{array}$ & $\begin{array}{l}\text { Service ID No. } \\
43040 C\end{array}$ \\
\hline Counting System & $\begin{array}{l}\text { NIST } 2 \pi \alpha \\
\text { proportional } \\
\text { counter }\end{array}$ & $\begin{array}{l}\text { NIST } 0.8 \pi \alpha \\
\text { defined-solid- } \\
\text { angle-counter }\end{array}$ \\
\hline Sources Calibrated For: & $\begin{array}{l}\text { Alpha-particle- } \\
\text { emission } \\
\text { rate into } 2 \pi \alpha \\
\text { steradians either } \\
\text { above } 400 \mathrm{KeV} \\
\text { or extrapolated } \\
\text { to zero } \mathrm{KeV}\end{array}$ & Total activity \\
\hline $\begin{array}{l}\text { Typical Relative } \\
\text { Expanded Uncertainty**(a) } \\
\qquad(\%)\end{array}$ & 1.0 & 1.0 \\
\hline Activity Range & $\approx\left(0.4\right.$ to $\left.10^{4}\right) \mathrm{Bq}$ & $\approx\left(40\right.$ to $\left.10^{4}\right) \mathrm{Bq}$ \\
\hline $\begin{array}{l}1.0 \% \text { Maximum Source } \\
\text { Diameter }\end{array}$ & $\begin{array}{l}10 \mathrm{~cm}(9 \mathrm{~cm} \\
\text { active surface) }\end{array}$ & $1.6 \mathrm{~cm}$ \\
\hline
\end{tabular}

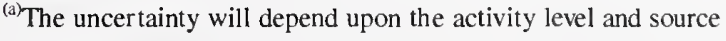
geometry.

**See Chapter 1, Section $\mathrm{H}$ for more information about uncertainty. 
Table 8.4. Specifications for Special Tests of Beta-Particle-Emitting Solution Sources

\begin{tabular}{|c|c|c|c|}
\hline \multirow[b]{2}{*}{$\begin{array}{l}\text { Radio- } \\
\text { nuclide }\end{array}$} & \multirow{2}{*}{$\begin{array}{l}\text { Typical } \\
\text { Relative } \\
\text { Expanded } \\
\text { Uncertainty*(a) } \\
\quad(\%)\end{array}$} & \multicolumn{2}{|c|}{ Suggested Chemical Composition $^{(b)}$} \\
\hline & & Carrier & Solution \\
\hline${ }^{3} \mathrm{H}$ & 0.7 & $\mathrm{H}_{2} \mathrm{O}$ & $\mathrm{H}_{2} \mathrm{O}$ \\
\hline${ }^{14} \mathrm{C}$ & 1.0 & $\mathrm{Na}_{2} \mathrm{CO}_{3}$ & $0.001 \mathrm{~mol} / \mathrm{L}, \mathrm{NaOH}$ \\
\hline${ }^{32} \mathbf{p}^{(\mathrm{c})}$ & 0.7 & $\mathrm{H}_{3} \mathrm{PO}_{4}$ & $0.0034 \mathrm{~mol} / \mathrm{L}, \mathrm{H}_{3} \mathrm{PO}_{4}$ \\
\hline${ }^{33} \mathrm{P}$ & 0.7 & $\mathrm{H}_{3} \mathrm{PO}_{4}$ & $0.0034 \mathrm{~mol} / \mathrm{L}, \mathrm{H}_{3} \mathrm{PO}_{4}$ \\
\hline${ }^{35} \mathrm{~S}$ & 0.7 & $\mathrm{Li}_{2} \mathrm{SO}_{4}$ & $0.1 \mathrm{~mol} / \mathrm{L}, \mathrm{HCl}$ \\
\hline${ }^{36} \mathrm{Cl}$ & 1.3 & $\mathrm{NaCl}$ & $\mathrm{H}_{2} \mathrm{O}$ \\
\hline${ }^{89} \mathrm{Sr}$ & 0.7 & $\mathrm{SrCl}_{2}$ & $1 \mathrm{~mol} / \mathrm{L}, \mathrm{HCl}$ \\
\hline${ }^{90} \mathrm{Sr}-{ }^{90} \mathrm{Y}$ & 0.7 & $\mathrm{SrCl}_{2} / \mathrm{YCl}_{3}$ & $1 \mathrm{~mol} / \mathrm{L}, \mathrm{HCl}$ \\
\hline${ }^{90} \mathrm{Y}$ & 0.7 & $\mathrm{YCl}_{3}$ & $1 \mathrm{~mol} / \mathrm{L}, \mathrm{HCl}$ \\
\hline${ }^{147} \mathrm{Pm}$ & 0.7 & $\mathrm{PmCl}_{3}$ & $1 \mathrm{~mol} / \mathrm{L}, \mathrm{HCl}$ \\
\hline${ }^{204} \mathrm{Tl}$ & 1.3 & $\mathrm{Tl}\left(\mathrm{NO}_{3}\right)_{3}$ & $1 \mathrm{~mol} / \mathrm{L}, \mathrm{HNO}_{3}$ \\
\hline
\end{tabular}

Special Tests of Beta-Particle-Emitting Solution Sources (43060S and 43070S)

Beta-particle-emitting solutions that conform to the physical, chemical, and activity specifications for measurement are assayed by liquid-scintillation counting. The specifications are shown in Table 8.4. The suggested radioactivity concentration range is (20 to 2000$) \mathrm{kBq} / \mathrm{g}$.

No examination is made for beta-particle-emitting impurities, except in the case of phosphorus-32 where a half-life fit is made. The sources will be examined for gamma-ray emitting impurities.

Measurement of beta-particleemitting solutions by techniques other than liquid-scintillation may be made by special arrangement.

\section{Special Alpha-Particle-Emitting Solid Sources (43090S)}

Special arrangements may be made for measurements of solid alphaparticle-emitting sources with emission rates exceeding $1.1 \times 10^{4} \mathrm{~Bq}$.

\section{References-Radioactivity Sources}

NBS Measurement Services: Radioactivity Calibrations with the " $4 \pi$ " Gamma Ionization Chamber and Other Radioactivity Calibration Capabilities, J. M. Calhoun, Natl. Bur. Stand.

(U.S.), Spec. Publ. 250-10 (Oct. 1987).

NBS Measurement Services: Alpha-Particle Calibrations, J. M. R. Hutchinson, Natl. Bur. Stand. (U.S.), Spec. Publ. 250-5 (July 1987).

NCRP Report 58, A Handbook of Radioactivity Measurements Procedures, Section 3.7-Alpha-Particle Counting, W. B. Mann, Ed., Natl. Council Rad. Protect. and Meas., Washington, DC (1985).

Study of the Scattering Correction for Thick Uranium-Oxide and OtherParticle Sources, I: Theoretical, L. L. Lucas and J. M. R. Hutchinson, Int. J. Appl. Radiat. Isotopes 27, 35 (1976).

Study of the Scattering Correction for Thick Uranium-Oxide and OtherParticle Sources, II: Experimental, J. M. R. Hutchinson, L. L. Lucas, and P. A. Mullen, Int. J. Appl. Radiat. Isotopes 27, 43 (1976).

Backscattering of Alpha Particles from Thick Metal Backings as a Function of Atomic Weight, J. M. R. Hutchinson, C. R. Naas, D. H. Walker, and W. B. Mann, Int. J. Appl. Radiat. Isotopes, 19, 517 (1968).

An Experimental Study of the Backscattering of $5.3 \mathrm{MeV}$-Alpha Particles from Platinum and Monel Metal, D. H. Walker, Int. J. Appl. Radiat. Isotopes 16, 183 (1965). 


\section{B. Neutron Sources and Neutron Dosimetry}

\author{
Technical Contacts:
}

James M. Adams
All Services Except
44060C
Tel:301/975-6205

\author{
Alan K. Thompson \\ 44060C, $44100 \mathrm{~S}$ \\ Tel: $301 / 975-4666$ \\ Email: alan.thompson@nist.gov
}

Mailing Address: Building 235, Room A159,

National Institute of Standards and Technology,

Gaithersburg, MD 20899-0001

Shipping Address: National Institute of Standards

and Technology,

Health Physics (Neutron Interactions and Dosimetry)

[Attn: Name of Technical Contact],

Building 245, Room B131,

Quince Orchard and Clopper Roads,

Gaithersburg, MD 20899-0001

Service

ID No. Items

44010C Radioactive Neutron Sources (emission rates $10^{5} \mathrm{~s}^{-1}$ to $10^{8} \mathrm{~s}^{-1}$ )

44020 C Radioactive Neutron Sources (emission rates $10^{8} \mathrm{~s}^{-1}$ to $10^{10} \mathrm{~s}^{-1}$ )

$44060 \mathrm{C}$ Personnel Protection Instrumentation, Californium Source Bare and Moderated

44070C Activation Detector Dosimetry, Thermal Neutrons

44080C Activation Detector Dosimetry, Californium Fission Neutrons

44090C Activation Detector Dosimetry, ${ }^{235} \mathrm{U}$ Cavity Fission Source

44100S Special Tests of Neutron Sources and Dosimeters

Radioactive Neutron Sources (44010C-44020C)

NIST provides calibration services for radioisotope neutron sources with emission rates from $5 \times 10^{5} \mathrm{~s}^{-1}$ to $1 \times 10^{10} \mathrm{~s}^{-1}$. Neutron source emission rates are determined by the manganous sulfate bath method, in which the emission-rate of the source to be calibrated is compared to the emission-rate of NBS-1, the national standard Ra-Be photoneutron source. Neutron source calibrations typically have a relative expanded uncertainty* of about $3.4 \%$, depending on the details of the source encapsulation.

*See Chapter 1, Section $\mathrm{H}$ for more information about uncertainty.

\section{Personnel Protection Instrumentation (44060C)}

Neutron personnel instruments, both passive (e.g., dosimeters) and active (e.g., remmeters) are calibrated on the basis of a certified free-field dose-equivalent or dose equivalent rate. Two ${ }^{252} \mathrm{Cf}$ sourcedriven neutron fields are available on a routine basis for this purpose: bare source and heavy-water-moderated ${ }^{252} \mathrm{Cf}$ fission neutron sources. Thermal neutron beams are also available for special requirements under Service ID No. 44100 S. For both bare and moderated ${ }^{252} \mathrm{Cf}$ source exposures, maximum doseequivalent rates are about $5 \mathrm{mSv} / \mathrm{h}$. The relative expanded uncertainty* is $10 \%$.

\section{Activation Detector Dosimetry (44070C-44090C)}

Passive neutron detectors, generally activation foils, can be irradiated to a certified neutron fluence (or average fluence-rate) in a fission neutron spectrum or a Maxwellian thermal neutron field. Typical irradiation parameters are given in Table 8.5.

Table 8.5. Irradiation Parameters for Fission Spectra and Maxwellian Thermal Neutron Fields

\begin{tabular}{lccc}
\hline & $\begin{array}{c}\text { Typical } \\
\text { Maximum } \\
\text { Neutron } \\
\text { Fluence } \\
\left(\mathbf{c m}^{-2}\right)\end{array}$ & $\begin{array}{c}\text { Typical } \\
\text { Maximum } \\
\text { Neutron } \\
\text { Fluence Rate } \\
\left(\mathbf{c m}^{-2} \cdot \mathbf{s}^{-1}\right)\end{array}$ & $\begin{array}{c}\text { Relative } \\
\text { Expanded } \\
\text { Uncertainty* } \\
(\%)\end{array}$ \\
\hline $\begin{array}{l}\text { Neutron Field } \\
{ }^{252} \text { Cf Fission Source }\end{array}$ & $5 \times 10^{12}$ & $2 \times 10^{7}$ & $2.6^{(b)}$ \\
${ }^{235}$ U Cavity Fission $_{\text {Source }}^{(\text {a) }}$ & $5 \times 10^{15}$ & $2 \times 10^{10}$ & $4.6^{(b)}$ \\
$\begin{array}{l}\text { Thermal Neutrons } \\
\text { Beam }\end{array}$ & $1 \times 10^{13}$ & $8 \times 10^{7}$ & 5 \\
\begin{tabular}{l} 
Isotropic \\
\hline
\end{tabular} & $>1 \times 10^{16}$ & $2 \times 10^{11}$ & 5 \\
\hline
\end{tabular}

(a) Threshold detectors only. Maximum size of detector disks: $12.7 \mathrm{~mm}$ dia. $\times$ about $3 \mathrm{~mm}$ thick. The radial gradient of the fluence: is about $20 \%$ center-to-edge.

(h) Uncertainty includes neutron scattering corrections.

(c) Maxwellian distribution corresponding to a temperature of about $40^{\circ} \mathrm{C}$.

*See Chapter 1, Section $\mathrm{H}$ for more information about uncertainty. 
Special Tests of Neutron Sources and Dosimeters (44100S)

Other tests of dosimetry instrumentation may be undertaken by special arrangement with the Ionizing Radiation Division. In particular for personnel protection instruments, a thermal beam can provide dose equivalent rates of up to approximately $10 \mathrm{mSv} / \mathrm{h}$ across a $30 \mathrm{~cm}$ diameter circle.

\section{References-Radioactive Neutron Sources}

NBS Measurement Services: Neutron Source Strength Calibrations at NBS by the Manganese Sulfate Bath Method, E. D. McGarry and E. W. Boswell, Natl. Bur. Stand. (U.S.), Spec. Publ. 250-18 (Mar. 1988).

Neutron Source Calibrations at NBS for Calibration Checks of Neutron Radiation Instruments, V. Spiegel, Jr., Proc. of Symp. on Meas. for the Safe Use of Radiation, Natl. Bur. Stand. (U.S.), Spec. Publ. 456, 87 (Nov. 1976).

Calibration of Thermal Neutron Absorption in Cylindrical and Spherical Neutron Sources, V. Spiegel, Jr., and W. M. Murphey, Metrologia 7, 34 (Jan. 1971).

The Correction Factor for Fast Neutron Reactions on Sulphur and Oxygen in the Manganous-Sulfate-Bath Calibration of Neutron Sources, W. M. Murphey, Nucl. Instrum. Methods 37, 13 (1965).

Absolute Calibration of the National Bureau of Standards Photoneutron Source: III. Absorption in a Heavy Water Solution of Manganous Sulfate, R. H. Noyce, E. R. Mosburg, Jr., S. B. Garfinkel, and R. S. Caswell, J. Nucl. Eng. 17 (7), 313 (1963).

Absolute Calibration of the National Bureau of Standards Photoneutron Standard: I., J. A. DeJuren, D. W. Padgett, and L. F. Curtiss, J. Res. Natl. Bur. Stand. (U.S.), 55, 63 (Aug. 1955).

\section{References-Personnel Protection Inst rumentation}

NBS Measurement Services: Neutron Personnel Dosimetry, R. B. Schwartz, Natl. Bur. Stand. (U.S.), Spec. Publ. 250-12 (July 1987).

Procedures for Calibrating Neutron Personnel Dosimeters, R. B. Schwartz, Natl. Bur. Stand. (U.S.), Spec. Publ. 250-12 (July 1987).

Calibration Techniques for Neutron Personnel Dosimetry, C. M. Eisenhauer, J. B. Hunt and R. B. Schwartz, Radiat. Prot. Dosim. 10, 43-57.

The Design and Construction of a $\mathrm{D}_{2} \mathrm{O}$ Moderated ${ }^{252} \mathrm{Cf}$ Source for Calibrating Neutron Personnel Dosimeters Used at Nuclear Power Reactors, R. B. Schwartz and C. M. Eisenhauer, U.S. Nucl. Reg. Com. Doc. NUREG/CR1204 (Jan. 1980).

\section{References-Activation Detector Dosimetry}

NBS Measurement Services: Activation Foil Irradiations at NBS by Californium Fission Sources, G. P. Lamaze and J. A. Grundl. Natl. Bur. Stand. (U.S.), Spec. Publ. 250-13 (Mar. 1988).

NBS Measurement Services: Activation Foil Irradiations at NBS by Reactor Cavity Sources, G. P. Lamaze and J. A. Grundl, Natl. Bur. Stand. (U.S.), Spec. Publ. 250-14 (Mar. 1988).

Derivation of Neutron Exposure Parameters from Threshold Detector Measurements, J. A. Grundl, Proc. Sixth ASTM-Euratom Symp. on Reactor Dosimeter, Jackson, WY (June 1987). Compendium of Benchmark Neutron Fields for Reactor Dosimetry, J. A. Grundl and C. M. Eisenhauer, Natl. Bur. Stand. (U.S.), NBSIR 85-3151 (Apr. 1985).

The U.S. ${ }^{235}$ U Fission Spectrum Standard Neutron Field Revisited, E. D. McGarry, C. M. Eisenhauer, D. M. Gilliam, J. A. Grundl, G. P. Lamaze, and A. Fabry, Proc. Fifth ASTM-Euratom Symp. on Reactor Dosimetry, Geesthacht, Germany (Sept. 1984). 
National Standards for Neutron Measurements, J. A. Grundl, Proc. of a Meeting on Traceability for Ionizing Radiation Measurements, Natl. Bur. Stand. (U.S.), NBS Spec. Publ. 609 (Feb. 1982).

Utilization of Standard and Reference Neutron Fields at NBS, C. M.

Eisenhauer, D. M. Gilliam, J. A. Grundl, and V. Spiegel, Proc. Second ASTM-Euratom Symp. on Reactor Dosimetry, Palo Alto, CA (Oct. 1977).
A Californium-252 Fission Spectrum Irradiation Facility for Neutron Reaction Rate Measurements, J. A. Grundl, V. Spiegel, C. M. Eisenhauer, H. T. Heaton II, D. M. Gilliam (NBS), and J. Bigelow (ORNL), Nucl. Tech. 32, 315 (Mar. 1977). 


\section{Dosimetry of X-Rays, Gamma-Rays, and Electrons}

\author{
Technical Contacts:
}

Steven M. Seltzer All Services

Tel: 301/975-5552

Email:s.seltzer@ nist.gov

C. Michelle $O$ 'Brien James T. $46010 \mathrm{C}-46050 \mathrm{~S}$ Weaver, Jr. Tel: 301/975.2014 47010C, 47011C, Email:michelle. $\quad \mathbf{4 7 0 4 0 S}$ obrien@nist.gov Tel: 301/975-5586 Email:james. weaver@nist.gov

Jileen Shobe $46010 \mathrm{C}-46050 \mathrm{~S}$, $47010 \mathrm{C}-47011 \mathrm{C}$ Tel:301/975-5595

Email:jileen.shobe @nist.gov $46010 \mathrm{C}-46050 \mathrm{~S}$

Tel: 301/975-5591 @nist.gov

Marc F.
Desrosiers
48010M-48011M
Tel:301975-5639
Email:marc.
desrosiers@
nist.gov

James M. Puhl $48010 \mathrm{M}-48011 \mathrm{M}$ Email:jpuhl@ nist.gov Tel:301/975-5581

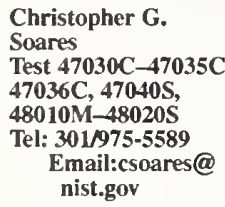

Christopher G. Soares Test $47030 \mathrm{C}-47035 \mathrm{C}$ $47036 \mathrm{C}, 47040 \mathrm{~S}$, $48010 \mathrm{M}-48020 \mathrm{~S}$ Tel: 301/975-5589 Email:csoares@ nist.gov

Mailing Address: Building 245, Room C229, National Institute of Standards and Technology, Gaithersburg, MD 20899-0001 Fax: 301/869-7682

\section{Shipment of Instruments:}

National Institute of Standards and Technology, Building 245, Room C229,

[For: 46010C-46050S; Attn: P. J. Lamperti]

[For: 47010C-47040S; Attn: J. T. Weaver (for Gamma-Ray Sources);

Attn: C. G. Soares (for Beta-Particle Sources)]

[For: 48010M-48020S; Attn: C. G. Soares]

I-270 at Quince Orchard Road,

Gaithersburg, MD 20899-0001

\section{Shipment of Sources:}

National Institute of Standards and Technology,

Health Physics,

Building 245, Room B131,

[For: 47010C-47040S;

Attn: J. T. Weaver (for Gamma-Ray Sources)]

Attn: C. G. Soares (for Beta-Particle Sources)]

I-270 at Quince Orchard Road,

Gaithersburg, MD 20899-0001

\begin{tabular}{|c|c|}
\hline $\begin{array}{l}\text { Service } \\
\text { ID No. }\end{array}$ & Items \\
\hline C. 0 & $\begin{array}{l}\text { Special Instructions for Using Electron and Photon } \\
\text { Dosimetry Services (46010C-48020S) }\end{array}$ \\
\hline C.1 & X-Ray and Gamma-Ray Measuring Instruments \\
\hline $46010 \mathrm{C}$ & $\begin{array}{l}\text { Radiation Detectors-Calibration/Correction } \\
\text { Factor, One Beam Quality (See Tables 8.6, } 8.7 \\
\text { and 8.8) }\end{array}$ \\
\hline $46011 \mathrm{C}$ & Each Additional Beam Quality or Condition \\
\hline $46020 \mathrm{C}$ & $\begin{array}{l}\text { Passive Dosimeters-Irradiation of Up to Six, One } \\
\text { Beam Quality at One Set-Up }\end{array}$ \\
\hline $46021 \mathrm{C}$ & $\begin{array}{l}\text { Up to Six Additional Dosimeters at Same Set-Up and } \\
\text { Beam Quality }\end{array}$ \\
\hline $46030 \mathrm{~S}$ & $\begin{array}{l}\text { Special Tests of High-Gain Electrometers-Charge } \\
\text { Sensitivity, One Set of Switch Positions, with } \\
46010 \mathrm{C} / 4601 \mathrm{1C} \text {, by Prearrangement }\end{array}$ \\
\hline $46040 \mathrm{~S}$ & $\begin{array}{l}\text { Special Tests of X-Ray Penetrameters, Ardran- } \\
\text { Crookes Type }\end{array}$ \\
\hline $46050 \mathrm{~S}$ & $\begin{array}{l}\text { Special Tests of X-Ray and Gamma-Ray Measuring } \\
\text { Instruments }\end{array}$ \\
\hline C. 2 & $\begin{array}{l}\text { Gamma-Ray Sources, Beta-Particle Sources, } \\
\text { and Measuring Instruments }\end{array}$ \\
\hline $47010 \mathrm{C}$ & $\begin{array}{l}\text { Gamma-Ray Sources Similar to NIST Standards- } \\
{ }^{60} \mathrm{Co} \text { or }{ }^{137} \mathrm{Cs} \text { Having Air-Kerma Strengths } 10 \mu \mathrm{Gy} \mathrm{m}^{2} / \mathrm{h} \\
\text { to } 1500 \mu \mathrm{Gy} \mathrm{m} / \mathrm{h} \text {, and }{ }^{225} \text { or or }{ }^{192} \text { Ir Sources: Same Type } \\
\text { Seeds Used to Calibrate Reentrant Chamber Having Air- } \\
\text { Kerma Strengths } 0.1 \mu \mathrm{Gy} \mathrm{m} \mathrm{m}^{2} / \mathrm{h} \text { to } 30 \mu \mathrm{Gy} \mathrm{m} \mathrm{m}^{2} / \mathrm{h}\end{array}$ \\
\hline $47011 \mathrm{C}$ & $\begin{array}{l}\text { Each Additional Gamma-Ray Source of Same } \\
\text { Radionuclide }\end{array}$ \\
\hline $47030 \mathrm{C}$ & $\begin{array}{l}\text { Beta-Particle Sources Calibrated for Surface } \\
\text { Dose Rate }\end{array}$ \\
\hline $47035 \mathrm{C}$ & $\begin{array}{l}\text { Beta-Particle Sources Calibrated for Radiation } \\
\text { Protection }\end{array}$ \\
\hline $47036 \mathrm{C}$ & $\begin{array}{l}\text { Ionization Chambers Calibrated with Beta-Particle } \\
\text { Sources for Radiation Protection }\end{array}$ \\
\hline $47040 \mathrm{~S}$ & $\begin{array}{l}\text { Special Tests of Gamma-Ray and Beta-Particle } \\
\text { Sources }\end{array}$ \\
\hline C.3 & Dosimetry of High-Energy Electron Beams \\
\hline $48010 \mathrm{M}$ & $\begin{array}{l}\text { Dose Interpretation of NIST-Packaged Dosimeters } \\
\text { Irradiated by Customer-Two Dosimeters }\end{array}$ \\
\hline $48011 \mathrm{M}$ & Each Additional Dosimeter \\
\hline $48020 \mathrm{~S}$ & Special Tests of Electron-Beam Dosimeters \\
\hline
\end{tabular}

\section{C.0 Special Instructions for Using}

Electron and Photon Dosimetry

Services $(46010 \mathrm{C}-48020 \mathrm{~S})$

The NIST dosimetry calibration and test services for $\mathrm{X}$ rays, gamma rays, beta particles, and electrons are performed in NIST's laboratories at Gaithersburg, Maryland. Inquiries should be addressed 
to the appropriate technical contacts listed at the beginning of this section. The inquirer must provide the name and telephone number of an individual who can answer technical questions that may arise in any inquiry, order, or shipment.

Upon receipt of a purchase order, a report number is assigned. Calibrations are generally performed in the sequence established by those numbers, except when greater efficiency can be achieved by combining similar calibrations, or when work for a calibration laboratory is given a higher priority. Arrangements for calibration must be made in advance by letter, fax, e-mail or telephone, so that the instrument or source to be calibrated will not be shipped to NIST until the time of its scheduled calibration approaches. Inquiry should be made as to scheduling and turn-around time.

Except in the event of negligence by its personnel, NIST assumes no responsibility for loss of or damage to the instruments or sources while in its possession. The risk should be covered by insurance.

The report of calibration or test will carry a DG number (e.g., DG 9603/95). Subsequent reference to that calibration or test should cite the DG number.

\section{C.1 X-Ray and Gamma-Ray Measur- ing Instruments (46010C-46050S)}

$\mathrm{X}$-ray measuring instruments are calibrated in terms of air kerma or exposure by a substitution method in an x-ray beam at a point where the rate has been determined by means of a free-air ionization chamber standard. In order to provide instrument calibrations over a wide range of $\mathrm{x}$-ray beam qualities, many combinations of generating potential and filtration are available. Tungsten (W) anode, $\mathrm{x}$-ray beams with U.S. established beam qualities are listed Table 8.6 as lightly (L), moderately (M), and heavily (H) filtered beams. Two beam qualities that do not fit into these categories are considered as special (S) qualities. Cobalt-60 and cesium-137 gamma-ray beams are also available. New W-anode, ISO $\mathrm{x}$-ray beam qualities, listed in Table 8.7 are being installed; check for availability. Molybdenum (Mo) and rhodium ( $R h$ ) anode $x$-ray beam qualities, with application to mammography, are listed in Table 8.8. Beam qualities are identified by beam codes given in the first column. The calibration beam qualities requested should be appropriate to the instrument submitted.

Gamma-ray measuring instruments are calibrated in terms of air kerma, or absorbed dose at points in the collimated cobalt-60 and cesium-137 gamma-ray beams that have been standardized by means of graphite cavity chambers or a graphite (or water) calorimeter. Rates at the time of calibration are computed from the original beam standardization data and appropriate decay corrections. Ionization chambers submitted for an air kerma calibration should have sufficient wall thickness to provide electron equilibrium for the highest energy selected. Ionization chambers submitted for an absorbed-dose calibration must be suitable for calibration in a phantom.

An ionization chamber and electrometer combination, with the electrometer scale in units of air kerma, exposure, or absorbed dose, is calibrated by providing a dimensionless correction factor for the electrometer scale. An ionization chamber and electrometer combination marked in electrical units is calibrated as follows: (1) the chamber is calibrated in terms of air kerma or absorbed dose per unit charge using an NIST electrometer; (2) the customer's electrometer is checked for linearity and charge measurement accuracy; and (3) the combination of chamber and electrometer is checked for consistency. An ionization chamber submitted without an electrometer is calibrated in terms of air kerma or absorbed dose per unit charge. Calibration can be based on measurements for positive or negative polarizing potential, or on the mean of measurements for both potentials, as requested. The ratio of ionization currents for full and half polarizing potentials and the corresponding ionization current will be stated in the calibration certificate, based on precalibration measurements. 
Table 8.6. Tungsten-Anode X-Ray and Gamma-Ray Beam-Quality Parameters

\begin{tabular}{|c|c|c|c|c|c|c|c|c|c|c|c|}
\hline \multirow{3}{*}{$\begin{array}{l}\text { Beam } \\
\text { Code }\end{array}$} & \multirow{2}{*}{\multicolumn{4}{|c|}{ Added Filter }} & \multirow{2}{*}{\multicolumn{2}{|c|}{$\begin{array}{l}\text { Half-Value } \\
\text { Layer }\end{array}$}} & \multirow{2}{*}{\multicolumn{2}{|c|}{$\begin{array}{l}\text { Homogeneity } \\
\text { Coefficient }\end{array}$}} & \multirow{3}{*}{$\begin{array}{l}\text { Effective } \\
\text { Energy } \\
(\mathrm{keV})\end{array}$} & \multicolumn{2}{|c|}{ Air-Kerma Rate } \\
\hline & & & & & & & & & & Min. & Max. \\
\hline & $\begin{array}{c}\text { Al } \\
(\mathbf{m m})\end{array}$ & $\begin{array}{c}\mathrm{Cu} \\
(\mathrm{mm})\end{array}$ & $\underset{(\mathrm{mm})}{\mathrm{Sn}}$ & $\begin{array}{c}\mathrm{Pb} \\
(\mathrm{mm})\end{array}$ & $\begin{array}{c}\text { Al } \\
(\mathrm{mm})\end{array}$ & $\begin{array}{c}\mathrm{Cu} \\
(\mathrm{mm})\end{array}$ & Al & $\mathbf{C u}$ & & $(\boldsymbol{\mu G y} / \mathbf{s})$ & $(\mathrm{mGy} / \mathrm{s})$ \\
\hline \multicolumn{12}{|c|}{ X-Ray Beams } \\
\hline L10 & 0 & & & & 0.029 & & 79 & & & 0.009 & 15 \\
\hline L15 & 0 & & & & 0.05 & & 74 & & & 0.009 & 37 \\
\hline $\mathrm{L} 20$ & 0 & & & & 0.071 & & 76 & & & 0.009 & 29 \\
\hline L30 & 0.265 & & & & 0.22 & & 60 & & & 0.009 & 4 \\
\hline $\mathrm{L} 40$ & 0.5 & & & & 0.49 & & 57 & & & 0.009 & 4 \\
\hline L50 & 0.639 & & & & 0.75 & & 58 & & & 0.009 & 4 \\
\hline L80 & 1.284 & & & & 1.83 & & 58 & & & 0.009 & 4 \\
\hline L100 & 1.978 & & & & 2.8 & & 59 & & & 0.009 & 4 \\
\hline M20 & 0.23 & & & & 0.152 & & 79 & & & 0.009 & 4.4 \\
\hline M30 & 0.5 & & & & 0.36 & & 64 & & & 0.009 & 3 \\
\hline M40 & 0.786 & & & & 0.73 & & 66 & & & 0.009 & 4 \\
\hline M50 & 1.021 & & & & 1.02 & 0.032 & 66 & 62 & & 0.009 & 4 \\
\hline M60 & 1.51 & & & & 1.68 & 0.052 & 68 & 64 & & 7 & 2 \\
\hline $\mathrm{M} 80^{\mathrm{a}}$ & & & & & 3 & & & & & & \\
\hline M100 & 5 & & & & 5 & 0.2 & 72 & 55 & & 9 & 3 \\
\hline $\mathrm{M} 120^{\mathrm{a}}$ & & & & & 7 & & & & & & \\
\hline M150 & 5 & 0.25 & & & 10.2 & 0.67 & 87 & 62 & & 9 & 4 \\
\hline M200 & 4.1 & 1.12 & & & 14.9 & 1.69 & 95 & 69 & & 9 & 3 \\
\hline M250 & 5 & 3.2 & & & 18.5 & 3.2 & 98 & 86 & & 9 & 2 \\
\hline M300 & 4. & & 6.5 & & 22 & 5.3 & 100 & 97 & & 4 & 0.7 \\
\hline $\mathrm{H} 10$ & 0.105 & & & & 0.048 & & 89 & & & 0.009 & 0.03 \\
\hline H15 & 0.5 & & & & 0.152 & & 87 & & & 0.009 & 0.03 \\
\hline $\mathrm{H} 20$ & 1.021 & & & & 0.36 & & 88 & & & 0.009 & 0.03 \\
\hline H30 & 4.13 & & & & 1.23 & 0.038 & 93 & 94 & & 0.009 & 0.03 \\
\hline $\mathrm{H} 40$ & 4.05 & 0.26 & & & 2.9 & 0.093 & 94 & 95 & & 0.009 & 0.03 \\
\hline H50 & 4 & & & 0.1 & 4.2 & 0.142 & 92 & 90 & 38 & 3 & 0.6 \\
\hline H60 & 4 & 0.61 & & & 6 & 0.24 & 94 & 89 & 46 & 0.2 & 0.04 \\
\hline $\mathrm{H} 100$ & 4 & 5.2 & & & 13.5 & 1.14 & 100 & 94 & 80 & 0.04 & 0.02 \\
\hline H150 & 4 & 4 & 1.51 & & 17 & 2.5 & 100 & 95 & 120 & 0.3 & 0.09 \\
\hline $\mathrm{H} 200$ & 4 & 0.6 & 4.16 & 0.77 & 19.8 & 4.1 & 100 & 99 & 166 & 0.2 & 0.05 \\
\hline $\mathrm{H} 250$ & 4 & 0.6 & 1.04 & 2.72 & 22 & 5.2 & 100 & 98 & 211 & 0.3 & \\
\hline $\mathrm{H} 300$ & 4.1 & & 3 & 5 & 23 & 6.2 & 99 & 98 & 252 & 0.4 & 0.03 \\
\hline S75 & 1.504 & & & & 1.86 & & 63 & & & 0.009 & 4 \\
\hline S60 & 4.0 & & & & 2.8 & 0.089 & 75 & 70 & & 3 & 0.5 \\
\hline \multicolumn{12}{|c|}{ Gamma-Ray Beams } \\
\hline${ }^{137} \mathrm{Cs}$ & & & & & & 10.8 & & & 662 & 1.5 & 1.1 \\
\hline${ }^{60} \mathrm{Co}$ & & & & & & 14.9 & & & 1250 & 0.11 & 6.2 \\
\hline
\end{tabular}

For the $x$-ray beam codes, the letter indicates light $(\mathrm{L})$, moderate $(\mathrm{M})$, heavy $(\mathrm{H})$, and special $(\mathrm{S})$ filtration and the number is the constant potential in kilovolts.

The inherent filtration is approximately $1.0 \mathrm{~mm}$ Be for beam codes L10-L100, M20-M50, H10-H40, and S75; and $3.0 \mathrm{~mm}$ Be for beam codes M60-M300, H50-H300, and S60.

The half-value layers for ${ }^{137} \mathrm{Cs}$ and ${ }^{60} \mathrm{Co}$ are calculated.

The homogeneity coefficient is taken as 100 (1st HVL/2nd HVL).

${ }^{a}$ Beam parameters are nominal; actual values should be available by 1998 . 
Table 8.7. Tungsten-Anode ISO X-Ray Beam Quality Parameters (available 1998)

\begin{tabular}{|c|c|c|c|c|c|c|c|c|}
\hline \multirow[t]{2}{*}{$\begin{array}{l}\text { Beam } \\
\text { Code }\end{array}$} & \multicolumn{4}{|c|}{ Added Filter } & \multicolumn{2}{|c|}{$\begin{array}{l}\text { Half-Value } \\
\text { Layer }\end{array}$} & \multicolumn{2}{|c|}{$\begin{array}{c}\text { Homogeneity } \\
\text { Coefficient }\end{array}$} \\
\hline & $\underset{(\mathbf{m m})}{\mathrm{Al}}$ & $\underset{(\mathrm{mm})}{\mathrm{Cu}}$ & $\begin{array}{c}\text { Sn } \\
(\mathbf{m m})\end{array}$ & $\begin{array}{l}\mathrm{Pb} \\
(\mathbf{m m})\end{array}$ & $\underset{(\mathbf{m m})}{\mathrm{Al}}$ & $\underset{(\mathbf{m m})}{\mathrm{Cu}}$ & Al & $\mathrm{Cu}$ \\
\hline HK10 & 0.15 & & & & 0.036 & 0.010 & 88 & 90 \\
\hline HK20 & 0.15 & & & & 0.12 & 0.007 & 15 & 78 \\
\hline HK30 & 0.52 & & & & 0.38 & 0.013 & 63 & 72 \\
\hline HK 60 & 3.2 & & & & 2.42 & 0.079 & 74 & 72 \\
\hline HK 100 & 3.9 & 0.15 & & & 6.56 & 0.30 & 81 & 64 \\
\hline HK200 & & 1.15 & & & 14.7 & 1.70 & 95 & 71 \\
\hline HK250 & & 1.6 & & & 16.6 & 2.47 & 96 & 75 \\
\hline HK280 & & 3.0 & & & 18.6 & 3.37 & 98 & 84 \\
\hline HK300 & & 2.5 & & & 18.7 & 3.40 & 97 & 82 \\
\hline WK60 & & 0.3 & & & & 0.18 & & 86 \\
\hline WS80 & & 0.5 & & & & 0.35 & & 80 \\
\hline WS110 & & 2.0 & & & & 0.96 & & 86 \\
\hline WS150 & & & 1.0 & & & 1.86 & & 89 \\
\hline WS200 & & & 2.0 & & & 3.08 & & 93 \\
\hline WS250 & & & 4.0 & & & 4.22 & & 96 \\
\hline WS300 & & & 6.5 & & & 5.20 & & 97 \\
\hline NS10 & 0.1 & & & & 0.047 & & 90 & \\
\hline 5 & 0.5 & & & & 0.14 & & 88 & \\
\hline NS20 & 1.0 & & & & 0.32 & & 86 & \\
\hline NS & 2.0 & & & & 0.66 & & 90 & \\
\hline NS30 & 4.0 & & & & 1.15 & & 88 & \\
\hline NS40 & & 0.21 & & & & 0.084 & & 92 \\
\hline NS60 & & 0.6 & & & & 0.24 & & 92 \\
\hline NS80 & & 2.0 & & & & 0.58 & & 94 \\
\hline NS 100 & & 5.0 & & & & 1.11 & & 95 \\
\hline NS120 & & 5.0 & 1.0 & & & 1.71 & & 97 \\
\hline NS150 & & & 2.5 & & & 2.36 & & 96 \\
\hline NS200 & & 2.0 & 3.0 & 1.0 & & 3.99 & & 99 \\
\hline NS250 & & & 2.0 & 3.0 & & 5.19 & & 99 \\
\hline NS300 & & & 3.0 & 5.0 & & 6.12 & & 100 \\
\hline LK10 & 0.3 & & & & 0.058 & & 99 & \\
\hline LK20 & 2.0 & & & & 0.42 & & & \\
\hline LK30 & 4.0 & 0.18 & & & 1.47 & & 99 & \\
\hline LK35 & & 0.25 & & & 2.20 & & 99 & \\
\hline LK55 & & 1.2 & & & & 0.25 & & 99 \\
\hline LK70 & & 2.5 & & & & 0.49 & & 99 \\
\hline LK100 & & 0.5 & 2.0 & & & 1.24 & & 99 \\
\hline LK125 & & 1.0 & 4.0 & & & 2.04 & & 99 \\
\hline LK170 & & 1.0 & 3.0 & 1.5 & & 3.47 & & 99 \\
\hline LK210 & & 0.5 & 2.0 & 3.5 & & 4.54 & & 100 \\
\hline LK240 & & 0.5 & 2.0 & 5.5 & & 5.26 & & 100 \\
\hline
\end{tabular}

In the beam codes, the letters indicate low air kerma rate (LK), high air kerma rate (HK), narrow spectrum (NS), and wide spectrum (WS); and the number is the constant potential in kilovolts.

The inherent filtration is approximately $1.0 \mathrm{~mm}$ Be for beam codes LK10-LK30, NS10-NS30, HK10-HK30; for all other techniques the inherent filtration is adjusted to $4 \mathrm{~mm} \mathrm{Al}$. Values of half-value layers and homogeneity coefficients are nominal; actual values and available air-kerma rates are being determined.
Ionization chambers are tested, prior to calibration, for connection to the atmosphere. Chambers found unsuitable for calibration will be returned with a statement of the reason for rejection. A charge may be made for time incurred on the tests.

Each instrument submitted to NIST for dosimetry calibration or test must be uniquely identified, usually by the manufacturer's name, model number, and instrument serial number. When the serial number is lacking, an alternative identifying mark should be provided. If none is found, NIST will mark the piece with an identification number. If the apparatus submitted has been calibrated previously by NIST, the serial number or identifying mark should be given on the new order so that a continuing record of stability can be maintained.

All shipments to NIST of instruments for dosimetry calibration must be in reusable containers. Even if properly packed, there can be no assurance that a calibrated instrument has maintained its calibration during shipment unless a method of verifying instrument stability has been established. Measurement should be made of the instrument response both before and after shipment, using a long-lived radioactive source and a highly reproducible measurement procedure. A long-term record of instrument stability using a suitable constancy check procedure is the most effective method for assuring the validity of the instrument calibration.

Irradiation of passive dosimeters, for readout by the customer, is available for most of the beam qualities listed in Table 8.6. These irradiations are generally in terms of air kerma; for passive dosimeters suitable for insertion in a phantom, irradiation in terms of absorbed dose can be provided by in-phantom irradiation using cobalt -60 gamma rays.

Calibrations of $x$-ray and gamma-ray measuring instruments and of passive dosimeters, described above, have a relative expanded uncertainty* of $1 \%$.

*See Chapter 1, Section $\mathrm{H}$ for more information about uncertainty. 
Table 8.8. Mammography X-Ray Beam-Quality Parameters

\begin{tabular}{lcccc}
\hline Beam & $\begin{array}{c}\text { Tube } \\
\text { Voltage } \\
\text { Code }\end{array}$ & $\begin{array}{c}\text { Added } \\
\text { Filter } \\
(\mathbf{m m})\end{array}$ & $\begin{array}{c}\text { Half-Value } \\
\text { Layer } \\
\text { (mm Al) }\end{array}$ & $\begin{array}{c}\text { Homogeneity } \\
\text { Coefficient } \\
\text { (Al) }\end{array}$ \\
\hline Mo Anode & & & & \\
Mo/Mo23 & 23 & $0.032 \mathrm{Mo}$ & 0.271 & 70 \\
Mo/Mo25 & 25 & $0.032 \mathrm{Mo}$ & 0.296 & 72 \\
Mo/Mo28 & 28 & $0.032 \mathrm{Mo}$ & 0.332 & 74 \\
Mo/Mo30 & 30 & $0.032 \mathrm{Mo}$ & 0.351 & 75 \\
Mo/Mo35 & 35 & $0.032 \mathrm{Mo}$ & 0.392 & 78 \\
Mo/Rh28 & 28 & $0.029 \mathrm{Rh}$ & 0.408 & 80 \\
Mo/Rh32 & 32 & $0.029 \mathrm{Rh}$ & 0.445 & 82 \\
Mo/Mo25x & 25 & $0.030 \mathrm{Mo}+2.0 \mathrm{Al}$ & 0.566 & 91 \\
Mo/Mo28x & 28 & $0.030 \mathrm{Mo}+2.0 \mathrm{Al}$ & 0.626 & 96 \\
Mo/Mo30x & 30 & $0.030 \mathrm{Mo}+2.0 \mathrm{Al}$ & 0.660 & 95 \\
Mo/Mo35x & 35 & $0.030 \mathrm{Mo}+2.0 \mathrm{Al}$ & 0.748 & 90 \\
Rh Anode & & & & \\
Rh/Rh25 & 25 & $0.029 \mathrm{Rh}$ & 0.351 & 76 \\
Rh/Rh30 & 30 & $0.029 \mathrm{Rh}$ & 0.438 & 81 \\
Rh/Rh35 & 35 & $0.029 \mathrm{Rh}$ & 0.512 & 86 \\
Rh/Rh40 & 40 & $0.029 \mathrm{Rh}$ & 0.559 & 90 \\
Rh/Rh30x & 30 & $0.029 \mathrm{Rh}+2.0 \mathrm{Al}$ & 0.814 & 96 \\
Rh/Rh35x & 35 & $0.029 \mathrm{Rh}+2.0 \mathrm{Al}$ & 0.898 & 95 \\
\hline
\end{tabular}

The beam codes are a combination of the chemical symbol of the anode and the filter respectively, followed by the constant potential in kilovolts. The letter " $x$ " ends the beam codes which denote "exit" beams. The exit beam qualities, which are intended to represent the transmission of the $x$-rays through the breast, are generated by an additional filtration of $2.0 \mathrm{~mm}$ of aluminum.

The inherent filtration is $1 \mathrm{~mm}$ Be for all beam qualities. The calibration distance is $1 \mathrm{~m}$. The half-value layers were determined through direct measurements with the primary standard free-air ionization chamber. The air kerma rates for the entrance beams are between $0.5 \mathrm{mGy} / \mathrm{s}$ and $1 \mathrm{mGy} / \mathrm{s}$, and less than $0.2 \mathrm{mGy} / \mathrm{s}$ for the exit beams.

\section{C.2 Gamma-Ray Sources, Beta- Particle Sources, and Measuring Instruments $(47010 \mathrm{C}-47040 \mathrm{~S})$}

Sources submitted to NIST for dosimetry calibration are subject to the following conditions:

A. Preparation: Sources submitted for calibration must be sealed so that there can be no escape of any radioactive material, including any gaseous decay products. The sources, shielding, and packaging must be free of contamination. Contaminated or leaking sources cannot be measured and may cause considerable loss of time and damage to laboratory facilities. Sources must have been sealed for a sufficient time to be substantially in radioactive equilibrium with their decay products when these contribute to the emitted radiation.

B. Packaging for shipment: Packages must be in compliance with the regulations of the Department of Transportation as specified in DOT 49CFR173.401173.476. Radionuclides must be packaged as Limited Quantities (DOT 49CFR 173.421-173.422) or in Type A packages (DOT 49CFR 173.412 and 173.433). Type A packages must bear the appropriate radioactive-hazard labels (DOT 49CFR 172.403). If the source is considered by the shipper to be in DOT Special Form, a Special Form certificate must be furnished to NIST in strict compliance with DOT 49CFR173.476.

Copies of the regulations cited above are available from the Government Printing Office, Washington, DC 20402.

All shipments to NIST of gamma-ray and beta-particle sources should be in reusable containers. A drawing showing the source container and a description of the method of source removal should be provided before the shipment is received at NIST.

If the nature of the shipment requires a Type B container subject to an NRC quality assurance program, documentation should be supplied to NIST certifying that the use of the container by NIST is part of the program of the shipper.

C. Possession of licensed materials: In submitting a source for calibration, it is necessary for the submitter to certify that he is duly authorized to possess the source under license by the applicable authority. In the case of individuals residing in a State that has entered into agreement with the Nuclear Regulatory Commission, State regulations are applicable to all sources. In the case of other individuals, NRC regulations are applicable. This certification may be by letter, by a suitable statement on the purchase order covering the calibration fee, or by a clear copy of the submitter's Possession License for the source. 
Calibration in terms of air kerma strength (air kerma rate in free space times the square of the distance of the calibration point from the source center along the perpendicular bisector) is provided for gamma-ray sources of cobalt-60, cesium-137, iridium-192, and iodine-125. Calibration in terms of absorbed-dose rate is provided for suitable encapsulated beta-particle sources; the dose rate to a low-atomicnumber material (graphite or plastic) is determined by measurement with an extrapolation chamber. The betaparticle sources may be either small-area sources such as ophthalmic applicators, or large-area plaques, and will be calibrated for absorbed dose rate to water either at the source surface or at a specified distance.

Ionization chambers to be calibrated with beta-particle sources must be parallel-plate chambers with thin walls. They can be calibrated with the radionuclides ${ }^{90} \mathrm{Sr}+{ }^{90} \mathrm{Y}$, or ${ }^{204} \mathrm{Tl}$, or ${ }^{147} \mathrm{Pm}$.

Measurement services in this series have uncertaities listed in Tables 8.9 and 8.10 .

Table 8.9: Uncertainties for GammaRay Source Calibrations, $47010 \mathrm{C}$ and $47011 \mathrm{C}$

\begin{tabular}{lc}
\hline Source & $\begin{array}{c}\text { Relative } \\
\text { Expanded } \\
\text { Uncertainty* } \\
(\%)\end{array}$ \\
\hline${ }^{60} \mathrm{Co}$ & 2 \\
${ }^{137} \mathrm{Cs}$ & 2 \\
${ }^{192} \mathrm{Ir}$ & 2 \\
${ }^{125} \mathrm{I}$ (no marker) & $5^{(a)}$ \\
${ }^{125} \mathrm{I}$ (Ag wire) & $6^{(a)}$ \\
${ }^{125} \mathrm{I}$ (Au wire) & $7^{(\mathrm{a})}$ \\
\hline
\end{tabular}

(a) A new standard and calibration measurement is under development for ${ }^{125}$ I seed sources. The new calibrations are anticipated to be available in 1998, with smaller uncertainties than those listed above. *See Chapter 1, Section H for more information about uncertainty.
Table 8.10. Uncertainties for Beta-Particle Source and Instrument Calibrations

\begin{tabular}{|c|c|c|}
\hline Service ID & Item & $\begin{array}{c}\text { Relative } \\
\text { Expanded } \\
\text { Uncertainty* } \\
(\%)\end{array}$ \\
\hline $47030 \mathrm{C}$ & $\begin{array}{l}\text { Sources calibrated for surface } \\
\text { dose rate }\end{array}$ & 12 \\
\hline $47035 \mathrm{C}$ & $\begin{array}{l}\text { Sources calibrated for radiation } \\
\text { protection, }{ }^{90} \mathrm{Sr}+{ }^{90} \mathrm{Y} \\
{ }^{204} \mathrm{Tl} \\
{ }^{147} \mathrm{Pm}\end{array}$ & $\begin{array}{c}4.5 \\
4.5 \\
9\end{array}$ \\
\hline $47036 \mathrm{C}$ & $\begin{array}{l}\text { Transfer ionization chambers for } \\
\text { radiation protection } \\
\text { Extrapolation chambers for radiation } \\
\text { protection, absolute } \\
\text { Extrapolation chambers for radiation } \\
\text { protection, relative to NIST standard } \\
\text { chamber in reference field }\end{array}$ & $\begin{array}{c}\text { same as } 47035 \mathrm{C} \\
\text { same as } 47035 \mathrm{C} \\
\mathrm{l}^{\text {(a) }}\end{array}$ \\
\hline
\end{tabular}

(a) Typical value. Actual value depends on response characteristics of submitted chamber.

*See Chapter 1, Section H for more information about uncertainty.

\section{C.3 Dosimetry of High-Energy Electron Beams (48010M-48020S)}

Dosimeters are provided twice a year to users requesting assistance with absorbed-dose measurements in highenergy electron beams. The dosimeters are alanine dosimeters. The user irradiates the two furnished dosimeters to between $50 \mathrm{~Gy}$ and $80 \mathrm{~Gy}$ (5000 and $8000 \mathrm{rad}$ ) to water at electron energies between $5 \mathrm{MeV}$ and $50 \mathrm{MeV}$, employing the irradiation geometry (field size, phantom, position of dosimeter in phantom) given in the "Protocol for Dosimetry of High-Energy Electrons," Physics in Medicine and Biology 11, 505 (1966).

After irradiation, the dosimeters are returned to NIST for evaluation in terms of absorbed dose in the phantom, using the appropriate methods. These dose interpretations ignore certain corrections for the effects of spectral perturbations, and so represent a measurement quality assurance service rather than a calibration service. 
The measurement procedure with alanine dosimeters is undergoing refinement; for the current procedure, the corresponding estimate of the relative expanded uncertainty* is $2.3 \%$.

\section{References-Dosimetry of X Rays, Gamma Rays, and Electrons}

\section{C.1 X-Ray and Gamma-Ray Measuring Instruments}

NBS Measurement Services: Calibration of X-Ray and Gamma-Ray Measuring Instruments, P. J. Lamperti, T. P. Loftus, and R. Loevinger, Natl. Bur. Stand. (U.S.), Spec. Publ. 250-16 (Mar. 1988).

The Photon-Fluence Scaling Theorem for Compton-Scattered Radiation, J. S. Pruitt and R. Loevinger, Med. Phys. 9, 176 (1982).

The Graphite Calorimeter as a Standard of Absorbed Dose for Cobalt-60 Gamma Radiation, J. S. Pruitt, S. R. Domen, and R. Loevinger, J. Res. Natl. Bur. Stand. (U.S.), 86, 495 (1981).

Medical Dosimetry Standards Program of the National Bureau of Standards, R. Loevinger, Proc. Symp. on Natl. and Intl. Standardization in Rad. Dosimetry, Atlanta, GA, Dec. 5-9, 1977, Intl. Atomic Energy Agency, Vienna (1978). (This article provides references for earlier publications on NBS exposure and absorbed-dose standards.)

Uncertainty in the Delivery of Absorbed Dose, R. Loevinger and T. P. Loftus, Ionizing Radiation Metrology, International Course at Varenna, Italy, 1974, E. Casnati, Ed., G-6, 459, Editrice Compositori, Bologna (1977).

Exposure Spectra from the NBS VerticalBeam ${ }^{60}$ Co Gamma-Ray Source, M. Ehrlich and C. G. Soares, Natl. Bur. Stand. (U.S.), NBSIR 76-1117 (1976). Spectrometry of a ${ }^{60} \mathrm{Co}$ Gamma-Ray Beam Used for Instrument Calibration, M. Ehrlich, S. M. Seltzer, M. J. Bielefeld, and J. I. Trombka, Metrologia 12, 169 (1976).

*See Chapter 1, Section H for more information about uncertainty.
C.2 Gamma-Ray Sources, Beta-Particle Sources, and Measuring Instruments

A Method for the Calibration of Concave ${ }^{90} \mathrm{SR}+{ }^{90} \mathrm{Y}$ Opthalmic Applicators, C. G. Soares, Phys. Med. Biol. 37, 1005 (1992).

Calibration of Ophthalmic Applicators at NIST-A Revised Approach, C. G. Soares, Med. Phys. 18, 787 (1991).

NBS Measurement Services: Calibration of Gamma-Ray-Emitting Brachytherapy Sources, J. T. Weaver, T. P. Loftus, and R. Loevinger, Natl. Bur. Stand. (U.S.), Spec. Publ. 250-19 (1988).

NBS Measurement Services: Calibration of Beta-Particle Radiation Instrumentation and Sources, J. S. Pruitt, C. G. Soares, and M. Ehrlich, Natl. Bur. Stand. (U.S.), Spec. Publ. 250-21 (Apr. 1988).

NBS Measurement Services: Calibration of Beta-Particle-Emitting Ophthalmic Applicators, J. S. Pruitt, Natl. Bur. Stand. (U.S.), Spec. Publ. 250-9 (July 1987).

Calibration of Beta-Particle Ophthalmic Applicators at the National Bureau of Standards, J. S. Pruitt, J. Res. Natl. Bur. Stand. (U.S.), 91, 165 (1986).

The Effect of Altitude on Beta-Ray Source Calibrations, J. S. Pruitt, Rad. Protec. Dosim. 11, 151 (1984).

Exposure Standardization of Iodine-125 Seeds Used for Brachytherapy, T. P. Loftus, J. Res. Natl. Bur. Stand. (U.S.), 89, 295 (1984).

Standardization of Iridium-192 GammaRay Sources in Terms of Exposure, T. P. Loftus, J. Res. Natl. Bur. Stand. (U.S.), 85, 19 (1980).

Medical Dosimetry Standards Program of the National Bureau of Standards, R. Loevinger, Proc. Symp. on Natl. and Intl. Standardization in Rad. Dosimetry, Atlanta, GA, Dec. 5-9, 1977, Intl. Atomic Energy Agency, Vienna (1978). (This article provides references for earlier publications on NBS exposure and absorbed-dose standards.) 
Standardization of Cesium-137 GammaRay Sources in Terms of Exposure Units (Roentgens), T. P. Loftus, J. Res. Natl. Bur. Stand. (U.S.), 74A, 1 (1970).

\section{C.3 Dosimetry of High-Energy Electron Beams}

NBS Measurement Services: Fricke Dosimetry in High-Energy Electron Beams, C. G. Soares, E. L. Bright, and M. Ehrlich, Natl. Bur. Stand. (U.S.), Spec. Publ. 250-4 (1987).

Radiation Dosimetry: Electron Beams with Energies between 1 and $50 \mathrm{MeV}$, Report 35, International Commission Radiation Units and Measurements, Bethesda, MD (1984).
Uniformity of High-Energy ElectronBeam Calibrations, M. Ehrlich and P. J. Lamperti, Phys. Med. Biol. 14, 305 (1969).

Proposed National Bureau of Standards Program for the Calibration of Instruments Used in High-Energy Electron and X-Ray Beams, M. Ehrlich, Ann. N.Y. Acad. Sci. 161, 139 (1969). 


\section{Dosimetry for High-Dose Applications}

\author{
Technical Contacts:
}

\begin{tabular}{|c|c|c|}
\hline Ste & Marc F. Desrosiers & Puhl \\
\hline Tel: & Tel: $301 / 975-5639$ & Tel: \\
\hline $\begin{array}{l}\text { Email: s.seltzer@ } \\
\text { nistgov } \\
\text { Fax: } 301 / 869.7682\end{array}$ & $\begin{array}{l}\text { Email: marc. } \\
\text { desrosiers@nist.gov }\end{array}$ & $\begin{array}{l}\text { Email: jan } \\
\text { nist.gov }\end{array}$ \\
\hline
\end{tabular}

Mailing Address: Building 245, Room C229, Attn: J. Puhl, National Institute of Standards and Technology, Gaithersburg, MD 20899-0001

Service

ID No.

Items

49010C Calibration Irradiations of Customer-Supplied Dosimeters with ${ }^{60} \mathrm{Co}$ Gamma Rays

49020C Dose Interpretation of NIST Transfer Dosimeters Irradiated by Customer, Three Dosimeters Plus Control(s)

49030C Dose Interpretation of Each NIST Transfer Dosimeter in Addition to Those Supplied under $49020 \mathrm{C}$

49040S Special Tests of Dosimeters by Reading with Spectrophotometer, Optical Absorbance at One to Five Wavelengths (Each Dosimeter)

49041S Spectrophotometric Readings of Dosimeters, Ultra-Violet and Visible Spectrum Scan (Each Dosimeter)

49050S Special Measurement Services for Dosimeter Response and Dose Distributions

Calibration Services and Special Tests of Dosimeters (49010C-49050S)

The following dosimetry services are for individual users of intense radiation fields, in particular large gamma-ray sources and electron accelerators up to approximately $10 \mathrm{MeV}$. These services include the administering of known absorbed doses of photons to customer-supplied dosimeters; supplying calibrated transfer standard dosimeters to customers for irradiation and subsequent readout and dose interpretation; and special measurement services such as the determination of temperature dependence, dose-rate dependency or reproducibility of dosimeter response.
Calibration of Dosimeters Irradiated with ${ }^{60} \mathrm{Co}$ Gamma Rays (49010C)

Calibration irradiations are available for customer-supplied dosimeters (such as solid radiochromic or liquid chemical types) or test samples that are sent to NIST, where they are packaged appropriately to provide electron equilibrium conditions. They are irradiated in the NIST standard ${ }^{60} \mathrm{Co}$ calibration facility to specific agreed-upon absorbed dose values in the nominal range of $\left(10\right.$ to $\left.10^{6}\right)$ Gy $\left(10^{3} \mathrm{rad}\right.$ to $\left.10^{8} \mathrm{rad}\right)$. The dosimeters are then sent back to the customer for analysis and evaluation. Dosimeters must fit within a cylindrical volume $5 \mathrm{~cm}$ in height and $5 \mathrm{~cm}$ diameter. For our standard calibrated geometries (radiochromic film, alanine pellets, $2 \mathrm{~mL}$ ampoules, and red perspex), the absorbed dose (water) delivered to the dosimeter has a relative expanded uncertainty* of $1.8 \%$.

\section{Transfer Reference Standard Dosimeters (49020C and 49030C)}

NIST provides transfer standards in the form of sets of calibrated radiochromic or alanine dosimeters packaged in polystyrene. The sealed, packaged dosimeters are sent to the customer for irradiation to nominal agreed-upon absorbed dose levels in a prescribed geometrical arrangement. The unopened packaged dosimeters are then returned to NIST to be read and evaluated and the results reported, thus providing calibration of the customer's irradiator. The absorbed dose range that is suitable for use with the transfer dosimeters is $50 \mathrm{~Gy}$ to $200 \mathrm{KGy}$ ( $5 \mathrm{rad}$ to $20 \mathrm{Mrad}$ ) in water, silicon, aluminum, graphite, or certain plastics. The transfer standard calibrations (absorbed dose in water) have a relative expanded uncertainty* of $2.2 \%$ for alanin dosimeters and $4.5 \%$ for radiochromic dosimeters.

* See Chapter 1, Section H for more information about uncertainty. 
Special Tests of Dosimeters: Spectrophotometric Reading (49040S-49041S)

Dosimeters may be read at several specific ultraviolet or visible optical wavelengths or as a spectral scan over an appropriate wavelength region of interest.

Special Measurement Services for Dosimeter Response and Dose Distributions (49050S)

Tests of dosimeter response, such as temperature dependence, dose rate dependence, and dose distributions in specific irradiation geometries, can be provided as special measurement services. These dose distribution measurements can include dose profiles in heterogenous absorbers and at interfaces of different materials.

\section{References-High-Dose Dosimetry}

Dosimetry Systems for Radiation Processing, W. L. McLaughlin and M. F. Desrosiers, Radial. Phys. Chem. 46, 1163 (1995).

ESR-Based Analysis in Radiation Processing, W. L. McLaughlin, M. F. Desrosiers and M. C. Saylor, Sterilization of Medical Products, Vol. VI (R. F. Morrissey, Ed.), Polyscience Publications, Inc. Marin Heights, Canada, p. 213 (1993).
ESR Dosimetry, W. L. McLaughlin,

Radial. Prot. Dosim. 47, 255 (1993).

NBS Measurement Services: Dosimetry for High-Dose Applications, J. C. Humphreys, D. Hocken, and W. L. McLaughlin, Natl. Bur. Stand. (U.S.), Spec. Publ. 250-11 (Mar. 1988).

Dosimetry for Industrial Radiation Processing, W. L. McLaughlin,

J. C. Humphreys, and A. Miller, Natl. Bur. Stand. (U.S.), Spec. Publ. 609 (1982).

A National Standardization Programme for High-Dose Measurements, W. L. McLaughlin, Technical Report No. 205, 17, Intl. Atomic Energy Agency, Vienna (1981).

Dye Film Dosimetry for Radiation Processing, J. C. Humphreys and W. L. McLaughlin, IEEE Trans. Nucl. Sci., NS-28, 2, 1797 (Apr. 1981).

The Measurement of Absorbed Dose and Dose Gradients, W. L. McLaughlin, Radiat. Phy. Chem. 15, 9 (1980).

Dosimetry Standards for Industrial Radiation Processing, W. L. McLaughlin, National and International Standardization of Radiation Dosimetry, 1, Intl. Atomic Energy Agency, Vienna (1978). 


\title{
Chapter
}

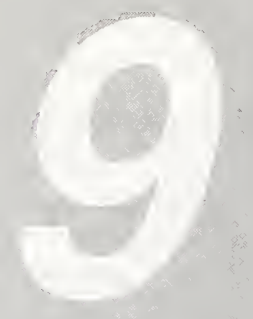

\author{
A Resistance Measurements \\ B Impedance Measurements (Except Resistors) \\ C Voltage Measurements \\ D Precision Ratio Measurements \\ E Phase Meters and Standards and VOR Measurements \\ F Power and Energy Measurements, Low-Frequency \\ G RF, Microwave and Millimeter-Wave Measurements \\ $H$ Electromagnetic Field Strength and Antenna Measurements \\ I Pulse Waveform Measurements
}




\section{Electromagnetic Measurements}

Resistance Measurements

\section{A.1 DC Resistance Standards and Measurements}

Technical Contacts:

$\begin{array}{ccl}\text { Ronald F. Dziuba } & \text { Randolph E. Elmquist } & \text { Denise D. Prather } \\ \text { Tel: 301/975-4239 } & \text { Tel: 301/975-6591 } & \text { Administration and } \\ \text { Email: rdziuba@ } & \text { Email: relmquist@ } & \text { Logistics } \\ \text { nist.gov } & \text { nist.gov } & \begin{array}{l}\text { Tel: 301/975-4221 } \\ \text { Email: dprather@ } \\ \end{array} \\ & & \begin{array}{c}\text { nist.gov } \\ \end{array}\end{array}$

Mailing Address: Building 220, Room B146, National Institute of Standards and Technology, Gaithersburg, MD 20899-0001

\begin{tabular}{ll} 
Service & \\
ID No. & Items \\
\hline $51100 \mathrm{~S}$ & $\begin{array}{l}\text { Special Resistance Measurement Services, by } \\
\text { Prearrangement }\end{array}$ \\
$51110 \mathrm{M}$ & $\begin{array}{l}\text { Measurement Assurance Program Services for } \\
\text { Resistance }\end{array}$ \\
$51130 \mathrm{C}$ & Standard Resistor, Thomas-Type, $1 \Omega$ \\
$51131 \mathrm{C}$ & Standard Resistor, Evanohm Wirewound High \\
& Precision, 10 $\Omega$ \\
$51132 \mathrm{C}$ & Standard Resistor, Four-Terminal, $0.0001 \Omega$ \\
$51133 \mathrm{C}$ & Standard Resistor, Four-Terminal, $0.001 \Omega$ \\
$51134 \mathrm{C}$ & Standard Resistor, Four-Terminal, $0.01 \Omega$ \\
$51135 \mathrm{C}$ & Standard Resistor, Four-Terminal, $0.1 \Omega$ \\
$51136 \mathrm{C}$ & Standard Resistor, Four-Terminal, $1 \Omega$ \\
$51137 \mathrm{C}$ & Standard Resistor, Four-Terminal, $10 \Omega$ \\
$51138 \mathrm{C}$ & Standard Resistor, Four-Terminal, $100 \Omega$ \\
$51139 \mathrm{C}$ & Standard Resistor, 1 k $\Omega$ \\
$51140 \mathrm{C}$ & Standard Resistor, 10 k $\Omega$ \\
$51141 \mathrm{C}$ & Standard Resistor, 100 k $\Omega$ \\
$51142 \mathrm{C}$ & Standard Resistor, $1 \mathrm{M} \Omega$ \\
$51143 \mathrm{C}$ & Standard Resistor, 10 M $\Omega$ \\
$51144 \mathrm{C}$ & Additional Voltage, $10 \mathrm{M} \Omega$ \\
$51145 \mathrm{C}$ & Standard Resistor, 100 M $\Omega$ \\
\hline
\end{tabular}

Service

ID No. Items

$51146 \mathrm{C}$ Additional Voltage, $100 \mathrm{M} \Omega$

51147C Standard Resistor, $1 \mathrm{G} \Omega$

51148C Additional Voltage, $1 \mathrm{G} \Omega$

51149C Standard Resistor, $10 \mathrm{G} \Omega$

$51150 \mathrm{C}$ Additional Voltage, $10 \mathrm{G} \Omega$

$51151 \mathrm{C}$ Standard Resistor, $100 \mathrm{G} \Omega$

$51152 \mathrm{C}$ Additional Voltage, $100 \mathrm{G} \Omega$

51153C Standard Resistor, $1 \mathrm{~T} \Omega$

$51154 \mathrm{C}$ Additional Voltage, $1 \mathrm{~T} \Omega$

51160C Standard Resistor for Current Measurements

(Shunts), with All Determinations at 300 A or Below, One Range, One Current Level

51161C Standard Resistor for Current Measurements (Shunts), with at Least One Determination Above 300 A (maximum current 2000 A) One Range, One Current Level

51162C Standard Resistor for Current Measurements (Shunts), Additional Range of a Multi-Range Resistor

51163C Standard Resistor for Current Measurements (Shunts), Additional Determination at Another Current Level 
Special DC Resistance Measurements, by Prearrangement $(51100 \mathrm{~S})$

Testing or evaluation of prototype resistance standards or measuring instruments; unique resistance measurements; and other calibration services not specified below, such as the determination of the pressure coefficient of Thomas-type or $10 \mathrm{k} \Omega$ resistors, the determination of the temperature coefficient of standard resistors, and the calibration of resistance standards in oil at temperatures other than $25^{\circ} \mathrm{C}$, are carried out under this Service ID number. Such measurements are made at the discretion of the NIST technical staff in a manner specifically agreed upon by the customer and the expert involved. Testing of component resistors will only be considered under the rare circumstance that the behavior of the resistors has been observed to approximate that of state-of-the-art standards under the same conditions.

\section{Measurement Assurance Program for Resistance (51110M)}

Resistance MAP transfers are generally carried out at the $1 \Omega$ and $10 \mathrm{k} \Omega$ levels. Four well-characterized commercial standard resistors are used as transport standards at each level. The suggested measurement schedule at the client laboratory consists of measurements on each transport resistor three times a week for a period of 4 to 6 weeks, depending upon the settling time of the resistors due to transportation effects.

Participation in this program is generally not advisable unless one is required to support resistance measurements with state-of-the-art or near state-of-theart uncertainties and is willing to adopt a system for the continuous surveillance of standards during the intervals between NIST MAP transfers. A successful transfer requires a considerable amount of data collection and a willingness to become involved in the data analysis process. Data supplied in the course of routine NIST calibrations suffice for normal measurement requirements of standards laboratories if proper methods are used by the laboratory to quantify the additional uncertainties caused by transportation and the laboratory's own measurement process.

\section{Special Standard Resistors $1 \Omega$ and $10 \mathrm{k} \Omega(51130 \mathrm{C}$ and $51131 \mathrm{C})$}

Thomas-type $1 \Omega$ resistors or their equivalent are calibrated directly against the NIST $1 \Omega$ reference group that is used to maintain the U.S. legal ohm. The values of the reference group are known in terms of the quantum Hall effect. Special $10 \mathrm{k} \Omega$ standard resistors designed for air or oil use are calibrated directly against the NIST $10 \mathrm{k} \Omega$ working standards. The special $10 \mathrm{k} \Omega$ standard resistors (Evanohm wirewound high-precision or equivalent) are characterized by resistance corrections within $10 \times 10^{-6}$ of nominal value, temperature coefficients of $0 \pm 1 \times 10^{-6} /{ }^{\circ} \mathrm{C}$ at the operating temperature, and drift rates of $\leq 1 \times 10^{-6} /$ year.

The customer's resistors are acclimatized in their respective test environments for approximately 1 week prior to their calibration. Measurement parameters of temperature and current level are shown in Table 9.1.

Table 9.1. Temperatures and Current Levels for Customer's Resistors

\begin{tabular}{cccc}
\hline Resistor & Medium & $\begin{array}{c}\text { Temperature } \\
\left({ }^{\circ} \mathbf{C}\right)\end{array}$ & $\begin{array}{c}\text { Current } \\
\text { (mA) }\end{array}$ \\
\hline $1 \Omega$ & oil & $25.000 \pm 0.003$ & 100 \\
$10 \mathrm{k} \Omega$ & oil & $25.000 \pm 0.005$ & 1 \\
$10 \mathrm{k} \Omega$ & air & $23.0 \pm 1.0$ & 1 \\
\hline
\end{tabular}

The temperature of the customer's resistor at the time of the measurement is given in the report of calibration. Since some of these resistors exhibit a significant pressure coefficient, the barometric pressure at the time of the measurement is also reported. Uncertainties are based upon (1) the random behavior of the measurement process as characterized by data from a large population of individual calibrations, and (2) an estimate of the systematic errors arising from such sources as temperature inaccuracies, pressure inaccuracies, scaling errors, etc. Uncertainties are listed in Table 9.2. 
Table 9.2. Calibration Uncertainties for DC Resistance Standards

\begin{tabular}{|c|c|c|c|c|}
\hline $\begin{array}{l}\text { Test } \\
\text { Number }\end{array}$ & $\begin{array}{l}\text { Nominal } \\
\text { Resistance } \\
(\Omega)\end{array}$ & $\begin{array}{c}\text { Terminal } \\
\text { Connection }\end{array}$ & $\begin{array}{c}\text { Maximum } \\
\text { Power } \\
\text { (mw) }\end{array}$ & $\begin{array}{r}\text { Nominal } \\
\text { Relative } \\
\text { Expanded } \\
\text { Uncertainty* } \\
\left(\times 10^{-6}\right)\end{array}$ \\
\hline $51130 \mathrm{C}$ & 1 (Thomas) & 4 & 10 & 0.05 \\
\hline $51131 \mathrm{C}$ & $10^{4}($ Special $)$ & 5 & 10 & 0.15 \\
\hline $51132 \mathrm{C}$ & $10^{-4}$ & 4 & $\cdot 100$ & 11 \\
\hline $51133 \mathrm{C}$ & $10^{-3}$ & 4 & 100 & 5 \\
\hline $51134 \mathrm{C}$ & $10^{-2}$ & 4 & 100 & 3 \\
\hline $51135 \mathrm{C}$ & $10^{-1}$ & 4 & 100 & 2 \\
\hline $51136 \mathrm{C}$ & 1 & 4 & 50 & 1 \\
\hline $51137 \mathrm{C}$ & 10 & 4 & 50 & 1 \\
\hline $51138 \mathrm{C}$ & $10^{2}$ & 2 & 10 & 0.5 \\
\hline $51139 \mathrm{C}$ & $10^{3}$ & 2 & 10 & 0.5 \\
\hline $51140 \mathrm{C}$ & $10^{4}$ & 2 & 10 & 0.5 \\
\hline $51141 \mathrm{C}$ & $10^{5}$ & 2 & 10 & 2 \\
\hline $51142 \mathrm{C}$ & $10^{6}$ & 2 & 10 & 3 \\
\hline $51143 C$ & $10^{7}$ & 3 & - & 14 to 140 \\
\hline $51145 \mathrm{C}$ & $10^{8}$ & 3 & - & 40 to 400 \\
\hline $51147 \mathrm{C}$ & $10^{9}$ & 3 & - & 140 to 700 \\
\hline $51149 \mathrm{C}$ & $10^{10}$ & 3 & - & 400 to 700 \\
\hline $51151 \mathrm{C}$ & $10^{11}$ & 3 & - & 700 \\
\hline $51153 \mathrm{C}$ & $10^{12}$ & 3 & - & 1400 \\
\hline
\end{tabular}

* See Chapter 1 , Section $\mathrm{H}$ for more information about uncertainty. - Resistors at this level are tested at customer-specified voltages up to $1 \mathrm{kV}$.

\section{Standard Resistors $10^{-4}$ to $10^{6} \Omega$ (51132C-51142C)}

Standard resistors with nominal decade values in the range between $10^{-4} \Omega$ and $10^{6} \Omega$ are calibrated by comparison with NIST working standards of equivalent value, known in terms of the Quantum Hall effect. In general, these standards are characterized by (1) resistance corrections within $500 \times 10^{-6}$ of nominal value, (2) temperature coefficients of $\leq 10 \times 10^{-6} /{ }^{\circ} \mathrm{C}$ at the temperature of use, and (3) drift rates of $\leq 5 \times 10^{-6}$ year. Normally, standard resistors are measured in an oil bath maintained at $(25.0 \pm 0.05)^{\circ} \mathrm{C}$, and at a power level of $\leq 0.1 \mathrm{~W}$. Resistors in temperaturecontrolled enclosures with fixed terminations are also accepted for calibration. At the levels of accuracy involved, fourterminal measurements are required for resistors whose nominal values are $100 \Omega$ or less. Expanded uncertainties* are based upon (1) the random behavior of the measurement process as characterized by data from a large population of individual calibrations, and (2) an estimate of the systematic errors. Uncertainties are given in Table 9.2.

\section{High-Value Standard Resistors: $10^{7} \Omega$ to $10^{12} \Omega(51143 C-51154 C)$}

High-value standard resistors in the range between $10^{7} \Omega$ and $10^{12} \Omega$ are calibrated in an air bath maintained at a temperature of $(23.0 \pm 0.1){ }^{\circ} \mathrm{C}$ and at a relative humidity of $(35 \pm 5) \%$. The resistors are maintained at these conditions at least 24 hours prior to testing. Customer resistors are compared 1:1 with NIST working standards of the same nominal value up to and including the $10^{10} \Omega$ level.

Above $10^{10} \Omega, 10: 1$ and 100:1 ratio techniques are employed. The maximum test voltage is $500 \mathrm{~V}$ for resistors $<10^{10} \Omega$ and $1000 \mathrm{~V}$ for resistors $\geq 10^{10} \Omega$. Uncertainties depend upon the stability and performance of the specific resistor involved and are given in Table 9.2. Only resistors that are mounted in a shielded enclosure with a permanent identifying number and have suitable terminations are accepted for calibration.

The resistance of thin-film, highvalued resistance standards is frequently highly voltage dependent. Hence, the magnitude of the test voltage should be specified by the customer when a resistor is submitted for calibration. The temperature, relative humidity, and test voltage of the resistor are given in the report of calibration.

\section{High-Current Standard Resistors- Shunts (51160C-51163C)}

Four-terminal standard resistors for use in the precise measurement of high direct currents (shunts) are calibrated by NIST only during May and November of the calendar year. Arrangements should be made with NIST prior to submitting a resistor for calibration. Normally only resistors of $0.04 \%$ relative uncertainty

* See Chapter 1, Section $\mathrm{H}$ for more information about uncertainty. 
or less are calibrated. The maximum test current available is $2000 \mathrm{~A}$. The uncertainty of measurement depends largely upon the performance of the customer's resistor involved.

\section{References-DC Resistance}

NIST Measurement Services for DC

Standard Resistors, R. F. Dziuba, P. A. Bounton, R. E. Elquist, D. G. Jarrett, T. P. Moore and J.D. Neal, Natl. Inst. Stand. Technol. Tech. Note 1298 (Nov. 1992).

Guidelines for Implementing the New Representation of the Volt and Ohm Effective January 1, 1990, N. B. Belecki, R. F. Dziuba, B. F. Field, and B. N. Taylor, Natl. Inst. Stand. Technol. Tech. Note 1263 (June 1989).

New Realization of the Ohm and Farad Using the NBS Calculable Capacitor, J. Q. Shields, R. F. Dziuba, and H. P. Layer, Conf. Precision Electromagnetic Meas. (CPEM '88), June 7-10,1988, Tsukuba Science City, Japan, Special Issue CPEM ' 88 IEEE Trans. Instrum. Meas. 38 (2), 249-251 (April 1989).

Determination of the Time-Dependence of $\Omega_{\mathrm{NBS}}$ Using the Quantized Hall Resistance, M. E. Cage, R. F. Dziuba, C. T. Van Degrift, and D. Yu, Conf. Precision Electromagnetic Meas. (CPEM '88), June 7-10, 1988, Tsukuba Science City, Japan, Special Issue CPEM ' 88 IEEE Trans. Instrum. Meas. 38 (2), 263-269 (April 1989).
Monitoring the U.S. Legal Unit of Resistance via the Quantum Hall Effect, M. E. Cage, R. F. Dziuba, B. F. Field, T. E. Kiess, and C. T. Van Degrift, IEEE Trans. Instrum. Meas. IM-36, 222 (June 1987).

The NBS Ohm Past-Present-Future, R. F. Dziuba, Proc. Meas. Science Conf., Irvine, CA (Jan. 1987).

A Test of the Quantum Hall Effect as a Resistance Standard, M. E. Cage, R. F. Dziuba, and B. F. Field, IEEE Trans. Instrum. Meas. IM-34, 301 (1985).

Automated NBS 1-Ohm Measurement System, K. R. Baker and R. F. Dziuba, IEEE Trans. Instrum. Meas. IM-32, 154 (1982).

An Integrated System for the Precision Calibration of Four-Terminal Standard Resistors, T. E. Wells and E. F. Gard, IEEE Trans. Instrum. Meas. IM-20, 253 (Nov. 1971).

Calibration Procedures for Direct Current Apparatus, P. Brooks, Natl. Bur. Stand. (U.S.), Monogr. 39 (Mar. 1962).

Measurement of Multimegohm Resistors, A. H. Scott, J. Res. Natl. Bur. Stand. (U.S.), 50, (3) (Mar. 1953).

Precision Resistors and Their Measurement, J. L. Thomas, Natl. Bur. Stand. (U.S.), Circular 470 (Oct. 1948).

Methods, Apparatus, and Procedures for the Comparison of Precision Standard Resistors, F. Wenner, J. Res. Natl. Bur. Stand. (U.S.), 25, Res. Paper RP1323 (Aug. 1940). 


\section{Resistance Measurements}

\section{A.2 High-Voltage Standard Resistors}

\author{
Technical Contacts:
}
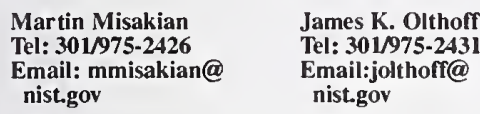

Denise D. Prather Administration and Logistics

Tel: 301/975-4221

Email: dprather@nist.gov

Mailing Address: Building 220, Room B 146, National Institute of Standards and Technology, Gaithersburg, MD 20899-0001

\section{Shipping Address:}

National Institute of Standards and Technology, [Attn: M. Misakian, Bldg. 220, Room B351, ext. 2426], I-270 at Quince Orchard Road,

Gaithersburg, MD 20899-0001

Service

ID No.

51210C High-Voltage Standard Resistors

High-Voltage Standard Resistors (51210C)

A routine calibration service is maintained for resistors designed for dc highvoltage applications. This service is for corona-free resistors designed for $\mathrm{dc}$ operation between $10 \mathrm{kV}$ and $150 \mathrm{kV}$.

Resistors may be hand-carried or shipped to NIST. If they are shipped, they should be packaged in sturdy reusable containers with convenient access to the resistor. The design of many high-voltage resistors makes them vulnerable to shear-type forces, so provisions should be made to minimize the likelihood of damage due to such forces when the device is in the shipping container.

Users of this service should first discuss scheduling of calibrations with a NIST technical contact. The purchase order should indicate the voltage test points, a mailing address for the calibration report, and a shipping address for the resistor.

\section{References-High-Voltage Standard} Resistors

High-Voltage Divider and Resistor Calibrations, M. Misakian, Natl. Bur. Stand. (U.S.), Tech. Note 1215 (July 1985).

Special Shielded Resistor for High-

Voltage Measurements, J. H. Park, J. Res. Natl. Bur. Stand. 66C (1), 1924 (Jan.-Mar. 1962). 


\section{Resistance Measurements A.3 High-Frequency Standard Resistors}

\author{
Technical Contacts:
}

$\begin{array}{ll}\text { George M. Free } & \text { Paula M. Hewitt } \\ \text { Tel: 303/497-3609 } & \text { Administration and } \\ \text { Email: gfree@nist.gov } & \text { Logistics } \\ & \text { Tel: 303/497-3753 } \\ & \text { Email: paula.hewitt@nist.gov } \\ & \text { Fax: 303/497-3970 }\end{array}$

Mailing Address: M.C. 813.10,

National Institute of Standards and Technology,

325 Broadway,

Boulder, CO 80303-3328

Service

ID No. Items

51310S High-Frequency Standard Resistors; Two-Terminal

\section{References-High-Frequency Standard Resistors}

The Measurement of Lumped Parameter Impedance: A Metrology Guide, R. N. Jones, Natl. Bur. Stand. (U.S.), Monogr. 141 (June 1974).

Impedance of Lumped Circuits, L. E. Huntley and R. N. Jones, Proc. IEEE, 55 (6), 900 (June 1967).

*See Chapter I, Section H for more information about uncertainty.

\section{High-Frequency Standard Resistors} (51310S)

The overall frequency range covered is $10 \mathrm{kHz}$ to $250 \mathrm{MHz}$. The range of resistance that can be calibrated depends upon the measurement frequency, as follows:

\section{Frequency Range Resistance Range \\ $10 \mathrm{kHz}$ to $2 \mathrm{MHz} \quad 0.1 \Omega$ to $10 \mathrm{k} \Omega$ $2 \mathrm{MHz}$ to $10 \mathrm{MHz} \quad 50 \Omega$ to $10 \mathrm{k} \Omega$ $10 \mathrm{MHz}$ to $250 \mathrm{MHz} \quad 20 \Omega$ to $1 \mathrm{k} \Omega$}

Measurement uncertainties are given in the reference; the relative expanded uncertainties* start at $0.1 \%$.

Reports of Calibration or Tests for resistors will include the inductance or capacitance associated with the resistor. Equivalent series values are normally given for inductive resistors and equivalent parallel values for capacitive resistors. 
Impedance Measurements (Except Resistors) B.1 Low-Frequency Capacitance and Inductance Measurements and Standards

\author{
Technical Contacts:
}

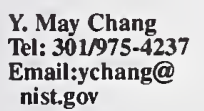

\author{
Summerfield B. Tillett \\ Tel: 301/975-4244 \\ Email:summerfield. \\ tillett@nist.gov
}

Denise D. Prather

Administration and Logistics

Tel: 301/975-4221

Email:dprather@nist.gov

Mailing Address: Building 220, Room B146,

National Institute of Standards and Technology,

Gaithersburg, MD 20899-0001

Service

ID No.

Items

52110 S Special LF Impedance Measurements, by Prearrangement

52120S Special Measurement Assurance Program for Standard Capacitors

$(100 \mathrm{pF}$ and $1000 \mathrm{pF}$, at a Frequency of $1000 \mathrm{~Hz}$ )

52130C Fixed Fused-Silica Dielectric Standard Capacitors $(1,10$, and 100$) \mathrm{pF}$, at a Frequency of $(100,400$, or 1000$) \mathrm{Hz}$

52131C Additional Measurement at One of the Above Frequencies

52140C Fixed Three-Terminal, High-Precision Nitrogen Dielectric Standard Capacitors with Coaxial Connectors, Small Uncertainty $(10,100$, and $1000) \mathrm{pF}$, at a Frequency of $(100,400$, or 1000$) \mathrm{Hz}$

52141C Additional Measurement at One of the Above Frequencies

52150C Physical Tests for Three-Terminal Nitrogen Dielectric Capacitors (at $1000 \mathrm{~Hz}$ only) as an Optional Supplement to the Small Uncertainty Calibration (52140C)

52160C Fixed Three-Terminal Standard Capacitors with Coaxial Connectors, Large Uncertainty $(0.001 \mathrm{pF}$ to $10,000 \mathrm{pF})$, at a Frequency of $(100,400$, or 1000$) \mathrm{Hz}$

52161C Additional Measurement at One of the Above Frequencies

52170C Two- or Three-Terminal Mica Dielectric Standard Capacitors with Binding Post Connectors $(0.001 \mu \mathrm{F}$ to $1 \mu \mathrm{F})$, at a Frequency of $(66,100,400,1000$, or 10,000$) \mathrm{Hz}$

52171C Additional Measurement at One of the Above Frequencies

52176C Two-Terminal Standard Capacitors with Precision High Frequency (HF) Coaxial Connectors $(0.001 \mathrm{pF}$ to $10,000 \mathrm{pF})$, at a Frequency of $1000 \mathrm{~Hz}$

$52180 \mathrm{C}$ Fixed Standard Inductors $(0.00005 \mathrm{H}$ to $10 \mathrm{H})$, at a Frequency of $(100,400,1000$, or 10,000$) \mathrm{Hz}$

52181C Additional Measurement at One of the Above Frequencies
Low-Frequency Capacitance and Inductance Measurements and Standards (52110S-52181C)

These services cover the calibration of standard capacitors and inductors in the audio-frequency range. Three-terminal standard capacitors having fused-silica $(1,10$, and 100$) \mathrm{pF}$, nitrogen $(10,100$, and 1000$) \mathrm{pF}$, and air, from $0.001 \mathrm{pF}$ to $10000 \mathrm{pF}$, dielectrics can be measured at $(100,400$, and 1000$) \mathrm{Hz}$. Two- or threeterminal capacitors with mica dielectrics in the range from $0.001 \mu \mathrm{F}$ to $1 \mu \mathrm{F}$ can be measured at $(66,100,400,1000$, and $10000) \mathrm{Hz}$. Two-terminal air and mica dielectric capacitors with high frequency (HF) coaxial connectors, from $1 \mathrm{pF}$ to $10000 \mathrm{pF}$, including GR900 terminations, are calibrated only at $1 \mathrm{kHz}$. Aircore standard inductors having nominal values between $0.05 \mathrm{mH}$ and $10 \mathrm{H}$ can be measured at (100, 400, and 1000) Hz. Standard inductors of $100 \mathrm{mH}$ or less also can be measured at $10 \mathrm{kHz}$. Calibration of impedance standards other than those mentioned above will be considered for Special Test Under Service ID Number 52110S (see below).

The calibration of some types of high frequency capacitance standards at frequencies as low as $1 \mathrm{kHz}$ can be provided by the NIST Electromagnetic Fields Division in Boulder, $\mathrm{CO}$, provided the uncertainty required exceeds $0.01 \%$. In some circumstances this can eliminate the necessity of sending a standard to both Gaithersburg and Boulder Laboratories for a complete calibration. See also Service ID Numbers 52210 C-52310C for calibration of capacitors at higher frequencies. For additional details please inquire at NIST/Boulder: Telephone (303) 497-3609.

\section{Special LF Impedance Measurements, by Prearrangement ( $52110 \mathrm{~S})$}

This service provides for the testing or evaluation of prototype impedance standards or measurement instrumentation at the state-of-the-art, and other 
impedance measurements (such as the calibration of decade or variable capacitance standards), at the discretion of NIST technical experts. Component capacitors, inductors, and resistors are not considered for testing by NIST unless their performance approximates that of the best available standards. Even under those conditions, calibration will only be done on a limited basis to ascertain the possible use of the components in precision measurement applications.

The cost for such tests are determined on a case-by-case basis, and may be considerably higher than the posted fee for Calibration Services because of needed additional preparation and extra measurements required to perform an uncertainty assessment.

\section{Special Measurement Assurance Program for Standard Capacitors (52120S)}

\section{The Capacitance MAP (C-MAP)} transfers are carried out for standard capacitors at the $1000 \mathrm{pF}$ and $100 \mathrm{pF}$ levels, at a frequency of $1 \mathrm{kHz}$. A commercial $1 \mathrm{kHz}$ capacitance meter is used as the transport standard. The client laboratory (Lab) is responsible for performing measurements (using the Lab calibration system and the transport standard) on its own reference and/or check standards, and on the two pairs of dummy capacitors from NIST of the same nominal values. Prior to the initiation of the C-MAP, the $\mathrm{Lab}$ is required to complete a CAPACITANCE MAP INFORMATION SHEET, and to provide a description of its calibration procedures. At the time the transport standard and the dummy capacitors are shipped to the Lab for a C-MAP transfer, the Lab will also receive detailed instructions for carrying out the C-MAP and the software for enabling the transport standard (commercial capacitance meter) to make measurements automatically. The Lab is also required to collect and reduce the data from its calibration system, and to enter the results on to the CAPACITANCE MAP DATA SHEET.

The transport standard and the dummy capacitors are normally kept in the Lab for about 4 to 6 weeks, as eight to twelve sets of measurements are required. After the completion of post MAP measurements and a data analysis at NIST, a REPORT OF CALIBRATION from NIST is issued to the Lab. This report provides the difference between the unit of capacitance maintained by the Lab and the farad, and the assigned values for the Lab reference standards (and their uncertainties) to bring the difference to zero.

\section{Fused-Silica Dielectric Standard Capacitors (52130C-52131C)}

Air-bath type, fused-silica dielectric standard capacitors are generally submitted in temperature-controlled ovens due to their $\left(10 \times 10^{-6}\right) /{ }^{\circ} \mathrm{C}$ temperature coefficient. Because of the magnitude of the temperature coefficient, it is recommended that a reliable temperature sensor having a resolution of $0.001{ }^{\circ} \mathrm{C}$, or better, be permanently mounted in the oven and thus included as part of the calibration. For baths not so equipped, the temperature is measured in terms of the International Temperature Scale of 1990 (ITS-90), using a standard platinum resistance thermometer.

Some capacitance standards consist of a fused-silica dielectric capacitor completely sealed within a temperaturecontrolled oven and the ancillary circuitry required for its operation, but with no means of measuring or monitoring the oven's internal temperature. Since the actual temperature of the capacitor cannot be measured, it is not reported. Some such standards measure and display the ambient temperature. For these, the mean value of the display readings taken at the times of measurement is reported, but the significance of this value is decided by the user. 
Oil-bath type, fused-silica dielectric capacitors are calibrated in an NIST oil bath maintained at $(25 \pm 0.01)^{\circ} \mathrm{C}$, if the normal temperature of use for these capacitors is approximately $25^{\circ} \mathrm{C}$. If the capacitors are supplied with built-in sensors, the sensors and the oil temperature are both measured. Requests for the calibration of oil-bath type, fused-silica dielectric capacitors are accepted as Special Tests (52110S).

Calibrations are carried out at $(100$, 400 , or 1000$) \mathrm{Hz}$, or any combination of these frequencies chosen by the client. A minimum of five measurements is made over a 2-week or longer period, comparing the test capacitor directly with an NIST fused-silica standard at $10 \mathrm{pF}$. The number of readings taken depends on the stability of the temperature of the test capacitors. The averages of the measured values of capacitance and temperature are reported. The uncertainty of the reported capacitance value depends on the stability of the temperature as well as on the performance of the capacitance standard itself. Because the temperature coefficients of individual standards are usually not known quantitatively, the results cannot be temperature corrected. Despite these factors, the Type A standard uncertainty* can be as low as $2 \times 10^{-8}$ of the capacitor's nominal value.

\section{Standard Capacitors (52140C-52176C)}

The following guidelines apply to the calibration of standard capacitors having dielectrics other than fused-silica.

Calibrations are ordinarily performed at a normal laboratory ambient temperature of $(23 \pm 1){ }^{\circ} \mathrm{C}$ except for measurements of high-stability nitrogen dielectric capacitors. These are measured more than once in a period of several days to observe their stabilities and to ensure that the variation of the measurements is within the required limit of the standard errors for these measurements.

* See Chapter l, Section H for more information about uncertainty.
Simultaneously, a digital thermometer with a resolution of $0.001{ }^{\circ} \mathrm{C}$ is placed near the capacitors to monitor the temperatures during calibrations. The calibration temperature, nominally $23^{\circ} \mathrm{C}$, is reported to within $\pm 0.01{ }^{\circ} \mathrm{C}$. Relative humidity is maintained at $50 \%$ or less in all cases.

Precision three-terminal nitrogen dielectric capacitors, such as ESI Model SC1000 and GENRAD Model 1404, have been found to be variously affected by mechanical shock and orientation. Accordingly, two types of calibrations, featuring different levels of uncertainty are offered. See Table 9.3. A qualification test $(52150 \mathrm{C})$ is available to supplement the small uncertainty calibration (52140C) in order to determine the effects of various impacts (physical shocks) and orientation on the capacitors. Results of this test should be coupled with the Type-B uncertainty* of the precision calibration that follows to provide an expanded uncertainty for the calibration of a particular standard. Requests for the small uncertainty calibration without the physical tests are also accepted. For the large uncertainty test $(52160 \mathrm{C})$, a similar calibration, but with reduced resolution, is performed. Three-terminal air dielectric capacitors are accepted for the large uncertainty calibration $(52160 \mathrm{C})$ only.

In the case of direct or three-terminal capacitance standards, the connectors are assumed to be coaxial, such as the GENRAD Type 874 . While the connectors available for this purpose are adequate, it should be noted that changes or instabilities in the impedance of the shield or guard connection of a threeterminal capacitor can change the capacitance significantly.

Capacitors requiring terminal plugs (banana plugs) for parallel connection should be sent to NIST together with the plugs that will be used with the capacitor after calibration. If such a capacitor arrives without plugs, NIST must attach plugs temporarily in order to calibrate 
the capacitor. Those used by NIST are GENRAD Type 274-P plugs. If, after calibration with these plugs, the capacitor is used with plugs of even slightly different length and base, the capacitance can differ significantly from that reported, and such differences will not be reflected in the calibration uncertainties reported.

Unless otherwise requested, the measured value reported by NIST is the added capacitance when the standard is plugged directly into the binding posts of the NIST bridge. For two-terminal GENRAD capacitors, Type 509 and Type 1409 (when used as a two-terminal capacitor), a capacitance increase ranging from $0.01 \mathrm{pF}$ to $0.04 \mathrm{pF}$ has been found for different plugs. No significant change in conductance has been found in either the two-terminal or three-terminal value. The importance of terminal connection methods becomes extremely critical when capacitance values of $0.01 \mu \mathrm{F}$ or less are being measured. Improved accuracy in two-terminal measurements can be realized if standards are provided with precision coaxial connectors.

The terminal connections, either as two-terminal or three-terminal capacitors, for capacitors with mica dielectric, should be specified in the customer's purchase order. Otherwise, they will be calibrated as two-terminal capacitors (with the case "Ground" connected to the "Low" terminal).

The capacitance value given is the equivalent parallel capacitance. In general, an accurate determination of the equivalent parallel conductance with high accuracy is not available. However, for mica dielectric capacitors in an approximate conductance value for each capacitor is also given.

The frequencies available for capacitance calibrations depend upon the type of capacitor and its connectors. In general, capacitors with binding posts or GR 274-P plugs can be calibrated at $(66,100,400,1000$, and 10000$) \mathrm{Hz}$. Capacitors with high frequency coaxial connectors (GENRAD Type 900) are calibrated only at $1000 \mathrm{~Hz}$.
The expanded uncertainty* stated in the Report of Calibration is determined by the random behavior of each type of capacitor (determined from the analysis of measurement data taken from a large population of individual calibrations), as well as an estimate of the systematic errors of the NIST measurement process. These are calculated using the approach of NIST Technical Note 1297, per NIST policy. The expanded uncertainties are given in Table 9.3 and Table 9.4.

The stated uncertainties are sufficiently broad to allow for variations in the stray capacitance at the connectors, in temperature of a few degrees Celsius, in relative humidity and atmospheric pressure, and in frequency deviations of a few percent from the stated test conditions. Depending on the frequency and the capacitance value, the relative expanded uncertainty* usually lies between $0.0004 \%$ and $0.05 \%$ (see Tables 9.3 and 9.4). The uncertainties do not include allowances for effects of transportation; these must be determined by the owner using pre- and post-calibration data from the owner's facility.

\section{Standard Inductors, Self or Mutual (52180C-52181C)}

Air-core standard inductors for use in ac bridges are tested at a room temperature of $(23 \pm 1)^{\circ} \mathrm{C}$ and a relative humidity of $50 \%$ or less. Measurements at $10000 \mathrm{~Hz}$ are limited to standard inductors of $0.1 \mathrm{H}$ or less. Most inductors used at $60 \mathrm{~Hz}$ can be tested at $100 \mathrm{~Hz}$ since the variation of inductance with frequency in this range is usually negligible. A metal-encased standard is calibrated with the case "Ground" connected to the "Low" terminal of the inductor unless other conditions are specified. The reported values are the self inductance values of the inductors.

* See Chapter 1, Section $\mathrm{H}$ for more information about uncertainty. 
Table 9.3. Calibration Uncertainties for Capacitance Standards with Coaxial Connectors

\begin{tabular}{|c|c|c|c|c|c|}
\hline \multirow{2}{*}{$\begin{array}{l}\text { Service ID } \\
\text { No. }\end{array}$} & \multirow[b]{2}{*}{ Dielectric } & \multirow{2}{*}{$\begin{array}{l}\text { Terminal } \\
\text { Connection }\end{array}$} & \multirow{2}{*}{$\begin{array}{l}\text { Nominal } \\
\text { Capacitance } \\
(\mathrm{pF})\end{array}$} & \multicolumn{2}{|c|}{ Relative Expanded Uncertainties* $\left(\times 10^{-6}\right)$} \\
\hline & & & & $100 \mathrm{~Hz}$ & $\begin{array}{l}\text { Frequency } \\
\quad 400 \mathrm{~Hz} \text { and } 1 \mathrm{kHz}\end{array}$ \\
\hline $\begin{array}{l}52130 C \\
\text { and } \\
52131 C\end{array}$ & Fused-Silica & 3 & $\begin{array}{l}1 \\
10 \\
100\end{array}$ & $\begin{array}{r}10 \\
4 \\
4\end{array}$ & $\begin{array}{l}4.1 \\
2.5 \\
2.5\end{array}$ \\
\hline $\begin{array}{l}52140 \mathrm{C} \\
\text { and } \\
52141 \mathrm{C}\end{array}$ & Nitrogen & 3 & $\begin{array}{c}10 \\
100 \\
1000\end{array}$ & $\begin{array}{l}6 \\
6 \\
6\end{array}$ & $\begin{array}{l}4 \\
4 \\
4\end{array}$ \\
\hline $\begin{array}{l}52160 \mathrm{C} \\
\text { and }\end{array}$ & Nitrogen & 3 & 10 to 1000 & 25 & 25 \\
\hline $52161 \mathrm{C}$ & Air & 3 & $\begin{array}{c}0.001 \\
0.01 \\
0.1 \\
1 \text { to } 1000 \\
10000\end{array}$ & $\begin{array}{c}\text { NA } \\
1500 \\
230 \\
100 \\
\text { NA }\end{array}$ & $\begin{array}{l}2000 \\
200 \\
100 \\
100 \\
150\end{array}$ \\
\hline $52176 \mathrm{C}$ & Air & 2 & $\begin{array}{c}1 \\
2 \\
5 \\
10 \\
20 \\
50 \text { to } 1000\end{array}$ & $\begin{array}{l}\text { NA } \\
\text { NA } \\
\text { NA } \\
\text { NA } \\
\text { NA } \\
\text { NA }\end{array}$ & $\begin{array}{c}\text { (only at } 1 \mathrm{kHz} \text { ) } \\
840 \\
420 \\
200 \\
100 \\
75 \\
60\end{array}$ \\
\hline & Mica & 2 & $\begin{array}{c}1000 \\
5000 \text { to } 10000\end{array}$ & $\begin{array}{l}\text { NA } \\
\text { NA }\end{array}$ & $\begin{array}{l}60 \\
65\end{array}$ \\
\hline & $\begin{array}{l}\text { Open-Circuit } \\
\text { Termination }\end{array}$ & $\begin{array}{l}2 \\
2\end{array}$ & $\begin{array}{l}0.172 \\
2.670\end{array}$ & $\begin{array}{l}\text { NA } \\
\text { NA }\end{array}$ & $\begin{array}{r}1000 \\
450\end{array}$ \\
\hline
\end{tabular}

*See Chapter 1 , Section $\mathrm{H}$ for more information about uncertainty. 
Table 9.4. Calibration Uncertainties for Capacitance Standards with Terminal (Banana) Plugs

\begin{tabular}{|c|c|c|c|c|c|c|c|c|}
\hline \multirow{5}{*}{$\begin{array}{c}\text { Service } \\
\text { ID. } \\
\text { No. }\end{array}$} & \multirow{5}{*}{$\begin{array}{l}\text { Dielec- } \\
\text { tric }\end{array}$} & \multirow{5}{*}{$\begin{array}{c}\text { Terminal } \\
\text { Connec- } \\
\text { tion }\end{array}$} & \multirow{5}{*}{$\begin{array}{c}\text { Nominal } \\
\text { Capaci- } \\
\text { tance } \\
(\mu F)\end{array}$} & \multicolumn{5}{|c|}{ Expanded Uncertainties* } \\
\hline & & & & \multicolumn{2}{|c|}{ Capacitance } & \multicolumn{2}{|c|}{ Conductance } & \multirow{4}{*}{$\begin{array}{r}10 \mathrm{kHz} \\
(\mu \mathrm{S})\end{array}$} \\
\hline & & & & \multicolumn{2}{|c|}{ Frequency } & \multicolumn{2}{|r|}{ Frequency } & \\
\hline & & & & $\begin{array}{l}66 \mathrm{~Hz} \text { to } \\
1 \mathrm{kHz}\end{array}$ & $10 \mathrm{kHz}$ & $\begin{array}{l}66 \mathrm{~Hz} \& \\
100 \mathrm{~Hz}\end{array}$ & $\begin{array}{l}400 \mathrm{~Hz} \& \\
1 \mathrm{kHz}\end{array}$ & \\
\hline & & & & $(\%)$ & $(\%)$ & $(\mu S)$ & $(\mu S)$ & \\
\hline $52170 \mathrm{C}$ & Mica & 2 & 0.001 & 0.018 & 0.018 & 0.0003 & 0.0006 & 0.001 \\
\hline and & & & 0.002 & 0.016 & 0.016 & 0.0003 & 0.0008 & 0.002 \\
\hline $52171 \mathrm{C}$ & & & 0.005 & 0.016 & 0.016 & 0.0003 & 0.001 & 0.005 \\
\hline & & & 0.01 & 0.018 & 0.018 & 0.0006 & 0.002 & 0.01 \\
\hline & & & 0.02 & 0.018 & 0.018 & 0.0006 & 0.003 & 0.02 \\
\hline & & & 0.05 & 0.018 & 0.020 & 0.002 & 0.006 & 0.01 \\
\hline & & & 0.1 & 0.018 & 0.040 & 0.005 & 0.02 & 0.4 \\
\hline & & & 0.2 & 0.018 & 0.060 & 0.008 & 0.04 & 1 \\
\hline & & & 0.5 & 0.018 & 0.10 & 0.02 & 0.13 & 6 \\
\hline & & & 1 & 0.018 & 0.20 & 0.04 & 0.4 & 20 \\
\hline & Mica & 3 & 0.001 & 0.012 & 0.012 & 0.0003 & 0.0006 & 0.001 \\
\hline & & & 0.002 & 0.010 & 0.010 & 0.0003 & 0.0008 & 0.002 \\
\hline & & & 0.005 & 0.010 & 0.010 & 0.0003 & 0.001 & 0.005 \\
\hline & & & 0.01 & 0.010 & 0.010 & 0.0006 & 0.002 & 0.01 \\
\hline & & & 0.02 & 0.010 & 0.012 & 0.0006 & 0.003 & 0.02 \\
\hline & & & 0.05 & 0.010 & 0.015 & 0.002 & 0.006 & 0.01 \\
\hline & & & 0.1 & 0.010 & 0.03 & 0.005 & 0.02 & 0.4 \\
\hline & & & 0.2 & 0.010 & 0.05 & 0.008 & 0.04 & 1 \\
\hline & & & 0.5 & 0.010 & 0.10 & 0.02 & 0.13 & 6 \\
\hline & & & 1 & 0.015 & 0.20 & 0.04 & 0.4 & 20 \\
\hline
\end{tabular}

*See Chapter 1, Section H for more information about uncertainty.

References-Low-Frequency Capacitance and Inductance Standards

NIST Measurement Assurance Program for Capacitance Standards at $1 \mathrm{kHz}$, Y. May Chang, NIST Technical Note 1417 (March 1996).

NIST Capacitance Measurement Assurance Program (MAP), Y. May Chang, Measurement Science Conference, Anaheim, CA, (January 1993).

New Realization of the Ohm and Farad Using the NBS Calculable Capacitor, J. Q. Shields, R. F. Dziuba, and H. P. Layer, Conf. Precision Electromagnetic Meas. (CPEM '88), June 7-10, 1988, Tsukuba Science City, Japan, Special Issue CPEM '88 IEEE Trans. Instrum. Meas. 38 (2), 249-251 (April 1989).
Testing to Quantify the Effects of Handling of Gas Dielectric Standard Capacitors, C. R. Levy, Natl. Bur. Stand. (U.S.), Tech. Note 1161 (1982).

New Measurements of the Absolute Farad and Ohm, R. D. Cutkosky, IEEE Trans. Instrum. Meas., IM-23 (4), 305 (Dec. 1974).

Applications of Coaxial Chokes to AC Bridge Circuits, D. N. Homan, J. Res. Natl. Bur. Stand. (U.S.), 72C (2) (June 1968).

Improved Ten-Picofarad Fused Silica Dielectric Capacitor, R. D. Cutkosky and H. L. Lee, J. Res. Nat1. Bur. Stand. (U.S.), 69C (3), 173 (Sept. 1965). 
Calibration of Inductance Standards in the Maxwell-Wein Bridge Circuit,T. L. Zapf, J. Res. Natl. Bur. Stand. (U.S.), 65C (3) (Sept. 1961).

Capacitance Bridge NBS Type 2, R. D. Cutkosky, Natl. Bur. Stand. (U.S.), Report 7103 (Mar. 1961).
NIST Calibration Service for Capacitance Standards at Low Frequency, Y. May Chang and Summerfield B. Tillett, NIST Technical Note (to be published). Error Analysis and Calibration Uncertainty of Capacitance Standards at NIST, Y. May Chang, NIST Technical Note (to be published). 


\section{Impedance Measurements (Except Resistors) B.2 High-Frequency Standard Capacitors and Inductors}

\author{
Technical Contacts:
}

\begin{abstract}
George M. Free Tel: 303/497-3609 Email:gfree@nist.gov
\end{abstract}

\author{
Paula M. Hewitt \\ Administration and Logistics \\ Tel: 303/497-3753 \\ Email:paula.hewitt@nist.gov \\ Fax:303/497-3970
}

Mailing Address: M.C. 813.10,

National Institute of Standards and Technology,

325 Broadway,

Boulder, CO 80303-3328

\begin{tabular}{|c|c|}
\hline $\begin{array}{l}\text { Service } \\
\text { ID No. }\end{array}$ & Items \\
\hline $52210 \mathrm{~S}$ & $\begin{array}{l}\text { Two-Terminal, Low-Loss Standard Capacitors- } \\
10 \mathrm{kHz} \text { to } 250 \mathrm{MHz} ; 1 \mathrm{pF} \text { to } 20 \mathrm{pF}\end{array}$ \\
\hline $52211 \mathrm{~S}$ & $\begin{array}{l}\text { Two-Terminal, Low-Loss Standard Capacitors } \\
\text { (High Accuracy)-10 kHz to } 30 \mathrm{MHz} \text {; } \\
(50,100,200,500 \text {, and } 1000) \mathrm{pF}\end{array}$ \\
\hline $52221 \mathrm{C}$ & $\begin{array}{l}\text { Three-Terminal, Low-Loss Standard Capacitors } \\
\text { (High Accuracy)- } 10 \mathrm{kHz} \text { to } 30 \mathrm{MHz} \text {; } \\
\left(10^{-2}, 10^{-1}, 1,10,10^{2} \text {, and } 10^{3}\right) \mathrm{pF}\end{array}$ \\
\hline $52310 \mathrm{~S}$ & $\begin{array}{l}\text { Two-Terminal, High- } Q \text { Standard Inductors } \\
\left(10^{-2} \mu \mathrm{H} \text { to } 1 \mathrm{H}\right)\end{array}$ \\
\hline
\end{tabular}

High-Frequency Standard Capacitors and Inductors (52210S-52310S)

Services provided in this category (and also Service ID Numbers 51310 S and $52710 \mathrm{C}$ ) are for passive devices over the frequency range from $10 \mathrm{kHz}$ to $250 \mathrm{MHz}$. Highest accuracy is obtained only for standards equipped with precision coaxial connectors. Standards submitted for calibration should be in good repair and, except for very minor cleaning of connector surfaces, should require no pre-calibration maintenance. NIST does not provide repair services; items received that require maintenance will be returned to the sender and a handling fee charged.

Calibration services for some types of capacitance standards at frequencies as low as $1 \mathrm{kHz}$ can be provided by the NIST Boulder Laboratory if the accuracy requirement does not exceed $0.01 \%$. In some circumstances this can eliminate the necessity of sending a standard to both the Gaithersburg and Boulder Laboratories for a complete calibration. For additional details, please consult with the technical contact listed at the beginning of this section.

Calibration services are not provided for measuring instruments such as bridges or meters. The uncertainty of these instruments should be verified by the owner through the use of stable standards especially selected for particular values and frequencies appropriate to the instrument in question.

All calibrations are performed under typical ambient laboratory conditions of $23{ }^{\circ} \mathrm{C}$, and an atmospheric pressure of approximately $\left((8.4 \pm 0.2) \times 10^{4}\right) \mathrm{Pa}$ at Boulder, Colorado. Services at ambient conditions outside these limits are not provided. Also, the power applied to any device being calibrated does not exceed $1 \mathrm{~W}$. Additional information about immittance (impedance and admittance) measurement and standards are contained in the references.

\section{Two-Terminal, Low-Loss Standard Capacitors (52210S-52211S)}

In the frequency range from $10 \mathrm{kHz}$ to $250 \mathrm{MHz}$, capacitance calibrations are available from $1 \mathrm{pF}$ to $1000 \mathrm{pF}$ depending upon frequency. The upper capacitance limit for calibration decreases as the frequency increases and is $50 \mathrm{pF}$ above $30 \mathrm{MHz}$.

From $100 \mathrm{kHz}$ to $30 \mathrm{MHz}$, a special high-accuracy service is available for capacitors with nominal values of (50, $100,200,500$, and 1000$) \mathrm{pF}$ if equipped with $14 \mathrm{~mm}$ coaxial connectors. 
The minimum relative expanded uncertainty* is $0.01 \%$ for the high accuracy device and $0.1 \%$ for the other other calibrations.

Reports of Calibration for capacitors normally do not give conductance values because the conductance values of capacitors of standard quality, especially those with air-dielectric, are too small to be measured accurately at the present state of the art.

A technique for extrapolating the $1 \mathrm{kHz}$ values of capacitance standards to high frequencies is described by R. N. Jones (see 1963 reference). That reference describes a technique for obtaining a high-frequency value of a capacitor equipped with an unshielded (banana plug) connector. The measurement technique yields effective capacitance values at high frequencies using the capacitance value at $1 \mathrm{kHz}$ and the residual series inductance. The same technique, with some modifications, is usable for three-terminal and four-terminal pair capacitors. It is emphasized that these extrapolation procedures are only usable for air dielectric capacitors or capacitors with insulating materials whose dielectric constant does not change with frequency.

\section{Three-Terminal, Low-Loss Standard Capacitors (52221C)}

Fixed-value reference standards are maintained by NIST for values of $10 \mathrm{pF}$, $100 \mathrm{pF}$, and $1000 \mathrm{pF}$. High-quality three-terminal air dielectric capacitance standards should have low residual series inductance $(<0.1 \mu \mathrm{H})$. This being the case, it may be assumed that, to within an expanded uncertainty* of $0.10 \%$, the capacitances of standards of $1 \mathrm{pF}$ or less with air-dielectric is the same at $1 \mathrm{MHz}$ as it is at $1 \mathrm{kHz}$. Thus, it is unnecessary to have capacitors smaller than $10 \mathrm{pF}$ calibrated at $1 \mathrm{MHz}$.

*See Chapter 1, Section H for more information about uncertainty.

\section{Two-Terminal, High- $Q$ Standard Inductors (52310S)}

In the frequency range from $10 \mathrm{kHz}$ to $250 \mathrm{MHz}$, inductance calibrations to a minimum expanded uncertainty* of $0.1 \%$ are available from $0.01 \mu \mathrm{H}$ to $1 \mathrm{mH}$. The upper inductance limit for calibration decreases as the frequency increases and is $1 \mu \mathrm{H}$ at $250 \mathrm{MHz}$. In the Report of Calibration, the resistance of the inductor is also given. Service is available only for air-core inductors or inductors whose value is independent of current.

\section{References-High-Frequency Standard Capacitors and Inductors}

Calibration Service for Low-Loss, Three-

Terminal Capacitance Standards at $100 \mathrm{kHz}$ and $1 \mathrm{MHz}, \mathrm{G}$. M. Free and R. N. Jones, Natl. Inst. Stand.

Technol. (U.S.), Tech. Note 1348 (Feb. 1992).

Evaluation of Three-Terminal and FourTerminal Pair Capacitors at High Frequencies, R. N. Jones, Natl. Bur. Stand. (U.S.), Tech. Note 1024 (Sept. 1980).

The Measurements of Lumped Parameter Impedance: A Metrology Guide, R. N. Jones, Natl. Bur. Stand. (U.S.), Monogr. 141 (June 1974).

A Precision High-Frequency Calibration Facility for Coaxial Capacitance Standards, R. N. Jones and L. E. Huntley, Natl. Bur. Stand. (U.S.), Tech. Note 386 (Mar. 1970).

Impedance of Lumped Circuits, L. E. Huntley and R. N. Jones, Proc. IEEE 55(6), 900 (June 1967).

A Technique for Extrapolating the $1 \mathrm{kc}$ Values of Secondary Capacitance Standards to Higher Frequencies, R. N. Jones, Natl. Bur. Stand. (U.S.), Tech. Note 201 (Nov. 1963). 


\section{Impedance Measurements (Except Resistors) B.3 Power-Frequency Capacitors}

\author{
Technical Contacts:
}

Eric D. Simmon

Tel:301/975-3956

Email:esimmon@nist.gov
Denise D. Prather Administration and Logistics

Tel:301/975-4221

Email:dprather@nist.gov

Mailing Address: Building 220, Room B146,

National Institute of Standards and Technology,

Gaithersburg, MD 20899-0001

\section{Shipping Address:}

National Institute of Standards and Technology,

[Attn: J. K. Olthoff, Bldg. 202, Room 167, ext. 2431]

I-270 at Quince Orchard Road,

Gaithersburg, MD 20899-0001

Service

ID No. Items

52400C Power-Frequency Capacitors

\section{References-Power-Frequency Capacitors}

A Calibration Service for Voltage Transformers and High-Voltage Capacitors, W. E. Anderson, Natl. Bur. Stand. (U.S.), Spec. Publ. 250-33 (June 1988).

An International Comparison of HighVoltage Capacitor Calibrations, W. E. Anderson, R. S. Davis, O. Petersons, and W. J. M. Moore, IEEE Trans. Power Appar. Syst. 97 (4), 1217 (July 1978).

A Wide Range High-Voltage Capacitance Bridge with One-ppm Accuracy, O. Petersons and W. E. Anderson, IEEE Trans. Instrum. Meas. IM-24 (4), 336 (Dec. 1975).

\section{Power-Frequency Capacitors (52400C)}

A calibration service is maintained for capacitors designed for $60-\mathrm{Hz}$ operation, especially at voltages above $100 \mathrm{~V}$.

Typical expanded uncertainties* for a calibration are $100 \times 10^{-6}$ of the capacitance, and $1 \%$ of the dissipation factor plus $1 \times 10^{-5}$. Routine calibrations are limited to devices with a dissipation factor of 0.011 or smaller and which are operated at sufficient voltages that at least $40 \mu \mathrm{A}$ passes through the device under test.

The high-power limit for routine tests is $10 \mathrm{kVA}$. Some capability to perform tests outside of these limits exists, and NIST should be contacted to discuss special arrangements for such tests.

* See Chapter 1, Section $\mathrm{H}$ for more information about uncertainty. 


\section{Impedance Measurements (Except Resistors) B.4 Q-Standards}

\section{Technical Contacts:}

$\begin{array}{ll}\text { George M. Free } & \text { Paula M. Hewitt } \\ \text { Tel: 303/497-3609 } & \text { Administrative and Logistics } \\ \text { Email:gfree@nist.gov } & \text { Tel: 303/497-3753 } \\ & \text { Email:paula.hewitt@nist.gov } \\ & \text { Fax:303/497-3970 }\end{array}$

Mailing Address: M.C. 813.10,

National Institute of Standards and Technology,

325 Broadway,

Boulder, CO 80303-3328

Service

ID No.

Items

$52710 \mathrm{C}$ Inductive $Q$-Standards; $50 \mathrm{kHz}$ to $45 \mathrm{MHz}, 0.25 \mu \mathrm{H}$ to $25 \mathrm{mH}$

52711C Each Additional Frequency for 52710C

\section{$Q$-Standards (52710C-52711C)}

Standards for $Q$-measurements are maintained at NIST. These are high- $Q$ inductors equipped with banana plug connectors at a spacing of 1 inch on centers. These standards have inductance values of $(0.25,2.5,25$, $250,2500$, and 25,000$) \mu \mathrm{H}$, and effective $Q$-values from 100 to approximately 600 . These serve as working standards for calibration of $Q$-standards of a similar type. Calibration frequencies range from $50 \mathrm{kHz}$ to $45 \mathrm{MHz}$. The calibration report includes effective resonating capacitance and effective $Q$. Relative expanded uncertainties* are of the order of $0.2 \%$ for capacitance and $2 \%$ for $Q$. Provisions are made for calibrating each $Q$-standard at three frequencies; however, adequate assurance of stability is usually provided by recalibrating only at the center frequency.

* See Chapter I, Section H for more information about uncertainty.

\section{References $-Q$-Standards}

Standards for the Calibration of $Q$-Meters, $50 \mathrm{kHz}$ to $45 \mathrm{MHz}$, R. N. Jones, J. Res. Natl. Bur. Stand. (U.S.), 58C (4), 243 (Oct.-Dec. 1964). 
Voltage Measurements

\section{1 DC Voltage Measurements and Standards}

\author{
Technical Contacts:
}

Yi-hua Tang
Tel: 301/975-4691
Email:ytang@nist.gov

Denise D. Prather

Administration and

Logistics

Tel: 301/975-4221

Email:dprather@nist.gov

Mailing Address: Building 220, Room B146, National Institute of Standards and Technology, Gaithersburg, MD 20899-0001

\begin{tabular}{|c|c|}
\hline $\begin{array}{l}\text { Service } \\
\text { ID No. }\end{array}$ & Items \\
\hline $53110 S$ & $\begin{array}{l}\text { Special DC Voltage Measurements, by } \\
\text { Prearrangement }\end{array}$ \\
\hline $53120 \mathrm{M}$ & Measurement Assurance Program for DC Voltage \\
\hline $53130 \mathrm{C}$ & First Saturated Standard Cell in a Group \\
\hline $53131 \mathrm{C}$ & Each Additional Cell \\
\hline $53140 \mathrm{C}$ & $\begin{array}{l}\text { Platinum Resistance Thermometer Temperature } \\
\text { Determination for Standard Cell Calibration }\end{array}$ \\
\hline $53150 \mathrm{C}$ & Unsaturated Standard Cells \\
\hline $53160 \mathrm{C}$ & $\begin{array}{l}\text { Tests of Solid-State Voltage Reference Standard } \\
\text { (One Output, } 1 \mathrm{~V} \text { to } 10 \mathrm{~V} \text { ) }\end{array}$ \\
\hline $53161 \mathrm{C}$ & Each Additional Output \\
\hline $53180 S$ & Special Handling (Equipment Pickup or Delivery) \\
\hline $53190 S$ & $\begin{array}{l}\text { Special Handling (Cleaning, Minor Repair, Return } \\
\text { Service Charge) }\end{array}$ \\
\hline
\end{tabular}

\section{General Information-DC Voltage Measurement Standards}

The service described in this section provides for the calibration of standards of direct voltage, saturated and unsaturated standard cells, and solidstate standards, and for dc voltage MAP services at the 1.02-volt level. The U.S. Representation of the Volt is maintained by monitoring the emfs of several groups of saturated standard cells in ovens on a monthly basis using the ac Josephson effect. Customer cells are calibrated by measuring the difference between their emfs and those of working groups of standard cells using automated systems comprised of low

thermal emf, computer-controlled switches and high-resolution digital voltmeters.

\section{Special DC Voltage Measurements, by Prearrangement (53110S)}

The evaluation, testing, or calibration of prototype dc voltage standards and measuring apparatus or unique voltage measurements are provided by this service. These measurements are performed only when deemed reasonable by the appropriate technical staff and serving the best long-term interests of the client, the measurement community, and NIST.

Table 9.5. Expanded Uncertainties* of NIST DC Voltage Measurement

\begin{tabular}{lr} 
& $\left(\times \mathbf{1 0}^{-6}\right.$ \\
\hline Josephson Calibrations of Primary Cells (1.018 V) & 0.04 \\
Unsaturated Standard Cells & $\geq 50$ \\
Saturated Standard Cells & $\geq 0.15$ \\
Volt Transfer Program (Saturated Standard Cells) & $\geq 0.20$ \\
Solid-State References (1.018 V,10 V) & $\geq 0.19$ \\
Solid-State References (5 V to 10 V) & $\geq 0.19$ \\
\hline
\end{tabular}

\section{Measurement Assurance Program Service (53120M)}

This MAP service provides a measurement of the error of dc voltage measurements in the customer laboratory at the 1.02 -volt level, the uncertainty of the results, and an updated assigned value for the client's reference standards. A transport standard, which consists of a standard cell enclosure containing four saturated standard cells, maintaining constant temperature via line and battery power, is used. Preferably, it is handcarried between NIST and the client laboratory, but arrangements may be made for air shipment. The standard is calibrated by NIST, the customer laboratory, and again by NIST to obtain the required data. The transport standard is capable of performing at the relative expanded uncertainty* level of $0.2 \times 10^{-6}$ to $0.3 \times 10^{-6}$ when hand-carried, and $0.5 \times 10^{-6}$ to $0.8 \times 10^{-6}$ otherwise.

* See Chapter 1, Section $\mathrm{H}$ for more information about uncertainty. 
The measurement uncertainty achieved in this service contains primarily random errors. The major components of random error can be attributed to:

A. Day-to-day fluctuations in temperature-corrected cell emfs caused by temperature-hysteresis effects;

B. The finite resolution of the measurement apparatus at both the client laboratory and NIST;

C. Thermal emfs, unstable with time, which occur in the measuring circuit due to room temperature and humidity changes and drafts;

D. Temperature coefficients of the enclosures as a whole, not compensated for by temperature corrections;

E. Lack of resolution or instability of the apparatus used to monitor the cell temperatures;

F. Slow changes in temperature gradients or enclosure temperatures possibly due to atmospheric "pumping" of cool air into the enclosures, or vibration effects on the control circuitry;

G. Controller instability caused by power-line noise;

H. Effects of electrostatic or electromagnetic pick-up on the measuring system;

I. Detector drift; and

J. Momentary upsets in cell emfs caused by small electrical currents passing through the cells.

The experimental design described for making the intercomparison measurements removes the effects of average "left-right" or offset errors. One potentially significant source of error not corrected for or quantified in the MAP service is that caused by scale-factor errors in the instrumentation used to measure the differences between cell emfs. An error from this source can be eliminated by using calibrated instruments and applying the appropriate calibration corrections to the results. The transport standard is normally kept in the client's laboratory for about 4 weeks, since eight to 12 measurement sets are generally required. Data analysis and issuance of the test report by NIST takes 4 to 5 weeks following the return of the transfer standards.
If the participating laboratory has a quality instrument that has been accurately calibrated and also has quality standards, the relative expanded uncertainty* of a single transfer of the unit of voltage using NIST transport standards is generally of the order of $0.5 \times 10^{-6}$ or less. The best achievable long-term relative expanded uncertainty*, resulting from five or more transfers over an extended time, is of the order of $0.2 \times 10^{-6}$ to $0.3 \times 10^{-6}$.

In this service, NIST provides detailed instructions for carrying out the transfer and making the required measurements. The participant must have in-house standards and instrumentation capable of sustained performance at the $0.1 \times 10^{-6}$ level. When a new participant (or group of participants) expresses a desire to use the voltage MAP service, NIST requests that a complete description of the participant's measurement system, including instruments, standards, wires, switches, and their use, be sent to the NIST technical staff. This description enables NIST personnel to assist in resolving measurement problems by telephone.

NIST requires evidence in the form of control charts of the existence of a formal quality-control program in the laboratory as a prerequisite to participation in the service. This requirement has been established to enable problems to be addressed in advance of the transfer and to reduce delays in returning the standards to NIST.

\section{Saturated Standard Cells (53130C-53140C)}

Routine calibrations of saturated standard cells involve the following considerations:

A. Saturated standard cells of the unshippable type should always be transported by messenger because such cells should never be tipped from an upright position by more than $45^{\circ}$ in any direction. Unshippable saturated cells contained in portable, temperature-regulated enclosures should also be transported by messenger and with the enclosure activated or under power if possible.

* See Chapter 1, Section $\mathrm{H}$ for more information about uncertainty. 
B. Saturated standard cells of the shippable type housed in portable thermoregulated enclosures should be packed carefully and shipped under power if possible. Any liquid-in-glass thermometer mounted in such a device should be removed and provided with additional rigid packing for protection against breakage. Enclosures having a nominal cell temperature of $28^{\circ} \mathrm{C}$ or lower should not be transported during the summer due to the danger of overheating. Enclosures should not be energized by using the ac power mains while they are in shipping containers as heat from the transformer will cause them to go over-temperature.

C. Saturated standard cells, which are maintained continuously at their nominal temperature of use during shipment, will undergo test starting 1 week after receipt for a period not to exceed 6 weeks, unless other arrangements are made. If such cells perform abnormally, the owner will be notified. Arrangements for further testing may be made at that time if desired. Cells will be returned as soon as possible after calibration.

D. Saturated cells arriving at a temperature other than their nominal temperature of use will be brought to their use temperature as soon as possible after receipt. Starting 1 month after they initially attain use temperature, daily readings will be taken to observe the stability of the cells. When the cells stabilize, 10 daily readings will be taken and averaged to assign values to them. This process will not exceed 90 days without special arrangements being made.

E. For an additional fee, the temperature of air bath enclosures for saturated standard cells will be determined using a calibrated NIST platinum resistance thermometer (Service ID Number 53140 C). Daily readings are taken and reported. The reported cell emfs are assumed to correspond to the mean of the temperatures measured on the same days as the emf readings were taken.
The client must understand that, when this is done, the uncertainties of the reported emfs include the emf equivalent of the uncertainty of the measured temperatures in terms of the International Temperature Scale of 1990 (ITS-90). Moreover, estimates of the uncertainties of any voltage measurements made by clients using these cells as a reference must include corresponding uncertainties of their own temperature measurements.

F. NIST accepts cells used in oil baths for calibration in NIST oil baths maintained at $28^{\circ} \mathrm{C}$. Cells used in oil baths operating at other nominal temperatures can best be calibrated using transport standards as in the MAP service. (See 53120M above.)

Calibration relative expanded uncertainties* generally range from $0.15 \times 10^{-6}$ to $0.50 \times 10^{-6}$. The stated uncertainties are those of the NISTmeasured average values, i.e., they do not reflect long-term behavior of the cells, transportation effects, etc.

\section{Unsaturated Standard Cells (53150C)}

Unsaturated cells require approximately 3 weeks for a complete calibration. The emfs of such cells are read daily for a minimum period of 10 days. These cells are compared with NIST saturated cells using a precision digital voltmeter to measure the difference emf directly. The calibration relative expanded uncertainty* is $0.005 \%$ of the measured voltage unless the cell is abnormal. If the measured emf fluctuates unduly or is unusually low, or if the cell behaves abnormally, the reported uncertainty will be increased appropriately. Unsaturated cells are not likely to be injured by normal transportation (mail or express) if they are packed carefully. Because of the possible hazard from freezing, shipment during extremely cold weather should be avoided.

* See Chapter 1, Section $\mathrm{H}$ for more information about uncertainty. 
Solid-State Voltage Reference Standards (53160C and 53161C)

Solid-state voltage standards with outputs in the range from $1 \mathrm{~V}$ to $10 \mathrm{~V}$ are calibrated using a self-calibrating automated system which scales to any multiple up to $10 \mathrm{~V}$ of $1.018 \mathrm{~V}$ from the emf of a working group of NIST saturated standard cells. It then measures the difference between the emf of the standard under test and the emf of its own output closest in voltage to that of the standard being measured and computes its emf. Measurements are taken daily for 12 to 15 working days and the mean value of the results reported.

Due to the limited battery life of many commercial standards, special shipping arrangements are advisable and can be made by contacting the Electricity Division.

Many solid-state standards have multiple outputs; to ensure proper testing, the outputs to be calibrated should be specified on the shipping papers as well as on the purchase order.

Voltmeter calibrators, multirange instruments with up to eight decimal digits of adjustability, are not considered by NIST to be standards and are not to be submitted routinely for calibration under this test category. Likewise, NIST will not accept component solid-state devices for routine calibration. However, new, state-of-the-art devices and instruments may be accepted for test under special circumstances (see Service ID Number 53110 ) at the discretion of NIST technical staff.

The NIST calibration service for voltage is directly tied to NIST Josephson-junction voltage-standard arrays. This 1-V standard fabricated from niobium trilayer resists the effects of cycling between its operating temperature of liquid helium and room temperature better than previous designs.

\section{References-Voltage Measurements} and Standards

Guidelines for Implementing the New Representation of the Volt and Ohm Effective January 1, 1990, N. B. Belecki, R. F. Dzuiba, B. F. Field, and B. W. Taylor, Natl. Inst. Stand. Technol., Tech. Note 1263 (June 1989). NBS Measurement Services: Solid-State DC voltage Standard Calibrations, B. F. Field, Natl. Bur. Sand. (U.S.), spec. Publ. 250-24 (Oct. 1987).

NBS Measurement Services: Standard Cell Calibrations, B. F. Field, Natl. Bur. Stand. (U.S.), Spec. Publ. 250-24 (Oct. 1987).

The NBS Josephson Array Voltage Standard, C. A. Hamilton, R. L. Kautz, F. L. Lloyd, R. L. Steiner, and B. F. Field, IEEE Trans. Instrum. Meas. IM-36, 258 (June 1987).

A Sub-PPM Automated One-to-Ten Volt Measuring System, B. F. Field, IEEE Trans. Instrum. Meas. IM-34, 327 (1985).

Volt Transfer Program Instructions, NBS Internal Document, Unpublished, Revised (1983).

A High-Resolution Prototype System for Automatic Measurement of Standard Cell Voltages, D. W. Braudaway and R. E. Kleinmann, IEEE Trans. Instrum. Meas. IM-23, 282 (1974).

Volt Maintenance at NBS via $2 \mathrm{e} / \mathrm{h}$ : A New Definition of the NBS Volt, B. F. Field, T. F. Finnegan, and J. Toots, Metrologia 9, 155 (1973).

Designs for Surveillance of the Volt Maintained by a Small Group of Saturated Standard Cells, W. G. Eicke and J. M. Cameron, Natl. Bur. Stand. (U.S.), Tech. Note 430 (Oct. 1967). Standard Cells Their Construction, Maintenance, and Characteristics, W. J. Hamer, Natl. Bur. Stand. (U.S.), Monogr. 84 (Jan. 1965). 
Voltage Measurements C.2 AC Voltage Measurements

\author{
Technical Contacts:
}

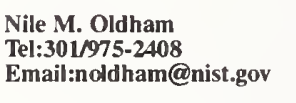

Mark E. Parker
Tel:301/975-2413
Email:mparker@nist.gov

Denise Prather Administration and

Logistics

Tel:301/975-4221

Email:dprather@nist.gov

Mailing Address: Building 220, Room B146, National Institute of Standards and Technology, Gaithersburg, MD 20899-000I

\begin{tabular}{|c|c|}
\hline $\begin{array}{l}\text { Service } \\
\text { ID No. }\end{array}$ & Items \\
\hline $53200 \mathrm{~S}$ & $\begin{array}{l}\text { Special Tests of High-Accuracy Digital } \\
\text { Multimeters, Multifunction Calibrators, } \\
\text { by Prearrangement }\end{array}$ \\
\hline $53201 \mathrm{~S}$ & $\begin{array}{l}\text { Special Tests of Low-Voltage AC-DC Transfer } \\
\text { Standards, by Prearrangement }\end{array}$ \\
\hline $53202 \mathrm{~S}$ & $\begin{array}{l}\text { Special 25-Point Test of Digital Multimeters (DMMs), } \\
\text { by Prearrangement }\end{array}$ \\
\hline $53203 \mathrm{~S}$ & Each Additional DMM Test Point for 53202S \\
\hline
\end{tabular}

Digital Multimeters (DMMs) and Multifunction Calibrators (53200S)

Voltage measurements are performed at $\mathrm{dc}$ at amplitudes between $1 \mathrm{mV}$ and $1 \mathrm{kV}$. Relative expanded uncertainties* as low as $1 \times 10^{-6}$ are possible in the mid-voltage range.

Low-frequency $(0.1 \mathrm{~Hz}$ to $100 \mathrm{~Hz})$ measurements of ac voltage are made between $1 \mathrm{mV}$ and $7 \mathrm{~V}$ using a NIST-developed calculable voltage standard in which waveforms are digitally synthesized using a lookup table and a digitalto-analog converter. Relative expanded uncertainties* as low as $5 \times 10^{-6}$ are possible around $7 \mathrm{~V}$.

Wideband ac voltage measurements between $10 \mathrm{~Hz}$ and $30 \mathrm{MHz}$ are made between $1 \mathrm{mV}$ to $1 \mathrm{kV}$ using a thermal voltage converter standard in an automatic calibration system.

* See Chapter 1, Section H for more information about uncertainty.
Relative expanded uncertainties* range from $10 \times 10^{-6}$ to $0.2 \%$.

$\mathrm{AC}$ current measurements are performed on the same automatic calibration system using a thermal current converter. Current sources can be measured from $10 \mathrm{~Hz}$ to $100 \mathrm{kHz}$ at current levels between $1 \mathrm{~mA}$ and $2 \mathrm{~A}$. Digital multimeters (DMM) tests are normally limited to an upper frequency of $5 \mathrm{kHz}$; however, special arrangements may be made for tests at higher frequencies and currents. Realtive expanded uncertainties* are typically less than $100 \times 10^{-6}$.

Direct current resistance measurements are performed between $1 \Omega$ to $100 \mathrm{M} \Omega$, for both DMMs and calibrators. Relative expanded uncertainties* of $2 \times 10^{-6}$ are possible for certain resistance values.

\section{Low-Voltage AC-DC Transfer Standards (53201S)}

Measurements of the ac-dc difference of low-voltage $(1 \mathrm{mV}$ to $200 \mathrm{mV})$ thermal transfer standards, micropotentiometers, and voltage dividers are also offered as a Special Test in the dc to $1 \mathrm{MHz}$ frequency range. Relative expanded uncertainties* of $15 \times 10^{-6}$ are possible in the audio-frequency range at $100 \mathrm{mV}$.

\section{Special 25-Point Test of Digital Multimeters (DMMs), by Prearrangement (53202S-53203S)}

This is a special reduced cost, 25-point test covering all five functions ( $\mathrm{ac}$ and $\mathrm{dc}$ voltage and current, and dc resistance) of most precision DMMs. DMMs submitted for test must have an IEEE-488 interface bus, and a list of DMM bus commands for the instrument may be required. The 25 test points available are shown in Table 9.6 below, together with the best possible expanded uncertainties*. Additional test points are available over a wide range of amplitudes and frequencies. 
Table 9.6. 25-Point Standard DMM Test

\begin{tabular}{|c|c|c|c|c|}
\hline Point & Function & Magnitude & $\begin{array}{c}\text { Frequency } \\
(\mathbf{k H z})\end{array}$ & $\begin{array}{c}\text { Relative } \\
\text { Expanded } \\
\text { Uncertainty* } \\
\left(\times 10^{-6}\right)\end{array}$ \\
\hline 1 & DC Voltage & $0.1 \mathrm{~V}$ & & 4 \\
\hline 2 & DC Voltage & $1 \mathrm{~V}$ & & 2 \\
\hline 3 & DC Voltage & $10 \mathrm{~V}$ & & 1 \\
\hline 4 & DC Voltage & $100 \mathrm{~V}$ & & 2 \\
\hline 5 & AC Voltage & $0.1 \mathrm{~V}$ & 0.3 & 50 \\
\hline 6 & AC Voltage & $0.1 \mathrm{~V}$ & 10.0 & 50 \\
\hline 7 & AC Voltage & $0.1 \mathrm{~V}$ & 1000.0 & 1000 \\
\hline 8 & AC Voltage & $1 \mathrm{~V}$ & 0.3 & 20 \\
\hline 9 & AC Voltage & $1 \mathrm{~V}$ & 10.0 & 20 \\
\hline 10 & AC Voltage & $1 \mathrm{~V}$ & 1000.0 & 500 \\
\hline 11 & AC Voltage & $10 \mathrm{~V}$ & 0.3 & 20 \\
\hline 12 & AC Voltage & $10 \mathrm{~V}$ & 10.0 & 20 \\
\hline 13 & AC Voltage & $10 \mathrm{~V}$ & 1000.0 & 500 \\
\hline 14 & AC Voltage & $100 \mathrm{~V}$ & 1.0 & 20 \\
\hline 15 & AC Voltage & $100 \mathrm{~V}$ & 100.0 & 50 \\
\hline 16 & DC Current & $10 \mathrm{~mA}$ & & 10 \\
\hline 17 & DC Current & $1 \mathrm{~A}$ & & 20 \\
\hline 18 & AC Current & $10 \mathrm{~mA}$ & 0.3 & 75 \\
\hline 19 & AC Current & $10 \mathrm{~mA}$ & 5.0 & 100 \\
\hline 20 & AC Current & $1 \mathrm{~A}$ & 0.3 & 100 \\
\hline 21 & AC Current & $1 \mathrm{~A}$ & 5.0 & 200 \\
\hline 22 & Resistance & $10 \Omega$ & & 8 \\
\hline 23 & Resistance & $1 \mathrm{k} \Omega$ & & 3 \\
\hline 24 & Resistance & $100 \mathrm{k} \Omega$ & & 5 \\
\hline 25 & Resistance & $10 \mathrm{M} \Omega$ & & 30 \\
\hline
\end{tabular}

* See Section H, Chapter 1, for more information about uncertainty.

\section{References-AC Voltmeters and} Sources

New Low-Voltage Standards in the DC to $1 \mathrm{MHz}$ Frequency Range, N. M.

Oldham and R. M. Henderson, Conf. Record of CPEM '90, Ottawa, Canada (June 1990).

A Calculable, Transportable AudioFrequency AC Reference Standard, N. M. Oldham, P. S. Hetrick, and X. Zeng, IEEE Trans. Instrum. Meas. 38 (2), 368-371 (April 1989).

A High-Accuracy, $10 \mathrm{~Hz}-1 \mathrm{MHz}$ Automatic AC Voltage Calibration System, N. M. Oldham, M. E. Parker, A.

Young, and A. G. Smith, IEEE Trans. Instrum. Meas. 36, 883-887 (Dec. 1987). 
Voltage Measurements

C.3 AC-DC Thermal Voltage and Current Converters (to $1 \mathrm{MHz}$ )

\author{
Technical Contacts:
}

\author{
Denise D. Prather \\ Administration and \\ Logistics \\ Tel:301/975-4221 \\ Email:denise.prather@nist.gov
}

Mailing Address: Building 220, Room B146,

National Institute of Standards and Technology,

Gaithersburg, MD 20899-0001

Service

ID No.

Items

53310S Special AC-DC Measurement Services, by Prearrangement

53350C Set-up (No Test Points Included) for an AC-DC Difference Calibration of a Standard or Set of Standards (Voltage or Current)

53351C First Frequency Point for Each Applied Voltage or Current Level

53352C Additional Points for Each Applied Voltage and Current Level (Additonal Frequency/Voltage or Frequency/Current Points)

\section{General Information-Thermal} Voltage and Current Converters

Alternating voltage and current are most accurately measured by comparing the heating effect of the alternating quantity to the average heating effect of both polarities of the direct quantity using thermal transfer standards. These devices may be simple thermoelements, thermal voltage converters consisting of high-performance thermal sensors and resistors, or thermal current converters consisting of a precision shunt used with a thermal sensor. Good quality thermal converters generally have small ac-dc differences which are constant with respect to frequency in the range from about $100 \mathrm{~Hz}$ to $20 \mathrm{kHz}$ at voltages from about $0.5 \mathrm{~V}$ to $100 \mathrm{~V}$ or currents up to about $5 \mathrm{~A}$.

The ac-dc differences generally increase (to large values in some cases) as the applied voltage or current is increased, or as the frequency departs from the audio region.

\section{Special AC-DC Measurement Services, by Prearrangement (53310S)}

This service provides for the measurement or evaluation of prototype ac voltage or current standards, sources, or measurement instrumentation, and for other measurements of alternating voltage, alternating current, or ac-dc difference not provided for below, at the discretion of NIST technical experts. Components used for ac-dc conversions will generally not be tested unless they show promise of standards-level behavior. Even then, such components will only be tested in very limited numbers to explore their possible use for precision measurements.

Special ac-dc difference calibrations of appropriate thermal voltage and thermal current converters are now offered with a relative expanded uncertainty* of $0.8 \times 10^{-6}$. This calibration service is the result of an extensive study of the group of multijunction thermal converters that make up the NIST primary standards. Thermal converters will be accepted for calibration with the $0.8 \times 10^{-6}$ expanded uncertainty* provided that their performance, including stability and square-law response, is compatible with the NIST standards and high-precision comparator system. In general, the uncertainty below $1 \times 10^{-6}$ is available for voltages from $2 \mathrm{~V}$ to $12 \mathrm{~V}$, currents from $5 \mathrm{~mA}$ to $20 \mathrm{~mA}$, and frequencies from $30 \mathrm{~Hz}$ to $10 \mathrm{kHz}$. As in the case of the other special ac-dc difference calibrations with reduced uncertainty, an additional cost and an extended turnaround time at NIST are required. Prospective clients are asked to contact J. R. Kinard to discuss the requirements and arrangements related to this service.

* See Chapter 1, Section $\mathrm{H}$ for more information about uncertainty. 


\section{AC-DC Difference Calibration of a Standard or Standards Set (Voltage or Current) (53350C-53352C)}

This service covers the calibration of thermal voltage and current converters, ac shunts, and primary standard thermoelements covering the ranges $2 \mathrm{~Hz}$ to $1 \mathrm{MHz}, 1 \mathrm{~mA}$ to $20 \mathrm{~A}$, and $0.2 \mathrm{~V}$ to $1000 \mathrm{~V}$. Measurements are recommended at all voltages or currents and frequencies where the transfer standard is used by the customer. In addition, if $1000 \mathrm{~V}$ or $1200 \mathrm{~V}$ ranges are measured, tests at $600 \mathrm{~V}$ are recommended to evaluate the effect of self-heating on the ac-dc difference of the resistor. Since some thermal transfer standards show large acdc differences at frequencies below about $40 \mathrm{~Hz}$, additional measurements may be required to define the low-frequency performance of the instrument. Unless the instrument has a previous calibration history, the user may wish to discuss the calibration parameters with the appropriate NIST staff.

The uncertainties offered and parameter space covered in Table 9.7 for this calibration service are presently being reevaluated. Significant reductions in the uncertainties and expansion of the parameter space are expected. To obtain the most recent information, customers are requested to contact the NIST staff. Routine calibrations of thermal voltage and current converters generally are carried out on a demand basis. However, occasional extensive calibration requests may create scheduling problems; therefore, to facilitate rapid turnaround, please contact T. E. Lipe or J. R. Kinard at the telephone numbers/ addresses cited above before sending the equipment.

Ongoing research at NIST will help to improve the Nation's capability to provide accurate alternating voltage and current and ac-dc difference calibrations to NIST customers. The present research focuses on the development of cryogenic resistive transition-edge sensors as new primary standards of ac-dc difference, and the design and fabrication of thin-film multijunction converters as working standards for ac-dc difference measurements.

Ac-dc difference calibrations at frequencies above $1 \mathrm{MHz}$ are performed in the NIST Boulder Laboratory.

Table 9.7. AC-DC Difference Calibration Service ${ }^{(a)}$

\begin{tabular}{|c|c|c|c|c|c|c|}
\hline Frequency: & $\begin{array}{c}2 \mathrm{~Hz} \\
\text { to } \\
5 \mathrm{~Hz}\end{array}$ & $\begin{array}{l}5 \mathrm{~Hz} \\
\text { to } \\
10 \mathrm{~Hz}\end{array}$ & $\begin{array}{c}10 \mathrm{~Hz} \\
\text { to } \\
20 \mathrm{kHz}^{\text {(b) }}\end{array}$ & $\begin{array}{c}20 \mathrm{kHz} \\
\text { to } \\
50 \mathrm{kHz}\end{array}$ & $\begin{array}{l}50 \mathrm{kHz} \\
\text { to } \\
100 \mathrm{kHz}^{(\text {b) }}\end{array}$ & $\begin{array}{c}100 \mathrm{kHz} \\
\text { to } \\
1 \mathrm{MHz}\end{array}$ \\
\hline Voltage Limits (V) & 50 & 100 & 1000 & 1000 & 1000 & 100 \\
\hline Current Limits (A) & & 0.05 & 20 & 20 & 20 & \\
\hline
\end{tabular}

Relative Expanded Uncertainties ${ }^{*}\left(\times 10^{-6}\right)^{(c)}$

Multirange Thermal Voltage Converters (TVCs)

$>100 \mathrm{~V}$

$\leq 100 \mathrm{~V}$

$200 \quad 100$

30
20

$50 \quad 70$

Coaxial Single Range TVCs

$>100 \mathrm{~V}$

$\leq 100 \mathrm{~V}$

200

100

20
$15^{\text {(d) }}$

30
25

50

Special $^{(e)}$

$10 \mathrm{~V} \leq x \leq 100 \mathrm{~V}$

$1 \mathrm{~V} \leq x \leq 10 \mathrm{~V}$

10

5

Thermal Current Converters (TCCs)

$>5 \mathrm{~A}$

$\leq 50 \mathrm{~mA}<x \leq 5 \mathrm{~A}$

$\leq 50 \mathrm{~mA}$

200

100

100
50
50

150
70

(a.b)

(a.b)

(3) The uncertainties offered and parameter space covered in the table for this calibration service are presently being reevaluated. Significant reductions in the uncertainties and expansion of the parameter space are expected. To obtain the most recent information, customers are requested to contact the NIST staff.

(b) Some voltage, current, and frequency combinations in this range are available only as a special test with uncertainty determined on an individual basis.

(c) The lower uncertainty applies at the crossover frequencies. Uncertainties may be increased if the ac-dc differences are large or affected by self heating or other instability. (d) $20 \times 10^{-6}$ from $20 \mathrm{~Hz}$ to $100 \mathrm{~Hz}, 15 \times 10^{-6}$ at $100 \mathrm{~Hz}$ and above.

(e) Normally available by prearrangement for coaxial, single-range TVCs between $100 \mathrm{~Hz}$ and $20 \mathrm{kHz}$, at additional cost and a longer turnaround time at NIST.

*See Chapter 1 , Section $\mathrm{H}$ for more information about uncertainty. 


\section{References-AC-DC Thermal Converters (to $1 \mathrm{MHz}$ )}

Extension of the NIST AC-DC Difference Calibration Service for current to $100 \mathrm{kHz}$, J. R. Kinard, T. E. Lipe, and C. B. childers, J. Res. Natl. Inst. Stand. Technol. 102 (1), 75 (Jan.-Feb. 1997).

A Reevaluation of the NIST Low-Frequency Standards for AC-DC Difference in the Voltage Range $0.6-100 \mathrm{~V}$, T. E. Lipe, IEEE Trans. Instrum. Meas. IM-45 (6), 913 (Dec. 1996).

Performance of Multilayer Thin-Film Multijunction Thermal Converters, J. R. Kinard, D. X. Huang, and D. B. Novotny, IEEE Trans. Instrum. Meas. IM-44 (2), 383 (April 1995).

AC-DC Difference Characteristics of High-Voltage thermal Converters, D. X. Huang, T. E. Lipe, J. R. Kinard, and C. B. Childers, IEEE Trans. Instrum. Meas. IM-44 (2), 387 (April 1995).
AC-DC Difference Characteristics of High-Voltage Thermal Converters, D. X. Huang, T. E. Lipe, J. R. Kinard, and C. B. Childers, IEEE Trans. Instrum. Meas. IM-44 (2), 387 (April 1995).

NIST Measurement Services: AC-DC Difference Calibrations, J. R.

Kinard, J. R. Hastings, T. E. Lipe, and C. B. Childers, Natl. Inst. Stand. Technol., Spec. Publ. 250-27 (May 1989).

Determination of AC-DC Difference in the $0.1-100 \mathrm{MHz}$ Frequency Range, J. R. Kinard and T. X. Cai, IEEE Trans. Instrum. Meas. IM-38 (2), 360 (April 1989).

Recharacterization of Thermal Voltage Converters after Thermoelement Replacement, J. R. Kinard and T. E. Lipe, IEEE Trans. Instrum. Meas. IM-38 (2), 351 (April 1989). 
Voltage Measurements

\section{C.4 RF-DC Thermal Voltage and Current Converters $(100 \mathrm{~Hz}-1 \mathrm{GHz})$}

\author{
Technical Contacts:
}

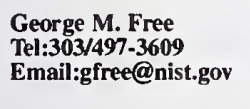

Paula M. Hewitt Administration and Logistics Tel:303/497-5753

Email:paula.hewitt@nist.gov Fax:303/497-3970

Mailing Address: M.C. 813.10,

National Institute of Standards and Technology,

325 Broadway,

Boulder, CO 80303-3328

Service

ID No.

Items

53405S Special Tests of AC Thermal Voltage Converters, by Prearrangement

53410C Low-Frequency TVC Calibration at One Frequency Selected from Those Given in Table 9.8 at Rated Voltage in the Range $0.1 \mathrm{~V}$ to $50 \mathrm{~V}$

53411C Additional Frequency Selected from Table 9.8 for Same TVC as in 53410C

53412S Same as 53410C, Except Customer Designates a Single Frequency (in Same Frequency Range) Other Than Those Given in Table 9.8

53413C Low-Frequency TVC Calibration at One Frequency Selected from Those Given in Table 9.8 at Rated Voltage in the Range $50-200 \mathrm{~V}$

53414C Additional Frequency Selected from Table 9.8 for Same TVC as in 53413C

53415S Same as 53413C, Except Customer Designates a Single Frequency (in Same Frequency Range) Other Than Those Given in Table 9.8

53420C High-Frequency TVC Calibration at One Frequency Selected from Those Given in Table 9.9 at Rated Voltage in the Range $0.2 \mathrm{~V}$ to $7.0 \mathrm{~V}$

53421C Additional Frequency Selected from Table 9.9 for Same TVC as in 53420 C

53430S Peak-to-Peak Detector Calibration at One Frequency Selected from Those Given in Table 9.10 at $1.2 \mathrm{~V}$ Peak-to-Peak Applied Rf Voltage

53431S Additional Frequency for Peak-to-Peak Detector in $53430 \mathrm{~S}$

53440S Special Tests of RF Micropotentiometers, by Prearrangement

53441C RF Micropotentiometer Calibration at One Frequency Selected from the Frequency Bands Given in Table 9.11

53445S Special Calibration of RF Micropotentiometer (Output Voltage Range, $200 \mu \mathrm{V}$ to $200000 \mu \mathrm{V}$ at Frequency Range, $0.05 \mathrm{MHz}$ to $1000 \mathrm{MHz}$ ) with Reduced Limits of Uncertainty

General Information-RF-DC

Thermal Voltage and Current

Converters, $100 \mathrm{~Hz}$ to $1 \mathrm{GHz}(53405 \mathrm{~S}-$ 53445S)

Services are available for three types of electromagnetic voltage measuring devices: (1) Thermal Voltage Converters (TVCs), (2) Peak-to-Peak Detectors, and (3) Voltage Comparators and one type of electromagnetic generating device: RF Micropotentiometers.

Assurance of device stability can be obtained by intercomparing a micropot or TVC with another similar device where voltage ranges overlap. For example, a 1 V TVC can be compared with a $3 \mathrm{~V} \mathrm{TVC}$ at $1 \mathrm{~V}$, etc.

TVC calibrations requiring relative uncertainties* less than $0.05 \%$ at frequencies below $1 \mathrm{MHz}$ are performed at NIST Gaithersburg in the Electricity Division (Service ID Nos. 53350C, 53351C, 53352C).

\section{RF Voltage Comparators (53405S)}

Special tests are performed on rf voltage comparators using TVCs and micropotentiometers at selected frequencies from $100 \mathrm{kHz}$ to $1 \mathrm{GHz}$ at voltages ranging from $10 \mathrm{mV}$ to $20 \mathrm{~V}$. Several calibration options are available to the customer. Therefore, consultation by telephone or written correspondence is recommended before the comparator is submitted for calibration.

\section{Thermal Voltage Converters (TVCs) (53410C-53421C)}

TVCs also include other devices such as Rawson rf voltmeters, thermal transfer standards, rf voltage standards, and ac-dc transfer standards.

Most converters have rf-dc differences within $0.01 \%$ of zero at $1 \mathrm{MHz}$ and below. Converters with previous calibration history that are submitted for recalibration should be evaluated at $1 \mathrm{MHz}$ and results compared to prior data. If the difference is negligible, no fur ther calibrations are usually necessary below $1 \mathrm{MHz}$.

*See Chapter 1, Section $\mathrm{H}$ for more information about uncertainty. 
The quantity measured by this calibration service is the rf-dc difference, defined as the percentage difference between the $\mathrm{rf}$ and dc input voltages required to produce the same thermocouple output, e.g.,

$$
\begin{gathered}
\text { RF-DC Difference }(\%)= \\
\left(\frac{V_{\mathrm{rf}}-V_{\mathrm{dc}}}{V_{\mathrm{dc}}}\right) \times 100 .
\end{gathered}
$$

Services available for low-frequency TVCs without a built-in $\mathrm{T}$ connector are given in Table 9.8. For high-frequency TVCs with a built-in T connector, the services available are given in Table 9.9. Calibrations above $100 \mathrm{MHz}$ are performed only on the new high-frequency TVCs with a $T$ connector as an integral

Table 9.8. Measurement Ranges and Uncertainties for LowFrequency TVC Services

\begin{tabular}{lcc}
$\begin{array}{l}\text { Recommended } \\
\begin{array}{c}\text { Frequencies } \\
\text { (MHz) }\end{array}\end{array}$ & $\begin{array}{c}\text { RF Voltage } \\
\text { Range } \\
\text { (V) }\end{array}$ & $\begin{array}{c}\text { Relative } \\
\text { Expanded } \\
\text { Uncertainty*(a) } \\
(\%)\end{array}$ \\
\hline $0.03,0.1,0.3,1$ & 0.1 to 200 & 0.04 \\
3 and 10 & 0.1 to 200 & 0.08 \\
30 & 0.1 to 200 & 0.16 \\
100 & 0.1 to 200 & 0.8 \\
\hline
\end{tabular}

${ }^{(a)} \mathrm{Rf}$-dc differences greater than $20 \%$ will not be reported. This normally limits the calibrations to $100 \mathrm{MHz}$ and below.

*See Chapter 1, Section H for more information about uncertainty.

Table 9.9. Measurement Ranges and Uncertainties for HighFrequency TVC Services

\begin{tabular}{lcc}
\hline $\begin{array}{c}\text { Frequency } \\
\text { (MHz) }\end{array}$ & $\begin{array}{c}\text { RF Voltage } \\
\text { Range } \\
\text { (V) }\end{array}$ & $\begin{array}{c}\text { Relative } \\
\text { Expanded } \\
\text { Uncertainty*(a) } \\
(\%)\end{array}$ \\
\hline 10 & 0.2 to 7.0 & 0.12 \\
30 & 0.2 to 7.0 & 0.24 \\
$100,200,300,400$ & 0.2 to 7.0 & 1.20 \\
$500,600,700$ & 0.2 to 7.0 & 1.20 \\
$800,900,1000$ & 0.2 to 7.0 & 1.20 \\
\hline
\end{tabular}

(a) Rf-dc differences greater than $20 \%$ will not be reported.

*See Chapter 1, Section H for more information about uncertainty. part of the converter housing. The measurement reference plane is at the Type $\mathrm{N}$ male output connector of the converter.

\section{Peak-to-Peak Detectors (53430S- 53431S)}

Measurements on peak-to-peak detectors are performed from $100 \mathrm{kHz}$ to $500 \mathrm{MHz}$ and are referenced to the center of a GR $874 \mathrm{~T}$ connector. The quantity measured by this service is the rf-ac difference, defined as the percentage of difference between the of and the ac input voltages required to produce "zero" dc detector output. A $50-\mathrm{kHz}$ ac reference signal is applied instead of dc. The services available are specified in Table 9.10 .

Table 9.10. Measurement Ranges and Uncertainties for Peak-to-Peak Detector Services

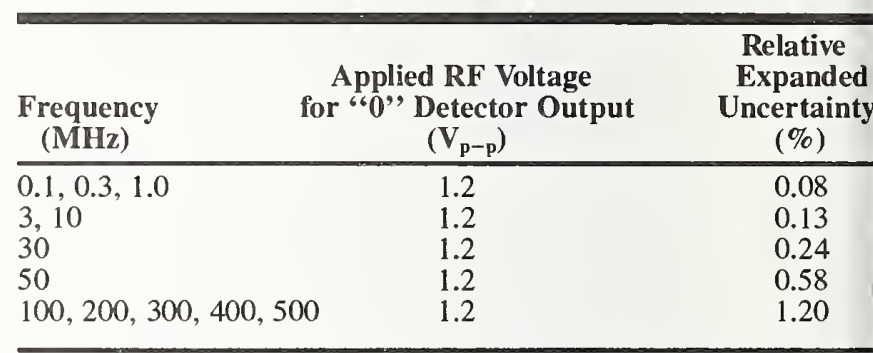

* See Chapter 1, Section $\mathrm{H}$ for more information about uncertainty.

\section{RF Micropotentiometers (53440S-53445S)}

Radiofrequency micropotentiometers are usually calibrated at their nominal rated output voltages. Frequencies suggested for a normal calibration are $(5,100,300$, 400, 500, 700, and 900) MHz. Special arrangements may be made for calibrations up to $1000 \mathrm{MHz}$ with reduced limits of uncertainty.

Radio frequency micropotentiometers having resistive elements greater than $10 \mathrm{~m} \Omega$ in combination with thermoelement housings between $5 \mathrm{~mA}$ and $100 \mathrm{~mA}$, usually have rf-dc differences within $1 \%$ at $5 \mathrm{MHz}$. Since the rf-dc difference approaches zero below 
$5 \mathrm{MHz}$, calibrations at $50 \mathrm{kHz}$ and $5 \mathrm{MHz}$ would suffice to determine interpolated points of interest between $50 \mathrm{kHz}$ and $5 \mathrm{MHz}$, with no appreciable loss of accuracy. Uncertainties are shown in Table 9.11.

An rf-dc difference of about $5 \%$ at $1 \mathrm{MHz}$ usually results from the effect of a $1 \mathrm{~m} \Omega$ resistive element with a thermoelement rated between $5 \mathrm{~mA}$ and $100 \mathrm{~mA}$ inclusive. Interpolation below $1 \mathrm{MHz}$ is not recommended in this case.

The $\mathrm{rf}$-dc difference is defined as the percentage difference between the $\mathrm{rf}$ and dc output voltages required to produce the same thermocouple output, with the resistive element terminated in $50 \mathrm{ohms}$, e.g.,

Table 9.11. Measurement Ranges and Uncertainties for RF Micropotentiometer Calibrations

\begin{tabular}{llc}
\hline $\begin{array}{l}\text { Any Frequency } \\
\text { within Band } \\
(\mathbf{M H z})\end{array}$ & $\begin{array}{c}\text { RF Voltage } \\
\text { Range } \\
(\boldsymbol{\mu V})\end{array}$ & $\begin{array}{c}\text { Relative } \\
\text { Expanded } \\
\text { Uncertainty*(a) } \\
(\%)\end{array}$ \\
\hline 0.05 to 100 & 1 to 100,000 & 2 \\
100 to 500 & 1 to 100,000 & 3 \\
500 to 900 & 1 to 100,000 & 6 \\
\hline
\end{tabular}

(a) For rf-dc differences greater than $20 \%$, the estimated limits of uncertainty are larger than those listed.

*See Chapter 1 , Section $\mathrm{H}$ for more information about uncertainty.

$$
\begin{gathered}
\text { RF-DC difference }(\%)= \\
\left(\frac{V_{\mathrm{rf}}-V_{\mathrm{dc}}}{V_{\mathrm{dc}}}\right) \times 100 .
\end{gathered}
$$

As a special service, if micropotentiometers with rated output voltage greater than $200 \mu \mathrm{V}$ can be calibrated from $0.05 \mathrm{MHz}$ to $1000 \mathrm{MHz}$, with reduced limits of relative expanded uncertainty* from $0.2 \%$ to $2 \%$. This uncertainty is dependent on frequency, output voltage level, and the rf-dc difference vs frequency response. For further details, consult the technical contact cited at the beginning of this section.

\section{References-RF-DC Voltage and Current Converters $(100 \mathrm{~Hz}-\mathbf{1 ~ G H z})$}

RF-DC Differences of Thermal Voltage Converters Arising from Input Connectors, D. X. Huang, J. R. Kinard, and G. Rebuldela, IEEE Trans. Instrum. Meas. 40 (2) (April. 1991). NBS RF Voltage Comparator, L. D.

Driver, F. X. Ries, G. Rebuldela, Natl. Bur. Stand. (U.S.), NBSIR 78-871 (Dec. 1978).

High-Frequency Microvolt Measurements, F. X. Ries and

G. Rebuldela, ISA Proc., 18, 1, 37.2.63, Instrum. Soc. of Amer. Res. Triangle Park, NC (Sept. 1963).

Thermal Voltage Converters for Accurate Voltage Measurements to 30 Megacycles Per Second, F. L. Hermach and E. S. Williams, Trans. AIEE, Pt. 1, Commun. Elect. 72, 200 (July 1960).

Accurate Radio Frequency Microvoltages, M. C. Selby, Trans. AIEE, Pt. 1, Commun. Elect. 72, 158 (May 1953).

Thermal Converters as AC-DC Transfer Standards for Current and Voltage Measurements at Audio Frequencies, F. L. Hermach,

J. Res. Natl. Bur. Stand. (U.S.), 48, 121 (1952).

* See Chapter 1, Section H for more information about uncertainty. 


\section{Drecision Ratio Measurements D. 1 Inductive Dividers}

\author{
Technical Contacts:
}

\author{
Andrew J. Secula \\ Tel:301/975-4243 \\ Email:asecula@ \\ nist.gov
}

Denise B. Prather

Administration and Logistics

Tel: 301/975-4221

Email:dprather@nist.gov

Mailing Address: Building 220, Room B146, National Institute of Standards and Technology, Gaithersburg, MD 20899-0001

Service

ID No.

Items

$54110 S$ Special Ratio Measurements and Tests of Inductive Voltage Dividers, by Prearrangement

54120 C Inductive Voltage Dividers--(Single Frequency, Voltage To Be Specified, Each Setting of 3 Most Significant Dials)

54121C Additional Frequency Points

54130 C Inductive Voltage Dividers-(Single Frequency, Voltage To Be Specified, Each Setting of Most Significant Dial Only)

54131C Additional Frequency Points

Special Ratio Measurements and Tests of Inductive Voltage Dividers, by Prearrangement (54110S)

This service category provides for the measurement and/or evaluation of prototype ratio devices and inductive voltage dividers based on new principles, and for unique ratio measurements at the highest accuracy levels, such as the determination of the ratios of Hamon resistance transfer devices or Silsbee-type voltage ratio standards. Such measurements are undertaken at the discretion of NIST technical staff and only when the need for them can be clearly demonstrated.

\section{Inductive Voltage Dividers (54120C-54131C)}

Inductive voltage dividers (decade transformer dividers) are accepted for calibration only at $(50,60,100,120,400,1000$, 5000 , and 10000$) \mathrm{Hz}$. The most significant dial only can be calibrated at $15 \mathrm{kHz}$ and $20 \mathrm{kHz}$.

Calibration voltages may be specified up to $100 \mathrm{~V}$ or the manufacturer's specified limit, whichever is lower. The largest contribution to instability in undamaged inductive voltage dividers is wear or dirt in the decade switches. Variable contact resistance in these switches sometimes affects the stability of voltage-ratio measurements to a significant extent but is most evident by its effect on the phase angle. When a decade inductive voltage divider exhibits large changes in phase angle for repeated measurements after the switches have been disturbed, the divider should no longer be considered satisfactory for use as a voltage-ratio reference standard. Inductive voltage dividers that use pushbutton switching or incorporate a resistive divider as a fine adjustment usually are not accepted for calibration.

Corrections to the separate decades of an inductive divider, in general, cannot be simply combined. However, the correction to a step setting of one of the higher decades usually is independent of the setting of the lower decades. The effects of stray impedances must be corrected by connecting the case to the divider at one point, and unless otherwise specified, the case will be connected to one of the "common" terminals, typically marked "GRD," "Case GND," or "Case GRD." Decade inductive voltage dividers are calibrated at NIST at room temperature $\left(22^{\circ} \mathrm{C}\right.$ to $\left.24^{\circ} \mathrm{C}\right)$ by comparison with a two-stage, three-decade transformer of known ratios. 


\section{References-Inductive Dividers}

American National Standard for Decade Transformer Dividers (Voltage Type), ANSI C100, 1-1972 Amer. Natl. Stand. Inst., New York, NY (Jan. 1972).

Instructions for the Use of the NBS Reference Inductive Divider, Wilbur C. Sze, Natl. Bur. Stand. (U.S.), NBSIR, unpublished (1970). (Available from NIST.)
Two-Stage, Guarded Inductive Voltage Divider for Use at $100 \mathrm{kHz}, \mathrm{D} . \mathrm{H}$. Hamon and T. L. Zaf, ISA Transactions, 9, 3, Instrum. Soc. of Amer. Res. Triangle Park, NC (1970).

Comparator for Calibration of Inductive Voltage Dividers from 1 to $10 \mathrm{kHz}$, W. C. Sze, ISA Transactions 6, 4, Instrum. Soc. of America, Res. Triangle Park, NC (1967). 
Precision Ratio Measurements D.2 Resistive Dividers

\author{
Technical Contacts:
}

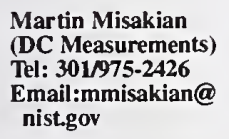

Gerald J. FitzPatrick
(60-Hz/Puised Measurements)
Tel:301/975-2737
Email:gfitzpatrick@nist.gov

Denise D. Prather

Administration and Logistics

Tel:301/975-4221

Email:dprather@ nist.gov

\section{Resistor and Resistive Dividers, DC Measurements (54210C-54211S)}

A calibration service is maintained at NIST to determine the dc voltage ratio of resistive dividers. The routine calibration service is available for applied voltages from $10 \mathrm{kV}$ to $150 \mathrm{kV}$. The calibrations are performed with a measurement system which has a relative expanded uncertainty* of $0.006 \%$ of the voltage ratio. To assure adequate sensitivity at the lowest applied voltage levels, calibrations are performed routinely only on dividers with ratios of $10^{5}: 1$ or smaller. The routine calibration service is also restricted to dividers with nominal ratios of $10^{5}: 1$, $10^{4}: 1$, or $10^{3}: 1$.

Resistive dividers are accepted for calibration only if they are nearly corona free at the rated operating voltage and are designed to have small temperature and voltage coefficients. Specifically, a device is not generally suitable for calibration by NIST if these coefficients produce a change in the ratio of $0.1 \%$ over the normal range of operating voltages. At a given voltage, dividers should not exhibit instabilities in their ratio value in excess of $0.005 \%$. NIST staff can provide some assistance in the identification of other calibration laboratories capable of certifying the response of less accurate dividers.

\section{Resistor and Resistive Dividers, $60 \mathrm{~Hz}$ Measurements (54212C-54213S)}

Resistive dividers of sufficient quality to be considered as transfer standards are calibrated at $60 \mathrm{~Hz}$ for applied voltages between $10 \mathrm{kV}$ and $100 \mathrm{kV}$ rms. Highvoltage dividers may perform satisfactorily as standards under dc voltages but do not perform well enough to be considered as standards when excited by $60-\mathrm{Hz}$ voltages. The design of an ac divider requires special features, beyond those of a dc divider. In particular, ac dividers

*See Chapter 1, Section $\mathrm{H}$ for more information about uncertainty. 
designed to be used as transfer standards may have to be equipped with external shielding to minimize the effects of capacitive coupling to surrounding objects.

If the device is not properly shielded, the effects of proximity to surrounding objects and pickup from high-voltage conductors can introduce large uncertainties into the measured value of the divider ratio. In such cases, the measurement of the ratio for one configuration would not necessarily be valid for another configuration. Consequently, a meaningful calibration of the device is difficult or impossible.

We therefore recommend that the following two preliminary proximity tests be performed before an ac divider is submitted for test to determine the suitability of the device as a transfer standard. Place the divider about $2.0 \mathrm{~m}$ from a vertical ground plane as measured from the center of the device. Energize the divider to some safe high-voltage level and measure the divider ratio. Repeat the measurement with the same applied high voltage but with the vertical ground plane (or divider) moved into a position $1.0 \mathrm{~m}$ from the center of the divider. If the measured divider ratio changes by $0.1 \%$ or more, the device has excessive capacitive coupling and is not suitable as a transfer standard.

To test for pickup, remove the highvoltage connection to the top of the divider and then connect the top of the divider to ground with a thin wire. Measure the output voltage of the divider under these conditions both with and without the high-voltage source energized. If the resulting change in the output voltage exceeds $0.1 \%$ of the expected output voltage when the high voltage is connected to the divider, then, again, there is excessive coupling, indicating that the device is not suitable as a transfer standard.

High-voltage ac dividers sent to NIST are first subjected to tests like those described above before any measurements are attempted. If such tests show variations in the measured ratio of more than $0.1 \%$ for either proximity or pickup, then no further tests will be performed and the device will be returned. Prior to performing any measurements, dividers sent to NIST will also be subjected to a breakdown test at the highest voltage for which measurements are requested. The customer will be charged for the cost of these tests.

NIST calibration of voltage transformers at $60 \mathrm{~Hz}$ is generally more accurate than its calibration of dividers at the same frequency. Therefore, customers having a requirement for a calibrated divider may find it advantageous to use a voltage transformer as the transfer standard and to use that transformer to calibrate the divider in their own facilities.

Routine tests are carried out for voltages between $10 \mathrm{kV}$ and $100 \mathrm{kV}$ rms and are performed with a measurement system having relative expanded uncertainties* of $0.03 \%$ in the determination of the ratio and $0.3 \mathrm{mrad}$ in the determination of the phase angle.

\section{Resistor and Resistive Dividers, Pulsed High-Voltage Conditions (54214S)}

Resistive divider ratios are also determined under pulsed high-voltage conditions. All pulsed measurements are by prearrangement. Determinations employ special-design pulse dividers and calibrated Kerr cells as reference standards. A variety of pulses may be applied to simulate the conditions under which the divider will be used. Calibrations are made at selected voltage intervals from $20 \mathrm{kV}$ to $300 \mathrm{kV}$ as requested and up to $500 \mathrm{kV}$ with certain pulse shapes. The typical relative expanded uncertainty* is $2 \%$ of the voltage ratio although smaller uncertainties can occasionally be reported as a special test.

\section{Shipping:}

Dividers can be hand-carried or shipped prepaid to NIST. Shipped dividers should be packaged in sturdy reusable containers with convenient

*See Chapter I, Section $\mathrm{H}$ for more information about uncertainty. 
access to the divider. The design of many high-voltage dividers makes them vulnerable to shear-type forces, so provisions should be made to minimize the likelihood of damage due to such forces when the device is in the shipping container.

\section{References-Resistive Dividers}

High-Voltage Divider and Resistor Calibrations, M. Misakian, Natl. Bur. Stand. (U.S.), Tech. Note 1215 (July 1985).

Evaluation of a Multimegavolt Impulse Measurement System, R. E. Hebner, D. L. Hillhouse, and R. A. Bullock, Natl. Bur. Stand. (U.S.), NBSIR 771933 (Nov. 1979).
Calibration of High-Voltage Pulse Measurement Systems Based on the Kerr Effect, Natl. Bur. Stand. (U.S.), NBSIR 77-1317 (Sept. 1977).

Special Shielded Resistor for HighVoltage Measurements, J. H. Park, J. Res. Natl. Bur. Stand. (U.S.), 66C (1), 19 (Jan.-Mar. 1962).

Comparative High Voltage Impusle Measurement, G. J. FitzPatrick and E. F. Kelley, J. Res. Natl. Inst. Stand. Technol. 101 (5), 639 (Sept.-Oct. 1996). 


\section{Drecision Ratio Measurements D.3 Capacitive Dividers}

\author{
Technical Contacts:
}

Gerald J. FitzPatrick
(60 Hz/Pulsed
Measurements)
Tel:301/975-2737
Email:gfitzpatrick@nist.gov

Denise D. Prather Administration and Logistics

Tel:301/975-4221

Email:dprather@nist.gov

Mailing Address: Building 220, Room B146, National Institute of Standards and Technology, Gaithersburg, MD 20899-0001

\section{Shipping Address:}

National Institute of Standards and Technology,

[For 54310S:

Attn: G. J. FitzPatrick, Bldg. 202, Room 167, ext. 2737] [For 54311S:

Attn: G. J. Fitzpatrick, Bldg. 202, Room 106, ext. 2737] I-270 at Quince Orchard Road, Gaithersburg, MD 20899-0001

\begin{tabular}{ll}
$\begin{array}{l}\text { Service } \\
\text { ID No. }\end{array}$ & Items \\
\hline $54310 \mathrm{~S}$ & $\begin{array}{l}\text { Special Tests of Capacitive Dividers at } 60-\mathrm{Hz}, \\
\text { by Prearrangement } \\
54311 \mathrm{~S}\end{array}$ \\
$\begin{array}{l}\text { Special Tests of Capacitive Dividers Under Pulsed } \\
\text { High-Voltage Conditions, by Prearrangement }\end{array}$
\end{tabular}

\section{Capacitive Dividers, $60-\mathrm{Hz}$ Measure- ments (54310S)}

Determinations of capacitive divider ratios at $60-\mathrm{Hz}$ ac employ the same equipment used for the calibration of ac resistive dividers (see 54212C). The same limitations pertain to shielding (proximity and pickup effects). The NIST measurement system imposes a negligible burden on the divider if its output voltage is 100 volts or less. Otherwise, the burden is equivalent to a $1000-\mathrm{pF}$ capacitor.

\section{Capacitive Dividers, Pulsed} High-Voltage Conditions (54311S)

Determinations of capacitive divider ratios under high-voltage pulse conditions employ special-design pulse dividers and calibrated Kerr cells as reference standards. A variety of pulses may be applied to simulate the conditions under which the divider will be used. Calibrations are made at selected voltage intervals from $20 \mathrm{kV}$ to $300 \mathrm{kV}$ as requested and up to $500 \mathrm{kV}$ with certain pulse shapes. The typical relative expanded uncertainty* is $2 \%$ of the voltage ratio although smaller uncertainties occasionally may be negotiated.

\section{References-Capacitive Dividers}

Comparative High Voltage Impulse Measurement, G. J. FitzPatrick and E. F. Kelley, J. Res. Natl. Inst. Stand. Technol. 101 (5), 639 (Sept.-Oct. 1996).

High-Voltage Divider and Resistor Calibrations, M. Misakian, Natl. Bur. Stand. (U.S.), Tech. Note 1215 (July 1985).

Evaluation of a Multimegavolt Impulse Measurement System, R. E. Hebner, D. L. Hillhouse, and R. A. Bullock, Natl. Bur. Stand. (U.S.), NBSIR 791933 (Nov. 1979).

Calibration of High-Voltage Pulse Measurement Systems Based on the Kerr Effect, Natl. Bur. Stand. (U.S.), NBSIR 77-1317 (Sept. 1977).

Special Shielded Resistor for HighVoltage Measurements, J. H. Park, J. Res. Natl. Bur. Stand. (U.S.), 66C (1), 19 (Jan.-Mar. 1962).

*See Chapter 1, Section H for more information about uncertainty. 


\section{Drecision Ratio Measurements D.4 Mixed Dividers}

\author{
Technical Contacts:
}

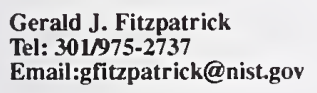

Denise D. Prather Administration and Logistics

Tel:301/975-4221

Email:dprather@

nist.gov

Mailing Address: Building 220, Room B146,

National Institute of Standards and Technology,

Gaithersburg, MD 20899-0001

\section{Shipping Address:}

National Institute of Standards and Technology,

[Attn: G. J. FitzPatrick, Bldg. 202, Room 106, ext. 2737]

I-270 at Quince Orchard Road,

Gaithersburg, MD 20899-0001

Service

ID No.

Items

54410S Pulse Voltage Measuring Systems, Including Kerr Cells

\section{References-Mixed Dividers}

Comparative High Voltage Impulse Measurement, G. J. FitzPatrick and E. F. Kelley, J. Res. Natl. Inst. Stand. Technol. 101 (5), 639 (Sept.-Oct. 1996).

Evaluation of a Multimegavolt Impulse Measurement System, R. E. Hebner, D. L. Hillhouse, and R. A. Bullock, Natl. Bur. Stand. (U.S.), NBSIR 791933 (Nov. 1979).

Calibration of High-Voltage Pulse Measurement Systems Based on the Kerr Effect, Natl. Bur. Stand. (U.S.), NBSIR 77-1317 (Sept. 1977).

Special Shielded Resistor for HighVoltage Measurements, J. H. Park, J. Res. Natl. Bur. Stand. (U.S.), 66C (1), 19 (Jan.-Mar. 1962).

\begin{abstract}
Mixed Dividers (54410S)
A mixed divider is one constructed of resistors and capacitors. Ratios of mixedvoltage dividers are determined under pulsed, high-voltage transient conditions. Determinations employ speciallydesigned pulse voltage dividers and calibrated Kerr cells as reference standards. A variety of pulse waveshapes may be applied to simulate the conditions under which the divider will be used. Calibrations are made at selected voltage intervals from $20 \mathrm{kV}$ to $300 \mathrm{kV}$ as requested and up to $500 \mathrm{kV}$ with certain pulse shapes. The typical relative expanded uncertainty* is $2 \%$ of the voltage ratio although smaller uncertainties can occasionally be reported as a special test.
\end{abstract}

*See Chapter 1, Section $\mathrm{H}$ for more information about uncertainty. 


\section{Drecision Ratio Measurements D.5 Voltage and Current Transformers}

\author{
Technical Contacts:
}

Eric D. Simmon
(Voltage Transformers)
Tel:301/975-3956
Email:esimmon@
nist.gov

\author{
Thomas L. Nelson \\ (Current Transformers) \\ Tel:301/975-2986 \\ Email:tnelson@nist.gov
}

Denise D. Prather

Administration and Logistics

Tel:301/975-4221

Email:dprather@nist.gov

Mailing Address: Building 220, Room B146,

National Institute of Standards and Technology,

Gaithersburg, MD 20899-0001

\section{Shipping Address:}

National Institute of Standards and Technology,

[For 54510C-54513C:

Attn: E. D. Simmon, Bldg. 202, Room 167, ext. 3956]

[For 54520C-54522C:

Attn: T. L. Nelson, Bldg. 220, Room B165, ext. 2986]

I-270 at Quince Orchard Road,

Gaithersburg, MD 20899-0001

Service

ID No. Items

54510C Voltage Transformer, Ratio \& Phase Angle, at $60 \mathrm{~Hz}$ on 1 Range, 1 Secondary Voltage, 1 Burden Primary $\mathrm{V}_{\text {rms }} \leqslant 150 \mathrm{kV}$

54511C Same as 54510C, Additional Similar Transformer at Same Time

54512C Same as 54510C and 54511C, Additional Burden or Range

54513C Same as 54510C-54512C, at Each Additional Secondary Voltage

54520C Current Transformer, Ratio \& Phase Angle, 1 Range at 1 Frequency and 1 Burden, Secondary Currents $(0.5$, $1,2,3,4,5) \mathrm{A}$, Primary Current Not Over $12000 \mathrm{~A}$

54521C Current Transformer, Ratio \& Phase, 1 Secondary Current, Additional Combination of Range, Frequency, and Burden, Primary Current Not Over $12000 \mathrm{~A}$

54522C Current Transformer, Ratio \& Phase at Each Additional Secondary Current, Same Combination of Range, Frequency, and Burden as 54520C or $54521 \mathrm{C}$

54600S Special Tests of Dividers and Transformers, by Prearrangement

\section{Voltage Transformers (54510C-54513C)}

NIST provides routine services for the measurement of complex voltage ratios (magnitude and phase angle) of transformers for primary voltages up to $150 \mathrm{kV}$ and for secondary voltages above $50 \mathrm{~V}$, subject to some constraints as to the maximum physical size of the device. Results of these routine tests are reported with expanded uncertainties* of $0.03 \%$ for ratio and $0.3 \mathrm{inrad}$ $(1 \mathrm{mrad}=3.438 \mathrm{~min})$ for phase angle. If the test conditions and the device under test warrant, special tests with smaller uncertainties can be performed. These special tests may require an extra fee. The customer must specify the secondary voltage and the secondary burden for each transformer or for each range of a multirange transformer. Ambiguity can be avoided if the impedance and power factor, or the resistance and reactance, are specified, rather than the volt-ampere rating of each burden.

The customer should note that the NIST calibration system represents a minimum burden of $1000 \mathrm{pF}$ for routine calibrations. The customer should give some care to the specification of a burden recognizing that the use of the transformer with a burden different from that used in the calibration can result in significant error.

Calibrations of voltage transformers are performed routinely only at $60 \mathrm{~Hz}$. Measurements are made with one side of both the primary and secondary windings connected together and to ground.

NIST does have some capability to perform measurements at voltages, frequencies, and burdens outside of the ranges described above. Calibrations can occasionally be provided at these nonroutine test points as a special test for an increased fee.

*See Chapter 1, Section $\mathrm{H}$ for more information about uncertainty. 
Current Transformers (54520C-54522C)

Normally NIST calibrates only current transformers of high quality for use as reference standards. The NIST equipment is designed to test current transformers with a rated secondary current of $5 \mathrm{~A}$, with test points chosen to be one or more of the following values: $(0.5,1,2$, $3,4,5)$ A.

Routine tests are carried out at $50 \mathrm{~Hz}$, $60 \mathrm{~Hz}$, and $400 \mathrm{~Hz}$. For measurements at $50 \mathrm{~Hz}$ or $60 \mathrm{~Hz}$, the results are generally reported with expanded uncertainties* of $0.01 \%$ in ratio and $0.1 \mathrm{mrad}$ in phase angle. For measurements at $400 \mathrm{~Hz}$, the reported expanded uncertainty* is $0.03 \%$ in ratio and $0.3 \mathrm{mrad}$ in phase angle.

The customer must specify the test frequency, the secondary currents, and the secondary burdens for each transformer or for each range of a multirange transformer. Current transformers should be tested with burdens equivalent to those which are imposed when the device is used as a transfer standard. Routine calibration using the burdens specified in the American National Standards Institute (ANSI) Standard C-57.13 is not recommended unless these burdens are subsequently used in the customer's factory or laboratory. Large errors can result if the values of ratio and phase angle obtained with an ANSI recommended burden are used for the transformer when it is connected to a different burden.

The burden is preferably specified in terms of the measured resistance and inductance. These values should include the effects of the leads used to make a connection to the transformer secondary. An alternative, which is sometimes feasible, is to submit the transformer together with its normal leads and connected burden for calibration as a unit. If neither of the above are possible, the burden may be stated in terms of the voltampere product and the power factor of the secondary circuit at the test frequency.

* See Chapter 1, Section $\mathrm{H}$ for more information about uncertainty.
For reference, it should be noted that the test equipment regularly used at NIST represents a minimum test burden of about $0.03 \Omega$ with a inductance of about $10 \mu \mathrm{H}$.

Because of contact resistance and current rectification, loose or dirty primary and secondary terminations may affect the measurement results. These surfaces should be tight and clean when the transformer is shipped to NIST to minimize this source of error.

Unless otherwise specified, current transformers are demagnetized prior to calibration. If it is desired to have a transformer tested as submitted (without demagnetization), this requirement should be stated on the purchase order and NIST staff should be informed by telephone before the transformer is shipped.

Many current transformers are not designed to be used as transfer standards, and most of these do not require calibration at NIST. NIST staff can provide some assistance in the assessment of the appropriateness of the device for NIST calibration and in the identification of alternative calibration sources. If NIST is required to perform laboratory measurements to determine whether or not a particular device can be calibrated, a charge for the cost of these measurements will be made.

\section{Special Tests of Dividers and Transformers (54600S)}

NIST maintains an active program of research and development in the area of electrical measurements at high-voltage levels. For this reason, NIST often is able to provide measurement support for highvoltage devices other than those listed above in this section. Special tests will generally be conducted by NIST, if the following criteria are met:

A. The requested tests are fully developed and documented. 
B. There is a significant technical or economic justification for traceability of the test on the item to national standards.

C. There has not been a routine or recurrent need for the test.

\section{References-Voltage and Current Transformers}

A Calibration Service for Current Transformers, J. D. Ramboz and O. Petersons, NIST Spec. Publ. 250-36 (June 1991).

A Calibration Service for Voltage Transformers and High-Voltage Capacitors, W. E. Anderson, Natl. Bur. Stand. (U.S.), Spec. Publ. 250-33 (June 1988).
An Electronic Ratio Error Set for Current Transformer Calibrations, R. L. Kahler, IEEE Trans. Instrum. Meas. IM-28 (2), 162 (June 1979).

A Wide-Range High-Voltage Capacitance Bridge with One-ppm Accuracy, O. Petersons and W. E. Anderson, IEEE Trans. Instrum. Meas. IM-24, (4), 336 (Dec. 1975).

Wide-Band Two-Stage Current Transformers of High Accuracy, T. M. Souders, IEEE Trans. Instrum. Meas. IM-21 (4), 340 (Nov. 1972). 


\section{Phase Meters and Standards and VOR Measurements}

\section{Technical Contacts:}

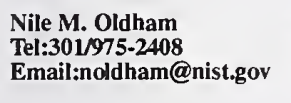

\author{
Mark E. Parker \\ Tel:301/975-2413 \\ Email:mparker@nist.gov
}

Denise D. Prather

Administration and

Logistics

Tel:301/975-4221

Email:dprather@nist.gov

Mailing Address: Building 220, Room B146, National Institute of Standards and Technology,

Gaithersburg, MD 20899-0001

Service

ID No.

Items

$55110 \mathrm{~S}$ Special Tests of Phase Standards and Related

Instruments, by Prearrangement

55120C Phase Meters-One Combination of Input Voltages

$(0.5 \mathrm{~V}$ to $120 \mathrm{~V})$ at One Frequency $(2 \mathrm{~Hz}$ to

$100 \mathrm{kHz}$ )-The Input Voltage Ratio Shall Not

Exceed 10

55121C Phase Meters-Each Additional Combination of Input Voltages $(0.5 \mathrm{~V}$ to $120 \mathrm{~V} \mathrm{rms})$ at the Same or at a Different Frequency (2 Hz to $100 \mathrm{kHz}$ ); The Input Voltage Ratio Shall Not Exceed 10

55130C Phase Meters-One Combination of One Input Voltage $(0.5 \mathrm{~V}$ to $120 \mathrm{~V})$ and One Input Current $(1 \mathrm{~A}$ to $5 \mathrm{~A}$ ) at One Frequency ( $2 \mathrm{~Hz}$ to $5 \mathrm{kHz}$ )

55131C Phase Meters-Each Additional Combination of One Input Voltage $(0.5 \mathrm{~V}$ to $120 \mathrm{~V})$ and One Input Current $(0.5$ A to $5 \mathrm{~A})$

$55140 \mathrm{C}$ Phase Meters-One Input Voltage (120 V to $240 \mathrm{~V})$ and Another Input Voltage ( $120 \mathrm{~V}$ to $240 \mathrm{~V}$ ) at One Frequency ( $2 \mathrm{~Hz}$ to $5 \mathrm{kHz}$ )

55141C Phase Meters-Each Additional Combination of One Input Voltage ( $120 \mathrm{~V}$ to $240 \mathrm{~V}$ ) and Another Input Voltage ( $(120 \mathrm{~V}$ to $240 \mathrm{~V})$ at the Same or at a Different Frequency ( $2 \mathrm{~Hz}$ to $5 \mathrm{kHz}$ )

\section{Special Tests of Phase Standards and Related Instruments, by Prearrangement (55110S)}

\section{Sinusoidal Phase Measurements}

NIST will perform special-test phase angle measurements on phase angle generators, quadrature detectors, and phase bridge-networks. Restrictions apply, and technical limitations and arrangements for these tests should be discussed with NIST; prior arrangements are essential.

\section{VOR Measurements}

The NIST Special Tests for VOR (Veryhigh-frequency Omnidrectional Range) air navigation signals are described in detail in VOR Calibration Service, NBS Technical Note 1069 (see references). Two services are offered to support the calibration of VOR phase meters and generators. NIST has designed and built a standard VOR audio generator, used to calibrate unknown VOR phase meters, and a standard VOR phase meter, used to calibrate unknown audio generators. Direct generation or measurement of standard VOR if signals are not a part of the service.

\section{Phase Meters (55120C-55141C)}

NIST has a capability for characterizing audio frequency phase meters over a frequency range of $2 \mathrm{~Hz}$ to $50 \mathrm{kHz}$. The standard used is a microcomputer-based system that synthesizes two sinusoidal voltages by means of digital techniques. The two signals are displaced relative to one another by a precisely known phase angle. Phase angles can be set with a resolution of $0.002^{\circ}$ up to $5 \mathrm{kHz}$ and $0.005^{\circ}$ above $5 \mathrm{kHz}$. The amplitude of the two output signals can be varied independently from $0.5 \mathrm{~V}$ to $100 \mathrm{~V}$ rms. At power frequencies, one of the signals can be a current from $0.5 \mathrm{~A}$ to $5 \mathrm{~A}$. The expanded uncertainty* in setting the standard is less than $0.01^{\circ}$ below $5 \mathrm{kHz}$ and increases to $0.04^{\circ}$ at $50 \mathrm{kHz}$ if the two output signals have the same amplitude. For unequal amplitudes, this uncertainty increases to $0.015^{\circ}$ and $0.09^{\circ}$ respectively, if the amplitude ratio is less than 10:1. Measurements at amplitude ratios up to 100:1 are performed as Special Tests.

* See Chapter 1, Section H for more information about uncertainty. 
Although the accuracy of the phase angle standard does not rely on the stability of the frequency, the generated output, which can be varied in steps of $1 \mathrm{~Hz}$, is locked to a crystal-controlled frequency synthesizer.

Special requirements for this service are as follows:

A. The voltage inputs of the phase meter to be tested must have impedances such that the current is limited to a few milliamperes at any applied voltage requested. Current inputs must have impedances low enough so that the compliance voltage does not exceed $2 \mathrm{~V}$.

B. NIST will test the instrument in the as-received condition, without making adjustments other than those normally required for testing. Meters that are not in operating condition upon receipt at NIST will be returned to the owner.

C. In some cases, the response of phase meters involves significant time constants; in these cases, readings will be taken $30 \mathrm{~s}$ after the setting of the standard.

D. For given voltage and frequency settings, at least three readings will be taken at each specified phase angle. The order of readings will be randomized.

E. The experimental data are fitted to a mathematical model from which the phase meter response can be predicted. From the closeness of fit to the model, it can be determined whether observed deviations from the predicted values are significant.

F. Each phase meter will be operated under power for at least $2 \mathrm{~h}$ before test data are taken.

G. Meters that are not in operating condition upon receipt at NIST will be returned to the owner without repairs.

\section{References-Phase Meters}

Characterized Generator Extends Phase Meter Calibrations from $50 \mathrm{kHz}$ to $20 \mathrm{MHz}$, N. M. Oldham and P. S. Hetrick, IEEE Trans. Instrum. Meas. 42 (2), 311-313 (Apr. 1993).

The NIST Sampling System for the Calibration of Phase Angle Generators from $1 \mathrm{~Hz}$ to $100 \mathrm{kHz}$, B. C. Waltrip, M. E. Parker, N. M. Oldham, and B. A. Bell, Proc. 1992 NCSL Workshop and Symp., 613-616 (July 1992).

NBS Measurement Services: Phase Angle Calibration Services, R. S. Turgel, J. M. Mulrow, and D. F. Vecchia, Natl. Bur. Stand. (U.S.), Spec. Publ. 250-26 (May 1988).

Phase Meter Calibrations at NBS, R. S. Turgel, J. Res. Natl. Bur. Stand. (U.S.), 93 (1), 53-59 (Jan. 1988).

Precision Calibration of Phase Meters, R. S. Turgel and D. F. Vecchia, IEEE Trans. Instrum. Meas., 36 (4), 915-922 (Dec. 1987).

NBS $50-\mathrm{kHz}$ Phase Angle Calibration Standard, R. S. Turgel, Natl. Bur. Stand. (U.S.), Tech. Note 1220 (Apr. 1986).

A Wideband Transconductance Amplifier for Current Calibrations, O. B. Laug, IEEE Trans. Instrum. Meas. 34 (4), 639-643 (Dec. 1985).

A Precision Phase Angle Calibration Standard for Frequencies Up to 50 $\mathrm{kHz}, \mathrm{R}$. S. Turgel, IEEE Trans. Instrum. Meas. 34 (4), 509-516 (Dec. 1985).

NBS Phase Angle Calibration Standard, R. S. Turgel, N. M. Oldham, G. N. Stenbakken, and T. H. Kibalo, Natl. Bur. Stand. (U.S.), Tech. Note 1144 (July 1981).

A High-Performance Phase-Sensitive Detector, L. A. Marzetta, IEEE Trans. Instrum. Meas., 27 (4), 460-464 (Dec. 1978).

High-Precision Audio-Frequency Phase Calibration Standard, R. S. Turgel and N. M. Oldham, IEEE Trans. Instrum. Meas. 27 (4), 460-464 (Dec. 1978).

VOR Calibration Services, N. T. Larsen, D. F. Vecchia, and G. R. Sugar, Natl. Bur. Stand. (U.S.), Tech. Note 1069 (April 1985).

Fourier Transformation of the Nonlinear VOR Model to Approximate Linear Form, D. F. Vecchia, Natl. Bur. Stand. (U.S.), Tech. Note 1021 (June 1980).

A Wide-Range Current Comparator System for Calibrating Current Transformers, T. M. Souders, IEEE Trans. Power Appar. Syst. 90 (1), 318 (Jan.-Feb. 1971). 


\section{Power and Energy Measurements,} Low-Frequency

\author{
Technical Contacts:
}

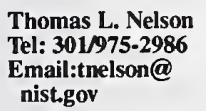

Denise D. Prather

Administration and Logistics

Tel:301/975-4221

Email:dprather@nist.gov

Mailing Address: Building 220, Room B146, National Institute of Standards and Technology,

Gaithersburg, MD 20899-0001

\section{Shipping Address:}

National Institute of Standards and Technology,

[Attn: T. L. Nelson, Bldg. 220, Room B165, ext. 2986]

I-270 at Quince Orchard Road,

Gaithersburg, MD 20899-0001

Test No. Items

\section{$56110 \mathrm{~S}$ Special Tests of AC-DC Wattmeters, by} Prearrangement

56200C Watt, Watthour, Var or Varhour Meter, Initial Two Determinations of Percentage Registration of Same Meter at $60 \mathrm{~Hz}$

56201C Each Additional Determination of Percentage Registration of Same Meter at $50 / 60 \mathrm{~Hz}$

56202C Initial Two Determinations of One or Two Meters Run Simultaneously with the First (56200C)

56210M Measurement Assurance Program for Watthour Meters

56220S Fast Turn-Around Energy Measurements, Low Frequency

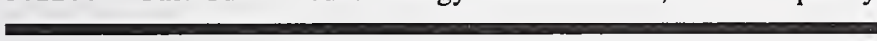

\section{Special Tests of AC-DC Wattmeters (56110S)}

Wattmeter calibrations at other than power frequencies are considered Special Tests and must be arranged on an individual basis. The following limitations apply:

A. Instruments must have separate voltage and current input terminals.

B. The instrument must have a selfcontained power indicator, or provide a direct current or voltage signal which is proportional to power, or provide an output frequency which is proportional to the power.

C. Measurements are generally limited to sinusoidal signals at frequencies

between dc and $100 \mathrm{kHz}$. Input signal levels should not exceed $240 \mathrm{~V}$ and $5 \mathrm{~A}$.

D. Instruments will be tested in the as-received condition, and test uncertainties will be based in part on the performance of the instrument during the test.

\section{Power and Energy Measurements, Low-Frequency (56200C-56202C)}

Only standard electronic-type watt, watthour, var and varhour meters are accepted for test. Rotating types are no longer accepted except by special arrangement. If necessary, the meters should be cleaned or adjusted by the customer before they are shipped to NIST. NIST does not adjust meters and does not knowingly begin tests of faulty meters.

The test conditions must be specified by the customer. These include the current and voltage ranges to be tested, the frequency, the applied voltages, the applied currents, and the power factors. Values of these parameters which are available for routine testing are summarized in Table 9.12.

Table 9.12. Available Values of the Parameters for Routine Wattmeter, Watthour, Varmeter and Varhour Testing

\begin{tabular}{ll}
\hline Parameter & Available Values \\
\hline Voltage (V) & 69 to 480 \\
Current (A) & 0.5 to 30 \\
Power Factor & 0 to 1.0 \\
Phase Angle & 0 to $360^{\circ}$ \\
Frequency $(\mathrm{Hz})$ & $50^{*}, 60,400^{*}$ \\
\hline
\end{tabular}

* Tests at 50 and $400 \mathrm{~Hz}$ are limited to voltages of $240 \mathrm{~V}$ or less and currents of $5 \mathrm{~A}$ or less.

If necessary, measurements can sometimes be made at other values of these parameters. These would, however, be considered special tests. Separate, specific arrangements and a higher fee will be charged than for a routine calibration. 
Prior to the calibration, the meters are energized for between $1 \mathrm{~h}$ and $4 \mathrm{~h}$ at rated voltage and current on one range. A calibration consists of at least two sets of measurements taken over a minimum period of $2 \mathrm{~d}$.

For wattmeters, the values of the reported corrections (in watts) generally have relative expanded uncertainties* of $0.05 \%$ of the full scale range in voltamperes. For watthour meters, the reported values of the percentage registration generally have relative expanded uncertainties* of $0.05 \%$ of the indicated value. Special, higher accuracy tests can be arranged for an additional fee. The relative expanded uncertainties* for power or energy measurements in these special tests may be as low as $0.005 \%$ if the short-term standard deviation of the device under test is appropriately small. For the highest accuracy, voltages are limited to $120 \mathrm{~V}$ and currents to $5 \mathrm{~A}$.

\section{Measurement Assurance Program for Watthour Meters (56210M)}

The Measurement Assurance Program for electric energy is designed to evaluate the performance of energy-measuring systems at the customer's laboratory. A NIST-owned, transport standard watthour meter of known stability is measured by NIST. It is then shipped to and measured by the customer, and shipped back to NIST. NIST analyzes the data and provides a report to the customer indicating the total uncertainty of the customer's measurement. This procedure enables the customer's standards to be measured relative to NIST standards without the downtime encountered when the customer's standards are shipped to and calibrated by NIST. In addition, and more important to those who calibrate standard watthour meters, the NIST MAP standard can be used by customers to evaluate their measurement process in a convenient and cost-effective way.

* See Chapter 1, Section H for more information about uncertainty.
The uncertainty of a MAP includes the effects of the long-term and shortterm instabilities of the NIST calibration system, the customer's calibration system, and the transport standard. Typically, the relative expanded uncertainty* in a wellcontrolled comparison ranges between $0.03 \%$ and $0.05 \%$.

The Electricity Division maintains an active program of research and development in the area of electric power and energy measurements. This program often enables NIST to provide measurement support for watt and watthour meters beyond that listed in this section. Special tests will generally be conducted when the following conditions prevail:

A. The requested tests are fully developed and documented.

B. There is a significant technical or economic justification for traceability of the test on the item to national standards.

C. There has not been a routine or recurrent need for the test.

\section{Fast Turn-Around Energy Measure- ments, Low-Frequency (56220S)}

This calibration service is offered for customers interested in a fast turn-around time, and reduced service cost for a limited number of specific test points. The three test points measured for this service are at $120 \mathrm{~V}$ and $5 \mathrm{~A}$ with power factors of unity, $0.5 \mathrm{lag}$, and 0.5 lead. These are the only test points offered for this service. If the customer requests additional test points, the price and turn-around time will be those for the routine calibration service (see Service ID Number $56200 \mathrm{C}$ ). The relative expanded uncertainty* assigned to a watthour meter for this service is $0.02 \%$. This service will only accept standard watthour meters that have a pulse output. The turn-around time will be two weeks. Due to the short turn-around time of this service, the customer will need to schedule this calibration with the appropriate contact, and a purchase order must be submitted either with the instrument, or be received before the instrument arrives at NIST. 


\section{References-Power and Energy Measurements, Low Frequency}

Digitally Synthesized Power Calibration Source, N. M. Oldham, O. B. Laug, and B. C. Waltrip, IEEE Trans. Instrum. Meas. IM-36 (2), 341 (June 1987).

NBS Wideband Sampling Wattmeter, G. N. Stenbakken, O. B. Laug, A. G. Perry, B. A. Bell, and T. H. Kibalo, Natl. Bur. Stand. (U.S.), Tech. Note 1221 (May 1987).

A Wideband Sampling Wattmeter, G. N. Stenbakken, IEEE Trans. Power Appar. Syst. PAS-103 (10), 2919 (Oct. 1984).

A Calibration Service for Wattmeters and Watthour Meters, J. D. Ramboz and R. C. McAuliff, Natl. Bur. Stand. (U.S.), Tech. Note 1179 (July 1983).
A Measurement Assurance Program for Electric Energy, N. M. Oldham, Natl. Bur. Stand. (U.S.), Tech. Note 930 (Sept. 1976).

Transfer of the Kilowatthour, S. R. Houghton, IEEE Trans. Power Appar. Syst. PAS-94 (4), 1232 (July-Aug. 1975).

Sampling Techniques for Electric Power Measurement, R. S. Turgel, Natl. Bur. Stand. (U.S.), Tech. Note 870 (June 1975).

A Current Comparator System to Establish the Unit of Electrical Energy at $60 \mathrm{~Hz}$, K. J. Lentner, IEEE Trans. Instrum. Meas. IM-23 (4), 334 (Dec. 1974). 


\section{RF, Microwave and Millimeter-Wave Measurements G.1 Thermistor Mounts}

\author{
Technical Contacts:
}

$\begin{array}{lccc}\begin{array}{c}\text { John R. Juroshek } \\ \text { Tel:303/497-5362 }\end{array} & \begin{array}{c}\text { Ronald A. Ginley } \\ \text { Tel:303/497-3634 } \\ \text { Email:jjuroshek@ } \\ \text { nist.gov }\end{array} & \begin{array}{c}\text { Fred R. Clague } \\ \text { Tel:303/497-5778 } \\ \text { nist.gov }\end{array} & \begin{array}{c}\text { George M. Free } \\ \text { Tel:303/497-3609 } \\ \text { nist.gov }\end{array} \\ \begin{array}{c}\text { Wayde Allen } \\ \text { Tel:303/497-3753 }\end{array} & \begin{array}{c}\text { Paula M. Hewitt } \\ \text { nist.gov }\end{array} \\ \begin{array}{ll}\text { Edministration and Logistics } \\ \text { Tel:303/497-3753 }\end{array} & \\ & \begin{array}{l}\text { Email:paula.hewitt@nist.gov } \\ \text { Fax:303/497-3970 }\end{array} & \end{array}$

Mailing Address: M.C. 813.10,

National Institute of Standards and Technology,

325 Broadway,

Boulder, CO 80303-3328.

Service

ID No.

Items

The following tests are for thermistor mounts with coaxial connectors.

$61110 \mathrm{~S}$ Coaxial Mounts at a Single Frequency in the Range of $0.1 \mathrm{MHz}$ to $10 \mathrm{MHz}$

$61111 \mathrm{~S}$ Each Additional Frequency for $61110 \mathrm{~S}$

$61120 \mathrm{~S}$ Coaxial Mounts at $10 \mathrm{MHz}$ Intervals within the Frequency Range of $10 \mathrm{MHz}$ to $100 \mathrm{MHz}$

$61121 \mathrm{~S}$ Additional Mount at the Same Frequencies as $61120 \mathrm{~S}$

$61122 \mathrm{~S}$ Coaxial Mounts at $50 \mathrm{MHz}$ Intervals within the Frequency Range of $100 \mathrm{MHz}$ to $1 \mathrm{GHz}$

$61123 \mathrm{~S}$ Additional Mount at the same Frequencies as $61122 \mathrm{~S}$

$61124 \mathrm{~S}$ Coaxial Mounts at $10 \mathrm{MHz}$ Intervals within the Frequency

Range of $10 \mathrm{MHz}$ to $100 \mathrm{MHz}$, and $50 \mathrm{MHz}$

Intervals within the Frequency Range of $100 \mathrm{MHz}$ to $1 \mathrm{GHz}$

61125S Additional Mount at the same Frequencies as 61124S

$61126 \mathrm{~S}$ Coaxial with GPC-7 Connectors at Frequencies shown in Table 9.13 irom $10 \mathrm{MHz}$ to $18 \mathrm{GHz}$

61127S Additional Mount at the same Frequencies as $61126 \mathrm{~S}$

$61128 \mathrm{~S}$ Coaxial Mounts with GPC-7 Connectors at $1 \mathrm{GHz}$ Intervals within the Frequency Range of $1 \mathrm{GHz}$ to $18 \mathrm{GHz}$

$61129 \mathrm{~S}$ Additional Mount at the same Frequencies as $61128 \mathrm{~S}$

61130 Soaxial Mounts with Type N Connectors at Frequencies shown in Table 9.13 from $10 \mathrm{MHz}$ to $18 \mathrm{GHz}$

61131S Additional Mount at the same Frequencies as $61130 \mathrm{~S}$

$61132 \mathrm{~S}$ Coaxial Mounts with Type $\mathrm{N}$ Connectors at $1 \mathrm{GHz}$ Intervals within the Frequency Range of $1 \mathrm{GHz}$ to $18 \mathrm{GHz}$

61133S Additional Mount at the same Frequencies as $61132 \mathrm{~S}$

$61134 \mathrm{~S}$ Coaxial Mounts with $3.5 \mathrm{~mm}$ Connectors at $1 \mathrm{GHz}$ Intervals within the Frequency Range of $2 \mathrm{GHz}$ to $18 \mathrm{GHz}$
Service

ID No. Items

$61135 \mathrm{~S}$ Coaxial Mounts with $3.5 \mathrm{~mm}$ Connectors at $1 \mathrm{GHz}$ Intervals within the Frequency Range of $18 \mathrm{GHz}$ to $26 \mathrm{GHz}$

$61136 \mathrm{~S}$ Additional Mount at the same Frequencies as $61134 \mathrm{~S}$ and $61135 \mathrm{~S}$

61137C NIST Model CN Coaxial Mounts at 124 Frequencies within the Frequency Range of $50 \mathrm{MHz}$ to $18 \mathrm{GHz}$

61138C NIST Model CN Coaxial Mounts at Customer Selected Frequencies within the Frequency Range of $50 \mathrm{MHz}$ to $18 \mathrm{GHz}$

The following tests are for thermistor mounts with waveguide flanges.

61144S Rectangular Waveguide Mounts with WR90 Flanges at $200 \mathrm{MHz}$ Intervals within the Frequency Range of $8.2 \mathrm{GHz}$ to $12.4 \mathrm{GHz}$

$61145 \mathrm{~S}$ Additional Thermistor Mount at the Same Frequencies as $61144 \mathrm{~S}$

61146S Rectangular Waveguide Mounts with WR62 Flanges at $250 \mathrm{MHz}$ Intervals within the Frequency Range of $12.4 \mathrm{GHz}$ to $18.0 \mathrm{GHz}$

$61147 \mathrm{~S}$ Additional Thermistor Mount at the Same Frequencies as $61146 \mathrm{~S}$

$61148 S$ Rectangular Waveguide Mounts with WR42 Flanges at $1 \mathrm{GHz}$ Intervals within the Frequency Range of $18 \mathrm{GHz}$ to $26.5 \mathrm{GHz}$

61149 S Additional Thermistor Mount at the Same Frequencies as $61148 \mathrm{~S}$

61150S Rectangular Waveguide Mounts with WR28 Flanges at $1 \mathrm{GHz}$ Intervals within the Frequency Range of $26.5 \mathrm{GHz}$ to $40 \mathrm{GHz}$

$61151 S$ Additional Thermistor Mount at the Same Frequencies as $61150 \mathrm{~S}$

$61152 S$ Rectangular Waveguide Mounts with WR22 Flanges at $1 \mathrm{GHz}$ Intervals within the Frequency Range of $33 \mathrm{GHz}$ to $50 \mathrm{GHz}$

$61153 \mathrm{~S}$ Additional Thermistor Mount at the Same Frequencies as $61152 \mathrm{~S}$

$61154 S$ Rectangular Waveguide Mounts with WR15 Flanges at a Single Frequency within the Frequency Range of $50 \mathrm{GHz}$ to. $75 \mathrm{GHz}$

$61155 S$ Rectangular-Waveguide Mounts with WR10 Flanges at a Single Frequency within the Frequency Range of $92 \mathrm{GHz}$ to $98 \mathrm{GHz}$

High Power Wattmeters

61160 S Calibration Factor of Continuous Wave (CW) High Power Wattmeters at Several Points within the Frequency Range of $2 \mathrm{MHz}$ to $30 \mathrm{MHz}$ (1 watt to 1000 watts) and $30 \mathrm{MHz}$ to $400 \mathrm{MHz}$ (1 watt to 500 watts)

$61190 \mathrm{~S}$ Special Microwave and RF Power Measurement Services, by Prearrangement 


\section{General Information}

Calibration services are available for thermistor mounts with GPC-7, Type N, and $3.5 \mathrm{~mm}$ coaxial connectors and several waveguide sizes ( $8.2 \mathrm{GHz}$ to $96 \mathrm{GHz}$ ).

Assistance is available for applying published, technically valid measurement techniques in lieu of previously available NIST calibration services for coaxial and waveguide calorimeters, thermoelectric power meters, and bolometer coupler units. The attainable limits of measurement uncertainty using these techniques are comparable to those of the previously available calibration services for these devices.

The Reports of Calibration and Special Test give the magnitude and phase of the reflection coefficient, effective efficiency, and calibration factor of the thermistor mount.

\section{Definitions:}

\section{Effective Efficiency $\eta_{\mathrm{c}}$}

The effective efficiency $\eta_{c}$ is the ratio of the bolometrically substituted dc power in the thermistor mount to the net $\mathrm{CW}$ if microwave power delivered to the thermistor mount.

Bolometrically Substituted dc Power The bolometrically substituted dc power is the change in dc (or audio frequency) bias power required to maintain the resistance of the thermistor element at a constant value following the application of $\mathrm{rf}$ or microwave power.

\section{Calibration Factor, $K_{\mathrm{B}}$}

The calibration factor is the ratio of the bolometrically substituted dc power in the thermistor mount to the $\mathrm{CW}$ if microwave power incident upon the thermistor mount. $K_{\mathrm{B}}=\eta_{\mathrm{c}}\left(1-|\Gamma|^{2}\right)$.
Reflection Coefficient Magnitude, $|\Gamma|$ and $\operatorname{Arg}(\Gamma)$

The reflection coefficient magnitude and phase (argument of reflection coefficient) is the ratio of the reflected wave voltage amplitude to the incident wave voltage amplitude and phase.

\section{Commercial Coaxial Thermistor Mounts (61110S-61136S)}

Specify frequencies in the range from $0.1 \mathrm{MHz}$ to $10 \mathrm{MHz}$ for special lowfrequency thermistor mounts (Service ID Number $61110 S$ ). Values for $\eta_{\mathrm{e}}$ and $|\Gamma|$ are calculated from voltage and resistance measurements.

$\eta_{\mathrm{e}}=\left(P_{\mathrm{dc}}\right) /\left(P_{\mathrm{rf}}\right)$, where $P_{\mathrm{rf}}=V^{2} / R_{\mathrm{P}}$, and $R_{\mathrm{P}}$ is the parallel equivalent resistance, and $P_{\mathrm{dc}}$ is the bolometrically substituted dc power in the bolometer.

The following table lists the frequencies at which measurements are made on thermistor mounts with GPC-7 or Type $\mathrm{N}$ connectors.

Table 9.13. Measurement Ranges and Uncertainties for Coaxial Thermistor Mounts

\begin{tabular}{lcc} 
Frequency & Interval & $\begin{array}{c}\text { Relative } \\
\text { Expanded } \\
\text { Uncertainty*a } \\
\text { in } \boldsymbol{\eta}_{\mathrm{e}} \\
(\%)\end{array}$ \\
\hline $10 \mathrm{MHz}$ to $100 \mathrm{MHz}$ & $10 \mathrm{MHz}$ Intervals & 0.3 to 0.5 \\
$100 \mathrm{MHz}$ to $1 \mathrm{GHz}$ & $50 \mathrm{MHz}$ Intervals & 0.3 \\
$1 \mathrm{GHz}$ to $2 \mathrm{GHz}$ & $50 \mathrm{MHz}$ Intervals & 0.3 \\
$2 \mathrm{GHz}$ to $4 \mathrm{GHz}$ & $100 \mathrm{MHz}$ Intervals & 0.3 \\
$4 \mathrm{GHz}$ to $8 \mathrm{GHz}$ & $200 \mathrm{MHz}$ Intervals & 0.4 \\
$8 \mathrm{GHz}$ to $12.4 \mathrm{GHz}$ & $200 \mathrm{MHz}$ Intervals & 0.4 \\
$12.4 \mathrm{GHz}$ to $18 \mathrm{GHz}$ & $250 \mathrm{MHz}$ Intervals & 0.5 to 0.7 \\
\hline
\end{tabular}

${ }^{a}$ These expanded uncertainties are typical for thermistor mounts with Type $\mathrm{N}$ connectors.

* See Chapter 1, Section $\mathrm{H}$ for more information about uncertainty. 
Uncertainties for the effective efficiency and calibration factor depend on the frequency and the characteristics of the unit being calibrated such as connector type, reflection coefficient, and repeatability.

\section{NIST Model CN Reference Standard (61137C-61138C)}

This premium service provides $\eta_{\mathrm{e}}$ measurements as a function of frequency for a NIST-designed coaxial reference standard with a Type $\mathrm{N}$ connector. The reference standard, designated Model CN (Coaxial with a Type $\mathrm{N}$ connector), is a bolometric, dc-substitution power detector that must be used with a NIST Type IV power meter (available from several commercial sources). The mount is designed as an optimum transfer standard which can be measured directly in the NIST coaxial microcalorimeter. To use this service, the customer needs to have a $\mathrm{CN}$ mount (contact Fred R. Clague for information).

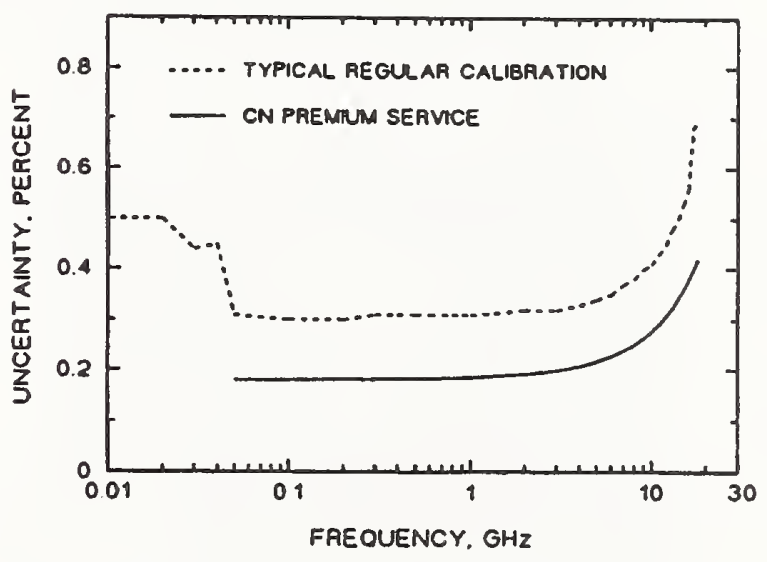

Figure 9.1. Expanded Uncertainty in $\eta_{e}$.
Measurements are made at 124 frequencies over the range from $50 \mathrm{MHz}$ to $18 \mathrm{GHz}$ (Service ID Number 61137C) or customer specified frequencies (Service ID Number 61138C). Figure $9.1 \mathrm{com}$ pares the expanded uncertainty of the premium service with that of the regular service for coaxial thermistor mounts.

\section{Waveguide Thermistor Mounts (61144S-61155S)}

Measurements of effective efficiency, efficiency factor, and reflection coefficient are made for various waveguide sizes as follows:

Table 9.14. Measurement Range and Uncertainties for Waveguide Thermistor Mounts

\begin{tabular}{lclc}
$\begin{array}{l}\text { Wave- } \\
\text { guide } \\
\text { Band }\end{array}$ & $\begin{array}{c}\text { Frequency } \\
\text { Range } \\
\text { (GHz) }\end{array}$ & $\begin{array}{c}\text { Measurement } \\
\text { Frequency or } \\
\text { Interval }\end{array}$ & $\begin{array}{c}\text { Expanded } \\
\text { Uncertainty* } \\
\text { in } \boldsymbol{\eta}_{\mathbf{e}} \\
\mathbf{( \% )}\end{array}$ \\
\hline WR90 & 8.2 to 12.4 & $200 \mathrm{MHz}$ Intervals & 1.1 \\
WR62 & 12.4 to 18 & $250 \mathrm{MHz}$ Intervals & 1.1 \\
WR42 & 18 to 26.5 & $1 \mathrm{GHz}$ Intervals & 1.1 \\
WR28 & 26.5 to 40 & $1 \mathrm{GHz}$ Intervals & 1.1 \\
WR22 & 33 to 50 & $1 \mathrm{GHz}$ Intervals & 2.6 \\
WR15 & 50 to 75 & Specify Frequency & 1.3 \\
WR10 & 92 to 98 & Specify Frequency & 2.1
\end{tabular}

*See Chapter 1, Section $\mathrm{H}$ for more information about uncertainty. 


\section{High-Power Wattmeter (61160S)}

A Special Test service is available for continuous wave $(\mathrm{CW})$ high power wattmeters. Measurements are available at several frequencies from $1 \mathrm{MHz}$ to $30 \mathrm{MHz}(1 \mathrm{~W}$ to $1000 \mathrm{~W})$ and $30 \mathrm{MHz}$ to $400 \mathrm{MHz}$ (1 W to $500 \mathrm{~W}$ ). Wattmeters must be controllable via an IEEE-488 bus, have a Type $\mathrm{N}$ male input connector, and either have a Type $\mathrm{N}$ female output connector or an appropriate termination. The calibration factor, defined as the ratio of the wattmeter reading to the power incident upon it, will be supplied at each measurement point. The relative expanded uncertainty* is typically less than $2 \%$, depending on frequency, power level and electrical characteristics of the wattmeter/load combination. Call the technical contact for further information.

\section{References-Thermistor Mounts}

Direct Comparison Transfer of Microwave Power Sensor Calibration, M. Weidman, Natl. Inst. Stand. Technol. (U.S.), Tech. Note 1379 (January 1996).

A Calibration Service for Reference Standards for Microwave Power, F. Clague, Natl. Inst. Stand. Technol., Tech. Note 1374 (May 1995).

Microcalorimeter for GPC-7 Coaxial Transmission Line, F. Clague, Natl. Inst. Stand. Technol., Tech. Note 1358 (August 1993).

Coaxial Reference Standard for Microwave Power, F. Clague and P. Voris, Natl. Inst. Stand. Technol., Tech. Note 1357 (April 1993).

Measurement Service for High-Power CW Wattmeter at the National Institute of Standards and Technology,

* See Chapter 1, Section H for more information about uncertainty.
J. A. Jargon and G. Rebuldela, Proc. of the Meas. Sci. Conf., Anaheim, CA (Jan. 1993).

Basic RF and Microwave Measurements: A Review of Selected Programs, A. J. Estin, J. R. Juroshek, R. B. Marks, F. R. Clague, and J. Wayde Allen, Metrologia 29, 135-151 (1992).

High Power CW Wattmeter Calibration at NIST, G. Rebuldela and J. A. Jargon, J. Res. Natl. Inst. Stand. Technol., 97 (6), pp. 673-687 (Nov.-Dec. 1992).

WR-10 Millimeter Wave Microcalorimeter, M. Weidman and P. Hudson, Natl. Bur. Stand. (U.S.), Tech. Note 1044 (June 1981).

A Semiautomated Six-Port for Measuring Millimeter-Wave Power and Complex Reflection Coefficient, $M$. Weidman, IEEE Trans. Micro. Theory Tech. MTT-25, 12 (Dec. 1977).

Performance Characteristics of an Automated Broad-Band Bolometer Unit Calibration System, E. Komarek, IEEE Trans. Micro. Theory Tech. MTT-25, 12 (Dec. 1977).

Theory of UHF and Microwave Measurements Using the Power Equation Concept, G. F. Engen, Natl. Bur. Stand. (U.S.), Tech. Note 637 (Apr. 1973). Application of an Arbitrary Six-Port Junction to Power Measurement Problems, G. Engen and C. Hoer, IEEE Trans. Instrum. Meas. IM-21, 470 (Nov. 1972).

WR-15 Microwave Calorimeter and Bolometer Unit, M. Harvey, Natl. Bur. Stand. (U.S.), Tech. Note 618 (May 1972).

Accurate Microwave High-Power Measurements Using a Cascaded Coupler Method, K. E. Bramall, J. Res. Natl. Bur. Stand. (U.S.), 75C (3 and 4), 185 (July-Dec. 1971). 


\section{G RF, Microwave, and Millimeter-Wave Measurements \\ G.2 Scattering Parameters of Passive Multi-Port Devices}

\section{Technical Contacts:}

$\begin{array}{cll}\text { John R. Juroshek } & \begin{array}{c}\text { Ronald A. Ginley } \\ \text { Tel:303/497-3634 }\end{array} & \begin{array}{l}\text { Paula M. Hewitt } \\ \text { Administration and Logistics } \\ \text { Tel:303/497-5362 }\end{array} \\ \begin{array}{c}\text { Email:jjuroshek@ } \\ \text { Email:rginley@ } \\ \text { nist.gov }\end{array} & \begin{array}{l}\text { Tel:303/497-3753 } \\ \text { nist.gov }\end{array} & \begin{array}{l}\text { Email:paula.hewitt@nist.gov } \\ \text { Fax:303/497-3970 }\end{array}\end{array}$

Mailing Address: M.C. 813.10,

National Institute of Standards and Technology,

325 Broadway,

Boulder, CO 80303-3328

Service

ID No. Items

The following tests are for two-port devices with coaxial connectors. See Table 9.15 for Measurement Ranges and Uncertainties.

61210S Coaxial Fixed and Variable Attenuators with GR900 Connectors

$61211 \mathrm{~S}$ Additional Two-Port Device at the Same Frequencies as $61210 \mathrm{~S}$

61212C Coaxial Fixed and Variable Attenuators with GPC-7 Connectors

61213S Additional Two-Port Device at the Same Frequencies as $61212 \mathrm{~S}$

61214S Coaxial Fixed and Variable Attenuators with Type N Connectors

$61215 S$ Additional Two-Port Device at the Same Frequencies as $61214 \mathrm{~S}$

61216S Coaxial Fixed and Variable Attenuators with $3.5 \mathrm{~mm}$ Connectors $[27 \mathrm{GHz}$ to $33 \mathrm{GHz}$ available by special request ]

61217S Additional Two-Port Device at the Same Frequencies at $61216 \mathrm{~S}$

$61218 \mathrm{~S}$ Coaxial Fixed and Variable Attenuators with $2.92 \mathrm{~mm}$ Connectors

61219S Additional Two-Port Device at the Same Frequencies as $61218 \mathrm{~S}$

61220 S Coaxial Fixed and Variable Attenuators with $2.4 \mathrm{~mm}$ Connectors

61221S Additional Two-port Device at the Same Frequencies as $61220 \mathrm{~S}$

The following tests are for two-port devices with waveguide connectors. See Table 9.16 for

Measurement Ranges and Uncertainties.

61230 WR90 Rectangular Waveguide Fixed and Variable Attenuators
Service

ID No. Items

61231S Additional Two-Port Device at the Same Frequencies as $61230 \mathrm{~S}$

61232S WR62 Rectangular Waveguide Fixed and Variable Attenuators

61233S Additional Two-Port Device at the Same Frequencies as $61232 \mathrm{~S}$

61234S WR42 Rectangular Waveguide Fixed and Variable Attenuators

61235 S Additional Two-Port Device at the Same Frequencies as $61234 \mathrm{~S}$

61236S WR28 Rectangular Waveguide Fixed and Variable Attenuators

61237S Additional Two-Port Device at the Same Frequencies as $61236 \mathrm{~S}$

61238S WR22 Rectangular Waveguide Fixed and Variable Attenuators

61239S Additional Two-Port Device at the Same Frequencies as $61238 \mathrm{~S}$

61240S WR15 Rectangular Waveguide Fixed and Variable Attenuators

61241S Additional Frequencies for Same Device Done on 61240 S

61242 S WR10 Rectangular Waveguide Fixed and Variable Attenuators

$61243 S$ Additional Frequencies for Same Device Done on $61242 \mathrm{~S}$

61249S Special Attenuation Measurements, by Prearrangement

61250 S Time Delay, Coaxial and Waveguide, by Prearrangement

The following tests are for one-port devices with coaxial connectors. See Table 9.17 for Measurement Ranges and Uncertainties.

$61260 S$ Coaxial One-Port Devices with GR900 Connectors

$61261 \mathrm{~S}$ Additional One-Port Device at the Same Frequencies as $61260 \mathrm{~S}$

61262C Coaxial One-Port Devices with GPC-7 Connectors

61263S Additional One-Port Device at the Same Frequencies as $61262 \mathrm{~S}$

61264S Coaxial One-Port Devices with Type N connectors

61265S Additional One-Port Device at the Same Frequencies as 61264 S

61266S Coaxial One-Port Devices with $3.5 \mathrm{~mm}$ Connectors

$61267 \mathrm{~S}$ Additional One-Port Device at the Same Frequencies as $61266 \mathrm{~S}$

61268S Coaxial One-Port Devices with $2.92 \mathrm{~mm}$ Connectors

61269S Additional One-Port Device at the Same Frequencies as $61268 \mathrm{~S}$

61270S Coaxial One-Port Devices with $2.42 \mathrm{~mm}$ Connectors

$61271 \mathrm{~S}$ Additional One-Port Device at the Same Frequencies as $61270 \mathrm{~S}$ 


\section{Service}

ID No.

\section{Items}

The following tests are for one-port devices with waveguide connectors. See Table 9.18 for Measurement Ranges and Uncertainties.

WR90 Rectangular Waveguide

$61281 \mathrm{~S}$
Additional One-Port Device at the Same Frequencies as 61280 S WR62 Rectangular Waveguide

Additional One-Port Device at the Same Frequencies as $61282 \mathrm{~S}$ WR42 Rectangular Waveguide

Additional One-Port Device at the Same Frequencies as 61284 S WR28 Rectangular Waveguide

Additional One-Port Device at the Same Frequencies as 61286S WR22 Rectangular Waveguide

Additional One-Port Device at the Same Frequencies as 61288S WR15 Rectangular Waveguide

Additional Frequencies for same Device Done on 61290 S WR10 Rectangular Waveguide

Additional Frequencies for same Device Done on $61292 \mathrm{~S}$ Special Reflection Coefficient Measurements, by Prearrangement Coaxial Fixed and Variable Phase Shifters;

Frequency Range $1 \mathrm{GHz}$ to $50 \mathrm{GHz}$, Phase Range $0^{\circ}$ to $360^{\circ}$

Waveguide Fixed and Variable Phase Shifters;

Specify Frequencies for Waveguide Sizes

WR10, WR15, WR22, WR28, WR42, WR62, and WR90

Special Tests of Phase Shifters, by Prearrangement

\section{General Information}

Microwave devices are characterized by their reflection and transmission properties. Single port devices such as matched terminations and offset shorts are characterized by measuring their reflection properties or voltage reflection coefficient. Multiport devices such as attenuators are characterized by measuring both their reflection and transmission properties.
Figure 9.2 shows the reflected and transmitted voltage waves for a typical twoport device. The voltage waves incident to the device are defined as $a_{1}$ and $a_{2}$. The voltage waves reflected from the device are defined as $b_{1}$ and $b_{2}$.

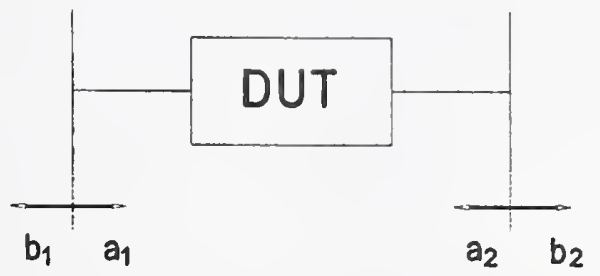

Figure 9.2. Reflected and Transmitted Voltage Waves for a Typical Two-Port Device.

The scattering parameters specify the relationship between the incident and reflected waves. In the case of the two-port in Figure 9.2, the scattering matrix is,

$$
\left[\begin{array}{l}
b_{1} \\
b_{2}
\end{array}\right]=\left[\begin{array}{ll}
S_{11} & S_{12} \\
S_{12} & S_{22}
\end{array}\right]\left[\begin{array}{l}
a_{1} \\
a_{2}
\end{array}\right]
$$

The scattering matrices shown are complex quantities conveying information on both the magnitude and phase of the quantities of interest.

The attenuation of a two-port device is defined as $S_{12}$ and $S_{21}$. Most passive microwave devices are reciprocal where $S_{12}=S_{21}$. The magnitude of the attenuation for a reciprocal device is commonly expressed in $\mathrm{dB}$ as

$$
\begin{aligned}
\mathrm{A} & =-20 \log _{10}\left(\left|S_{12}\right|\right), \mathrm{dB} \\
& =-20 \log _{10}\left(\left|S_{21}\right|\right), \mathrm{dB}
\end{aligned}
$$


Similar definitions exist for single port devices such as terminations and offset shorts. A one port device can be thought of as the special case of a two port device where $S_{12}=S_{21}=0$. The voltage reflection coefficient for a one port device is commonly given as

$$
\Gamma=b / a,
$$

where $a$ is the voltage wave incident on the device, and $b$ is the voltage wave reflected from the device.

All scattering parameters are referenced to some idealized transmission line. At NIST, all coaxial measurements are referenced to an idealized, air dielectric, $50 \Omega$ transmission line of specified dimensions. Similarly, all waveguide measurements are referenced to an idealized, air dielectric, precision waveguıde section of specified dimensions. Details of the reference standard are available on request.

Standards submitted for calibration should be in good repair and require only very minor cleaning of connector surfaces. NIST does not provide repair services. Items received requiring maintenance will be returned to the customer, and a handling fee will be charged.

\section{Coaxial Fixed and Variable Attenua- tors (61210S-61221S)}

Coaxial fixed and variable attenuators are measured on either a NIST Dual Six-Port Vector Network Analyzer (VNA) over the frequency range from $10 \mathrm{MHz}$ to $26.5 \mathrm{GHz}$ or on a commercial VNA over the frequency range from $50 \mathrm{MHz}$ to $50 \mathrm{GHz}$.

Coaxial attenuators are normally measured relative to a reference characteristic impedance of $50 \Omega$. For fixed coaxial attenuators, the complete set of complex scattering parameters are measured. For reciprocal devices, the Reports of Calibration give the magnitude and phase of $S_{11}, S_{22}$ and $S_{12}=S_{21}$.
For variable attenuators, normally only the change in attenuation from the zero setting is of interest. The test report for variable attenuators show the change in the magnitude of $S_{12}$ from the zero setting versus frequency for selected attenuator settings. Complete scattering parameter measurements for variable attenuators are available by special request. Uncertainties depend on the nominal attenuation, connector type, and frequency.

Attenuation measurements are available for devices with $2.4 \mathrm{~mm}, 2.92 \mathrm{~mm}$, $3.5 \mathrm{~mm}$, GPC-7, $14 \mathrm{~mm}$, and Type $\mathrm{N}$ connectors as shown in Table 9.15. Measurements not listed may be available and you should call the technical contact to discuss the availability. The cost of such services must be negotiated and will, in general, be higher than other established services. Consultation is available by telephone.

Table 9.15. Measurement Ranges and Uncertainties for Coaxial Two-Port Devices

\begin{tabular}{llll}
$\begin{array}{l}\text { Coaxial } \\
\text { Connector } \\
\text { Type }\end{array}$ & \multicolumn{1}{c}{$\begin{array}{c}\text { Frequency } \\
\text { Range }\end{array}$} & $\begin{array}{c}\text { Attenuation } \\
\text { Range } \\
\text { (dB) }\end{array}$ & $\begin{array}{c}\text { Expanded } \\
\text { Uncertainty* } \\
\left|\mathbf{S}_{\mathbf{1 2}}\right|=\left|\mathbf{S}_{\mathbf{2 1}}\right| \\
\text { (dB) }\end{array}$ \\
\hline GR900 & $10 \mathrm{MHz}$ to $8.5 \mathrm{GHz}$ & 0 to 60 & 0.01 to 0.2 \\
GPC-7 & $10 \mathrm{MHz}$ to $18 \mathrm{GHz}$ & 0 to 60 & 0.01 to 0.2 \\
Type N & $10 \mathrm{MHz}$ to $18 \mathrm{GHz}$ & 0 to 60 & 0.01 to 0.2 \\
$3.5 \mathrm{~mm}$ & $10 \mathrm{MHz}$ to $33 \mathrm{GHz}$ & 0 to 60 & 0.01 to 0.2 \\
$2.92 \mathrm{~mm}$ & $10 \mathrm{MHz}$ to $40 \mathrm{GHz}$ & 0 to 60 & 0.01 to 0.2 \\
$2.4 \mathrm{~mm}$ & $10 \mathrm{MHz}$ to $50 \mathrm{GHz}$ & 0 to 60 & 0.01 to 0.2
\end{tabular}

*See Chapter 1, Section H for more information about uncertainty.

\section{Rectangular Waveguide Fixed and Variable Attenuators (61230S-61249S)}

Fixed and variable (usually rotary vane) waveguide attenuators are calibrated on the NIST Dual 6-Port VNA. Service is available for frequencies corresponding to waveguide sizes WR 10, WR15, WR22, WR28, WR42, WR62, and WR90 as shown in Table 9.16. 
Table 9.16. Measurement Ranges and Uncertainties for Waveguide Two-Port Devices

\begin{tabular}{lcccc}
$\begin{array}{c}\text { Waveguide } \\
\text { Band }\end{array}$ & $\begin{array}{c}\text { Frequency } \\
\text { Range } \\
\text { (GHz) }\end{array}$ & Intervals & $\begin{array}{c}\text { Attenuation } \\
\text { Range } \\
\text { (dB) }\end{array}$ & $\begin{array}{c}\text { Expanded } \\
\text { Uncertainty* } \\
\left|S_{21}\right| \\
\text { (dB) }\end{array}$ \\
\hline WR90 & 8.2 to 12.4 & $200 \mathrm{MHz}$ & 0 to 60 & 0.02 to 0.2 \\
WR62 & 12.4 to 18 & $250 \mathrm{MHz}$ & 0 to 60 & 0.02 to 0.2 \\
WR42 & 18 to 26.5 & $1 \mathrm{GHz}$ & 0 to 50 & 0.02 to 0.3 \\
WR28 & 26.5 to 40 & $1 \mathrm{GHz}$ & 0 to 50 & 0.02 to 0.3 \\
WR22 & 33 to 50 & $1 \mathrm{GHz}$ & 0 to 50 & 0.02 to 0.5 \\
WR15 & 50 to 75 & Specify & 0 to 50 & 0.02 to 0.5 \\
WR10 & 92 to 98 & Specify & 0 to 40 & 0.03 to 0.5
\end{tabular}

*See Chapter 1, Section $\mathrm{H}$ for more information about uncertainty.

Time Delay, Coaxial and Waveguide (61250S)

Time delay calibration services are available for both coaxial and waveguide delay lines. The time delay for the device under test is determined from phase measurements that are made on a vector network analyzer. The frequency range for the measurements ranges from $0.1 \mathrm{GHz}$ to $100 \mathrm{GHz}$ depending on the connectors involved. Devices submitted for calibration should be equipped with either precision coaxial connectors or precision waveguide flanges. The length of the device should typically be less than $30 \mathrm{~cm}$. However, delay measurements can be made on longer devices in certain circumstances. Because of the specialized nature of these measurements, prior discussions should be held with NIST staff before submission of any device for testing.

\section{Coaxial One-Port Devices (61260S to 61271S)}

Services are available for complex reflection coefficient of passive devices with $2.4 \mathrm{~mm}, 2.92 \mathrm{~mm}, 3.5 \mathrm{~mm}, \mathrm{GPC}-7$, Type N and GR900 connectors. Available calibration frequencies are listed in Table 9.17.

Table 9.17. Measurement Ranges and Uncertainties for Coaxial One-Port Devices

\begin{tabular}{llc}
$\begin{array}{l}\text { Coaxial } \\
\text { Connector } \\
\text { Type }\end{array}$ & \multicolumn{1}{c}{$\begin{array}{c}\text { Frequency } \\
\text { Range }\end{array}$} & $\begin{array}{c}\text { Expanded } \\
\text { Uncertainty* } \\
\left|S_{11}\right| \text { and }\left|S_{22}\right| \\
\text { (dB) }\end{array}$ \\
\hline GR900 & $10 \mathrm{MHz}$ to $8.5 \mathrm{GHz}$ & 0.002 to 0.004 \\
GPC-7 & $10 \mathrm{MHz}$ to $18 \mathrm{GHz}$ & 0.003 to 0.005 \\
Type N & $10 \mathrm{MHz}$ to $18 \mathrm{GHz}$ & 0.003 to 0.007 \\
$3.5 \mathrm{~mm}$ & $10 \mathrm{MHz}$ to $33 \mathrm{GHz}$ & 0.006 to 0.013 \\
$2.92 \mathrm{~mm}$ & $10 \mathrm{MHz}$ to $40 \mathrm{GHz}$ & 0.008 to 0.020 \\
$2.4 \mathrm{~mm}$ & $10 \mathrm{MHz}$ to $50 \mathrm{GHz}$ & 0.014 to 0.038
\end{tabular}

*See Chapter 1, Section $\mathrm{H}$ for more information about uncertainty.

\section{Waveguide One-Port Devices (61280S- 61294S)}

The terminations must be fitted with standard waveguide flange connectors. The faces of these flanges should be machined flat and smooth and should not contain protrusions or indentations. Considerable care must be exercised in keeping the mating connector flange surfaces smooth and clean. Accurate alignment of the waveguide joint and flanges is also very important. The back of the flange which makes contact with the connecting bolts should be nominally flat and free of soft materials, including paint. The connecting holes of the flange should be symmetrically and accurately aligned to the rectangular waveguide opening. Available calibration frequencies are listed in Table 9.18. 
Table 9.18. Measurement Ranges and Uncertainties for Waveguide One-Port Devices

\begin{tabular}{lccc}
$\begin{array}{c}\text { Waveguide } \\
\text { Band }\end{array}$ & $\begin{array}{c}\text { Frequency } \\
\text { Range } \\
\text { (GHz) }\end{array}$ & Intervals & $\begin{array}{c}\text { Expanded } \\
\text { Uncertainty* } \\
\left|S_{\mathbf{L}}\right| \begin{array}{c}\text { and }\left|S_{\mathbf{2 2}}\right| \\
\text { (dB) }\end{array}\end{array}$ \\
\hline WR90 & 8.2 to 12.4 & $200 \mathrm{MHz}$ & 0.005 \\
WR62 & 12.4 to 18 & $250 \mathrm{MHz}$ & 0.002 \\
WR42 & 18 to 26.5 & $1 \mathrm{GHz}$ & 0.004 \\
WR28 & 26.5 to 40 & $1 \mathrm{GHz}$ & 0.004 \\
WR22 & 33 to 50 & $1 \mathrm{GHz}$ & 0.009 \\
WR15 & 50 to 75 & Specify & 0.009 \\
WR10 & 92 to 98 & Specify & 0.012 \\
\hline
\end{tabular}

* See Chapter 1, Section $\mathrm{H}$ for more information about uncertainty.

\section{Phase Shifters, RF and Microwave} (61295S-61297S)

The specific phase shift services are available on a limited basis. Because of the specialized nature of coaxial phase shifting components, prior discussions should be held with NIST staff before submission of any devices to NIST. Items to be calibrated must be fitted with connectors having a know plane of reference, such as sexless precision connectors, or Type N connectors meeting Mil. Std. C39012. The phase angle measured is $\Psi+360 n$, where $n$ is an integer. The value of $n$ is not determined. The expanded uncertainty* is $0.5^{\circ}$.

For rectangular waveguide, the measurement services are normally limited to phase shift difference. Measurements are made on continuously variable waveguide phase shifters with the zero value of the scale as the nominal reference position. The expanded uncertainty* is typically $0.5^{\circ}$.
References- $S$-Parameters of Passive 1- and 2-Port Devices

Measurements of the characteristic Impedance of coaxial Air Line Standards, J. R. Juroshek and G. M. Free, IEEE Trans. on MTT, 42 (2), 186-191 (Feb. 1994).

Basic RF and Microwave Measurements: A Review of Selected Programs, A. J. Estin, J. R. Juroshek, R. B. Marks, F. $\mathrm{R}$. Clague, and J. Wayde Allen, Metrologia 29, 35-151 (1992).

"Thru-Reflect-Line": An Improved Technique for Calibrating the dual Six-Port Automatic Network Analyzer, G. F. Engen and C. A. Hoer, IEEE Trans. Micr. Theory Tech. MTT-27, 987 (Dec. 1979).

A Network Analyzer Incorporating Two Six-Port Reflectometers, C. A. Hoer, IEEE Trans. Micr. Tech. MTT-25, 1070 (Dec. 1977).

The Six-Port Reflectometer: An Alternative Network Analyzer, G. F. Engen, IEEE Trans. Micr. Theory Tech.

MTT-25, 1075 (Dec. 1977).

Application of Waveguide and Circuit Theory to the Development of Accurate Microwave Measurement Methods and Standards, R. W. Beatty, Natl. Bur. Stand. (U.S.), Monogr. 137 (Aug. 1973).

Specifications and Test Methods for Fixed and Variable Attenuators, dc to $40 \mathrm{GHz}$, IEEE Standard 474 (1973).

Basic Theory of Waveguide Junctions and Introductory Microwave network Analysis, D. M. Kearns and R. W. Beatty, Intl. Ser. of Monogr. in Electromag. Waves 13, 59, Pergammon Press, New York, NY (1967)

Electrical Parameters of Precision Coaxial, Air Dielectric Transmission Lines, R. E. Nelson and M. R. Coryell, Natl. Bur. Stand. (U.S.), Monogr. 96 (June 1966).
*See Chapter 1, Section $\mathrm{H}$ for more information about uncertainty. 


\section{(7) RF, Microwave, and Millimeter-Wave Measurements \\ G.3 High Accuracy Attenuation Measurements}

Technical Contacts:

$\begin{array}{lll}\text { Ronald A. Ginley } & \text { Jeft A. Jargon } & \text { Paula M. Hewitt } \\ \text { Tel:303/497-3634 } & \text { Tel:303/497-3596 } & \text { Adminstration and } \\ \text { Email:rginley@nist.gov } & \text { Email:jjargon@nist.gov } & \begin{array}{l}\text { Logistics } \\ \text { Tel:303/497-3753 } \\ \end{array} \\ & & \text { Email:paula.hewitt@nist.gov }\end{array}$

Mailing Address: M.C. 813.10,

National Institute of Standards and Technology,

325 Broadway,

Boulder, CO 80303-3328

Service

ID No.

61310C Coaxial Fixed and Variable Attenuators Measured at $30 \mathrm{MHz}$, Attenuation $0 \mathrm{~dB}$ to $120 \mathrm{~dB}$

61320C Waveguide Below-Cutoff (Piston) Attenuators, Coaxial Connectors Measured at $30 \mathrm{MHz}$, Attenuation $0 \mathrm{~dB}$ to $120 \mathrm{~dB}$ (Total Insertion Loss)

61330 Attenuation Measurements of Three-Port and Two-Port Devices at $1.25 \mathrm{MHz}, 0 \mathrm{~dB}$ and $6 \mathrm{~dB}$

61350C Coaxial Fixed and Variable Phase Shifters; Characteristics Phase Shift Difference; Precision Connectors; Measured at $30 \mathrm{MHz}$, Range $0^{\circ}$ to $360^{\circ}$

\section{Coaxial Fixed and Variable Attenuators (61310C)}

Coaxial fixed and variable attenuators are measured with reference to the NIST waveguide-below-cutoff (piston) attenuator at a fixed frequency of $30 \mathrm{MHz}$.

Coaxial attenuators are normally measured in a system having a characteristic impedance of $50 \Omega$. Typical expanded uncertainties* range from $0.01 \mathrm{~dB}$ to $1 \mathrm{~dB}$ depending on the nominal attenuation and connector repeatability.

\section{Waveguide-Below-Cutoff (Piston) Attenuator Measurements at $30 \mathrm{MHz}$ (61320C)}

Incremental attenuation is the change in attenuation of an adjustable attenuator

* See Chapter 1, Section H for more information about uncertainty. between a reference setting (usually zero) and any other setting. The same restraints of system conditions apply as for attenuation. The term "attenuation difference" is sometimes applied to this case and usually refers to two nonzero settings.

Measurements on waveguide belowcutoff (piston) attenuators are performed at $30 \mathrm{MHz}$. In any measurement, the maximum power delivered to the test attenuator is $400 \mathrm{~mW}$. If the attenuator cannot tolerate this power level, some reduction of measurement range will be required.

Piston attenuators are normally calibrated in a system having a characteristic impedance of $50 \Omega$. Since only measurements of incremental attenuation are made on this type of attenuator, Type $\mathrm{BNC}, \mathrm{C}, \mathrm{TNC}$, and similar connectors are acceptable, but precision connectors are preferred to reduce rf leakage. The uncertainties depend upon the quality of the attenuator and connectors, as well as upon the VSWR (voltage standing-wave ratio) of the attenuator, and the magnitude of attenuation. Typical Type B standard uncertainties* range from $0.003 \mathrm{~dB}$ to $0.005 \mathrm{~dB}$ per $10 \mathrm{~dB}$ of attenuation. Total insertion loss must be less than $120 \mathrm{~dB}$.

\section{Attenuation Measurements at $1.25 \mathrm{MHz}$ (61330S)}

An additional measurement service is available for attenuation measurements of special three-port devices at $1.25 \mathrm{MHz}$. A measurement system has been developed to measure the change in the ratio $S_{21} / S_{31}$ of special stable two-position, three-port devices sometimes called voltage doublers, at $1.25 \mathrm{MHz}$. The device must have an input for a 1.25 MHz source (port 1), a reference output (port 3), and an output (port 2) with a level switchable to two different values. The two levels of the bi-level output have a nominal ratio of $6.0206 \mathrm{~dB}$. 
If $P_{\mathrm{r} 1}$ is the reference power level when the bi-level output is at level $1\left(P_{\mathrm{b} 1}\right)$, and $P_{\mathrm{r} 2}$ is the reference power level when the bi-level output is at level $2\left(P_{\mathrm{b} 2}\right)$, then the parameter measured is given by the following equation:

$$
10 \log _{10}\left(\frac{P_{\mathrm{b} 1}}{P_{\mathrm{r} 1}}\right)-10 \log _{10}\left(\frac{P_{\mathrm{b} 2}}{P_{\mathrm{r} 2}}\right), \mathrm{dB}
$$

where the subscripts (1) and (2) refer to the switch positions 1 and 2 , respectively. The above is equivalent to

$$
10 \log _{10}\left|\frac{S_{21}(1) / S_{31}(1)}{S_{21}(2) / S_{31}(2)}\right|^{2} .
$$

The loads presented to the two outputs are $50 \Omega$. The device must allow the signal input to be of such strength that the bi-level output is at least $10 \mathrm{~mW}$ in the high-level position.

The Type A standard uncertainty* of the measurement system in measuring a $6 \mathrm{~dB}$ change in attenuation is $8.2 \mu \mathrm{B}$. Typical Type B standard uncertainties* are on the order of $0.3 \mu \mathrm{B}$ to $0.5 \mu \mathrm{B}$ $\left(1 \mu \mathrm{B}=10^{-5} \mathrm{~dB}\right)$. Two-port step attenuators having a nominal change in attenuation of $6 \mathrm{~dB}$ can also be measured by this system at $1.25 \mathrm{MHz}$.

\section{Phase Shifters (61350C)}

The specific phase shift services are available on a limited basis depending on other demands and staff availability. Measurements not listed may possibly be provided if sufficient advance notice is

* See Chapter I, Section $\mathrm{H}$ for more information about uncertainty. given. The cost of such services must be negotiated and will, in general, be higher than the established phase shift services. Consultation by telephone or written correspondence is suggested. Often a measurement technique can be suggested that will permit the customer to perform calibrations in-house with appropriate reference to other NIST-supported standards. The expanded uncertainty* is $0.5^{\circ}$.

\section{References-High Accuracy Attenua- tion Measurements}

A $30 \mathrm{MHz}$ Comparison Receiver, J. A. Jargon, Asia-Pacific Microwave Conf. Proc., Taejon, Korea (Oct. 1995).

A Revised Uncertainty Analysis for the NIST $30 \mathrm{MHz}$ Attenuation Calibration System, J. A. Jargon, Proc. of the Meas. Sci. Conf., Pasadena, CA (Jan. 1994).

Basic RF and Microwave Measurements: A Review of Selected Programs, A. J. Estin, J. R. Juroshek, R. B. Marks, F. R. Clague, and J. Wayde Allen, Metrologia 29, 135-151 (1992).

A Calibration Service for $30 \mathrm{MHz}$ Attenuation and Phase Shift, R.T. Adair and D. H Russell, Natl. Bur. Stand. (U.S), SP 250-32 (1988)

1.25 MHz Attenuation Measurement System, R. A. Ginley and C. M. Allred, IEEE Trans. Instrum. Meas., IM-35 (4), Pt. 1 (Dec. 1986).

Specifications and Test Methods for Fixed and Variable Attenuators, dc to $40 \mathrm{GHz}$, IEEE Standard 474 (1973).

UHF and Microwave Phase Shift Measurements, D. A. Ellerbach, Proc. IEEE 55 (6), 960 (June 1967). 


\section{(2) RF, Microwave, and Millimeter-Wave Measurements G.4 Thermal Noise Measurements}

\author{
Technical Contacts:
}

James P. Randa

Tel:303/497-3150

Email:jranda@nist.gov

\author{
Chriss Jones \\ Tel:303/497-5958 \\ Email:jones@boulder. \\ nist.gov
}

Paula M. Hewitt

Adminstration and

Logistics

Tel:303/497-3753

Email:paula.hewitt@

nist.gov

Fax:303/497-3970
Mailing Address: M.C. 813.10,

National Institute of Standards and Technology,

325 Broadway,

Boulder, CO 80303-3328

\begin{tabular}{|c|c|c|c|}
\hline $\begin{array}{l}\text { Service } \\
\text { ID No. }\end{array}$ & Frequency & Connector & $\begin{array}{l}\text { Device Requirements/ } \\
\text { Service }\end{array}$ \\
\hline $61410 \mathrm{~S}$ & $\begin{array}{l}30 \mathrm{MHz} \\
60 \mathrm{MHz}\end{array}$ & $\begin{array}{l}\text { Coaxial } \\
\text { N Precision (PIN) } \\
\text { GPC } 3.5 \text { (PIN) } \\
\text { GPC } 7 \\
14 \mathrm{~mm}\end{array}$ & $\begin{array}{l}\text { Temperature }<15000 \mathrm{~K} \\
(\text { ENR }<17 \mathrm{~dB}) \\
\text { VSWR }<1.2\end{array}$ \\
\hline \multirow[t]{2}{*}{$61420 \mathrm{~S}$} & $\begin{array}{l}1.0 \mathrm{GHz} \text { to } \\
12.0 \mathrm{GHz} \\
\text { Continuous } \\
\text { Frequencies }\end{array}$ & $\begin{array}{l}\text { Coaxial } \\
\text { N Precision (PIN } \\
\text { GPC } 3.5 \text { (PIN) } \\
\text { GPC } 7\end{array}$ & $\begin{array}{l}\text { Temperature }<15000 \mathrm{~K} \\
(\text { ENR }<17 \mathrm{~dB}) \\
\text { Reflection Coefficient }<0.2\end{array}$ \\
\hline & $\begin{array}{l}1 \mathrm{GHz} \text { to } \\
4 \mathrm{GHz}\end{array}$ & $14 \mathrm{~mm}$ & \\
\hline $61425 \mathrm{~S}$ & $\begin{array}{l}12.4 \mathrm{GHz} \text { to } \\
18.0 \mathrm{GHz} \\
\text { Continuous } \\
\text { Frequencies }\end{array}$ & $\begin{array}{l}\text { Coaxial } \\
\text { N Precision (PIN) } \\
\text { GPC } 3.5 \text { (PIN) } \\
\text { GPC } 7\end{array}$ & $\begin{array}{l}\text { Temperature }<15000 \mathrm{~K} \\
(\text { ENR }<17 \mathrm{~dB}) \\
\text { Reflection Coefficient }<0.2\end{array}$ \\
\hline $61430 S$ & $\begin{array}{l}18.0 \mathrm{GHz} \text { to } \\
26.0 \mathrm{GHz} \\
\text { Continuous } \\
\text { Frequencies }\end{array}$ & $\begin{array}{l}\text { Coaxial } \\
\text { GPC } 3.5(\text { PIN })\end{array}$ & $\begin{array}{l}\text { Temperature }<15000 \mathrm{~K} \\
(\mathrm{ENR}<17 \mathrm{~dB}) \\
\text { Reflection Coefficient }<0.2\end{array}$ \\
\hline $61450 \mathrm{~S}$ & $\begin{array}{r}8.2 \mathrm{GHz} \\
9.0 \mathrm{GHz} \\
9.5 \mathrm{GHz} \\
9.8 \mathrm{GHz} \\
10.0 \mathrm{GHz} \\
10.5 \mathrm{GHz} \\
11.2 \mathrm{GHz} \\
11.8 \mathrm{GHz} \\
12.4 \mathrm{GHz}\end{array}$ & $\begin{array}{l}\text { Waveguide } \\
\text { WR90 }\end{array}$ & $\begin{array}{l}\text { Temperature between } \\
9000 \mathrm{~K} \text { and } 17000 \mathrm{~K} \\
(14.6 \mathrm{~dB}<\mathrm{ENR}<17 \mathrm{~dB}) \\
\text { Reflection Coefficient }<0.09\end{array}$ \\
\hline
\end{tabular}

\begin{tabular}{|c|c|c|c|}
\hline $\begin{array}{l}\text { Service } \\
\text { ID No. }\end{array}$ & Frequency & Connector & $\begin{array}{c}\text { Device Requirements/ } \\
\text { Service }\end{array}$ \\
\hline $61455 \mathrm{~S}$ & $\begin{array}{l}12.4 \mathrm{GHz} \text { to } \\
18.0 \mathrm{GHz} \\
\text { Continuous } \\
\text { Frequencies }\end{array}$ & $\begin{array}{l}\text { Waveguide } \\
\text { WR62 }\end{array}$ & $\begin{array}{l}\text { Temperature }<15000 \mathrm{~K} \\
(\text { ENR }<17 \mathrm{~dB}) \\
\text { Reflection Coefficient }<0.2\end{array}$ \\
\hline $61460 \mathrm{~S}$ & $\begin{array}{l}18.0 \mathrm{GHz} \text { to } \\
26.0 \mathrm{GHz} \\
\text { Continuous } \\
\text { Frequencies }\end{array}$ & $\begin{array}{l}\text { Waveguide } \\
\text { WR42 }\end{array}$ & $\begin{array}{l}\text { Temperature }<15000 \mathrm{~K} \\
(\text { ENR }<17 \mathrm{~dB}) \\
\text { Reflection Coefficient }<0.2\end{array}$ \\
\hline $61465 S$ & $\begin{array}{l}26.5 \mathrm{GHz} \text { to } \\
40.0 \mathrm{GHz} \\
\text { Continuous } \\
\text { Frequencies }\end{array}$ & $\begin{array}{l}\text { Waveguide } \\
\text { WR28 }\end{array}$ & $\begin{array}{l}\text { Temperature }<15000 \mathrm{~K} \\
(\text { ENR }<17 \mathrm{~dB}) \\
\text { Reflection Coefficient }<0.2\end{array}$ \\
\hline $61495 S$ & Special Noise & rature Measure & nts, by Prearrangement \\
\hline
\end{tabular}

Noise Temperature Measurements (61410S-61465S)

Noise temperature measurements are available on single-port, coaxial and rectangular-waveguide noise sources under conditions of continuous, unmodulated operation. Precision coaxial connectors or clean, smooth, and flat standard EIA waveguide flanges are required. Measurement results on devices submitted with adapters attached may apply only to the source/ adapter combination. Complete operating instructions and special electronic connectors should be supplied, and pertinent operating conditions (voltages, circuits, etc.) should be specified for the noise source to be measured. Devices submitted that are not of sufficient quality or not mechanically compatible with the measuring system will be rejected, and an appropriate fee will be charged. Availability of measurements at specific frequencies and for various connector types are specified above. An attempt is being made to expand services to include additional types of precision connectors and waveguide sizes. 
The measurement uncertainty varies with noise temperature, reflection coefficient, and source and connector stability. The relative expanded uncertainty* typically lies between $0.9 \%$ and $1.5 \%$ of the noise temperature.

\section{Special Noise Temperature Measure- ments (61495S)}

Measurements of electromagnetic thermal noise other than those listed above can sometimes be arranged on a case-bycase basis. These may include measurements through adapters, measurements out of the parameter ranges specified above, and measurements on systems currently under development. Such measurements should be discussed with one of the technical contacts before submitting a device for calibration.

\section{References (Noise Temperature Measurements)}

Radiometer Equation for Noise Comparison Radiometers, D. F. Wait, IEEE Trans. on Instr. \& Meas. 44(2), pp. 336-339 (April, 1995).
* See Chapter 1, Section H for more information about uncertainty.
Uncertainties of the NIST Coaxial Noise Calibration System, S. P. Pucic, 1994 Conference on Precision Electromagnetic Measurements Digest, (Boulder, CO, 6/27/94-7/1/94) 254-255.

Basic RF and Microwave Measurements: A Review of Selected Programs, A. J. Estin, J. R. Juroshek, R. B. Marks, F. R. Clague, and J. Wayde Allen, Metrologia 29, 135-151 (1992).

Radiometer Equation and Analysis of Systematic Errors for the NIST Automated Radiometers, W. C. Daywitt, NIST Tech. Note 1327 (March, 1989).

Horn Design Equations for the NBS Horn-Type Nose Standards, W. C. Daywitt, NBS Internal Report NBSIR 87-3073 (August 1987).

A Coaxial Noise Standard for the $1 \mathrm{GHz}$ to $12.4 \mathrm{GHz}$ Frequency Range, W. C. Daywitt, NBS Tech. Note 1074 (March, 1984).

Noise Standards, Measurements, and Receiver Noise Definitions, C. K. S. Miller, W.C. Daywitt, and M. G. Arthur, Proc. IEEE 55 (6), 865-877 (June 1967). 
RF, Microwave and Millimeter Wave

Measurements

\title{
G.5 Dimensional Verification of Coaxial Air Line Standards
}

\section{Technical Contacts:}

\author{
George M. Free \\ Tel:303/497-3609 \\ John R. Juroshek \\ Glen V. Sherwood \\ Tel:303/497-5362 \\ Tel:303/497-3939 \\ Email:gfree@nist.gov \\ Email:jjuroshek@nist.gov \\ Email:gsherwood@nist.gov \\ Paula M. Hewitt \\ Administration and Logistics \\ Tel:303/497-3753 \\ Email:paula.hewitt@nist.gov \\ Fax:303/497-3970
}

Mailing Address: M.C. 813.10,

National Institute of Standards and Technology,

325 Broadway,

Boulder, CO 80303-3328

\section{Service}

ID No. Items

61510S Dimensional Measurement of Air Lines and

Verification of Characteristic Impedance

from Dimensional Measurements, by Prearrangement

\section{Coaxial Air Lines (61510S)}

Dimensional measurements are made on the inner and outer conductors of a beadless, coaxial, air line standard. The characteristic impedance of the air line standard is then computed from these dimensional measurements. The service is currently available for $1.85 \mathrm{~mm}, 2.4 \mathrm{~mm}, 2.92 \mathrm{~mm}, 3.5 \mathrm{~mm}$, GPC-7, $14 \mathrm{~mm}$, and Type $\mathrm{N}$ air line standards. The computations for characteristic impedance is made over the normal operating frequency range of the air line standard. Consultation is available by telephone. 


\section{(2) RF, Microwave, and Millimeter Wave Measurements \\ G.6 Dielectric and Magnetic Material Measurements}

Technical Contacts:
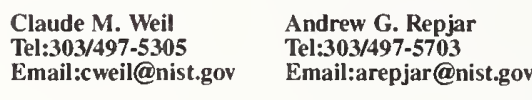

Paula M. Hewitt

Administrative and

Logistics

Tel:303/497-3753

Email:paula.hewitt@nist.gov

Fax:303/497-3970

Mailing Address: M.C. 813.10,

National Institute of Standards and Technology,

325 Broadway,

Boulder, CO 80303-3328

Service

ID No.

Items

61620S Special Tests for Dielectric and Magnetic Materials $1 \mathrm{kHz}$ to $60 \mathrm{GHz}$

61640S Special Consulting and Advisory Services for Dielectric and Magnetic Materials, by Prearrangement

\section{Special Tests for Dielectric and Magnetic Materials (61620S)}

A special-test measurement service is available for measuring the complex permittivity, $\epsilon^{*}$ and permeability, $\mu^{*}$ of dielectric and magnetic materials, as well as the surface resistance of conductors, at selected $\mathrm{RF} /$ microwave frequencies in the spectral range $1 \mathrm{kHz}$ to $60 \mathrm{GHz}$. The service is capable of characterizing fluids, powders, or bulk solids at room temperatures $\left(23^{\circ} \mathrm{C}\right)$ and, in some cases, over a temperature range of approximately $-80^{\circ} \mathrm{C}$ to $150^{\circ} \mathrm{C}$. Customers interested in high frequency material characterization measurements should contact NIST staff to discuss their specific needs. The optimal measurement technique used is selected from a number of measurement techniques developed at NIST. The selection depends on a number of factors including whether the material is in fluid, powder or solid form, the volume of material available, its shape factor (for solids), its anticipated loss factor, whether the material is anisotropic, and the desired measurement frequencies and ambient temperature. The resulting measurement uncertainties depend on the technique selected as well as the nominal permittivity of the material under test.

Upon request, NIST staff will prepare a detailed cost quotation that includes estimates of the measurement uncertainties. For the case of solids, each measurement method requires accurately machined test samples with opticalstandard tolerances for dimensions, flatness and parallelism. NIST can either perform the machining of test samples, the cost of which is included in the price quotation, or furnish drawings of sample specifications for the customer to perform the necessary machining.

The measurement techniques available at NIST can be divided into three categories: a) cavity resonator methods for low-loss materials ( $\tan \delta<0.01$ ),

b) broadband transmission line methods for medium to high-loss materials, and c) low-frequency impedance measuring methods. Most cavity resonators operate at frequencies above $100 \mathrm{MHz}$ and usually provide single-frequency data, unless the resonators are tunable or can be operated on higher-order modes. Data are usually provided in tabular form. In general, better measurement uncertainties* are achievable using cavities and are about $0.5 \%$ for $\epsilon^{\prime}$.

Broadband transmission line techniques include coaxial air lines and waveguides of various dimensions, as well as 1- and 2-port open-ended coaxial probe methods. Measured broadband data are normally provided as linear or logarithmic plots of $\epsilon^{\prime}, \epsilon^{\prime \prime}$ and $\mu^{\prime}, \mu^{\prime \prime}$ as a function of frequency with uncertainties included; relative uncertainties of $5 \%$ to $10 \%$ are typical. The low-frequency impedance measuring methods typically cover the frequency range $1 \mathrm{kHz}$ to $10 \mathrm{MHz}$ and involve measuring capacitance changes for dielectric materials and inductance changes for magnetic materials.

*See Chapter 1, Section $\mathrm{H}$ for more information about uncertainty. 


\section{References-Dielectric and Magnetic Material Measurements}

Complex Permeability of Demagnetized Microwave Ferrites Near and Above Gyromagnetic Resonance, J. Krupka et al, IEEE Trans. Mag. 32 (3) pp. 1924 1933 (May 1996).

Dielectric and Magnetic Measurements from $-50{ }^{\circ} \mathrm{C}$ to $200{ }^{\circ} \mathrm{C}$ and in the Frequency Band $50 \mathrm{MHz}$ to $2 \mathrm{GHz}$, J. Baker-Jarvis et al, NIST Internal Report 5045 (March 1996).

Dielectric Measurements of PrintedWiring and Circuit Boards, Thin Films, and Substrates: An Overview, J. Baker-Jarvis et al, MRS Symp. Proc. 381, pp. 153-164 (April 1995).

Analysis of an Open-Ended Coaxial Probe with Lift-Off for Nondestructive
Testing, J. Baker-Jarvis et al, IEEE Trans I\&M, 43 (5) pp 711-718 (Oct. 1994).

Transmission/Reflection and Short-

Circuit Line Methods for Measuring Permittivity and Permeability,

J. Baker-Jarvis et al, NIST Tech. Note 1355-R (Dec. 1993).

The NIST 60-mm Diameter Cylindrical Cavity Resonator: Performance Evaluation for Permittivity Measurements, E J. Vanzura et al, NIST Technical Note 1354 (Aug. 1993).

NIST Measurement Service for Electromagnetic Characterization of Materials, J. H. Grosvenor, NIST Internal Report 5006 (Aug. 1993).

Shielded Open-Circuited Sample Holders for Dielectric and Magnetic Measurements of Liquids and Powders, J. Baker-Jarvis et al, NIST Internal Report 5001 (March 1993). 


\section{Electromagnetic Field Strength
and Antenna Measurements H.1 Microwave Antenna Parameter Measurements}

\author{
Technical Contacts:
}

$\begin{array}{lll}\begin{array}{l}\text { Andrew G. Repjar } \\ \text { (63100S-63400S) }\end{array} & \begin{array}{l}\text { Katherine MacReynolds } \\ (63100 S)\end{array} & \begin{array}{l}\text { Michael H. Francis } \\ (63200 S)\end{array} \\ \text { Tel:303/497-5703 } & \begin{array}{l}\text { Tel:303/497-3471 } \\ \text { Email:arepjar@nist.gov }\end{array} & \begin{array}{l}\text { Tel:303/497-5873 } \\ \text { nist.gov }\end{array} \\ & & \text { Email:mfrancis@nist.gov } \\ \text { Paula M. Hewitt } & \\ \text { Administration and Logistics } & \\ \text { Tel:303/497-3753 } & \\ \text { Email:paula.hewitt@nist.gov } & \\ \text { Fax:303/497-3970 } & \end{array}$

Mailing Address: M.C. 813.10,

National Institute of Standards and Technology,

325 Broadway,

Boulder, CO 80303-3328

Shipping Address: Room 1300, Bldg. 24,

National Institute of Standards and Technology,

325 Broadway,

Boulder, CO 80303-3328

Service

ID No. Items

63100S Gain and Polarization Calibrations of Standard Antennas Using Extrapolation Range

63200 S Measurement of Pattern, Gain, and Polarization of Arbitrary Antennas Using Near-Field Scanning Techniques

63300 Special Test Service for Calibration of Probes Used with Near-Field Scanning Facilities

63400 S Special Consulting, Advisory, and Other Services
Antenna Parameter Measurements (Microwave)-General Information

Accurate measurements of antenna gain, pattern, and polarization are generally available from about $1 \mathrm{GHz}$ to about $75 \mathrm{GHz}$. However, because the measurement accuracy, capability, and cost depend on the frequency, type, and size of antenna, and the parameters to be measured, a particular measurement service must be negotiated in advance.
Antennas submitted for evaluation should be mechanically and electrically stable in order to retain a calibration for a significant length of time. Antennas with either coaxial or waveguide connectors can be measured; however, if coaxial connectors are employed, they should be precision connectors to minimize uncertainties due to a lack of connector repeatability. In particular, the use of SMA and APC-7 connectors is strongly discouraged because of poor connector repeatability. The following methods and facilities are used for these measurements.

\section{Gain and Polarization Calibrations of Standard Antennas Using Extrapola- tion Range (63100S)}

This calibration service is offered primarily for determining the absolute on-axis gain and polarization of standard gain horns, which, in turn, are used as reference standards in determining the gain and polarization of other antennas by the gain comparison technique. In the extrapolation method, three antennas are normally utilized, and three pairwise combinations are determined. The received signal transmitted between each pair of antennas is measured as a function of the separation distance between the antennas. The antennas need not be identical, and no assumptions concerning the polarization are required. The method is not well suited for pattern measurements but is the most accurate technique known for absolute gain and polarization measurements. For gain measurements from $2 \mathrm{GHz}$ to $30 \mathrm{GHz}$, the uncertainties are typically $0.10 \mathrm{~dB}$; above $30 \mathrm{GHz}$, the uncertainties are typically $0.15 \mathrm{~dB}$. Uncertainties of $0.05 \mathrm{~dB} / \mathrm{dB}$ for polarization axial ratio measurements are typical. There are antenna size limitations associated with existing NIST extrapolation ranges. These limitations depend on the type of antenna, the frequency, and the desired measurements and accuracies. Therefore, negotiations must be conducted prior to submitting antennas for calibration to ascertain whether all requirements can be met. 
Measurement of Pattern, Gain, and Polarization of Arbitrary Antennas Using Near-Field Scanning Techniques (63200S)

With this technique, gain, pattern, and polarization parameters are calculated from near-field amplitude and phase measurements taken over a surface close to the test antenna. The absolute gain can be determined to within about $0.2 \mathrm{~dB}$, the polarization axial ratio to within about $0.10 \mathrm{~dB} / \mathrm{dB}$, and side lobe levels can be obtained down to $-50 \mathrm{~dB}$ or $-60 \mathrm{~dB}$. The exact uncertainties in these parameters will depend on such factors as the frequency, type and size of antenna. Antennas with apertures up to about $3 \mathrm{~m}$ in diameter can be managed. Measurements can be made from about $1 \mathrm{GHz}$ to about $75 \mathrm{GHz}$. Measurements are most commonly made over a plane surface in front of the antenna being evaluated, but the capability also exists for measuring over a cylindrical or spherical surface surrounding the antenna when it is advantageous to do so. Calibrated probes are normally required for these measurements. These near-field scanning measurements are offered as a special-test service because nearly every measurement is unique and it is difficult to build up a statistical history as required for a regular calibration service.

\section{Special-Test Service for Calibrating Probes Used with Near-Field Scanning Facilities (63300S)}

This special-test service is available to support those organizations that have established their own near-field measurement facilities and need to characterize the probes used in performing the nearfield measurements. In order to achieve accurate results with either the planar, cylindrical, or spherical near-field method, the transmitting or receiving properties of the probe must be known. With this information, the measured data can be corrected for the nonideal pattern and polarization properties of the probe.
Probes are characterized by a three-step process: (1) The on-axis gain and polarization properties are measured using the extrapolation technique described above; (2) the far-field amplitude and phase patterns are measured for two nominally orthogonal polarizations of the incident field; and (3) the on-axis and pattern data are combined to obtain the probe correction coefficients at the desired lattice points for the measurement surface specified by the customer. The final output consists of a computer disk containing the measured far-field patterns and the calculated probe coefficients. Typical types of probes are open-ended waveguides and small horns. Both linearly and circularly polarized probes can be evaluated.

\section{Special Consulting, Advisory, and Other Services (63400S)}

A variety of special consultation and advisory services related to the measurements described above are available upon request. These services are offered to disseminate NIST technologies and to assist other organizations in establishing their own measurement facilities and capabilities. Included are cooperative measurement programs. A customer actually participates directly in the measurement of his device in order to become familiar with the measurement methods and assist in the analysis of the results. This is a useful approach when one is attempting to establish a new measurement capability that is related to or based upon NIST measurement techniques.

\section{References-Microwave Antenna Parameter Measurements}

A Certification Plan for a Planar Near-

Field Range Used for High-

Performance Phased-Array Testing, M. H. Francis, A. G. Repjar, and D. P. Kremer, NIST Internal Report 3991 (July 1992). 
Improvements in Polarization Measurements of Circularly Polarized Probes, A. C. Newell, D. P. Kremer, J. R. Guerrieri, Proceedings of the Antenna Measurement Techniques Association, pp. 1-30 through 1-35 (October 1989). Antenna Calibrating Standards Using $\mathrm{CW}$ and Pulsed-CW Measurements and the Planar Near-Field Method, D. P. Kremer and A. G. Repjar, Proceedings, Antenna Meas. and Techniques Assoc., pp. 13-21 through 1329 (September 1988).

Effect of Random Errors in Planar NearField Measurement, A. C. Newell and C. F. Stubenrauch, IEEE Trans. Antennas and Propagation, Special Issue on Near-Field Scanning, 36 (6), 769-773 (June 1988).

Accurate Determination of Planar NearField Correction Parameters for Linearly Polarized Probes, A. G. Repjar, A. C. Newell, and M. H. Francis, IEEE Trans. Antennas and Propagation, Special Issue on Near-Field Scanning, 36 (6), 855-868 (June 1988).

Improved Polarization Measurements Using a Modified Three-Antenna Technique, IEEE Trans. Antennas and Propagation, Special Issue on NearField Scanning, 36 (6), 852-854 (June 1988).

Gain and Power Parameter Measurements Using Planar Near-Field Techniques, A. C. Newell, R. Ward, and E. McFarlane, IEEE Trans. Antennas and Propagation, Special Issue on Near-Field Scanning, 36 (6), 792-803 (June 1988).
Error Analysis Techniques for Planar Near-Field Measurements, A. C. Newell, IEEE Trans. Antennas and Propagation, 36, 754-768 (June 1988).

Extrapolation Range Measurements for Determining Antenna Gain and Polarization, A. G. Repjar, A. C. Newell, and D. T. Tamura, NBS Tech. Note 1311 (August 1987).

The Determination of Near-Field Correction Parameters for Circularly Polarized Probes, A. C. Newell, M. H. Francis, D. P. Kremer, Proceedings Antenna Measurement Techniques Assoc. , pp. 3A3-1 through 3A3-29 (October 1984).

A Method of Determining the Mismatch Correction in Microwave Power Measurements, G. Engen, IEEE Trans. Instrum. Meas. IM-17, 4 (Dec. 1968).

Bolometric Microwave Power Calibration Techniques at the National Bureau of Standards, R. F. Desch and R. E. Larson, IEEE Trans. Instrum. Meas. IM-12, 1 (June 1963).

A Bolometer Mount Efficiency Measurement Technique, G. Engen, J. Res. Natl. Bur. Stand. (U. S.), 65C, 113 (Apr. -June 1961).

A Transfer Instrument for the Intercomparison of Microwave Power Meters, G. Engen, IRE Trans. Instrum. Meas. 19, 202 (Sept. 1960).

A Refined X-Band Microwave Microcalorimeter, G. Engen, J. Res. Natl. Bur. Stand. (U.S.), 63C, 77 (1959). 
Electromagnetic Field Strength and Antenna Measurements H.2 Field Strength Parameter
Measurements

\author{
Technical Contacts:
}

Kenneth H. Cavcey

Email:cavcey@nist.gov Tel:303/497-3995

\author{
Motohisa Kanda \\ Tel:303/497-5320 \\ Email:mkanda@nist.gov
}

Paula M. Hewitt Administration and Logistics

Tel:303/497-3753 Email:paula.hewitt@ nist.gov

Fax:303/497-3970
Mailing Address: M.C. 813.10,

National Institute of Standards and Technology,

325 Broadway,

Boulder, CO 80303-3328

\section{Service}

ID No.

Items

64100S Special-Test Service for Antennas/Field Strength Measurements, Utilizing the Transverse

Electromagnetic (TEM) Cell Method ( $10 \mathrm{kHz}$ to $300 \mathrm{MHz}$ )

$64200 S$ Special-Test Service for Antennas/Field Strength Measurements, Utilizing the Open Area Test Site and Standard Antenna Method

$64300 S$ Special-Test Service for Antennas/Field Strength/ Reflectivity Measurements, Utilizing the Anechoic Chamber and Standard Field Method

Special-Test Service for Antennas/Field Strength Measurements, Utilizing the Transverse Electromagnetic (TEM) Cell Method (64100S)

Standard electromagnetic fields are generated in TEM cells and used to calibrate electrically small antennas and antenna systems used for electromagnetic field probes in the frequency range $10 \mathrm{kHz}$ to $300 \mathrm{MHz}$.
Special-Test Service for Antennas/Field Strength Measurements, Utilizing the Open Area Test Site and Standard Antenna Method (64200S)

These measurements include calibration of antenna factor and gain of antennas used in conjunction with field strength meters, and of electrically small antennas used in electromagnetic field probes. The following methods and facilities are used for these measurements:

A. Dipoles, log-periodic, and other antennas (25 MHz to $1000 \mathrm{MHz}$ ) are used to generate electromagnetic fields which are used for calibrating various antennas and electromagnetic field probes. The field strength is established using the standard receiving antenna method.

B. Monopoles ( $30 \mathrm{kHz}$ to $300 \mathrm{MHz}$ ) are used to generate standard electric fields for calibrating antennas and electromagnetic field probes.

C. Loop antennas (14 kHz to $50 \mathrm{MHz}$ ) are used to generate standard magnetic fields for calibrating loop antennas used in conjunction with field strength meters.

Special-Test Service for Antennas/Field Strength Measurements, Utilizing the Anechoic Chamber and Standard Field Method (64300S)

A. Open-end waveguides $(200 \mathrm{MHz}$ to $450 \mathrm{MHz}$ ) are used to generate standard electromagnetic fields for calibrating antennas and electromagnetic field probes.

B. Pyramidal horns $(0.45 \mathrm{GHz}$ to $40 \mathrm{GHz}$ ) are used to generate standard electromagnetic fields for calibrating antennas and electromagnetic field probes.

Table 9.19 summarizes the field parameters, frequency ranges, and radiating antenna sources for the various NIST field strength measurement facilities. 
Table 9.19. Summary of NIST Standard Field Strength Facilities

\begin{tabular}{|c|c|c|c|}
\hline $\begin{array}{c}\text { Field } \\
\text { Parameter }\end{array}$ & $\begin{array}{l}\text { Type of } \\
\text { Measurement } \\
\text { Facility }\end{array}$ & $\begin{array}{c}\text { Frequency } \\
\text { Range }\end{array}$ & $\begin{array}{c}\text { Radiating } \\
\text { Antenna } \\
\text { Source }\end{array}$ \\
\hline $\mathrm{H}$ & $\begin{array}{l}\text { Wood } \\
\text { building }\end{array}$ & $\begin{array}{l}14 \mathrm{kHz} \text { to } \\
50 \mathrm{MHz}\end{array}$ & Loop $(20 \mathrm{~cm})$ \\
\hline E (vertical) & $\begin{array}{l}\text { Open Area Test Site } \\
\text { (ground screen) }\end{array}$ & $\begin{array}{l}30 \mathrm{kHz} \text { to } \\
30 \mathrm{MHz}\end{array}$ & $\begin{array}{l}\text { Short } \\
\text { monopole }\end{array}$ \\
\hline$E$ (vertical) & $\begin{array}{l}\text { Open Area Test Site } \\
\text { (ground screen) }\end{array}$ & $\begin{array}{l}30 \mathrm{kHz} \text { to } \\
30 \mathrm{MHz}\end{array}$ & $\begin{array}{l}\text { Quarter wave } \\
\text { length } \\
\text { monopole }\end{array}$ \\
\hline E (horizontal) & $\begin{array}{l}\text { Open Area Test Site } \\
\text { (ground screen) }\end{array}$ & $\begin{array}{l}30 \mathrm{MHz} \text { to } \\
300 \mathrm{MHz}\end{array}$ & $\begin{array}{l}\text { Dipole, log- } \\
\text { periodic } \\
\text { antenna, etc. }\end{array}$ \\
\hline $\mathrm{E}$ and $\mathrm{H}$ & TEM cell & $\begin{array}{l}25 \mathrm{MHz} \text { to } \\
1000 \mathrm{MHz}\end{array}$ & \\
\hline Power Density & $\begin{array}{l}\text { Anechoic } \\
\text { chamber }\end{array}$ & $\begin{array}{l}200 \mathrm{MHz} \text { to } \\
450 \mathrm{MHz}\end{array}$ & $\begin{array}{l}\text { Open-end } \\
\text { waveguide }\end{array}$ \\
\hline Power Density & $\begin{array}{l}\text { Anechoic } \\
\text { chamber }\end{array}$ & $\begin{array}{l}0.45 \mathrm{GH} \text { to } \\
46 \mathrm{GHz}\end{array}$ & $\begin{array}{l}\text { Pyramidal } \\
\text { horn }\end{array}$ \\
\hline
\end{tabular}

References-Electromagnetic Field Strength Parameter Measurements

Methodology for Standard Electromagnetic Field Measurements,

N. S. Nahman, M. Kanda, E. B.

Larsen, and M. L. Crawford, IEEE

Trans. Instrum. Meas. IM-34, 4

(Dec. 1985).

A Review of Electromagnetic Compatibility/Interference Measurement Methodologies, M. T. Ma,

M. Kanda, M. L. Crawford, and E. B. Larsen, Proc. IEEE, 73, 3, 388 (Mar. 1985). 


\section{Pulse Waveform Measurements}

\author{
Technical Contacts:
}

\begin{tabular}{|c|c|c|}
\hline $\begin{array}{l}\text { John P. Deyst } \\
\text { Tel:301/975-2437 } \\
\text { Email:john.deyst@nist.gov }\end{array}$ & $\begin{array}{l}\text { T. Michael Souders } \\
\text { Tel:301/975-2406 } \\
\text { Email:tsouders@nist.gov }\end{array}$ & $\begin{array}{l}\text { Denise D. Prather } \\
\text { Administration and } \\
\text { Logistics } \\
\text { Tel:301/975-4221 } \\
\text { Email:dprather@ } \\
\text { nist.gov }\end{array}$ \\
\hline
\end{tabular}

Mailing Address: Building 220, Room B146, National Institute of Standards and Technology, Gaithersburg, MD 20899-0001

\begin{tabular}{ll}
$\begin{array}{l}\text { Service } \\
\text { ID No. }\end{array}$ & Items \\
\hline $65100 S$ & Impulse Spectrum Amplitude $(50 \Omega)$ \\
$65200 S$ & Fast Repetitive Pulse Transition Parameters $(50 \Omega)$ \\
$65250 S$ & Fast Repetitive Pulse Settling Parameters $(50 \Omega)$ \\
$65300 S$ & Network Impulse Response (Transfer Function) of Coaxial \\
& Networks \\
$65400 S$ & Pulse Time Delay Interval
\end{tabular}

\section{Pulse Waveform Measurements- General Information}

NIST offers special-test services for a number of baseband pulse parameters. These are broken down into five categories: impulse spectrum amplitude, fast repetitive pulse transition parameters, fast repetitive pulse settling parameters, network impulse response, and pulse time delay interval. All of the special test services except the fast repetitive pulse settling parameters service are performed using the NIST Automatic Waveform Analysis and Measurement System (AWAMS). The AWAMS consists of a pulse generator, a calibrated wide-band sampling oscilloscope (input impedance $50 \Omega$, and nominal bandwidth of dc to $20 \mathrm{GHz}$, equivalent to a step response transition duration of $17.5 \mathrm{ps}$ ), and dedicated microcomputer system interfaced to the oscilloscope. The fast repetitive pulse settling parameters test service uses the NIST Sampling Comparator System (SCS), a NIST-designed sampling comparator oscilloscope, controlled by a microcomputer. The SCS has a $50 \Omega$ input impedance, nominal bandwidth of dc to $2.5 \mathrm{GHz}$ (equivalent to a step response transition duration of $140 \mathrm{ps}$ ), and settling $<1 \%$ within $1 \mathrm{~ns}$ and to $0.1 \%$ within $10 \mathrm{~ns}$. All of these special tests are performed at cost, and by prearrangement. References pertaining to these four services are located at the end of this section.

\section{Impulse Spectrum Amplitude (65100S)}

In response to calibration needs from the electromagnetic interference (EMI) community, NIST has a special-test service to calibrate the broadband spectrum amplitude output from impulse generators. Such generators can then be used as transfer standards of broadband impulsive noise for field calibration of spectrum analyzers and field intensity meters. The NIST special-test service uses the time-domain measurement/ frequency-domain deconvolution computational method for calibration of impulse generators. The AWAMS wideband (dc to $20 \mathrm{GHz}$ ) sampling oscilloscope is used to measure the time-domain waveform from the impulse generator. The spectrum amplitude, $S(f)$, versus frequency is then computed using fast Fourier transform (FFT). NIST will provide 50 to 200 data points over a wide frequency range for a single fee. NIST impulse spectrum amplitude measurement service capabilities are shown in Table 9.20. 
Table 9.20. NIST Impulse Generator Spectrum Amplitude Measurement Service Capabilities

\begin{tabular}{|c|c|c|}
\hline Parameter & Limits & Notes \\
\hline $\begin{array}{l}\text { Maximum impulse } \\
\text { amplitude without } \\
\text { attenuators }\end{array}$ & $600 \mathrm{mV}$ & 1,2 \\
\hline $\begin{array}{l}\text { Maximum impulse } \\
\text { amplitude with } \\
\text { external attenuators }\end{array}$ & $1.2 \mathrm{kV}$ & 2,3 \\
\hline$S(f)$ range & $\begin{array}{l}-15 \mathrm{~dB}(\mu \mathrm{V} / \mathrm{MHz}) \\
<\left[S(f)-S_{0}\right] \\
<+5 \mathrm{~dB}(\mu \mathrm{V} / \mathrm{MHz})\end{array}$ & 4,5 \\
\hline $\begin{array}{l}S(f), \text { expanded } \\
\text { uncertainty* }\end{array}$ & $\begin{array}{l}\text { Nominally } f<100 \mathrm{MHz}, 0.6 \mathrm{~dB} \\
100 \mathrm{MHz}<f<10 \mathrm{GHz}, 0.3 \mathrm{~dB} \\
4 \mathrm{GHz}<f<10 \mathrm{GHz}, 2.0 \mathrm{~dB}\end{array}$ & $4,5,7$ \\
\hline Frequency range & $10 \mathrm{MHz}$ to $10 \mathrm{GHz}$ & $4,5,7$ \\
\hline Frequency spacing & $\Delta f \geq 10 \mathrm{MHz}$ & 7 \\
\hline $\begin{array}{l}\text { Frequency, expanded } \\
\text { uncertainty }\end{array}$ & Nominally $0.3 \%$ & \\
\hline Load impedance & $50.0 \Omega$ & \\
\hline $\begin{array}{l}\text { Load impedance, } \\
\text { expanded uncertainty }\end{array}$ & Nominally $0.5 \Omega$ & 5,8 \\
\hline Trigger pulse amplitude & $\leq 1.0 \mathrm{~V}$ & 9 \\
\hline $\begin{array}{l}\text { Trigger pulse transition } \\
\text { duration }\end{array}$ & $<5 \mathrm{~ns}$ & 9 \\
\hline $\begin{array}{l}\text { Trigger to impulse } \\
\text { delay interval }\end{array}$ & $\geq 45 \mathrm{~ns}$ & 9 \\
\hline $\begin{array}{l}\text { Trigger to impulse } \\
\text { jitter }\end{array}$ & $<10 \mathrm{ps}, \mathrm{rms}$ & 9 \\
\hline
\end{tabular}

* See Chapter 1, Section $\mathrm{H}$ for more information about uncertainty.

Notes:

1. Impulse generator with an adjustable-amplitude impulse output will be calibrated with the generator adjusted to give a peak amplitude in the range of $300 \mathrm{mV}$ to $500 \mathrm{mV}$.

2. Impulse generators with fixed output amplitudes greater than $600 \mathrm{mV}$ must have the impulse attenuated to a level of $300 \mathrm{mV}$ to $500 \mathrm{mV}$ by $50 \Omega$ wideband coaxial attenuators.

3. Either customer-supplied or NIST attenuators may be used.

4. Data will not be given in the first spectrum null or at frequencies above. Typically about 100 data points are supplied.

5. Only for impulse amplitudes less than $600 \mathrm{mV}$.

6. If external attenuators and/or a delay-line network are used, then the uncertainties associated with the attenuator and/or network calibration are added to these values.

7. Measurements at frequency spacing less than $10 \mathrm{MHz}$ are available as a special test.

8. Load impedance uncertainty depends upon input impedance of external attenuators when used.

9. If the impulse generator does not supply a trigger output or if the trigger output does not have the proper characteristics, then a delay-line network will be used to provide a suitable trigger pulse.

\section{Fast Repetitive Pulse Transition Parameters, $50 \Omega$ (65200S)}

NIST offers a special-test service for fast repetitive pulses, for parameters related to the pulse transition. These parameters are measured with the NIST AWAMS described above. This service is optimized for measuring the durations of very fast pulse transitions (transition durations less than $350 \mathrm{ps,} \mathrm{i.e.,} \mathrm{band-}$ widths greater than $1 \mathrm{GHz}$ ). The parameters, ranges, and estimated uncertainty limits for this service are listed in Table 9.21.

Table 9.21. Uncertainty for Calibration of Fast Repetitive Pulse Transition Parameters

\begin{tabular}{|c|c|c|}
\hline Parameter & Range & $\begin{array}{c}\text { Typical } \\
\text { Expanded } \\
\text { Uncertainty* }\end{array}$ \\
\hline $\begin{array}{l}\text { Pulse Baseline } \\
(0 \% \text { level })\end{array}$ & $\pm 500 \mathrm{mV}$ & $(0.5 \% V+2 \mathrm{mV})$ \\
\hline $\begin{array}{l}\text { Pulse Topline } \\
\text { (100\% level) }\end{array}$ & $\pm 500 \mathrm{mV}$ & $(0.5 \% V+2 \mathrm{mV})$ \\
\hline Pulse Amplitude & $\pm 500 \mathrm{mV}$ & $(0.5 \% V+2 \mathrm{mV})$ \\
\hline $\begin{array}{l}\text { Pulse First Transition } \\
\text { Duration (Rise Time) }\end{array}$ & $10 \mathrm{ps}$ to $100 \mathrm{~ns}$ & $(0.5 \% t+3 \mathrm{ps})$ \\
\hline $\begin{array}{l}\text { Pulse Second Transition } \\
\text { Duration (Fall Time) }\end{array}$ & $10 \mathrm{ps}$ to $100 \mathrm{~ns}$ & $(0.5 \% t+3 \mathrm{ps})$ \\
\hline $\begin{array}{l}\text { Pulse Duration } \\
\text { (Between } 50 \% \text { levels) }\end{array}$ & $10 \mathrm{ps}$ to $100 \mathrm{~ns}$ & $(0.5 \% t+3 \mathrm{ps})$ \\
\hline
\end{tabular}

*See Chapter 1, Section H for more information about uncertainty. 


\section{Restrictions and Notes:}

1. Customer's device must generate a repetitive pulse with repetition rate between $100 \mathrm{~Hz}$ and $1 \mathrm{GHz}$.

Alternatively, NIST can provide a range of trigger signals.

2. Customer's device must have a nominal output impedance of 50 ohms.

3. Customer's device must have a precision coaxial output connector, e.g., SMA, APC-7, Type N, APC-3.5, etc.

4. Maximum pulse amplitude measurable without attenuators is $600 \mathrm{mV}$. For larger pulse amplitudes, the customer shall supply an attenuator to decrease the pulse amplitude to $600 \mathrm{mV}$ or less.

5. Pulse topline is measured only for "step-like" pulses.

6. Pulse second transition duration and pulse duration are measured only for "impulse-like" pulses.

Measurements of other pulse parameters or parameter ranges may be provided by special arrangement. Consulting and advisory services also are available.

\section{Repetitive Pulse Waveform Measure- ments, Including Settling Parameters (65250S)}

NIST offers a special-test service for measurement of repetitive pulse waveforms whose major frequency components are below $1 \mathrm{GHz}$. Waveform measurement data can be provided on diskette, along with a report of measurement uncertainties as a function of the duration from the mesial $(50 \%)$ point of the pulse transition. When required, certain derived waveform parameters can also be provided. For step-like waveforms, these include waveform settling errors, with respect to a defined reference level. For impulse-like waveforms, pulse energy into an ideal $50 \Omega$ load can be provided. The waveforms are measured with the NIST Sampling Comparator System described above. Waveforms within $\pm 2 \mathrm{~V}$ into $50 \Omega$ can be accommodated directly. Higher amplitudes require the use of external attenuators. Both $50 \Omega$ and $2 \mathrm{k} \Omega$ attenuators are available for amplitudes up to $20 \mathrm{~V}$ peak; however, the $2 \mathrm{k} \Omega$ attenuator substantially reduces the bandwidth of the measurement system. Typical measurement epochs range from $10 \mathrm{~ns}$ to $1 \mu \mathrm{s}$, and record lengths range from 1000 to 4000 samples.

Representative uncertainties for settling parameter measurements are listed in Table 9.22.

Table 9.22. Uncertainty for Measurement of Repetitive Pulse Settling Parameters

\begin{tabular}{ccc}
$\begin{array}{c}\text { Pulse Amplitude } \\
\text { (V) }\end{array}$ & $\begin{array}{c}\text { Duration from } \\
\text { Mesial Point } \\
\text { (ns) }\end{array}$ & $\begin{array}{c}\text { Typical Expanded } \\
\text { Uncertainty* } \\
\text { (\% of pulse } \\
\text { amplitude) }\end{array}$ \\
\hline 0.25 & 1 & 1.0 \\
& 2 & 0.3 \\
& 5 & 0.1 \\
& 10 & 0.1 \\
& 100 & 0.05 \\
& 1000 & 0.02 \\
& 1 & 0.5 \\
& 1 & 0.2 \\
& 2.5 & 0.1 \\
& 4 & 0.06 \\
& 5 & 0.05 \\
6 & 0.03 \\
8 & 0.02 \\
& 10 & 0.02 \\
20 & 0.02 \\
50 & 0.01 \\
& 100 & 0.01 \\
\hline
\end{tabular}

* See Chapter 1 , Section $\mathrm{H}$ for more information about uncertainty. 


\section{Restrictions and Notes:}

1. All measurements are performed with a $50 \Omega$ input impedance. The input connector is a female SMA type. The sampling probe is connected directly to the output connector of the waveform source; no intervening cables are used unless they are specifically provided for this purpose by the customer.

2. The settling error at time $t$ (measured from the mesial point) is defined as the largest absolute difference between the waveform and the reference level occurring in the interval from time $t$ to the end of the data record.

3. Unless otherwise requested, the reference level is the final $\mathrm{dc}$ or steady state value of the final level. This level is measured by inputting a steady state logic level to the generator under test corresponding to the final level.

4. Short term settling can also be measured with respect to the final level in a specified time epoch, if requested. In this case, long term settling error-the difference between the value at the end of the specified epoch and the dc value-also will be reported.

5. Pulse generators that are internally clocked must provide a separate trigger output pulse. For best results, this should lead the waveform under test by at least $35 \mathrm{~ns}$. If the trigger pulse leads by less than $35 \mathrm{~ns}$, the waveform measurement will begin one cycle later, with a resulting increase in jitter and time-quantization errors. If the pulse generator can be clocked externally, NIST will provide the clock signal and the necessary trigger output signal, when required.

6. The clock pulse requirements should be specified including high level, low level, repetition rate, and duty cycle. Repetition rates between $10 \mathrm{kHz}$ and $10 \mathrm{MHz}$ are preferred.
Measurements of other pulse parameters or parameter ranges may be provided by special arrangement. Consulting and advisory services also are available.

\section{Network Impulse Response (65300S)}

The network time-domain impulse response measurement service for coaxial networks has been offered previously at NIST; currently the service is being reworked and is not being offered, except by special arrangement. When available, the measurements will be accomplished by use of the NIST AWAMS described above. Two waveforms are measured, one with the pulse generator connected directly to the oscilloscope, and the other with the unknown network inserted between the generator and the oscilloscope. The time-domain impulse response function and/or the frequency domain scattering parameter, $S_{21}(f)$, are then calculated using an NIST-developed deconvolution algorithm. A wide variety of connectors can be accommodated. The resulting data are in the form of a discrete waveform vector, normally 1024 points in length, with a time window range from 1 ns to $100 \mathrm{~ns}$. Also, using discrete Fourier transforms, the associated frequency-domain transfer function data $\left(S_{21}[f]\right)$ are provided over a frequency range of $10 \mathrm{MHz}$ to $10 \mathrm{GHz}$ and a gain or loss range of $0 \mathrm{~dB}$ to $40 \mathrm{~dB}$. The approximate limits of the expanded uncertainty* are expected to be less than $2 \%$ for all parameters.

\section{Pulse Time Delay Interval (65400S)}

NIST offers a special-test service for measuring pulse time delay interval, using the NIST AWAMS described above. The pulse time delay interval range is $10 \mathrm{ps}$ to $100 \mathrm{~ns}$ with typical expanded uncertainties* of $(0.2 \% t+1 \mathrm{ps})$.

* See Chapter 1, Section $\mathrm{H}$ for more information about uncertainty. 


\section{Restrictions:}

1. Customer's device must utilize precision coaxial connectors for both delay ports, e.g., SMA, APC-7, Type N, APC-3.5, etc.

2. Customer should provide the driving pulse generator if possible. First transition duration (rise time) of the driving pulse generator should not exceed $10 \%$ of the pulse time delay interval to be measured.

Measurements for other ranges and configurations may be made by special arrangement. Consulting and advisory services are available.

\section{References-Pulse Waveform Measurements}

A Custom Integrated Circuit Comparator for High-Performance Sampling Applications, O. B. Laug, T. M. Souders, and D. R. Flach, IEEE Trans. Instrum. Meas. 41 (6), 850 (Dec. 1992).

Dynamic Calibration of Waveform Recorders and Oscilloscopes Using Pulse Standards, W. L. Gans, IEEE Trans. Instrum. Meas, 39 (6), 952 (Dec. 1990).

Characterization of a Sampling Voltage Tracker for Measuring Fast, Repetitive Signals, T. M. Souders, H. K. Schoenwetter, P. S. Hetrick, IEEE Trans. Instrum. Meas. IM-36 (4), 956 (Dec. 1987).

Calibration and Error Analysis of a Picosecond Pulse Waveform Measurement System at NBS, W. L. Gans, Proc. IEEE, 74 (1), 86 (Jan. 1986).
Deconvolution of Time Domain Waveforms in the Presence of Noise, N. S. Nahman and M. E. Guillaume, Natl. Bur. Stand. (U.S.), Tech. Note 1047 (Oct. 1981).

Spectrum Amplitude Definition, Generation, and Measurement, J. R. Andrews and M. G. Arthur, Natl. Bur. Stand. (U.S.), Tech. Note 699 (Oct. 1977).

IEEE Standard Pulse Terms and Definitions, IEEE Std. 194-1977; and IEEE Standard on Pulse Measurement and Analysis by Objective Techniques, IEEE Std. 181-1977, Inst. Electrical and Electronic Engrs., New York, NY (July 1977).

Impulse Generator Spectrum Amplitude Measurement Techniques, J. R. Andrews, IEEE Trans. Instrum. Meas., IM-25 (4), 280 (Dec.1976).

Present Capabilities of the NBS Automatic Pulse Measurement System, W. L. Gans, IEEE Trans. Instrum. Meas. IM-25, 384 (Dec. 1976).

Time Domain Automatic Network Analyzer for Measurement of RF and Microwave Components,

W. L. Gans and J. R. Andrews, Natl. Bur. Stand. (U.S.), Tech. Note 672 (Sept. 1975).

Pulsed Wavemeter Timing Reference for Sampling Oscilloscope Calibration, J. R. Andrews and W. L. Gans, IEEE Trans. Instrum. Meas. IM-24, 82 (Mar. 1975).

Pulse Techniques and Apparatus, Part 1: Pulse Terms and Definitions; Part 2: Pulse Measurements and Analysis, General Considerations, IEC Publications 469-1 and 469-2, Intl. Electrotech. Com. (IEC), Geneva, Switzerland (1974). 


\section{Chapter}

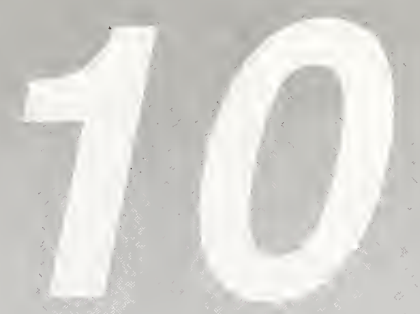

A Broadcast and Measurement Services

$B$ Characterization of Oscillators 


\section{Time and Frequency Measurements}

\author{
Technical Contacts:
}

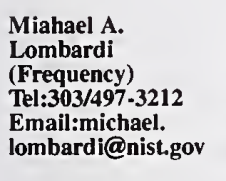

Paula Hewitt Administration and Logistics Tel:303/497-3753 Email:paula. hewitt@nist.gov

Mailing Address: M.C. 847.40,

National Institute of Standards and Technology,

325 Broadway,

Boulder, CO 80303-3328

Shipping Address: M.C. 847.40, Room 4039, National Institute of Standards and Technology, 325 Broadway,

Boulder, CO 80303-3328

Service

ID No.

Items

Broadcast Services (WWW, WWVH, WWVB, GOES, ACTS, and NTS)

$76100 S$ Frequency Measurement Service (Frequency Delivered to User's Site)

$76110 S$ Global Time Service (Frequency and Time Delivered to User's Site)

\section{NIST Broadcasts of Time and Frequency Signals}

NIST time and frequency broadcast services are available free of charge to the general public. Services are provided via $\mathrm{HF}, \mathrm{LF}$, and UHF radio, as well as via telephone lines and Internet connection. NIST broadcast services are coordinated with similar services in other countries. Commercial receivers (for radio signals) and software packages (for computer time services) are available from several manufacturers. NIST publications are available that explain how to use these services.

HF Signals-Broadcasts from WWV (Fort Collins, Colorado) and WWVH (Kauai, Hawaii) can be received on conventional shortwave receivers nearly anywhere in the world. Broadcast frequencies are $2.5 \mathrm{MHz}, 5 \mathrm{MHz}$,
$10 \mathrm{MHz}$, and $15 \mathrm{MHz}$ for both stations and $20 \mathrm{MHz}$ for WWV only. Standard uncertainties of $1 \mathrm{~ms}$ to $10 \mathrm{~ms}$ in time and a relative standard uncertainty* in frequency of $1 \times 10^{-7}$ are typical from these broadcasts. The HF broadcasts provide standard frequencies, standard time intervals, time-of-day announcements, a binary-coded-decimal (BCD) time code, astronomical time corrections, and public service announcements for other government agencies. For individuals without receivers, the audio from both stations is simulcast by telephone. The telephone signal has a standard uncertainty* of $30 \mathrm{~ms}$ or less due to delays in cross-country telephone line routings. The phone numbers (not toll free) are (303) 499-7111 for WWV and (808) 335-4363 for WWVH.

LF Signals-Radio station WWVB (Fort Collins, Colorado) provides standard uncertainties of $0.5 \mathrm{~ms}$ in time and a relative standard uncertainty* in frequency of $1 \times 10^{-11}$. The station broadcasts a $60 \mathrm{kHz}$ carrier and a BCD time code. Effective January 1, 1998, the transmitted power of WWVB will increase by $6 \mathrm{~dB}$ to approximately $50 \mathrm{~kW}$ and the coverage area will include most of North America.

GOES Satellite-The GOES satellites (Geostationary Operational Environmental Satellite) broadcast NIST time on a frequency of about $468 \mathrm{MHz}$. The signals are usable in North and South America with a standard uncertainty of $100 \mu$ s. Two satellites (GOES-East and GOESWest) are used for this service. The satellites are located at approximately $75^{\circ}$ and $135^{\circ}$ west longitude, respectively.

Automated Computer Time Service (ACTS)-This service allows computer users with modems to synchronize their clocks by telephone. The phone number for ACTS is (303) 494-4774. Users can connect at speeds of up to 9600 baud and obtain time signals with standard uncertainty* of $5 \mathrm{~ms}$.

Network Time Service (NTS) - This service allows users to synchronize computer clocks via the Internet. The service responds to time requests from any

* See Chapter 1, Section H for more information about uncertainty. 
Internet client in several formats including the Daytime (RFC-867), Time (RFC-868), and Network Time Protocol (NTP, RFC-1305). The service is being expanded and uses multiple time servers (call for current server addresses).

\section{Frequency Measurement Service (76100S)}

Frequency calibrations with a relative standard uncertainty* of $5 \times 10^{-13}$ can be obtained using the NIST Frequency Measurement Service (FMS). The FMS uses signals from Global Positioning System (GPS) satellites as reference frequency. Subscribers to the FMS receive a complete frequency measurement system which they install in their lab (the equipment remains the property of NIST). The system inciudes a GPS receiver and all of the hardware and software necessary to automate the calibration process. The system can simultaneously calibrate up to five frequency standards (quartz, rubidium or cesium), and graphically display the results.

NIST provides all of the equipment, documentation, supplies, and technical support needed to operate the FMS, and offers a free training seminar to teach the subscriber. The subscriber's only requirements are to supply the frequency standards to be measured, and a dedicated phone line. The phone line allows NIST personnel to call each system to verify and analyze the data, and quickly troubleshoot any problems that might arise. If any component fails, NIST replaces it immediately using an overnight delivery service. Each subscriber receives a monthly certificate of calibration which certifies that their primary frequency standard is traceable to NIST. This traceability can assist customers seeking accreditation through NVLAP (National Voluntary Laboratory Accreditation Program) or seeking compliance with ISO requirements.

* See Chapter 1, Section H for more information about uncertainty.

\section{Global Time Service (76110S)}

This service uses the Global Positioning System (GPS) satellites in a common-view mode and provides better time and frequency transfer than is afforded directly by GPS. Data from a receiver located at the user's facility are automatically downloaded (by phone) to a NIST computer. The computer stores the data, determines which data are suitable for time transfer calculations, and provides optimally filtered values for the time and frequency of the user's clock relative to UTC (NIST). Monthly reports are sent to the user, and users also receive an account on a NIST computer that allows them to access a daily, preliminary analysis.

Tests between widely separated receivers have demonstrated standard uncertainties* for time comparisons of less than $10 \mathrm{~ns}$ and relative standard uncer tainties* for frequency comparisons of less than $1 \times 10^{-13}$, both for averaging times of $1 \mathrm{~d}$. The uncertainty decreases as the averaging time increases. The frequency uncertainty is limited by the relative standard uncertainty of the NIST primary frequency standard which is $5 \times 10^{-15}$.

\section{References-Broadcast and Measurement Services}

An Introduction to Frequency Calibration: Part I, M. A. Lombardi, Cal. Lab. Int. J. Metrology, pp. 17-28 (Jan.-Feb. 1996).

An Introduction to Frequency Calibration: Part II, M. A. Lombardi, Cal. Lab. Int. J. Metrology, pp. 28-34 (Mar.-Apr. 1996).

NIST Time and Frequency Services, R. Beehler and M. A. Lombardi, Natl. Inst. Stand. Technol., Spec. Publ. 432 (1991).

Accuracy of International Time and Frequency via Global Positioning System Satellites in Common View, D. W. Allan, M. A. Weiss, D. D. Davis, and A. V. Clements, IEEE Trans. I \& M, IM-34, 118 (June 1985). 


\section{Characterization of Oscillators}

\author{
Technical Contacts:
}

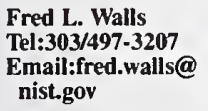

Paula Hewitt

Administration and Logistics

Tel:303/487-3753

Email:paula.hewitt@nist.gov

Mailing Address: M.C. 847 ,

National Insitute of Standards and Technology,

325 Broadway,

Boulder, CO 80303-3328

Service

ID No. Items

77100C Oscillator Frequency Calibration

77110C Characterization of Atomic Frequency Standards

77120C Characterization of Oscillators: Time Domain

77130C Characterization of Oscillators and Amplifiers: Phase

Noise in the Frequency Domain

77131C Characterization of Oscillators and Amplifiers:

Amplitude Noise in the Frequency Domain

77135C Tests of RF PM/AM Noise Measurement Systems: On-Site Tests

77136C Tests of Microwave PM/AM Noise Measurement Systems: On-Site Tests

77140S Special Time/Frequency Measurements: Oscillators and Other Components

\section{Oscillator Frequency Calibration (77100C)}

Oscillators with an output frequency of $1 \mathrm{MHz}$ to $50 \mathrm{GHz}$ can be sent to NIST for calibration. The relative standard uncertainty* is nominally that of the NIST frequency standard, which is $5 \times 10^{-15}$, but is limited by noise in the oscillator under test. The frequency stability of the oscillator can also limit the calibration, since oscillators often change frequency during shipment. Higher frequencies $(50 \mathrm{GHz}$ to $110 \mathrm{GHz}$ ) are covered under Service ID Number 77140 S.

* See Chapter 1, Section $\mathrm{H}$ for more information about uncertainty.

Characterization of Atomic Frequency Standards (77110C)

An atomic standard is characterized by introducing it as a member of the NIST time scale system. The output of the standard is sampled every $2 \mathrm{~h}$ in sequence with the other clocks in the time scale, and the performance of the standard under test is readily determined. The standard test involves $30 \mathrm{~d}$ of measurements. The square root of the Allan variance $\sigma_{y}(\tau)$ is measured to $3 \times 10^{-15}$ for averaging times of $7200 \mathrm{~s}$ to $10^{6} \mathrm{~s}$. The relative standard uncertainty* of the time scale is $5 \times 10^{-15}$ and the fractional frequency drift is less than $2 \times 10^{-16}$ per day. The actual values transferable to the standard are often limited by the oscillator's stability and noise properties.

Characterization of Oscillators: Time Domain (77120C)

For oscillator frequencies of $5 \mathrm{MHz}$, $10 \mathrm{MHz}$, and $100 \mathrm{MHz}$, the stability in terms of the square root of the Allan deviation $\sigma_{y}(\tau)$ is determined by repeated measurements at $0.5 \mathrm{~s}$ intervals. $\sigma_{y}(\tau)$ is determined to $4 \times 10^{-13} / \tau^{-1 / 2}$ for averaging times of $0.5 \mathrm{~s}$ to $10000 \mathrm{~s}$ and frequency offset is measured with a relative standard uncertainty* of $5 \times 10^{-15}$, limited by the noise level and type in the oscillator under test. The frequency measurement transferable to the oscillator is often limited by the oscillator's stability due to transport between laboratories and on-off cycling. Measurements of Allan deviation from approximately $1 \mu$ s to $0.5 \mathrm{~s}$ can be determined by integration of the oscillator phase noise. This inversion of the data is performed by NIST. Thus, measurements in this range should be done under Service ID Numbers $77130 \mathrm{C}$ or $77140 \mathrm{~S}$. Characterization of time domain stability at other frequencies is covered under Service ID Number $77140 \mathrm{~S}$. 
Characterization of Oscillators and Amplifiers: Phase Noise in the Frequency Domain $(77130 \mathrm{C})$

For frequencies of $5 \mathrm{MHz}$ to $26 \mathrm{GHz}$, phase modulation (PM) noise $S_{\phi}(f)$ of single oscillators and amplifiers can be determined for Fourier frequency offsets from the carrier of $0.1 \mathrm{~Hz}$ to $10 \mathrm{MHz}$. The PM noise is measured for only a few user-specified frequency offsets (typically 3 points per decade). All measurements of phase noise are made relative to $1 \mathrm{rad}^{2} / \mathrm{Hz}$. At a carrier frequency of $5 \mathrm{MHz}, S_{\phi}(f)$ can be measured to $-145 \mathrm{~dB}$ for a frequency offset of $1 \mathrm{~Hz}$ and $-190 \mathrm{~dB}$ for an offset of $10 \mathrm{kHz}$. At a carrier frequency of $100 \mathrm{MHz}, S_{\phi}(f)$ can be measured to $-150 \mathrm{~dB}$ for a frequency offset of $1 \mathrm{~Hz}$ and $-190 \mathrm{~dB}$ for an offset of $50 \mathrm{kHz}$. A typical value of standard uncertainty* is $1 \mathrm{~dB}$, but specific values depend on the carrier frequency and the offset frequency. Specific measurement requirements should be discussed prior to placing an order. PM noise for frequencies above this range (but less than $110 \mathrm{GHz}$ ) are covered under Service ID Number 77140S.

\section{Characterization of Oscillators and Amplifiers: Amplitude Noise in the Frequency Domain (77131C)}

For frequencies from $1 \mathrm{MHz}$ to $26 \mathrm{GHz}$, amplitude modulation (AM) noise $S_{a}(f)$ of single oscillators and amplifiers can be determined for Fourier frequency offsets from the carrier of $0.1 \mathrm{~Hz}$ to $10 \mathrm{MHz}$. The AM noise is measured for only a few user specified frequency offsets (typically 3 points per decade). All measurements of amplitude noise are made relative to $1 \mathrm{~Hz}$. At a carrier frequency of $5 \mathrm{MHz}, S_{a}(f)$ can be measured to $-140 \mathrm{~dB}$ for a frequency offset of $1 \mathrm{~Hz}$, and $-180 \mathrm{~dB}$ for an offset of $10 \mathrm{kHz}$. At a carrier frequency of $100 \mathrm{MHz}, S_{a}(f)$ can be measured to $-130 \mathrm{~dB}$ for a frequency offset of $1 \mathrm{~Hz}$ and $-180 \mathrm{~dB}$ for an offset of $50 \mathrm{kHz}$. A typical value of standard uncertainty* is $1 \mathrm{~dB}$, but specific values depend on the carrier frequency and the offset frequency. Specific measurement requirements

* See Chapter 1, Section H, for more information about uncertainty. should be discussed prior to placing an order. AM noise for frequencies above this range (but less than $110 \mathrm{GHz}$ ) are covered under Service ID Number 77140 S.

\section{Tests of RF PMVAM Noise Measure- ment Systems: On Site Tests (77135C)}

The noise floor and performance of PM and AM noise measurement systems can be evaluated at the customer's site using NIST's portable PM/AM noise standard for carrier frequencies of $5 \mathrm{MHz}, 10 \mathrm{MHz}$, and $100 \mathrm{MHz}$. The PM/AM noise standard produces two signals with approximately $10 \mathrm{~dB}$ to $15 \mathrm{~dB}$ power (relative to $1 \mathrm{~mW}$ ). The residual PM noise between the two outputs (relative to $1 \mathrm{rad}^{2} / \mathrm{Hz}$ ) is typically less than $-190 \mathrm{~dB}$ for a frequency offset from the carrier of $100 \mathrm{kHz}$ for the three rf carrier frequencies. The calibrated PM or AM noise is typically constant with Fourier frequency offset to $\pm 0.1 \mathrm{~dB}$ out to $3 \%$ of the carrier frequency. After each calibration a calibration report is issued which certifies that the specific measurement system is traceable to NIST for PM and/or AM measurements at the frequencies tested. This traceability can serve as a solid basis for meeting NVLAP (National Voluntary Laboratory Accreditation Program) and ISO requirements.

\section{Tests of Microwave PM/AM Noise Measurement Systems: On Site Tests (77136C)}

The noise floor and performance of PM and AM noise measurement systems can be evaluated at the customer's site using NIST's portable PM/AM noise standard for carrier frequencies of $10.6 \mathrm{GHz}, 21.2 \mathrm{GHz}$, and $42.4 \mathrm{GHz}$. The PM/AM noise standard produces two signals with approximately $+10 \mathrm{~dB}$ power (relative to $1 \mathrm{~mW}$ ). The residual PM noise between the two outputs (relative to $1 \mathrm{rad}^{2} / \mathrm{Hz}$ ) is typically less than $-176 \mathrm{~dB}$ for a frequency offset from the carrier of $10 \mathrm{kHz}$ and $-190 \mathrm{dBc} / \mathrm{Hz}$ for offsets of 
$1 \mathrm{MHz}$ from the carrier frequency. The calibrated PM or AM noise is typically constant with Fourier frequency offset to $\pm 0.2 \mathrm{~dB}$ out to $100 \mathrm{MHz}$. After each calibration a report is issued which certifies that the specific measurement system is traceable to NIST for PM and/or AM measurements at the frequencies tested. This traceability can serve as a solid basis for meeting NVLAP (National Voluntary Laboratory Accreditation Program) and ISO requirements.

\section{Special Time/Frequency Measure- ments: Oscillators and Other Components (77140S)}

Frequency and time domain measurements can be made at frequencies other than those cited in the above tests up to $110 \mathrm{GHz}$, but the uncertainty and cost are dependent upon the specific user requirements. Given two or more oscillators, synthesizers, frequency multiplier/dividers, or amplifiers, relative phase noise can be measured with low uncertainty and the frequency for the measurement is not as restrictive as above. Also, the 1 pulse per second output of atomic frequency standards can be measured with a standard uncertainty of $0.5 \mathrm{~ns}$ given an adequately defined pulse. Limited frequency and PM/AM noise measurements can be made from $75 \mathrm{GHz}$ to $110 \mathrm{GHz}$. Please call to discuss your requirements.

\section{References-Characterization of Oscillators}

Secondary Standard for PM and AM Noise at 5, 10, and $100 \mathrm{MHz}$, F. L. Walls, IEEE Trans. I\&M 42, 126 (Apr. 1993).

Introduction to the Time Domain Characterization of Frequency Standards, J. Jesperson, Proc. 25th Annu. Precise Time and Time Interval (PTTI) Meeting, Pasadena, CA, 83-102 (Dec. 1991).

An Introduction to Frequency Standards, L. Lewis, Proc. IEEE 79 (7), 927-935 (July 1991).

Properties of Signal Sources and Measurement Methods, D. A. Howe, D. W. Allan, and J. A. Barnes, in Characterization of Clocks and Oscillators, edited by D. B. Sullivan, D. W. Allan, D. A. Howe, and F. L. Walls, Nat1. Inst. Stand. Technol. Tech. Note 1337, 14-16 (1990).

Characterization of Clocks and Oscillators, D. B. Sullivan, D. W. Allan, D. A. Howe, and F. L. Walls, eds., NIST Tech. Note 1337 (Mar. 1990). Frequency and Time-Their Measurement and Characterization, S. R. Stein, Precision Frequency Control, Vol. 2, edited by E. A. Gerber and A. Ballato (Academic Press, NY), 191-232 (1985). 


\section{ALPHABETICAL CROSS-INDEX}

Item

Service ID

Number or

Other Reference

Absolute pressure transducers . . . . . . . . . . . . . . . . . 30010C-30011C

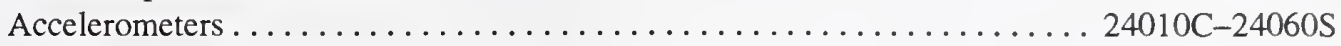

Ac-dc thermal converters (to $1 \mathrm{MHz}$ ) ...................... 53350C-53352C

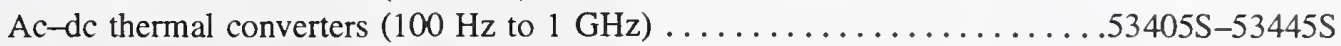

Ac-dc watthour or varhour meters . . . . . . . . . . . . . . . . . . 56110S-56210M

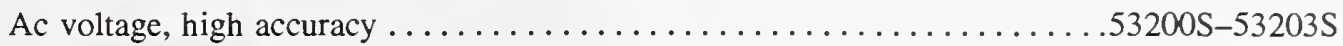

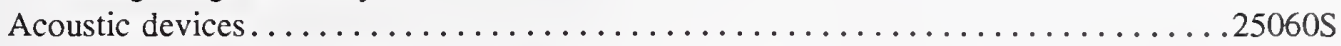

Acoustic emission transducers and sensors....................... 26200C

Acoustic measurements ............................ 25010C-25070s

Activation detector dosimetry . . . . . . . . . . . . . . . . . . 44070C-44090C

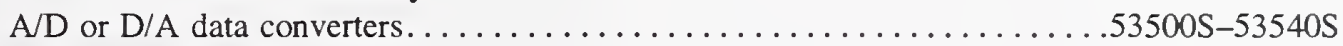

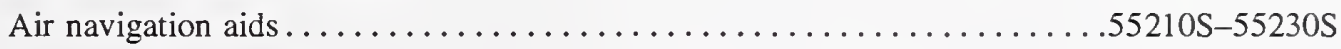

Air-speed indicators............................ 19010C-19040S

Alpha-particle-emitting solid sources................. 43030C-43050C

Aluminum ultrasound reference blocks ......................

$26070 \mathrm{~S}$

American Petroleum Institute gages . . . . . . . . . . . . . . . . . . 12010 C

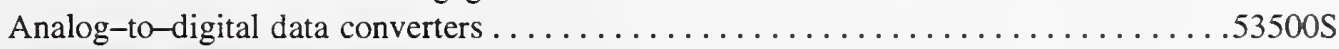

Anechoic chambers.............................. 25010C-25070S

Anemometers .................................. 19010C-19040S

Angle gage blocks ................................... 14010C

Angular measurements . . . . . . . . . . . . . . . . . . . 14010C-14050S

Antenna parameter measurements, microwave ..............6. 63100S-63400S

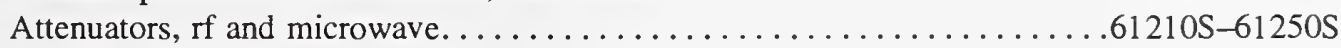

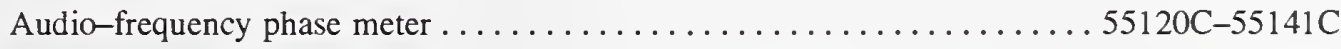

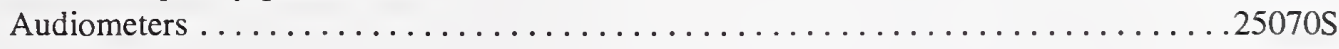

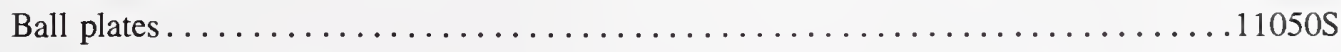

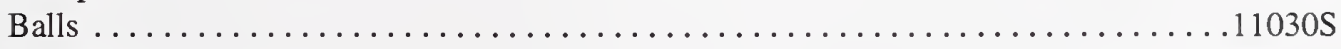

Barometers ....................................29035C,30010C-

$30011 \mathrm{C}$

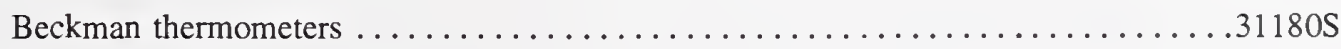

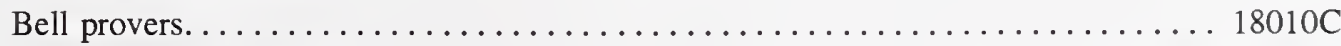

Beta particle applications.......................... 47030C-47040S

Beta-particle emitting sources........................ 43060S,43070S

$47030 \mathrm{C}-47040 \mathrm{~S}$

Bolometer units, if and microwave ...................61110S-61138C

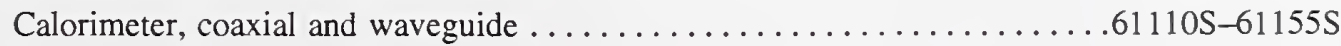

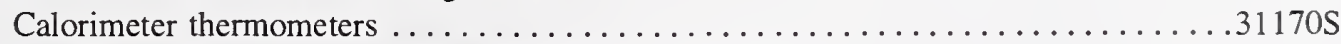

Capacitance and inductance measurements, high frequency ...........52210S-52310S

Capacitance and inductance measurements, low frequency . . . . . . . . 52110S-52181C

Capacitive voltage dividers ................................. 
Capacitors, dielectric.

.52130C

Capacitors, high frequency.

$52210 \mathrm{~S}-52221 \mathrm{~S}$

Capacitors, low frequency.

$52110 \mathrm{~S}-52171 \mathrm{C}$

Capacitors, power frequency $52400 \mathrm{C}$

Coaxial air line standards $61510 \mathrm{~S}$

Coaxial attenuators

$61210 S-61211 \mathrm{C}$

Coaxial terminations and reflection coefficients $61310 \mathrm{C}$

Coaxial thermistor mounts

$1110 \mathrm{~S}-61138 \mathrm{C}$

Color temperature

$37010 \mathrm{C}-37050 \mathrm{~S}$

Complex dimensional standards .....................................12010C-12040S

Converters, A/D and D/A ...................................... 53500S-53540S

Coordinate measuring machines ................................11050S,12040S,

$15010 \mathrm{C}-15040 \mathrm{C}$

- software algorithms

10070S-10081S

- socketed ball bars.

SRMs (p. 2)

- probe performance spheres

SRMs (p. 2)

Cryogenic flow measurements $18800 \mathrm{~S}$

Current and voltage transformers

$4510 \mathrm{C}-54600 \mathrm{~S}$

Data converters, A/D and D/A $53500 \mathrm{~S}$

Dc resistance measurements

$51100 \mathrm{~S}-51163 \mathrm{C}$

Dc voltage measurements

$53110 \mathrm{~S}-53190 \mathrm{~S}$

Deadweight piston gages $29010 \mathrm{C}$

Deadweight tester, ball type $30025 \mathrm{C}$

Density measurements, liquids $17040 \mathrm{~S}$

Detector standards, windowed photodiode

$0560 \mathrm{C}-40561 \mathrm{C}$

Detector standards, windowless photodiode

$40510 \mathrm{C}-40540 \mathrm{C}$

Detectors, IR $39080 \mathrm{~S}$

Detectors, near ultraviolet to soft $\mathrm{x}$-ray region 40599S

Detectors, radiometric $39080 \mathrm{~S}$

Detectors, spectroradiometric

$39071 \mathrm{~S}-39090 \mathrm{~S}$

Detectors, used with lasers

$42110 \mathrm{C}-42180 \mathrm{~S}$

Deuterium arc lamps... $40030 \mathrm{C}$

Deuterium lamps. $39050 \mathrm{C}$

Dew-point hygrometers $36010 \mathrm{C}-36020 \mathrm{C}$

Diameter measurements

$11010 \mathrm{~S}-11060 \mathrm{~S}$

Dielectric and magnetic materials $61620 \mathrm{~S}$

Differential pressure transducers $30020 \mathrm{C}-30021 \mathrm{C}$

Digital multimeters, low frequency.

$53200 \mathrm{~S}-53203 \mathrm{~S}$

Digital-to-analog data converters $53500 \mathrm{~S}$

Dimensional metrology $10010 \mathrm{C}-14050 \mathrm{~S}$

Dividers, capacitive

$54310 \mathrm{~S}-54311 \mathrm{~S}$

Dividers, inductive $54110 \mathrm{~S}-54131 \mathrm{C}$

Dividers, mixed $54410 \mathrm{~S}$

Dividers, resistive $54210 \mathrm{C}-54214 \mathrm{~S}$

Dosimeters, electron beam $48010 \mathrm{M}-48020 \mathrm{~S}$

Dosimeters, high dose. . $49010 \mathrm{C}-49050 \mathrm{~S}$

Dosimeters, neutron. $44100 \mathrm{~S}$

Dosimeters, radiochromic.

$49010 \mathrm{C}-49030 \mathrm{C}$ 
Dosimeters, spectrophotometric reading

$49040 S-49041 S$

Dosimeters, x-ray, gamma-ray, and electron.........................46010C-48020S

Dosimetry, neutron...............................................44010C-44100S

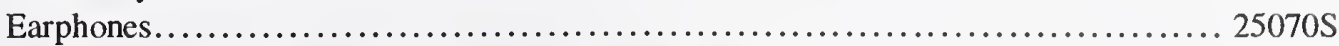

Electromagnetic field-strength parameter measurements................6.64100S-64300S

Electrometers ............................................................ 46030S

Electron beam dosimetry .................................. 48010M-48020S

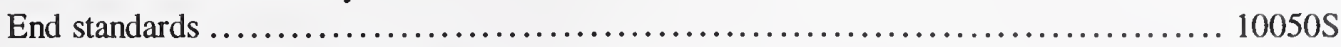

Energy and power measurements, low frequency................... 56110S-56210M

Ferrous-ferric dosimeters ....................................48010M-48011M

Fiber optic power meters...................................42130C-42180S

Field strength measurements, electromagnetic ......................64100S-64300S

Filament lamps, ribbon ..........................................

$39010 \mathrm{C}-39030 \mathrm{C}$

Filters, spectral transmittance ..................................38010C-38040C

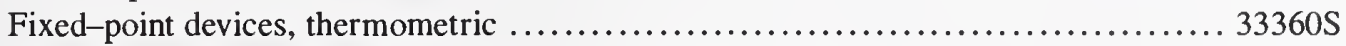

Flashing-light photometers............................................ $37110 \mathrm{~S}$

Flats, optical reference .............................................. 13010S

Flow measurements, cryogenic........................................ 18800

Flowrate meters, liquid and gas .................................. 18010C-18050S

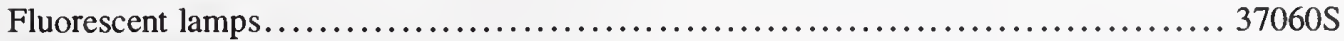

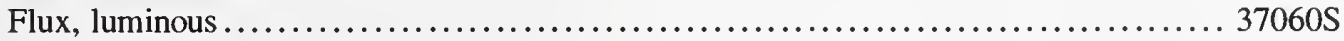

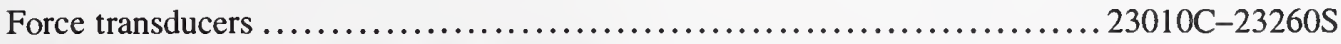

Frequency and time measurement services........................ 76100S-76110S

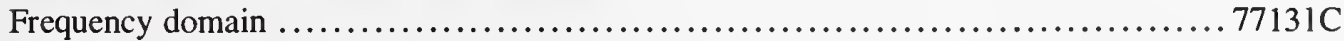

Gage blocks....................................................... 10010C

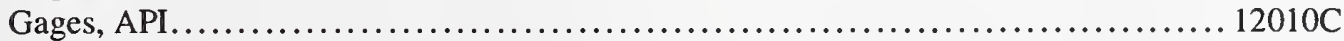

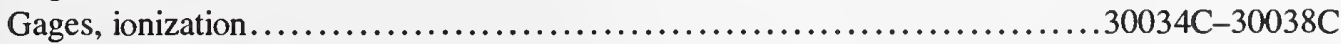

Gages, low pressure ................................................ $30040 \mathrm{~S}$

Gages, molecular drag .........................................30029C-30031C

Gages, piston.................................................29010C-29020C

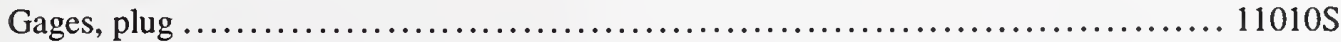

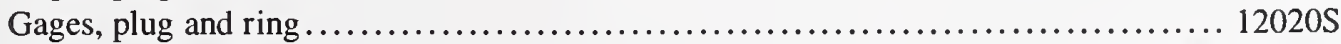

Gages, pressure ................................................29010C-29040S

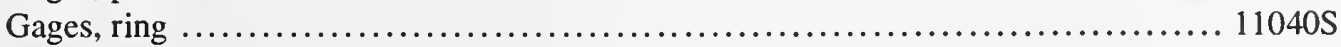

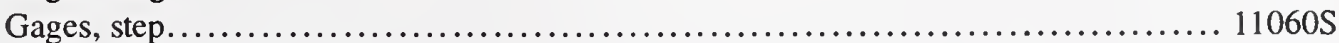

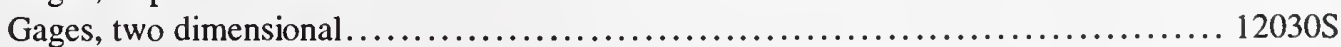

Gages, vacuum.........................................................

Gamma-ray dosimeters .........................................46010C-46021C

Gamma-ray emitting sources ................................43010C-43020C,

$47010 \mathrm{C}-47011 \mathrm{C}$

Gas flowmeters .................................................18010C, 18050S

Gear measuring wires................................................. 11020

Germanium resistance thermometers....................................... 33140C

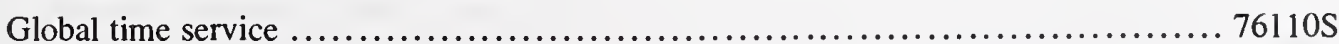

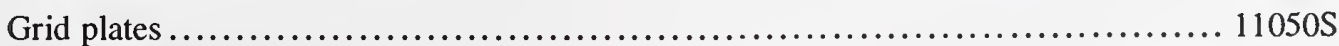

Helium permeation leaks......................................... 30060S-30062S

High dose dosimetry ...................................... 49010C-49050S 
High-frequency standard capacitors and inductors

$52210 \mathrm{~S}-52310 \mathrm{~S}$

High-frequency standard resistors.

$51310 \mathrm{~S}$

High-vacuum gages

$30029 \mathrm{C}-30038 \mathrm{C}$

High-voltage resistors.

$51210 \mathrm{C}$

Humidity measurements

$36010 \mathrm{C}-36070 \mathrm{~S}$

Hydrometers $16010 \mathrm{C}$

Hygrometers

$36010 \mathrm{C}-36070 \mathrm{~S}$

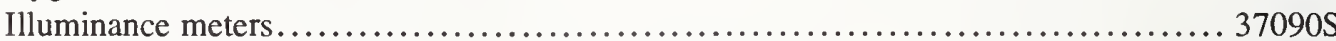

Impedance measurements ............................................... 52110S

Impulse generator spectrum amplitude.....................................6 65100S

Impulse response of coaxial networks .....................................6. 65300S

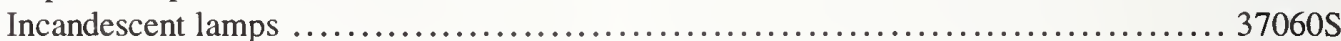

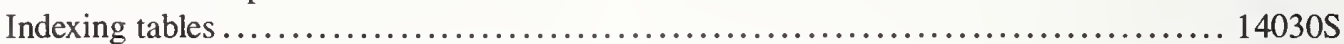

Inductance and capacitance measurements, low frequency ...............52110S-52181C

Inductance and capacitance measurements, high frequency .............. 52210S-52310S

Inductive voltage dividers .......................................5 54110S-54131C

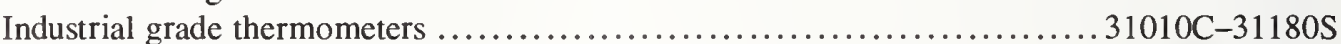

Intensity, luminous .............................................................

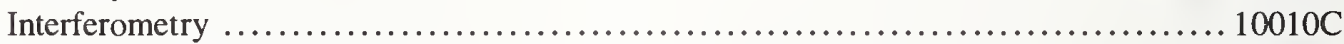

Internal diameter standards................................................ 11040S

Ionization chambers...................................................... 47036C

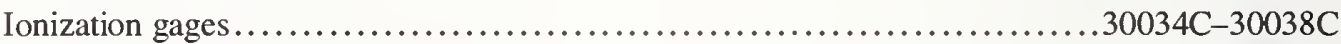

Irradiance sources..............................................39040C-39050C,

$40010 \mathrm{C}, 40030 \mathrm{C}$

Kerr cells ............................................................. 54410S

Laboratory thermometers ............................................31010C-31180S

Lamps, deuterium arc...........................................39050C, 40030C

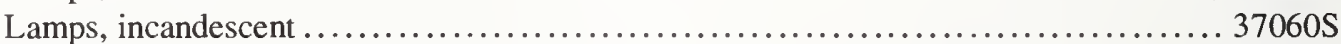

Lamps, quartz halogen .............................................39040C-39045C

Lamps, ribbon filament ...........................................

$39010 \mathrm{C}-39030 \mathrm{C}$

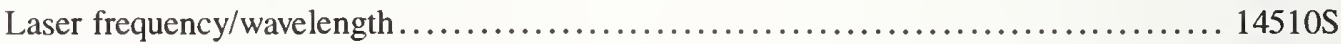

Laser power and energy measurements ..........................42110C-42180S

Leak artifacts ............................................... 30060S-30062S

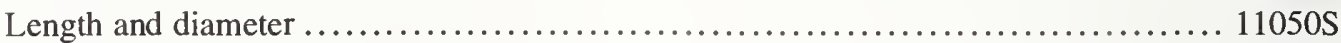

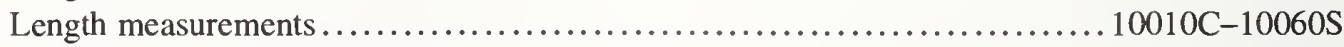

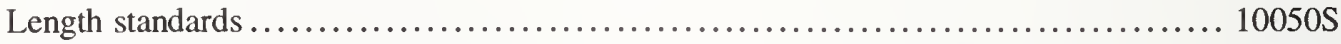

Line standards...................................................... 10020 C

Liquid flow meters........................................... 18010C-18050S

Liquid-in-glass thermometers .....................................

Load cells................................................23010C-23260S

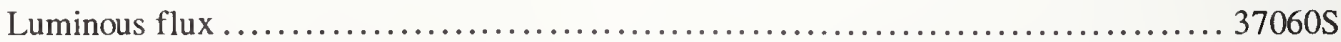

Luminous intensity.............................................37010C-37020S

Luminous intensity of retroreflectors .................................... 38070M

Mammography $x$-ray measuring instruments.........................46010C-46050S

Manometers........................................................... 29035C

Mass measurements........................................22010C-22180M 


\section{MEASUREMENT ASSURANCE PROGRAMS}

Dc resistance

Dc voltage

$53120 \mathrm{M}$

Dose interpretation of ferrous-ferric dosimeters

$48010 \mathrm{M}-48011 \mathrm{M}$

Laser power and energy

$42120 \mathrm{M}, 42140 \mathrm{M}$

$42150 \mathrm{M}$

Mass.

$22180 \mathrm{M}$

Platinum resistance thermometry

$33370 \mathrm{M}-33380 \mathrm{M}$

Retroreflectors, luminous intensity

$38070 \mathrm{M}-38074 \mathrm{M}$

Transmittance, spectral $38080 \mathrm{M}$

Watthour meters $56210 \mathrm{M}$

Mercury-in-glass thermometer

$31010 \mathrm{C}-31180 \mathrm{~S}$

Meteorological airspeed instrumentation .................................. 19030S

Meters, flow rate $18030 \mathrm{C}$

Meters, laser power and energy

$42110 \mathrm{C}, 42170 \mathrm{~S}$

Meters, optical fiber power

42130C, 42140M,

Meters, phase

$55110 \mathrm{~S}-55141 \mathrm{C}$

Meters, turbine

$18010 \mathrm{C}-18020 \mathrm{C}$

Microphones, pressure and free-field response

$25010 \mathrm{C}-25050 \mathrm{C}$

Micropotentiometers, low voltage

$53201 \mathrm{~S}$

Micropotentiometers, rf

$53440 \mathrm{~S}-53445 \mathrm{~S}$

Microwave antenna parameter measurements

$63100 S-63400 S$

Mixed voltage dividers. $54410 \mathrm{~S}$

Molecular drag gages

$30029 \mathrm{C}-30031 \mathrm{C}$

Neutron dosimeters $44100 \mathrm{~S}$

Neutron sources

$44010 \mathrm{C}-44020 \mathrm{C}$

Noise temperature measurements, coaxial and waveguide

$61410 \mathrm{~S}-61495 \mathrm{~S}$

Non-Mercurial barometers and manometers ...

$29035 \mathrm{C}$

Oil gaging and surveying tapes.

$10030 \mathrm{C}$

Opal glass transmittance standard.

$37070 \mathrm{C}$

Optical fiber power meters

$42130 \mathrm{C}, 42140 \mathrm{M}$,

$42180 \mathrm{~S}$

Optical flats

$13010 \mathrm{~S}$

Optical polygons ..................................................... 14020S

Optical pyrometers....................................................

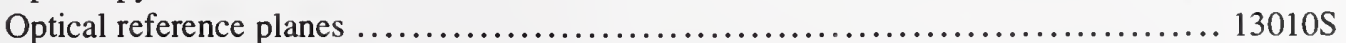

Oscillator characterization ...........................................17100C-77140S

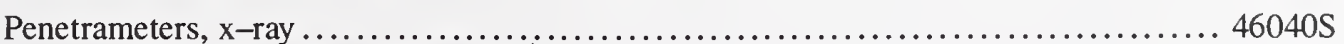

Personnel protection instrumentation ..................................... 44060C

Phase measurements ............................................55110S-55141C

Phase shifters, if and microwave ...................................61295S-61297S

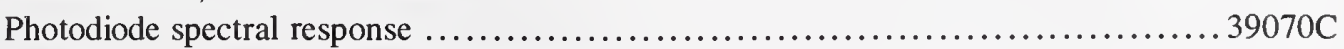

Photodiodes, windowed and windowless .............................40510C-40560C

Photographic step tablets.......................................... See SRMs (p. 2)

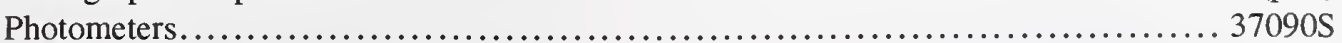

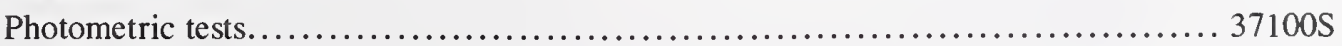

Photometry ......................................................... $37010 \mathrm{C}-3710 \mathrm{~S}$ 
Pickup sensitivity . . $24010 \mathrm{C}-24030 \mathrm{C}$ $24050 \mathrm{~S}$

Piston gages, controlled clearance.......................................29020 C

Piston gages, dead weight .................................................. 29010C

Pitot-static tubes .................................................. 19010C

Platinum resistance thermometers....................................33010C-33310C

Plug and ring gages ..........................................12010C-12020S

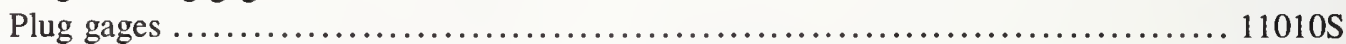

Pneumatic bridge hygrometers ................................................36060C

Polygons, optical..................................................... 14020S

Power and energy measurements, low frequency ..................... 56110S-56210M

Power meters, optical fiber.................................... 42130C-42140M

42180S

Power meters, thermoelectric ....................................6 61110S-61155S

Pressure gages and transducers ............................................ 29030C

Pressure gages, low absolute ........................................30010C-30011C

Pressure gages, low differential .....................................30020C-30021C

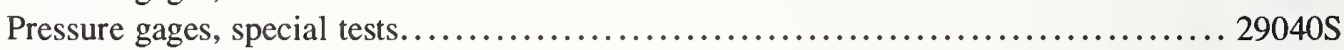

Pressure measurements........................................ 29010C-29040S,

$30010 \mathrm{C}-30062 \mathrm{C}$

Proving rings. . . . . . . . . . . . . . . . . . . . . . . 23010C-23260S

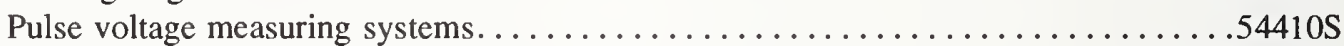

Pulse waveform measurements . . . . . . . . . . . . . . . . . . . . .65100S-65400S

Pyrometer indicators. . . . . . . . . . . . . . . . . . . . . . . . . . . . . 32100C

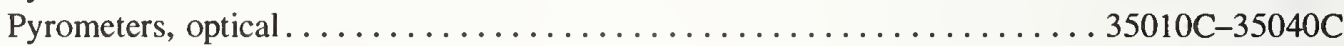

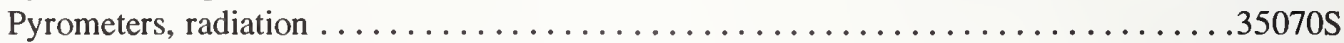

Q-standards........................................

Quartz halogen lamps............................... 39040C-39045C

Radiance standard sources . . . . . . . . . . . . . . . . . . . .39010C-39030C, $40020 \mathrm{C}$

Radiance temperature measurements... . . . . . . . . . . . . . . . 35010C-35070S

Radiant energy detectors . . . . . . . . . . . . . . . . . . . . . . . . . . . 39070C

Radiation detectors. . . . . . . . . . . . . . . . . . . . . . . 46010C-4601IC

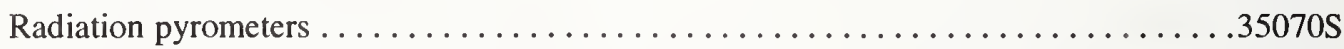

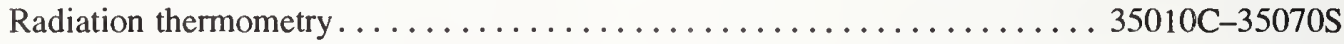

Radioactive sources, alpha emitting .................. $43090 \mathrm{~S}$

Radioactive sources, beta emitting ....................43060S-43070S

Radioactive sources, gamma emitting . . . . . . . . . . . . . . . 43010C-43020C

Radioactive sources, neutron emitting. . . . . . . . . . . . . . . . . 44010C-44020C

Radiochrometric dosimeters. . . . . . . . . . . . . . . . . . . . . . . . . . 49020C-49030C

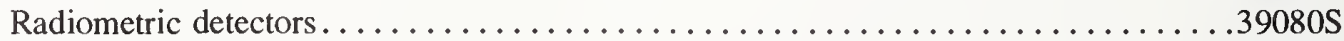

Radiometric measurements. . . . . . . . . . . . . . . . . . . . . . . 39010C-39060S, $40010 \mathrm{C}-40040 \mathrm{~S}$

$40510 \mathrm{C}-40599 \mathrm{~S}$

Radiometric sources.....................................39060S

Radionuclides .................................... 43010C-43090S

Reference block measurements, ultrasonic . . . . . . . . . . . . . . . . 26030S-26070S 
Reflection coefficients, coax and waveguide terminals

$61310 S-61350 S$

Resistance measurements, dc...................................51100S-51163C

Resistance thermometers........................................33010C-33310C

Resistive voltage dividers....................................54210C-54214S

Resistors, high frequency............................................ 51310S

Resistors, high-precision standard, dc ............................51130C-51154C

Resistors, high voltage ............................................. 51210C

Resistors, megohm ............................................ $14142 \mathrm{C}-51154 \mathrm{C}$

Resistors for current measurements .............................51160C-51163C

Retroreflectors, coefficient of luminous intensity ....................38070M-38074M

Ribbon filament lamps......................................35050C-35060C

Ring gages ....................................................... 11040S

R-meters................................................46010C-46011C

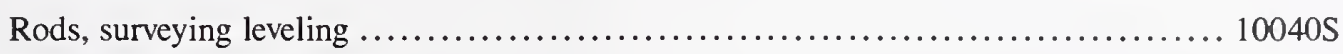

Rotary and indexing tables .......................................... 14030S

Roughness calibration standards...................................15010C-15020C

Roundness measurements ......................................13020S-13030S

Saturated standards cells .........................................53130C-53131C

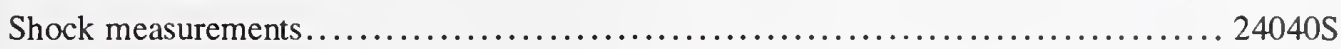

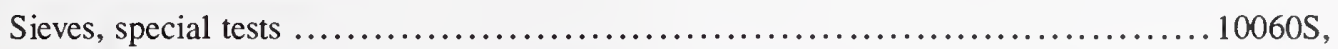

also SRMs (p. 2)

Spectral irradiance .......................................39040C-39050C,

40010C, 40030C

Spectral irradiance, lamps....................................39040C-39050C

Spectral radiance............................................. 39010C-39030C,

$40020 \mathrm{C}$

Spectral radiance, lamps .......................................39010C-39030C

Spectral response, laser ............................................ 42164S

Spectral response, photodiode........................................ 39081S

Spectral transmittance filters....................................38010C-38040C

Spectrophotometric measurements........................... 38010C-38080M,

also SRMs (p. 2)

Spectroradiometric detectors ................................. 39071S-39090S

Spectroradiometric sources ....................................39010C-39060S

Spherical diameter standards, balls..................................... 11030S

Stage micrometer .................................................... 10020 C

Standard voltage cells ..........................................53130C-53150C

Steel ultrasound reference blocks .............................. 26040S, 26060S,

$26070 \mathrm{~S}$

Step gages, length................................................... 11060S

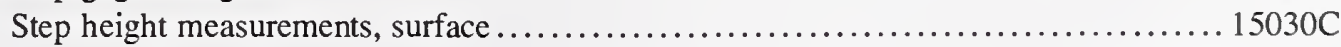

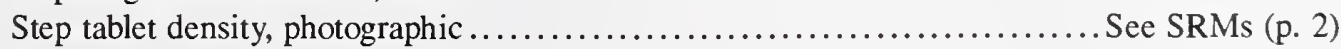

Sucker rods ............................................................ 12010C

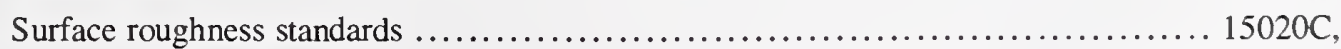

also SRMs (p. 2)

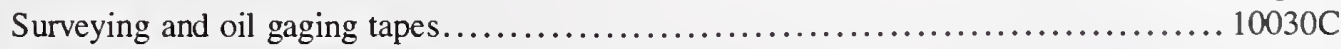

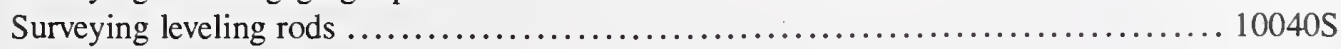

Tapes.............................................................. 10030 
Thermal voltage and current converters $(100 \mathrm{~Hz}-1 \mathrm{GHz})$

$53405 S-53445 S$

Thermal voltage converters (to $1 \mathrm{MHz}$ )

$53350 \mathrm{C}-53352 \mathrm{C}$

Thermistor mounts

$61110 \mathrm{~S}-61155 \mathrm{~S}$

Thermocouples and thermocouple materials .......................32010C-32150S

Thermorneters, Beckmann

$31180 \mathrm{~S}$

Thermometers, calorimetric type

$31170 \mathrm{~S}$

Thermometers, cryogenic type

$33140 \mathrm{C}-33141 \mathrm{C}$

Thermometers, germanium resistance.

$33140 \mathrm{C}-33141 \mathrm{C}$

Thermometers, laboratory

$31010 \mathrm{C}-31260 \mathrm{~S}$

Thermometers, platinum resistance

$33010 \mathrm{C}-33310 \mathrm{C}$

Thermometers, rhodium-iron resistance

$33140 \mathrm{C}-33141 \mathrm{C}$

Thermometric fixed-point devices 33360S,

also SRMs (p. 2)

Thermometry, radiation

35010C-35070S

Thread measuring wires $11020 \mathrm{C}$

Threaded plug and ring gages. $12020 \mathrm{~S}$

Time and frequency measurement services

$76100 \mathrm{~S}-76110 \mathrm{~S}$

Time domain.... $77120 \mathrm{C}$

Titanium ultrasound reference blocks

26040S, 26060S, $26070 \mathrm{~S}$

Transducer measurements, acoustic emission. $26200 \mathrm{C}$

Transducer measurements, ultrasonic $26100 \mathrm{C}$

Transducers, low pressure

$30010 \mathrm{C}-30021 \mathrm{C}$

Transformers, voltage and current.

$54510 \mathrm{C}-54600 \mathrm{~S}$

Transmittance, Measurement Assurance Program $38080 \mathrm{M}$

Transmittance filters, spectral

$38010 \mathrm{C}-38040 \mathrm{C}$

Transmitting diffusers $37080 \mathrm{~S}$

Turbine flow meters

$18010 \mathrm{C}-18020 \mathrm{C}$

Two-dimensional gages $12030 \mathrm{~S}$

Ultrrasonic reference block measurements .

$26030 S-26070 S$

Ultrasonic system power, calorimetric ................................... 26100C

Ultrasonic transducer measurements ....................................... 26100C

Ultrasonic transducer power, radiation pressure............................. 26100C

Ultraviolet detectors

40510C-40599S

Ultraviolet sources

$40010 \mathrm{C}-40040 \mathrm{~S}$

Unsaturated standard cells $53150 \mathrm{C}$

Vacuum gages $30029 \mathrm{C}-30038 \mathrm{C}$, $30050 \mathrm{~S}$

Vacuum measurements 30010C-30050S

Vacuum ultraviolet radiometric measurements ........................40010C-40040S

Var, varhour meters ...........................................56200C-56202C

Very-high-frequency omnidirectional measurements .....................55210C-55230S

Vibration and shock measurements ................................24010C-24060S

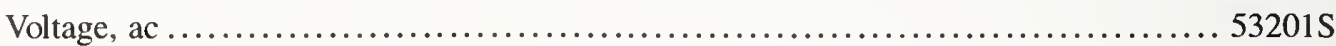

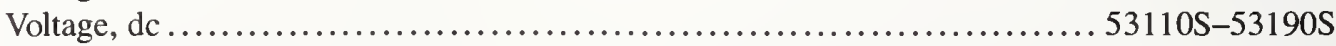

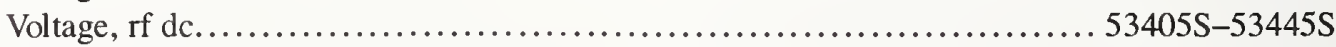

Voltage and current transformers.................................54510C-54600S

Voltage dividers, capacitive ................................. 54310S-54311S 
Voltage dividers, inductive

$.54110 \mathrm{~S}-54131 \mathrm{C}$

Voltage dividers, mixed $54410 \mathrm{~S}$

Voltage dividers, resistive

$54210 \mathrm{C}-54214 \mathrm{~S}$

Voltage reference standards, solid state.

$53160 \mathrm{C}-53161 \mathrm{C}$

Voltmeters, high accuracy, ac $53200 \mathrm{~S}$

Volume standards $17010 \mathrm{C}-17020 \mathrm{~S}$

VOR measurements $55110 \mathrm{~S}$

Watt, watthour meters $56110 \mathrm{~S}-56210 \mathrm{M}$

Wattmeters, high power $61160 S, 61190 \mathrm{~S}$

Waveform measurements, pulse $65100 \mathrm{~S}-65400 \mathrm{~S}$

Waveguide attenuators $61230 \mathrm{~S}$

Waveguide terminations and reflection coefficients

$61320 \mathrm{~S}-61350 \mathrm{~S}$

Waveguide thermistor mounts $61144 \mathrm{~S}-61155 \mathrm{~S}$

Wavelength standards $38050 \mathrm{C}$

Wedges $14040 \mathrm{~S}$

Weights (mass standards) $22010 \mathrm{C}-22180 \mathrm{M}$

Wires for thread and gear measurements $11020 \mathrm{C}$

$\mathrm{X}$-ray and photographic step tablets. See SRMs (p. 2)

$\mathrm{X}$-ray dosimeters $46010 \mathrm{C}-46050 \mathrm{~S}$

$\mathrm{X}$-ray penetrameters $46040 \mathrm{~S}$

$\mathrm{X}$-ray step tablets See SRMs (p. 2) 


\section{C}


$\square$ Iraceability and Accuracy

Q Conformity Assessment

0 Education

$\square$ Guest Researchers

Q Conferences

D Publications

Interlaboratory Comparisons

0 Consultations

Cooperative Research and Development Agreements 

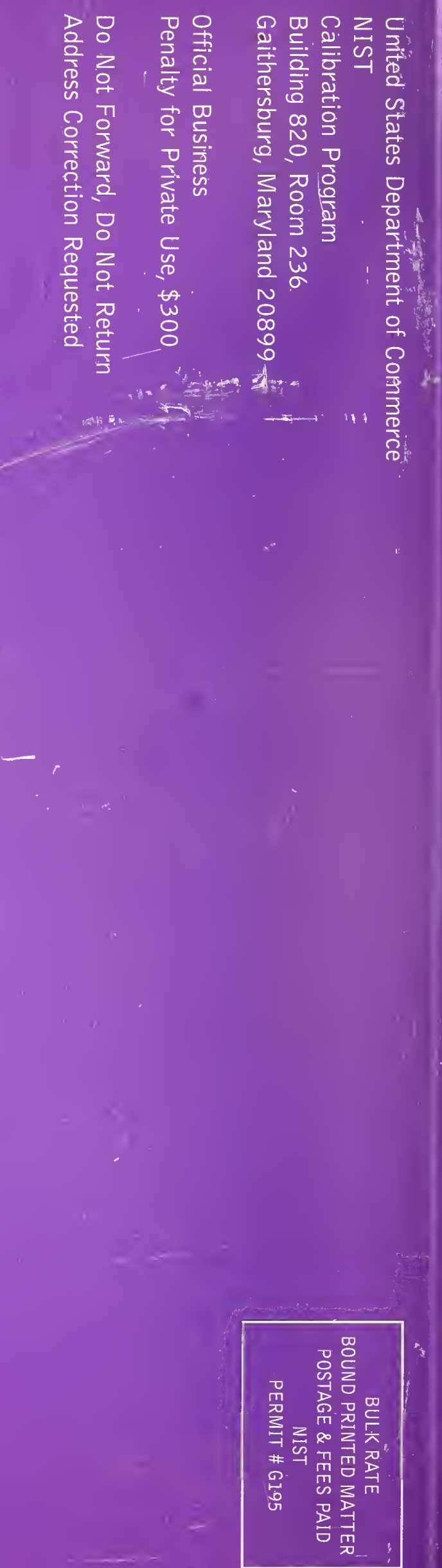